\title{
Prostaglandins and Phosphodiesterases in the urinary bladder wall
}

Citation for published version (APA):

Rahnama'i, M. S. (2013). Prostaglandins and Phosphodiesterases in the urinary bladder wall. [Doctoral Thesis, Maastricht University]. Maastricht University. https://doi.org/10.26481/dis.20131122mr

Document status and date:

Published: 01/01/2013

DOI:

10.26481/dis.20131122mr

Document Version:

Publisher's PDF, also known as Version of record

\section{Please check the document version of this publication:}

- A submitted manuscript is the version of the article upon submission and before peer-review. There can be important differences between the submitted version and the official published version of record.

People interested in the research are advised to contact the author for the final version of the publication, or visit the DOI to the publisher's website.

- The final author version and the galley proof are versions of the publication after peer review.

- The final published version features the final layout of the paper including the volume, issue and page numbers.

Link to publication

\footnotetext{
General rights rights.

- You may freely distribute the URL identifying the publication in the public portal. please follow below link for the End User Agreement:

www.umlib.nl/taverne-license

Take down policy

If you believe that this document breaches copyright please contact us at:

repository@maastrichtuniversity.nl

providing details and we will investigate your claim.
}

Copyright and moral rights for the publications made accessible in the public portal are retained by the authors and/or other copyright owners and it is a condition of accessing publications that users recognise and abide by the legal requirements associated with these

- Users may download and print one copy of any publication from the public portal for the purpose of private study or research.

- You may not further distribute the material or use it for any profit-making activity or commercial gain

If the publication is distributed under the terms of Article $25 \mathrm{fa}$ of the Dutch Copyright Act, indicated by the "Taverne" license above, 
Prostaglandins and Phosphodiesterases in the Urinary Bladder Wall

Mohammad Sajjad Rahnama'i 
Prostaglandins and Phosphodiesterases in the Urinary Bladder Wall - Mohammad Sajjad Rahnama'i (sajjad_r@yahoo.com) (c) 2013 Mohammad Sajjad Rahnama'i

ISBN 978-90-820560-0-6

Design, Printing \& Binding: 5nul8 Grafische Producties, Valkenburg a/d Geul, The Netherlands - info@5nul8.nl Sponsors: Stichting Wetenschappelijke Activiteiten Maastrichtse Urologie (WAMU); Astellas Pharma; Zambon Nederland; GlaxoSmithKline; Ipsen Farmaceutica; Goodlife Pharma; AbbVie; Pohl-Boskamp; Eurocept Pharmaceuticals; Takeda; Lilly; Rochester Medical; Allergan; Mundi Pharma; A.N.W. Nederland; M.M.S. en ChipSoft bv.

All rights reserved. No part of this thesis may be reproduced, stored in a retrieval center of any nature, or transmitted, in anyform or by any means, electronic, mechanical, photocoping, recording or otherwise, without the permission of the author. 


\title{
Prostaglandins and Phosphodiesterases in the Urinary Bladder Wall
}

\author{
PROEFSCHRIFT
}

ter verkrijging van de graad van doctor aan de Universiteit Maastricht, op gezag van de Rector Magnificus, Prof. Dr. L.L.G. Soete, volgens het besluit van het College van Decanen,

in het openbaar te verdedigen

op vrijdag 22 november 2013 om 14:00

door

Mohammad Sajjad Rahnama'i

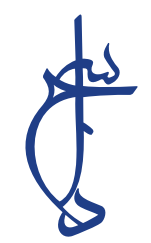




\section{Promotores}

Prof. Dr. Ph.E.V. Van Kerrebroeck

Prof. Dr. S.G.G. de Wachter (universiteit van Antwerpen)

\section{Co-promotor}

Dr. G.A. van Koeveringe

\section{Beoordelingscommissie}

Prof. Dr. H. Steinbusch (voorzitter)

Prof. Dr. M. Drake (Urological Research Institute Bristol, United Kingdom)

Prof. Dr. J. Schalken (Radboud Universiteit Nijmegen)

Prof. Dr. Y. Temel

Prof. Dr. A. zur Hausen

Dit proefschrift is tot stand gekomen middels een persoonlijke onderzoeksprijs (mozaïek-prijs) aan de promovendus Drs. M.S. Rahnama'i, verleend door de Nederlandse Organisatie voor Wetenschappelijke Onderzoek (NWO)

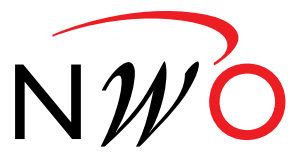

Netherlands Organisation for Scientific Research 


\section{Contents}

Chapter 1: Introduction

Chapter 2: The Role of Prostanoids in Urinary Bladder Physiology

(Nature Reviews Urology, 2012)

Chapter 3: Prostaglandin Receptor EP1 and EP2 Site in Guinea Pig Bladder Urothelium and Lamina Propria

(The Journal of Urology, 2010)

Chapter 4: The Relationship Between Prostaglandin E Receptor 1 and Cyclooxygenase I

Expression in Guinea Pig Bladder Interstitial Cells

Proposition of a Signal Propagation System

(The Journal of Urology, 2011)

Chapter 5: The Distribution of the Prostaglandin E Receptor Type 2 (EP2) in the

Detrusor of the Guinea Pig

(Prostaglandins and Other Lipid Mediators, 2012)

Chapter 6: The Effect of Indomethacin on the Muscarinic Induced Contractions in the Isolated Normal Guinea Pig Urinary Bladder

(BioMed Central Urology, 2013)

Chapter 7: The Role of Phosphodiesterases in Bladder Pathophysiology

(Nature Reviews Urology, 2013)

Chapter 8: The Distribution of Phosphodiesterase Type 5 Enzyme (PDE5)

in The Lateral Wall of The Guinea Pig Urinary Bladder

(British Journal of Urology International, 2013)

Chapter 9: General Discussion

Summary

Samenvatting

Acknowledgements / Dankwoord 
Abbreviations

List of Publications

199

Abstracts and Presentations

Curriculum Vitae 




\section{Chapter 1 \\ General Introduction}

\section{The clinical problem}

The overactive bladder syndrome (OAB) is defined by the International Continence Society (ICS) as urinary urgency which is accompanied by urinary frequency and nocturia, with or without urgency urinary incontinence ${ }^{1,2}$. OAB has a greater impact on people's quality of life than diabetes ${ }^{3-6}$ and an economic burden and cost comparable to rheumatoid arthritis and asthma ${ }^{7}$. Therefore, $O A B$ deserves more research resources and research efforts. Those affected by the symptoms of $O A B$ tend to curtail their participation in social activities and isolate themselves and are predisposed to depression ${ }^{8}$. Furthermore, many patients are often too embarrassed to seek medical treatment which contributes to an underestimation of the prevalence and difficulties in understanding the social burden of the disease $e^{3,9}$. It is estimated that about $60 \%$ of all patients seeking help, experience some symptoms of bladder dysfunction ${ }^{10}$. The symptoms encompassing OAB still present a therapeutic challenge. An unmet medical need clearly exists for an effective and well tolerated pharmacological therapy. The current treatment mainly consists of anticholinergic drugs, which have a slightly better effect than placebo, but poor patient compliance, due to the side effects and the lack of sufficient efficacy".

Hence, $O A B$ is a major problem affecting a large number of individuals. The underlying causes are not known and the precise mode of action of pharmacological treatments, remains unclear. Therefore, new insights into the problem and new therapeutic modalities are urgently needed.

\section{Relevance of the problem for society}

$O A B$ affects nearly 100 million people in the Western world ( 33 million in the US and 66 million in the European Union) $)^{12,13}$ and has severe effects on quality of life and ability to work. $O A B$ is reported to have an incidence of, up to $17 \%$ in the Western population ${ }^{12}$ and an overall prevalence of 16.6 $\%$ in Europe ${ }^{13}$. This number is significantly higher in the older population where up to $40 \%$ of the individuals over the age of 70 is reported to be affected' 3 . A recent study has estimated the prevalence of $O A B$ in the United States to range from 26 to $33 \%$ in men and from 27 to $46 \%$ in women'4.

The total economic cost of OAB is high. In 2002 the costs in the US were approximately $\$ 12.7$ billion which increased to $€ 22$ billion/year in 2005 . Approximately $25 \%$ of this expenditure, is spent on treatment (drug therapy, clinical consultation, surgery and incontinence pads). From those who suffer from $O A B$, only $28 \%$ sought help and only half of those currently receive treatment. Less than $3 \%$ of the patients regain long lasting continence. Therefore, the above mentioned costs are likely to be an underestimation and most probably, the problem is much large ${ }^{11-13,15}$. As the incidence of $O A B$ increases with age, it will be an increasing problem in aging societies. 
The exact economic costs and prevalence of $O A B$ in the Netherlands are unknown. However, it has been calculated that about $€ 200$ million are annually spent on protective material such as incontinence pads. In Germany, the direct annual costs have been estimated to be comparable to those of other chronic diseases such as dementia or, diabetes mellitus ${ }^{16}$.

A better management of the symptoms of $O A B$, will improve quality of life, decrease morbidity and disease related costs.

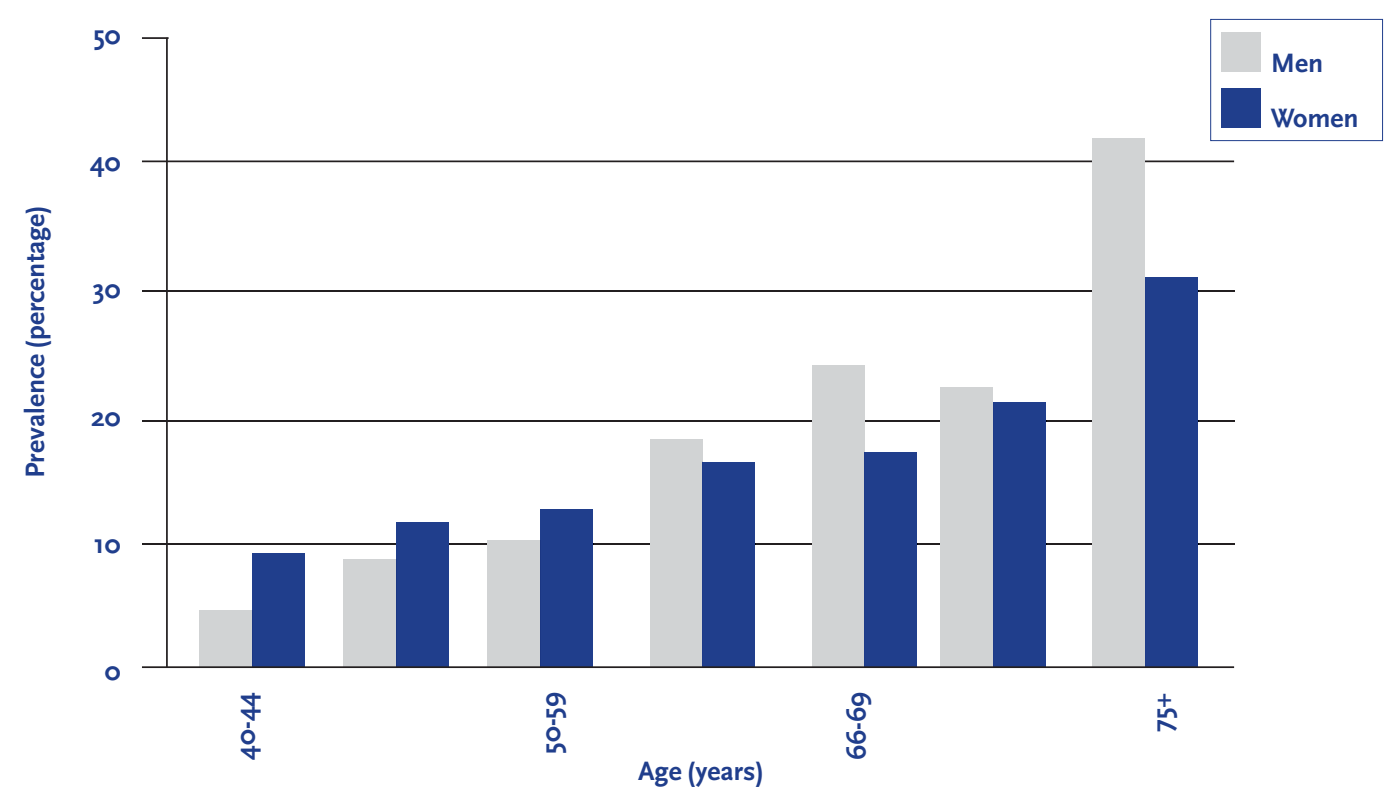

Figure 1. The Prevalence of OAB in Different Age Groups in West-Europe. ${ }^{4}$

\section{Overactive bladder syndrome}

$O A B$ occurs in both men and women. In some patients, it is accompanied by uncontrolled contractions of the detrusor muscle during bladder filling, called detrusor overactivity (DO). However, patients with OAB do not always present with DO. In fact, DO is detected in only about half of patients with $\mathrm{OAB}$ by conventional techniques. But, up to $50 \%$ of patients presenting with DO on urodynamics, do not complain of clinical symptoms ${ }^{17,18}$. The differences in the relationship between sensation and bladder activity, may be indicative of different clinical states. However, it is more likely that we don't understand the true nature of the clinical condition yet.

The only currently available tool to link OAB and DO is urodynamics. Nevertheless, DO and OAB share therapeutic options and, partially, common pathophysiological mechanisms ${ }^{17,18}$.

The characteristic symptom of $O A B$ is a sudden and strong sudden desire to void, that can not be postponed (urgency). In some patients, this can result in involuntary urine loss, which is called urgency incontinence. 
The term frequency refers to an increased number of micturitions per day (more than 8 times a day) and can occur as a result of reduced functional bladder capacity. Frequency is at least partly caused by patients' adaptation ('coping mechanism') to avoid leaking urine by maintaining a relatively low urinary volume in the bladder. Patients with OAB usually try to keep their bladder as empty as possible and therefore, pass urine more than 8 times during the day to maintain continence. Despite this adaptive coping mechanism, incontinence may still be a significant problem. Even a small increase in urgency and/or frequency can have a marked effect on the patient, depending upon when it occurs. Urgency incontinence is the most bothersome symptom of overactive bladder and is reported in around $20 \%$ of men and $40 \%$ of women with overactive bladder symptoms ${ }^{15,19,20}$. The diagnosis of OAB is made on the basis of symptoms alone. However, cystometry can be used to verify that uncontrolled contractions during bladder filling are responsible for the OAB symptoms.

$O A B$ symptoms can also be attributed to spinal cord injury or neuronal lesions within the spinal cord or the central nervous system (e.g. as a result of multiple sclerosis, Alzheimer's disease, stroke or Parkinson's disease). This condition is also known as neurogenic OAB and has a different aetiology as compared to the aforementioned group of patients with $O A B$, also called idiopathic $O A B$. While a number of theories have been proposed, the true pathophysiology of OAB remains uncertain and therefore the syndrome of $O A B$ is described as idiopathic.

\section{Current therapies for $O A B$}

Since OAB symptoms have been shown to be associated with detrusor overactivity, it was argued that drugs affecting contractility would alleviate symptoms ${ }^{21}$. Activity in the bladder smooth muscle is initiated by muscarinic receptor stimulation. Drugs designed to target these muscarinic receptors are proven to have some effect in decreasing urgency sensation and incontinence. Currently, antimuscarinic drugs are the first-line treatment for OAB. These drugs produce good initial response rates. However, adverse effects and decreasing efficacy cause poor long-term compliance $^{22}$. Therefore, it is desirable that alternative treatment methods are developed and made available for patients. At the moment, a lot of research is focused on compounds with potential efficacy for the treatment of $O A B$ some of which are undergoing preclinical and clinical testing. In $O A B$, there are many potential pathophysiological targets for intervention. This is reflected in the broad variety of mechanisms amongst the agents that are under development. In general, the new drugs for $O A B$ are being designed to target mucosal (urothelial) signalling, myocyte signalling or, aim at modulating the central nervous system.

The focus of therapy has been shifted from the efferent side, trying to reduce muscle activity (e.g. by inhibiting muscarinic receptors in the neuromuscular junction) to the afferent side, trying to reduce the afferent outflow by interacting through different peripheral and central signalling molecules. This thesis focuses on the local signalling molecules and more specifically on two possible targets for therapy called prostaglandins and phosphodiesterases. 


\section{Anatomy of the lower urinary tract}

The urethra, the bladder and in some opinions also the distal part of the ureters, are referred to as the lower urinary tract. These structures are located in the lower pelvis and are supported by muscles and ligaments. The urethra contains both smooth and striated muscles. The bladder can be divided into two main components: the bladder dome, which is located above the ureteral orifices, and the base, consisting of the trigone, ureterovesical junction, lateral wall of the detrusor along with the anterior bladder wall. The bladder is essentially a hollow organ composed of separate layers i.e. the urothelium, the suburothelial layer and the detrusor muscle (figure 2). The detrusor muscle consists of a complex network of smooth muscle fibers, connective and nervous tissue that is responsible for bladder contractility. The inner lining of the bladder is called the urothelium, which has a barrier function and is thought to act as a sensor which is also a site of production of many physiologically active molecules. The detrusor muscle is built up by smooth muscle cells and is structurally and functionally different from trigonal and urethral smooth muscle.

In both men and women, continence is based upon the preservation of low pressure within the bladder during urine storage and a high tonic tension of the sphincter muscle of the bladder outlet. The latter comprises the smooth muscle of the bladder neck, proximal urethra, and the striated muscle fibers (also referred to as the rhabdosphincter, external urethral sphincter or the striated urethral sphincter) that wrap around the urethra. Furthermore, the pelvic floor muscles are important in the maintenance of urinary continence and in preventing the descent of the pelvic organs.

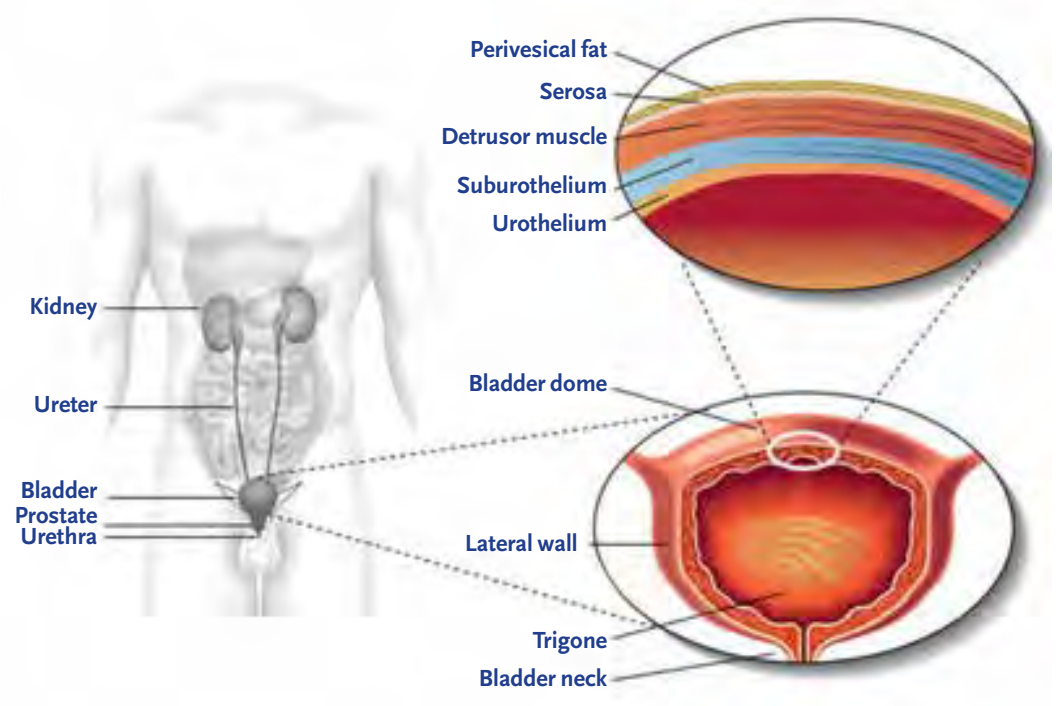

Figure 2. A Schematic View of Bladder Anatomy. 


\section{Histology of the bladder wall}

The bladder wall can be divided into three main layers: the urothelium, the suburothelial layer and the muscle layer (figure 3). The urothelial surface cells are covered by a glycosaminoglycan layer (GAG). The function of the GAG layer remains controversial. Suggested tasks of this layer include an osmotic barrier function and also an antibacterial coating of the urothelium (low adherence of the bacteria) ${ }^{23}$.

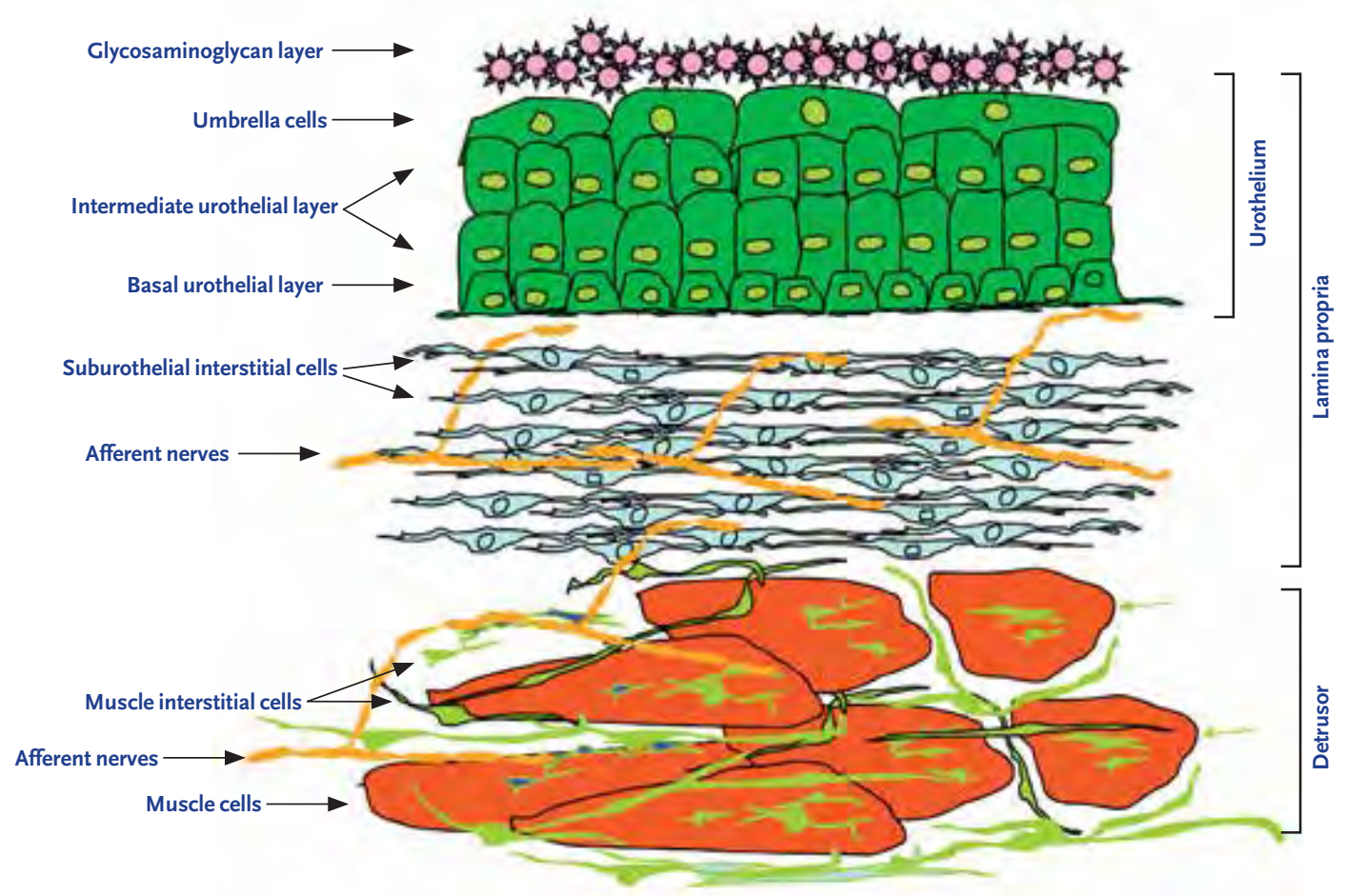

Figure 3. A Schematic View of the Cellular Structures in the Different Bladder Layers.

\section{Urothelium}

The uro-epithelium, better known as urothelium, is the interface between the lumen of the urinary tract and underlying tissues. The urothelium is composed of at least three layers: a basal cell layer attached to a basement membrane, an intermediate layer, and a superficial or apical layer composed of large hexagonal cells (25-250 $\mu$ m diameter) known as 'umbrella cells'24,25. The umbrella cells are interconnected by tight junctions (which are composed of multiple proteins such as the claudins) and are covered on their apical surface (nearly 70-80\%) by crystalline proteins called uroplakins that assemble into hexagonal plaques ${ }^{26-28}$. The urothelium is more than a barrier that separates 
urine from extracellular fluid. It also has substantial sensory properties ${ }^{29}$. Moreover, the lamina propria has been shown to be extensively innervated ${ }^{30,31}$. Receptors for bradykinin, purines ( $\mathrm{P}_{2} \mathrm{X}$ and $P_{2} Y$ ) norepinephrine ( $\alpha$ and $\beta$ ), acetylocholine (nitrotinic and muscarinic), and neurotrophions have been shown to be present in the urothelium ${ }^{29,32-36}$ as well as a number of transient receptor potential (TRP) channels (TRPV 1,2 and 4$)^{37,38}$. Urothelium is shown to release several substances in response to physical and chemical stimulation. These substances include adenosine triphosphate (ATP), nitric oxide (NO), substance P, acetylcholine, prostaglandins (PGs) and cytokines ${ }^{39-43}$, which suggest the existence of reciprocal communication with neighbouring urothelial cells, nerves and interstitial cells. The urothelium is thought to serve as a mechano-sensor, which can control activity in afferent nerves through the production of NO, ATP, acetylcholine and other mediators ${ }^{44}$. Therefore, the urothelium is considered an important regulatory part of the bladder wall and a possible target for therapeutic agents.

\section{Suburothelium}

The area between the urothelium and underlying smooth muscle layers is called the suburothelium. This layer is richly supplied by blood vessels, nerves and fibroblasts including myofibroblasts or interstitial cells (IC), which are embedded in a collagen matrix ${ }^{30,45}$. Suburothelial interstitial cells have been identified in human and animal bladders.

At present, there is still debate on what precisely defines an interstitial cell in the bladder. Several terms have been used to describe cells in the bladder interstitium including; myofibroblasts, interstitial cells of Cajal, and interstitial cells. The initial description of physiologically active interstitial cells in the human and guinea pig bladder was based on their ability to show a rise in Guanosine 3', 5'- cyclic monopohsphate (cGMP) in response to NO donors ${ }^{46,47}$. Interstitial cells have also been subdivided based on their location in the bladder wall. A rough subdivision is made between interstitial cells lying in the suburothelial layer and those in the muscle layer ${ }^{46}$. The muscle layer's interstitial cells are further subdivided. Different cell markers, predominantly c-kit and vimentin, have been used to identify interstitial cells ${ }^{45,48-53}$. Both c-kit and vimentin positive cells, are found in the lamina propria and around the muscle bundles of the inner and outer muscle layers. Neither a c-kit, nor vimentin , nor cGMP labeling seem to be ideal for identification of interstitial cells. A large proportion of interstitial cells do not express c-kit ${ }^{45}$. Vimentin identifies several interstitial cell types. However, other cell types such as non-physiologically active fibroblasts can express vimentin 45 .

Furthermore, cGMP staining identifies, besides interstitial cells, other cells such as umbrella cells and some nerves ${ }^{47}$. True identification of cells, such as interstitial cells, requires investigations of their ultrastructural properties using transmission electron microscopy. Ultrastructural features include: the presence of abundant intermediate filaments, numerous mitochondria, moderately developed Golgi apparatus, smooth endoplasmatic reticulum, contacts with nerves and the formation of gap junctions with each other and with smooth muscle cells ${ }^{54}$. The suburothelial interstitial cells 
found in the bladder are located in close association with afferent nerves, and it has been suggested that these cells play a role in modulating the activity of the suburothelial sensory nerves ${ }^{50}$. For example, isolated c-kit positive cells from the suburothelial layer, can respond to stimuli such as caffeine, muscarinic and purinergic agonists with a rise in intracellular calcium concentration ${ }^{55,56}$. Furthermore, vanilloid receptors have been identified on interstitial cells ${ }^{57}$.

\section{Muscle layer}

In many species, such as the guinea pig, the bladder muscle is divided in an inner and an outer muscle layer which is surrounded by a thin layer of interstitial cells called the muscle coat. In the guinea pig, three types of muscle interstitial cells have been described based on their location: 1. cells in the outer muscle coat (muscle coat interstitial cells) 2. cells on the surface of the muscle bundles (surface muscle interstitial cells) and 3. cells within the muscle bundles (intra muscle interstitial cells $\left.{ }^{35,47,58}\right)$. A subpopulation of cells may be identified based on their expression of choline acetyl transferase ${ }^{59}$. The muscle interstitial cells are similar to the interstitial cells of Cajal in the gut that mediate peristaltic contractions. Therefore, a pacing role has been suggested for these cells in the bladder wall ${ }^{60,61}$. Interstitial cells maintain close contact with intramural nerves, which might indicate that these cells may be under influence of nerves.

\section{Bladder physiology}

As urine is produced in the kidneys, it enters the bladder via the ureters at a rate of $0.5-5 \mathrm{ml} / \mathrm{min}$. The pressure within the bladder (intravesical pressure) remains relatively constant throughout the filling process. During this filling phase the pressure in the urethra must exceed that in the bladder to maintain continence. The ability to maintain a constant low pressure in the bladder during filling is possible as a result of the elastic and visco-elastic properties of the bladder wall, together with activation of neuronal mechanisms that inhibit the detrusor muscle from contracting ${ }^{62}$.

The desire to void usually starts when the bladder has reached about half its physiological capacity, after which the desire to void is suppressed by inhibitory input mainly from the cerebral cortex, until a suitable time and place for micturition has been chosen. When the micturition process is initiated, urethral pressure decreases (as a result of voluntary relaxation of the urethral sphincter), the pelvic floor muscles relax and the bladder neck forms a funnel. Next, increased parasympathetic stimulation leads to detrusor muscle contraction and an increase in intravesical pressure leads to the voluntary initiation of micturition. Detrusor muscle contraction is maintained throughout voiding. When urine flow is terminated, the pelvic floor contracts to elevate and close the bladder neck, urethral pressure increases and pressure within the bladder falls. Any urine within the proximal urethra is forced back into the bladder and bladder filling recommences.

The urinary bladder has two control mechanisms, a central and a peripheral mechanism, the later being the focus of this thesis. 


\section{Central nervous system control}

As the bladder fills during the urine storage phase, the detrusor muscle remains relatively quiescent and the urethral outlet is kept in a contracted state. During the micturition phase, the detrusor muscle contracts and the urethral outlet relaxes. This involves a complex pattern of efferent (motor) and afferent (sensory) signalling in the autonomic and somatic nervous system. The nerves involved are part of a reflex pathway, with an incorporated conscious control component ${ }^{63}$. The cerebral cortex, brain stem and spinal cord ( $\mathrm{S}_{2}-\mathrm{S}_{4}$ segments) are the main structures involved in the regulation of lower urinary tract function. The micturition cycle is thought to be initiated in the brain stem, specifically in a region known as the pontine micturition center. This area is in turn controlled by impulses from the cerebral cortex, which has an inhibitory effect on the detrusor muscle during bladder filling.

Both the autonomic (parasympathetic and sympathetic) and somatic nervous systems innervate the lower urinary tract (figure 4). Autonomic innervation includes parasympathetic (pelvic) neurons derived from the $\mathrm{S}_{2}-\mathrm{S}_{4}$ segments of the spinal cord and sympathetic (hypogastric) neurons from the T10-L2 segments. The parasympathetic nervous system mediates contraction of the detrusor muscle (micturition) while the sympathetic nervous system contributes to urine storage via relaxation of the detrusor muscle and contraction of the bladder neck and to a lesser extent the urethra ${ }^{64}$. The postganglionic neurotransmitter in parasympathetic neurons is acetylcholine, while in postganglionic sympathetic neurons the transmitter is noradrenaline (norepinephrine). Somatic nerves originate from the $\mathrm{S}_{2}-\mathrm{S}_{4}$ segments of the spinal cord and are thought to be solely responsible for direct innervation of the striated muscle of the urethral sphincter and pelvic floor using acetylcholine as the neurotransmitter.

\section{Peripheral control}

The bladder appears to have a peripheral control mechanism located in the bladder wall. This control mechanism is formed by the co-operative interaction of numerous regulatory cell types, of which the interstitial cells and the peripheral neurons are particularly important ${ }^{65}$.

In the past decade, there have been a number of advances in our understanding of the detailed structure of the bladder and its more complex functions. One key step forward, was the appreciation that the urothelium released a range of substances when stretched ${ }^{21}$. This led to the concept that these chemical agents modify afferent nerve activity and sensation. The urothelium is an integral part of a 'chemical' sensory system' and plays a role in generating and modulating bladder sensation. If the urothelium or sensory nerves become defective, as in for example the OAB syndrome, this would result in increased sensation of urgency. Urothelial cells express various receptors or ion channels that are responsive to external agents or mechanical or thermal changes, such as receptors to bradykinin,15 trkA, and p7516; purines $\left(P_{2} X \text { and } P_{2} Y\right)^{29}$; noradrenaline 33; acetylcholine (nicotinic and muscarinic) ${ }^{66}$; protease activated receptors ${ }^{67}$; epithelial $\mathrm{Na}^{+}$channels $(\mathrm{ENaC})^{68}$, the Deg/ENaC family ${ }^{69}$ and a number of transient receptor potential (TRP) channels 


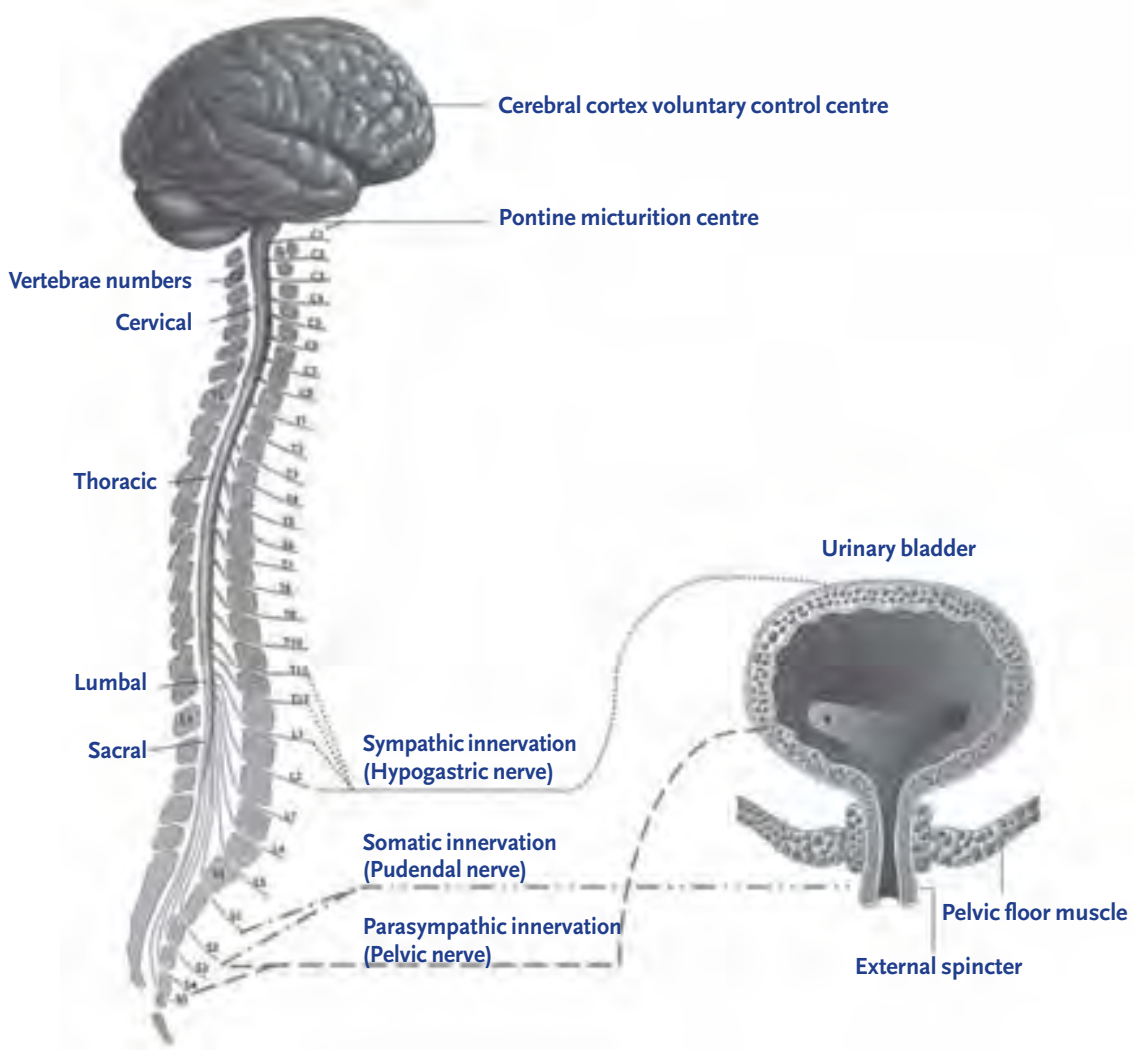

Figure 4. A Schematic View of Bladder Neuronal Control.

(TRPV1, TRPV2, TRPV4, TRPM8, TRPA1) ${ }^{70-72}$. Stimulation of these urothelial sensor molecules in turn can control the release of chemicals, such as ATP, PGs, acetylcholine, and NO43, which have excitatory and inhibitory actions on afferent nerves located close to or in the urothelium ${ }^{72,73}$. A second development was the concept that phasic activity during the filling phase is likely to be necessary for an adequate bladder sensation.

Although this idea was originally put forward over 100 years ago ${ }^{74}$, its significance as part of a motorsensory system contributing to the generation of bladder sensation, has only recently been put into a physiological and pathophysiological context74,75. The theory proposed, is that altered motor activity, will alter afferent firing and therefore sensation. This idea is embodied into the autonomous bladder hypothesis or theory ${ }^{76}$.

As a consequence of this, it is generally accepted that the structure and functions of the bladder are more complex than previously thought. Many laboratories are describing and characterising new cell types, among them, the interstitial cells $\mathrm{s}^{47,48,77}$ and neural networks ${ }^{78}$. The interstitial cells all play a role in the complex physiological and pathological events. An integral component, generating the 
non-voiding contractions in the bladder, is the concept that there is a specialised system operating within the bladder wall itself 75 . This system does not involve the post-ganglionic parasympathetic innervation of the detrusor, rather, it is thought to be generated and propagated within a network of specialised cells, the interstitial cells.

\section{The role of Prostaglandins in bladder physiology}

Arachidonic metabolites, more specifically PGs, are released from the bladder into the general circulation in response to distension ${ }^{79-81}$. It was found that PGs in the bladder wall originate from both the urothelial and muscle layers ${ }^{79,80}$. The exact role of this endogenous PG is not known, but it is well documented that exogenous PG alters bladder motor activity in vitro and in vivo and that it can also influence the micturition reflex in humans $\mathrm{s}^{82-84}$, rats $^{85}$, guinea pigs $\mathrm{s}^{86}$, rabbits ${ }^{87}$ and monkeys ${ }^{88}$. The main PGs synthesized in the bladder are $\mathrm{PGE}_{2}{ }^{79-81}$ and $\mathrm{PGI}_{2}{ }^{89}$. $\mathrm{PGs}$ are locally synthesized in the bladder muscle and mucosa. This synthesis is initiated by stretch of the detrusor muscle, bladder nerve stimulation, bladder mucosa damage and inflammation mediators. The effects of PGs in the bladder have been studied in numerous studies. These studies have shown, that bladder infusion with $\mathrm{PGE}_{2}$ enhances the micturition reflex and that urine levels of $P G E_{2}$ are increased in patients with $O A B^{90,91}$. Moreover, $P G_{2}$ has been suggested to facilitate afferent nerve activity via $\mathrm{EP}_{1}$ receptors during urinary bladder inflammation in rats $^{92}$. The level of $P G E_{2}$, released by bladder strips taken from rats with spinal cord injury, was greater than that observed in normal bladders ${ }^{79}$. This finding was confirmed in bladders from patients with neurogenic overactive bladder or detrusor overactivity due to spinal cord injury compared to healthy controls ${ }^{79}$. Furthermore, the increased number and amplitude of nonvoiding bladder contractions resulting from spinal cord injury in rats could be counteracted by the administration of an EP1 receptor antagonist. This antagonist also increased micturition volume $^{79}$. More data supporting the involvement of $\mathrm{PGE}_{2}$ in detrusor activity came from a study showing that intravesical instillation with $\mathrm{PGE}_{2}$ increased frequency of micturition and increased basal intravesical pressure in normal, conscious rats ${ }^{93}$.

Although the role of EP1 receptors on bladder function has been subject of different studies ${ }^{92,93}$, the cellular localization and the expression of EP receptors in the bladder wall remain unknown. This information would provide useful data that would help to increase our understanding of how these receptors are involved in the regulation of the micturition reflex. Regarding the actions of PG on the smooth muscle, it was thought, that PG might be co-released with acetylcholine at efferent nerve endings and so, directly contribute to muscle excitation ${ }^{88}$. Alternatively, PG might act indirectly on pre-synaptic motor terminals to affect the release of excitatory transmitters ${ }^{85}$. It has also been postulated that PG might also inhibit acetylcholine esterase ${ }^{84}$ or enhance myogenic bladder activity ${ }^{94}$. With regard to PG related changes in the micturition reflex, it was envisaged that they might act directly on the afferent nerves to modulate firing and so, trigger micturition at lower bladder volumes ${ }^{95}$. Such an action could arise anywhere in the bladder wall where PG are 
synthesised and where there are afferent nerves. One specific location where this could occur is the urothelium and suburothelial layer. It is conceivable that they could act upon suburothelial nerve fibres. This would represent a situation similar to the one proposed for urothelial derived ATP and its subsequent activation of afferent nerves ${ }^{52}$. The idea that PG might affect afferent firing directly has yet to be demonstrated. In the guinea pig, it has recently been shown that the enzymes cyclo oxygenase type $1\left(\mathrm{COX}_{1}\right)$ and cyclo oxygenase type $2\left(\mathrm{COX}_{2}\right)$ are located within specific cell types within the lamina propria. $\mathrm{COX}_{1}$ is found in the basal layers of the urothelium and associated with the distributed network of lamina propria interstitial cells ${ }^{96}$. In contrast, $\mathrm{COX}_{2}$ is associated with the nuclei of a population of umbrella cells and the nuclei of the suburothelial interstitial cells. Thus, PG signalling in this region of the bladder wall may be complex with multiple sites of production and sites of action.

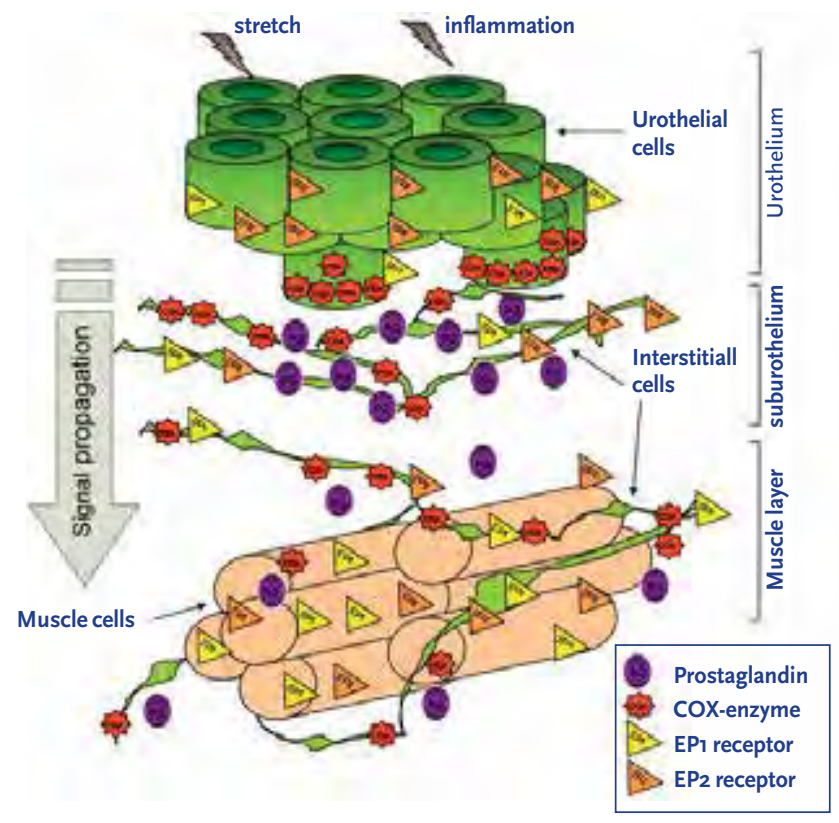

Figure 5. A Schematic View of the Prostaglandin System in the Bladder. 


\section{Prostaglandins in the treatment of $O A B$}

Prostaglandin is known to be increased in the urine of patients with pathological bladder conditions, including $O A B^{97}$. These findings have generated interest in $P G$ as a possible therapeutic target for $\mathrm{OAB}$. There is also interest in the use of enzyme of the COX enzyme which is an essential enzyme in the conversion of arachidonic acid to PGs. The use of non-selective COX enzyme improved neurogenic detrusor overactivity in cerebrally infarcted rats ${ }^{98}$. In this regard, modulation of PC receptors would be another interesting target possibly through the peripheral afferent systems in the bladder wall. The efficacy of COX inhibitors and PG receptor antagonists in decreasing muscular tone and spontaneous contractile activity of the bladder has been confirmed repeatedly in various animal model studies ${ }^{99-101}$. Intravesical aspirin instillations in partially obstructed rabbit bladders attenuated, albeit not significantly, the contractile response to cholinergic stimulation ${ }^{102}$. The effects of dexketoprofen (a nonselective COX inhibitor) and NS-398 (a selective COX 2 inhibitor) have been studied in normal and inflamed bladders ${ }^{99}$. The results suggest that modulation of the PG production via $\mathrm{COX}_{1}$, might modulate the threshold for the activation of the micturition reflex in normal rats and that inhibiting $\mathrm{COX}_{2}$ could prevent the urodynamic changes associated with bladder inflammation ${ }^{99}$.

\section{The role of NO-cGMP in bladder physiology}

Research in Maastricht has shown that interstitial cells responded to exogenous NO with a rise in $\mathrm{CGMP}^{46}$. Later, these findings were extended, demonstrating that the network of interstitial cells consists of several cell types: cells in the suburothelium (suburothelial interstitial cells; SU-ICs), cells which lie on the surface of the smooth muscle bundles (superficial muscle interstitial cells; SM-ICs) and cells which lie within the muscle bundles (intra-muscular interstitial cells IM-ICs). Examples of these cells are shown in several studies ${ }^{31,47,51-5,59,103-106}$. Most direct evidence that these interstitial cells are responsible for this phasic activity comes from work in the mouse. In the mouse bladder, the only NO responsive cells appear to be the interstitial cells, associated with the outer muscle layer ${ }^{107}$. Phasic activity can be generated in these preparations, using muscarinic agonists. Application of $\mathrm{NO}$ completely inhibits this muscarinic induced phasic activity.

From this, it can be concluded that the muscle interstitial cells are involved in the generation of this phasic activity and that a rise in CGMP inhibits this phasic activity. Interstitial cells in the bladder can respond to NO and influence contraction. They are thought to have the characteristics of a network, with pacemaker and conducting elements ${ }^{108}$. Furthermore, it is known that the bladder urothelium and suburothelial cells (mucosa) from several different species, including human, releases a number of substances that have an inhibitory effect on smooth muscle contractility and include NO, PGs, and adenine nucleotides. However, there is no clear understanding of the role that these substances play in physiological or pathophysiological control of bladder contractility. In muscle bath studies of several different animal species, surgical removal of the mucosal layer increases the contractile response to several different agonists ${ }^{73}$. This indicates that the mucosa releases agents that depress 
muscle contractility and metabolizes or otherwise inactivates these agonists. Furthermore, the mucosa acts as a barrier for diffusion and penetration of agents into the muscle or responds to the agonists through the release of substances that modulate the contraction of the underlying muscle. During the voiding phase, the NO-cGMP signalling pathway is activated in men, allowing efficient voiding through the relaxation of the urethra and prostate ${ }^{109}$. Systemic NO augmentation lowers functional bladder outlet resistance very rapidly in men and the NO-cGMP pathway may be a future target in the treatment of lower urinary tract symptoms ${ }^{109}$.

\section{Phosphodiesterase inhibitors in the treatment of $O A B$}

Phosphodiesterase (PDE) inhibitors prevent the degradation of cyclic guanosine monophosphate (cGMP) and cyclic adenosine monophosphate (CAMP), which are important mediators in maintaining smooth muscle tone. PDE inhibitors were originally designed to treat increased coronary artery tone in cardiovascular disease and were later used for the treatment of erectile dysfunction. Recently, they have been shown to be of potential therapeutic use in the treatment of OAB and male LUTS. There are 11 members in the family of PDE-inhibitors characterized and three more are suggested to exist ${ }^{110-112}$. Initial evidence regarding the utilisation of PDE inhibitors originates from a study of 19 patients with refractory urgency incontinence ${ }^{113}$. Patients were treated with a PDE1 inhibitor, vinpocetine, and $58 \%$ of these patients demonstrated an improvement in either clinical or urodynamic parameters. In vitro and in vivo studies are on-going since PDE inhibitors are a logic treatment for OAB. Another recent development has been the finding that PDE type 5 inhibitors (sildenafil, tadalafil and vardenafil) improve urinary symptoms in men with erectile dysfunction and $O A B$, and this finding has been confirmed in several well-designed randomized controlled trials ${ }^{114-117}$. Despite the potential benefits of PDE5-inhibitors in OAB, the mechanism of action on the bladder is not known yet. It was demonstrated in the anaesthetised rat, that the PDE5-inhibitor vardenafil, has an inhibitory effect on the non-voiding contractions during the filling phase, suggesting an action on the smooth muscle ${ }^{118,119}$. Furthermore, it has been demonstrated, that PDE5-inhibitors can reduce the force generated in strips of the detrusor muscle $^{119}$. In this paper, it was also reported that the PDE5-enzyme was located within the muscle fibers. Using these data, it was argued that the observed muscle relaxation due to PDE5 inhibition, was the result of a raised cGMP, resulting in inhibition of detrusor contraction.

However, there are several published reports, which demonstrate that, after stimulation of the production of cGMP by NO, the muscle cells of human, mice and guinea pig bladders do not respond with a rise in $\mathrm{CGMP}^{46,47,107}$. Nonetheless, a rise in cGMP does occur in cells of a different type, lying in between the muscle cells, the so called, interstitial cells. Based on these observations, it can be argued, that NO doesn't have a direct relaxing effect on the detrusor muscle, through a rise in cGMP. Instead, it is hypothesized that the aforementioned NO excitable interstitial cells play a role in the regulation of the bladder contractions and that these might be the site of PDE inhibitor action in the bladder. 


\section{Research question of this thesis}

This thesis has focused on two control mechanisms in bladder physiology and pathophysiology; first, the role and working mechanisms of PGs and second, the NO/CGMP/PDE system in the bladder physiology.

As PG pathways have been suggested to be a possible promising pharmacological target in the treatment of $O A B$, the first part of the thesis focuses on the $P G$ receptors of the predominant prostanoid type shown in the bladder, which is $\mathrm{PGE}_{2}$. The choice of $\mathrm{EP}_{1}$ and $E \mathrm{PP}_{2}$ is based on two reasons. First, $E P_{1}$ and $E P_{2}$ receptors in the bladder have not yet been studied with immunohistochemistry, whereas $\mathrm{EP}_{4}$ and $\mathrm{EP}_{3}$ immunohistochemical characterization in the bladder had been addressed before ${ }^{120,121}$. Second, at the time of our research there was a large phase I trial with a $\mathrm{PGE}_{2}$ receptor subtype $\mathrm{EP}_{1}$ antagonist, which was thought to be a promising new drug in the treatment of $\mathrm{OAB}^{122}$. Experiments, using visualisation techniques have been used to pinpoint the target and production site of PGs in order to answer our first research question on the localization and the role of $\mathrm{EP}_{1}$ and $\mathrm{EP}_{2}$ receptors in the bladder and on the possible use of these receptors as a target in the treatment of voiding disorders.

The second part of the thesis concentrates on the PDE inhibitors. Recently, some studies have been conducted with PDE 5 inhibitors as a possible treatment target in order to improve urinary symptoms ${ }^{114,123}$. These studies have shown the positive effect of PDE5 inhibitors on men with mild to moderate lower urinary tract symptoms (LUTS). It is presumed, although unproven, that the working mechanism of this medication is through bladder neck/prostatic smooth muscle relaxation. It has also been shown that there are many cell types in the bladder wall, that respond to NO with a rise in intracellular CGMP47,107. It was generally assumed that if the PDE5-inhibitors are acting on the bladder, it should be upon one of these cell types. Our research was focused on identification of the cells which specifically expressed the PDE5 enzyme. Immuno-histochemical techniques were used in order to identify the location of PDE5. The tissue was exposed to the PDE5 inhibitor in combination with nitric oxide that stimulates the guanylyl cyclase enzyme resulting in a rise in CGMP. An increase in CGMP, was visualised using highly selective antibodies against cGMP. $\mathrm{PDE}_{5}$ was chosen as PDE 5 inhibitors are the most widely known and clinically applied of all available PDE inhibitors. Our second research question was the location and the physiological role of the PDE5 enzyme in the bladder, in order to form a basis for the study of the effect and possible use of PDE5 inhibitors in voiding dysfunctions.

\section{Thesis outline}

This thesis is composed of two main sections. The first four chapters focus on the distribution and the role of PGs in the guinea pig bladder. The general introduction presented in Chapter 1 introduces the problem of $O A B$, and gives a brief overview of bladder anatomy and physiology. The current literature on what is known on PGs and their role in the bladder are displayed in Chapter 2. In Chapter 3, the distribution of the $P \mathrm{PE}_{2}$ receptors $E \mathrm{P}_{1}$ and $E \mathrm{P}_{2}$ in the urothelium and suburothelium 
of the guinea pig urinary bladder are presented. Chapter 4 and 5 deal with the EP1 and EP2 receptor distribution in the detrusor muscle layers. In Chapter 6, a study of the physiological role of PG is presented, with the results of an ex vivo study of the effects of inhibition of the enzyme responsible for PG production by a COX inhibitor (indomethacin) on the guinea pig bladder.

The second part of the thesis focuses on the distribution of PDE 5 in the guinea pig urinary bladder. In Chapter 7, a review of the literature is presented summarizing the current knowledge of the role of phosphodiesterases in bladder pathophysiology. The distribution and the site of action of PDE5 in the guinea bladder are discussed in Chapter 8 , based on an indirect visualization technique. A general discussion of all the studies presented in the thesis is given in Chapter 9. 


\section{References}

1. Abrams, P., Cardozo, L., Fall, M., Griffiths, D., Rosier, P., Ulmsten, U., Van Kerrebroeck, Ph.E.V., Victor, A. \& Wein, A. The standardisation of terminology in lower urinary tract function: report from the standardisation sub-committee of the International Continence Society. Urology 61, 37-49 (2003).

2. Haylen, B.T., de Ridder, D., Freeman, R.M., Swift, S.E., Berghmans, B., Lee, J., Monga, A., Petri, E., Rizk, D.E., Sand, P.K. \& Schaer, G.N. An International Urogynecological Association (IUGA)/International Continence Society (ICS) joint report on the terminology for female pelvic floor dysfunction. Neurourology and Urodynamics 29, 4-20 (2010).

3. Abrams, P., Kelleher, C.J., Kerr, L.A. \& Rogers, R.G. Overactive bladder significantly affects quality of life. American Journal of Managed Care 6, S580-590 (2000).

4. Hashim, H. \& Abrams, P. Overactive bladder: an update. Current Opinion in Urology 17, 231-236 (2007).

5. Komaroff., A.L Fagioli, L.R., Doolittle, T.H., Gandek, B., Gleit, M.A., Guerriero, R.T., Kornish, R.J. $2^{\text {nd }}$., Ware, N.C., Ware, J.E. Jr., \& Bates, D.W. Health status in patients with chronic fatigue syndrome and in general population and disease comparison groups. American Journal of Medicine 101, 281-290 (1996).

6. Liberman, J.N., Hunt, T.L., Stewart, W.F., Wein, A., Zhou, Z., Herzog, A.R., Lipton, R.B.\& Diokno. A.C. Healthrelated quality of life among adults with symptoms of overactive bladder: results from a U.S. communitybased survey. Urology 57, 1044-1050 (2001).

7. Coyne, K.S., Sexton, C.C., Thompson, C.L., Clemens, J.Q., Chen, C.I., Bavendam, T. \& Dmochowski, R. Impact of overactive bladder on work productivity. Urology 80, 97-103 (2012).

8. Ouslander, J.G. Management of overactive bladder. New England Journal of Medicine 350, 786-799 (2004).

9. Chiaffarino, F., Parazzini, F., Lavezzari, M. \& Giambanco, V. Impact of urinary incontinence and overactive bladder on quality of life. European Urology 43, 535-538 (2003).

10. Goepel, M., Hoffmann, J.A., Piro, M., Rubben, H. \& Michel, M.C. Prevalence and physician awareness of symptoms of urinary bladder dysfunction. European Urology 41, 234-239 (2002).

11. Cardozo, L. The overactive bladder syndrome: treating patients on an individual basis. British Journal of Urology International 99 Suppl 3, 1-7 (2007).

12. Hu, T.W., Wagner, T.H., Bentkover, J.D., Leblanc, K., Zhou, S.Z. \& Hunt, T. Costs of urinary incontinence and overactive bladder in the United States: a comparative study. Urology 63, 461-465 (2004).

13. Milsom, I., Abrams, P., Cardozo, L., Roberts, R.G., Thüroff, J. \& Wein, A.J. How widespread are the symptoms of an overactive bladder and how are they managed? A population-based prevalence study. British Journal of Urology International 87, 760-766 (2001).

14. Coyne, K.S., Margolis, M.K., Kopp, Z.S. \& Kaplan, S.A. Racial differences in the prevalence of overactive bladder in the United States from the epidemiology of LUTS (EpiLUTS) study. Urology 79, 95-101 (2012).

15. Van Kerrebroeck, Ph.E.V. A treatment algorithm for the overactive bladder. British Journal of Urology International 83 Suppl 2, 29-30 (1999).

16. Klotz, T., Bruggenjurgen, B., Burkart, M. \& Resch, A. The economic costs of overactive bladder in Germany. European Urology 51, 1654-1662; discussion 1662-1653 (2007). 
17. Cerruto, M.A., Asimakopoulos, A.D., Artibani, W., Del Popolo, G., La Martina, M.,Carone, R. \& FinazziAgrò, E. Insight into new potential targets for the treatment of overactive bladder and detrusor overactivity. Urologia Internationalis 89, 1-8 (2012).

18. Abrams, P., et al. Fourth International Consultation on Incontinence Recommendations of the International Scientific Committee: Evaluation and treatment of urinary incontinence, pelvic organ prolapse, and fecal incontinence. Neurourology and Urodynamics 29, 213-240 (2010).

19. Cardozo, L.D. \& Stanton, S.L. Genuine stress incontinence and detrusor instability--a review of 200 patients. British Journal of Obstetrics and Gynaecology 87, 184-190 (1980).

20. Feneley, R.C., Shepherd, A.M., Powell, P.H. \& Blannin, J. Urinary incontinence: prevalence and needs. British Journal of Urology 51, 493-496 (1979).

21. Andersson, K.E. \& Arner, A. Urinary bladder contraction and relaxation: physiology and pathophysiology. Physiological Reviews 84, 935-986 (2004).

22. Andersson, K.E. Drugs and future candidates. Canadian Urological Association Journal 5, S131-133 (2011).

23. Engles, C.D., Hauser, P.J., Abdullah, S.N., Culkin, D.J. \& Hurst, R.E. Intravesical chondroitin sulfate inhibits recruitment of inflammatory cells in an acute acid damage "leaky bladder" model of cystitis. Urology 79, 483 e413-487 (2012)

24. Lewis, S.A. Everything you wanted to know about the bladder epithelium but were afraid to ask. American Journal of Physiology. Renal Physiology 278, F867-874 (2000).

25. Apodaca, G. The uroepithelium: not just a passive barrier. Traffic 5, 117-128 (2004).

26. Hicks, R.M. The mammalian urinary bladder: an accommodating organ. Biological Revision Cambridge Philosophical Society 50, 215-246 (1975).

27. Liang, F.X., Riedel, I., Deng, F.M., Zhou, G., Xu, C., Wu, X.R., Kong, X.P., Moll, R. \& Sun. T.T. Organization of uroplakin subunits: transmembrane topology, pair formation and plaque composition. The Biochemical Journal 355, 13-18 (2001).

28. Sun, T.T. Altered phenotype of cultured urothelial and other stratified epithelial cells: implications for wound healing. American Journal of Physiology 291, F9-21 (2006).

29. Birder, L.A., Ruan, H,Z., Chopra, B., Xiang, Z., Barrick. S., Buffington, C.A., Roppolo, J.R., Ford, A.P., de Groat, W.C. \& Burnstock, G. Alterations in $\mathrm{P}_{2} \mathrm{X}$ and $\mathrm{P}_{2} \mathrm{Y}$ purinergic receptor expression in urinary bladder from normal cats and cats with interstitial cystitis. American Journal of Physiology 287, F1084-1091 (2004).

30. Wiseman, O.J., Brady, C.M., Hussain, I.F., Dasgupta, P., Watt, H., Fowler, C.J., Landon, D.N., The ultrastructure of bladder lamina propria nerves in healthy subjects and patients with detrusor hyperreflexia. The Journal of Urology 168, 2040-2045 (2002).

31. Gillespie, J.I., Markerink-van Ittersum, M. \& de Vente, J. Expression of neuronal nitric oxide synthase (nNOS) and nitric-oxide-induced changes in CGMP in the urothelial layer of the guinea pig bladder. Cell and Tissue Research 321, 341-351 (2005).

32. Chopra, B., Barrick, S.R., Meyers, S., Beckel, J.M., Zeidel, M.L., Ford, A.P., de Groat, W.C. \& Birder, L.A. Expression and function of bradykinin $\mathrm{B}_{1}$ and $\mathrm{B}_{2}$ receptors in normal and inflamed rat urinary bladder urothelium. Journal of Physiology 562, 859-871 (2005). 
33. Birder, L.A., Nealen, M.L., Kiss, S., de Groat, W.C., Caterina, M.J., Wang, E., Apodaca, G. \& Kanai, A.J., Betaadrenoceptor agonists stimulate endothelial nitric oxide synthase in rat urinary bladder urothelial cells. The Journal of Neuroscience 22, 8063-8070 (2002).

34. Burnstock, G. \& Knight, G.E. Cellular distribution and functions of $\mathrm{P}_{2}$ receptor subtypes in different systems. International Review of Cytology 240, 31-304 (2004).

35. Chess-Williams, R. Muscarinic receptors of the urinary bladder: detrusor, urothelial and prejunctional. Autonomic Q Autacoid Pharmacology 22, 133-145 (2002).

36. Gotti, C. \& Clementi, F. Neuronal nicotinic receptors: from structure to pathology. Progress in Neurobiology 74, 363-396 (2004).

37. Birder, L.A., Nakamura, Y., Kiss, S., Nealen, M.L., Barrick, S., Kanai, A.J., Wang, E., Ruiz, G., De Groat, W.C., Apodaca, G., Watkins, S. \& Caterina, M.J., Altered urinary bladder function in mice lacking the vanilloid receptor TRPV1. Nature Neuroscience 5, 856-860 (2002).

38. Birder, L.A., Kanai, A.J., de Groat, W.C., Kiss, S., Nealen, M.L., Burke, N.E., Dineley, K.E., Watkins, S., Reynolds, I.J. \& Caterina, M.J.Vanilloid receptor expression suggests a sensory role for urinary bladder epithelial cells. Proceedings of National Academy of Science of USA 98, 13396-13401 (2001).

39. Birder, L.A., Apodaca, G., De Groat, W.C. \& Kanai, A.J. Adrenergic- and capsaicin-evoked nitric oxide release from urothelium and afferent nerves in urinary bladder. American Journal of Physiology 275, F226-229 (1998).

40. Burnstock, G. Purine-mediated signalling in pain and visceral perception. Trends in Pharmacological Science 22, 182-188 (2001).

41. Ferguson, D.R., Kennedy, I. \& Burton, T.J. ATP is released from rabbit urinary bladder epithelial cells by hydrostatic pressure changes--a possible sensory mechanism? Journal of Physiology 505 ( Pt 2), 503-511 (1997).

42. Mikhailidis, D.P., Jeremy, J.Y. \& Dandona, P. Urinary bladder prostanoids--their synthesis, function and possible role in the pathogenesis and treatment of disease. The Journal of Urology 137, 577-582 (1987).

43. Yoshida, M., Inadome, A., Maeda, Y., Satoji, Y., Masunaga, K., Sugiyama, Y. \& Murakami, S. Non-neuronal cholinergic system in human bladder urothelium. Urology 67, 425-430 (2006).

44. Birder, L.A., Kanai, A.J., Cruz, F., Moore, K. \& Fry, C.H. Is the urothelium intelligent? Neurourology and Urodynamics 29, 598-602 (2010).

45. Drake, M.)., Fry, C.H. \& Eyden, B. Structural characterization of myofibroblasts in the bladder. British Journal of Urology International 51 97, 29-32 (2006).

46. Smet, P.J., Jonavicius, J., Marshall, V.R. \& de Vente, J. Distribution of nitric oxide synthase-immunoreactive nerves and identification of the cellular targets of nitric oxide in guinea-pig and human urinary bladder by cGMP immunohistochemistry. Neuroscience 71, 337-348 (1996).

47. Gillespie, J.I., Markerink-van Ittersum, M. \& de Vente, J. cGMP-generating cells in the bladder wall: identification of distinct networks of interstitial cells. British Journal of Urology International 94, 1114-1124 (2004).

48. McCloskey, K.D. \& Gurney, A.M. Kit positive cells in the guinea pig bladder. The Journal of Urology $168,832-$ 836 (2002). 
49. Davidson, R.A.\& McCloskey, K.D. Morphology and localization of interstitial cells in the guinea pig bladder: structural relationships with smooth muscle and neurons. The Journal of Urology 173, 1385-1390 (2005).

50. Brading, A.F. \& McCloskey, K.D. Mechanisms of Disease: specialized interstitial cells of the urinary tract-an assessment of current knowledge. Nature Clinical Practice. Urology 2, 546-554 (2005).

51. Grol, S., Essers, P.B., van Koeveringe, G.A., Martinez-Martinez, P., de Vente, J. \& Gillespie, J.I. M(3) muscarinic receptor expression on suburothelial interstitial cells. British Journal of Urology International 104, 398-405 (2009).

52. de Jongh, R., Grol, S., van Koeveringe, G.A, Van Kerrebroeck, Ph.E.V., de Vente, J. \& Gillespie, J.I. The localization of cyclo oxygenase immuno-reactivity (COXI-IR) to the urothelium and to interstitial cells in the bladder wall. Journal of Cellular and Molecular Medicine 13, 3069-3081 (2009).

53. Grol, S., van Koeveringe, G.A., de Vente, J., Van Kerrebroeck, Ph.E.V. \& Gillespie, J.I. Regional differences in sensory innervation and suburothelial interstitial cells in the bladder neck and urethra. British Journal of Urology International 102, 870-877 (2008).

54. Komuro, T. Comparative morphology of interstitial cells of Cajal: ultrastructural characterization. Microscopy Research and Technique 47, 267-285 (1999).

55. McCloskey, K.D. Calcium currents in interstitial cells from the guinea-pig bladder. British Journal of Urology International 97, 1338-1343 (2006).

56. Wu, C., Sui, G.P. \& Fry, C.H. Purinergic regulation of guinea pig suburothelial myofibroblasts. Journal of Physiology 559, 231-243 (2004).

57. Ost, D., Roskams, T., Van Der Aa, F. \& De Ridder, D. Topography of the vanilloid receptor in the human bladder: more than just the nerve fibers. The Journal of Urology 168, 293-297 (2002).

58. Lagou, M., Drake,. M.J., Markerink-van Ittersum, M., de Vente, J., \& Gillespie, J.I. Location of interstitial cells and neurotransmitters in the mouse bladder. British Journal of Urology International 97, 1332-1337 (2006).

59. Gillespie, J.I., Markerink-van Ittersum, M. \& De Vente, J. Interstitial cells and cholinergic signalling in the outer muscle layers of the guinea-pig bladder. British Journal of Urology International 97, 379-385 (2006).

6o. Sanders, K.M. A case for interstitial cells of Cajal as pacemakers and mediators of neurotransmission in the gastrointestinal tract. Gastroenterology 111, 492-515 (1996).

61. Ward, S.M., Sanders, K.M. \& Hirst, G.D. Role of interstitial cells of Cajal in neural control of gastrointestinal smooth muscles. Neurogastroenterology and Motility 16 Suppl 1, 112-117 (2004).

62. Andersson, K.E. Changes in bladder tone during filling: pharmacological aspects. Scandinavian Journal of Urology and Nephrology. Supplementum 201, 67-72; discussion 76-99 (1999).

63. Van Arsdalen, K. Wein, A.J. Physiology of Micturition and Continence. Clinical Neuro-urology, $2^{\text {nd }}$ edition. Boston: Little, Brown and Co. pp 25-82. (1991)

64. de Groat, W.C. Anatomy and physiology of the lower urinary tract. The Urologic Clinics of North America 20, 383-401 (1993).

65. Drake, M.). The integrative physiology of the bladder. Annals of the Royal College of Surgeons of England 89, $580-585$ (2007). 
66. Beckel, J.M., Kanai, A., Lee, S.J., de Groat, W.C. \& Birder, L.A. Expression of functional nicotinic acetylcholine receptors in rat urinary bladder epithelial cells. American Journal of Physiology 290, F103-110 (2006).

67. D'Andrea, M.R., Saban, M.R., Nguyen, N.B., Andrade-Gordon, P. \& Saban, R. Expression of proteaseactivated receptor-1, $-2,-3$, and -4 in control and experimentally inflamed mouse bladder. The American Journal of Pathology 162, 907-923 (2003).

68. Du, S., Araki, I., Mikami, Y., Zakoji, H., Beppu, M., Yoshiyama, M. \& Takeda, M., Amiloride-sensitive ion channels in urinary bladder epithelium involved in mechanosensory transduction by modulating stretchevoked adenosine triphosphate release. Urology 69, 590-595 (2007).

69. Yoshimura, N., Yoshimura, N., Kaiho, Y., Miyazato, M., Yunoki, T., Tai, C., Chancellor, M.B. \& Tyagi, P.Therapeutic receptor targets for lower urinary tract dysfunction. Naunyn-Schmiedeberg's Archives of Pharmacology 377, 437-448 (2008).

70. Streng, T., Axelsson, H.E., Hedlund, P., Andersson, D.A., Jordt, S.E., Bevan, S., Andersson, K.E., Högestätt, E.D. \& Zygmunt, P.M. Distribution and function of the hydrogen sulfide-sensitive TRPA 1 ion channel in rat urinary bladder. European Urology 53, 391-399 (2008).

71. Stein, R.J., Santos, S., Nagatomi, J., Hayashi, Y., Minnery, B.S., Xavier, M., Patel, A.S., Nelson, J.B., Futrell, W.J., Yoshimura, N., Chancellor, M.B. \& De Miguel, F. Cool (TRPM8) and hot (TRPV1) receptors in the bladder and male genital tract. The Journal of Urology 172, 1175-1178 (2004).

72. Birder, L., Kullmann, F.A., Lee, H., Barrick, S., de Groat, W., Kanai, A. \& Caterina, M. Activation of urothelial transient receptor potential vanilloid 4 by 4 alpha-phorbol 12,13-didecanoate contributes to altered bladder reflexes in the rat. The Journal of Pharmacology and Experimental Therapeutics 323, 227-235 (2007).

73. Birder, L.A., Ruggieri, M., Takeda, M., van Koeveringe, G.A., Veltkamp, S., Korstanje, C., Parsons, B. \& Fry, C.H., How does the urothelium affect bladder function in health and disease? ICI-RS 2011. Neurourology and Urodynamics 31, 293-299 (2012).

74. Starling, E.H. Elements of Human Physiology, London - J. and A. Churchill (1905).

75. Gillespie, J.I. The autonomous bladder: a view of the origin of bladder overactivity and sensory urge. British Journal of Urology International 93, 478-483 (2004).

76. Gillespie, J.I. A developing view of the origins of urgency: the importance of animal models. British Journal of Urology International 96 Suppl 1, 22-28 (2005).

77. Sui, G.P., Rothery, S., Dupont, E., Fry, C.H. \& Severs, N.J. Gap junctions and connexin expression in human suburothelial interstitial cells. British Journal of Urology International 90, 118-129 (2002).

78. Gillespie, J.I., Markerink-van Ittersum, M. \& de Vente, J. Sensory collaterals, intramural ganglia and motor nerves in the guinea-pig bladder: evidence for intramural neural circuits. Cell and Tissue Research 325, 33-45 (2006).

79. Masunaga, K., Yoshida, M., Inadome, A., Iwashita, H., Miyamae, K., \& Ueda, S. Prostaglandin E2 release from isolated bladder strips in rats with spinal cord injury. International Journal of Urology 13, 271-276 (2006).

80. Park, J.M Yang,T., Arend, L.J., Schnermann, J.B., Peters, C,A., Freeman, M.R. \& Briggs, J.P. Obstruction stimulates $\mathrm{COX} 2$ expression in bladder smooth muscle cells via increased mechanical stretch. The American Journal of Physiology 276, F129-136 (1999). 
81. Pinna, C., Zanardo, R. \& Puglisi, L. Prostaglandin-release impairment in the bladder epithelium of streptozotocin-induced diabetic rats. European Journal of Pharmacology 388, 267-273 (2000).

82. Andersson, K.E., Ek, A. \& Persson, C.G. Effects of prostaglandins on the isolated human bladder and urethra. Acta physiologica Scandinavica 100, 165-171 (1977).

83. Bultitude, M.I., Hills, N.H. \& Shuttleworth, K.E. Clinical and experimental studies on the action of prostaglandins and their synthesis inhibitors on detrusor muscle in vitro and in vivo. British Journal of Urology 48, 631-637 (1976).

84. Borda, E., Contreras-Ortiz, N., Gutnisky, R. \& Gimeno, M.F. In vitro effect of acetylcholine and bethanechol on the contractions of the human detrusor muscle. Influence of prostaglandins. Archives Internationales de Pharmacodynamie et de Therapie 259, 31-39 (1982).

85. Choo, L.K. \& Mitchelson, F. The effect of indomethacin and adenosine 5'-triphosphate on the excitatory innervation of the rate urinary bladder. Canadian Journal of Physiology and Pharmacology 58, 1042-1048 (1980).

86. Burnstock, G., Cocks, T., Crowe, R. \& Kasakov, L. Purinergic innervation of the guinea-pig urinary bladder. British Journal of Pharmacology 63, 125-138 (1978).

87. Downie, J.W. \& Larsson, C. Prostaglandin involvement in contractions evoked in rabbit detrusor by field stimulation and by adenosine 5'-triphosphate. Canadian Journal of Physiology and Pharmacology 59, 253-260 (1981).

88. Johns, A. \& Paton, D.M. Effect of indomethacin on atropine-resistant transmission in rabbit and monkey urinary bladder: evidence for involvement of prostaglandins in transmission. Prostaglandins 13, 245-254 (1977).

89. Jeremy, J.Y., Mikhailidis, D.P. \& Dandona, P. The rat urinary bladder produces prostacyclin as well as other prostaglandins. Prostaglandins, Leukotrienes, and Medicine 16, 235-248 (1984).

9o. Takeda, H., Yamazaki, Y., Igawa, Y., Kaidoh K., Akahane, S., Miyata. H., Nishizawa, O., Akahane, M.\& Andersson, K.E. Effects of beta(3)-adrenoceptor stimulation on prostaglandin E(2)-induced bladder hyperactivity and on the cardiovascular system in conscious rats. Neurourology and Urodynamics 21, 558-565 (2002).

91. Kim, J.C., Park, E.Y., Seo, S.I., Park, Y.H. \& Hwang, T.K. Nerve growth factor and prostaglandins in the urine of female patients with overactive bladder. The Journal of Urology 175, 1773-1776; discussion 1776 (2006).

92. Ikeda, M., Kawatani, M., Maruyama, T. \& Ishihama, H. Prostaglandin facilitates afferent nerve activity via EP1 receptors during urinary bladder inflammation in rats. Biomedical Research (Tokyo, Japan) 27, 49-54 (2006).

93. Ishizuka, O., Mattiasson, A. \& Andersson, K.E. Prostaglandin E2-induced bladder hyperactivity in normal, conscious rats: involvement of tachykinins? The Journal of Urology 153, 2034-2038 (1995).

94. Andersson, K.E. Current concepts in the treatment of disorders of micturition. Drugs 35, 477-494 (1988).

95. Burnstock, G. Purinergic cotransmission. Experimental physiology 94, 20-24 (2009).

96. de Jongh, R., van Koeveringe, G.A., Van Kerrebroeck, Ph.E.V., Markerink-van Ittersum, M., de Vente, J. \&Gillespie, J.I. The effects of exogenous prostaglandins and the identification of constitutive cyclooxygenase I and II immunoreactivity in the normal guinea pig bladder. British Journal of Urology International 100, 419-429 (2007). 
97. Kim, J.C., Park, E.Y., Hong, S.H., Seo, S.I., Park, Y.H. \& Hwang, T.K. Changes of urinary nerve growth factor and prostaglandins in male patients with overactive bladder symptom. International Journal of Urology 12 , 875-880 (2005).

98. Tanaka, I., Nagase, K., Tanase, K., Aoki, Y., Akino, H. \& Yokoyama, O. Improvement in neurogenic detrusor overactivity by peripheral C fiber's suppression with cyclooxygenase inhibitors. The Journal of Urology 183 , 786-792 (2010).

99. Lecci, A., Birder, L.A., Meini, S., Catalioto, R.M., Tramontana, M., Giuliani, S., Criscuoli, M. \& Maggi, C.A. Pharmacological evaluation of the role of cyclooxygenase isoenzymes on the micturition reflex following experimental cystitis in rats. British Journal of Pharmacology 130, 331-338 (2000).

100. Andersson, K.E., Chapple, C.R., Cardozo, L., Cruz, F., Hashim, H., Michel, M.C., Tannenbaum, C. \& Wein, A.J. Pharmacological treatment of overactive bladder: report from the International Consultation on Incontinence. Current Opinion Urology 19, 380-394 (2009).

101. Morikawa, K., Fukuoka, M., Kakiuchi, M., Kato, H., Ito, Y. \& Gomi Y. Detrusor hyperreflexia induced by intravesical instillation of xylene in conscious rats. Japanese Journal Pharmacology 52, 587-595 (1990).

102. Kibar, Y., Irkilata H,C., Yaman, H., Onguru, O., Coguplugil, A.E., Ergin, G., Seyrek, M., Yildiz, O. \& Dayanc, $M$. The effect of intravesical acetylsalicylic acid instillation on tissue prostaglandin levels after partial bladder outlet obstruction in rabbits. Neurourology and Urodynamics 30, 1646-1651 (2011).

103. Grol, S., Essers, P.B., van Koeveringe, G.A., de Vente, J. \& Gillespie, J.I. Ubiquitin hydrolase (protein gene product 9.5) in the obstructed bladder: evidence for tissue remodelling involving a subset of interstitial cells. British Journal of Urology International 104, 698-706 (2009).

104. de Jongh, R., van Koeveringe, G.A., Van Kerrebroeck, Ph.E.V., Markerink-van Ittersum, M., de Vente, J. \& Gillespie, J.I., Alterations to network of NO/cGMP-responsive interstitial cells induced by outlet obstruction in guinea-pig bladder. Cell and Tissue Research 330, 147-160 (2007).

105. Gillespie, J.I., Markerink-van Ittersum, M. \& De Vente, J. Endogenous nitric oxide/cGMP signalling in the guinea pig bladder: evidence for distinct populations of suburothelial interstitial cells. Cell and Tissue Research 325, 325-332 (2006).

106. Sawyer, R.T., Parsons, C.E., Fontenot, A.P., Maier, L.A., Gillespie, M.M., Gottschall, E.B., Silveira, L. \& Newman, L.S. Beryllium-induced tumor necrosis factor-alpha production by $\mathrm{CD}_{4}+\mathrm{T}$ cells is mediated by HLA-DP. American Journal of Respiratory Cell and Molecular Biology 31, 122-130 (2004).

107. Lagou, M., Gillespie, J., Kirkwood, T., Harvey, I. \& Drake, M.). Muscarinic stimulation of the mouse isolated whole bladder: physiological responses in young and ageing mice. Autonomic Q Autacoid Pharmacology 26, 253-260 (2006).

108. de Jongh, R., van Koeveringe, G.A., Van Kerrebroeck, Ph.E.V., Markerink-van Ittersum, M., de Vente, J. $\&$ Gillespie, J.I. Damage to the bladder neck alters autonomous activity and its sensitivity to cholinergic agonists. British Journal of Urology International 100, 919-929 (2007).

109. Klarskov, N. \& Lose, G. Urethral pressure reflectometry and pressure profilometry in healthy volunteers and stress urinary incontinent women. Neurourology and Urodynamics 27, 807-812 (2008). 
110. Essayan, D.M. Cyclic nucleotide phosphodiesterase (PDE) inhibitors and immunomodulation. Biochemical Pharmacology 57, 965-973 (1999).

111. Soderling, S.H., Bayuga, S.J. \& Beavo, J.A. Cloning and characterization of a cAMP-specific cyclic nucleotide phosphodiesterase. Proceedings of National Acadamy of Sciences of USA 95, 8991-8996 (1998).

112. Soderling, S.H., Bayuga, S.J. \& Beavo, J.A. Identification and characterization of a novel family of cyclic nucleotide phosphodiesterases. Journal of Biological Chemistry 273, 15553-15558 (1998).

113. Truss, M.C., Stief, C.G., Uckert, S., Becker, A.J., Schultheiss, D., Machtens, S. \& Jonas, U. Initial clinical experience with the selective phosphodiesterase-I isoenzyme inhibitor vinpocetine in the treatment of urge incontinence and low compliance bladder. World Journal of Urology 18, 439-443 (2000).

114. Sairam, K., Kulinskaya, E., McNicholas, T.A., Boustead, G.B. \& Hanbury, D.C. Sildenafil influences lower urinary tract symptoms. British Journal of Urology International 90, 836-839 (2002).

115. McVary, K.T., Kaufman, J., Young, J.M. \& Tseng, L.J. Sildenafil citrate improves erectile function: a randomised double-blind trial with open-label extension. International Journal of Clinical Practice 61, 1843-1849 (2007).

116. McVary, K.T., Roehrborn, C,G., Kaminetsky, J,C., Auerbach, S.M., Wachs, B., Young, J.M., Esler, A., Sides, G.D., \& Denes, B.S. Tadalafil relieves lower urinary tract symptoms secondary to benign prostatic hyperplasia. The Journal of Urology 177, 1401-1407 (2007).

117. Stief, C.G., Porst, H., Neuser, D., Beneke, M. \& Ulbrich, E. A randomised, placebo-controlled study to assess the efficacy of twice-daily vardenafil in the treatment of lower urinary tract symptoms secondary to benign prostatic hyperplasia. European Urology 53, 1236-1244 (2008).

118. Filippi, S., Morelli A, Sandner, P., Fibbi, B., Mancina, R., Marini, M., Gacci, M., Vignozzi, L., Vannelli, G.B., Carini, M., Forti, G.\& Maggi, M..Characterization and functional role of androgen-dependent PDE5 activity in the bladder. Endocrinology 148, 1019-1029 (2007).

119. Tinel, H., Stelte-Ludwig, B., Hutter, J. \& Sandner, P. Pre-clinical evidence for the use of phosphodiesterase-5 inhibitors for treating benign prostatic hyperplasia and lower urinary tract symptoms. British Journal of Urology International 98, 1259-1263 (2006).

120. Chuang, Y.C., Yoshimura, N., Huang, C.C., Wu, M., Chiang, P.H., \& Chancellor, M.B. Intravesical botulinum toxin $\mathrm{A}$ administration inhibits $\mathrm{COX}_{2}$ and $\mathrm{EP}_{4}$ expression and suppresses bladder hyperactivity in cyclophosphamide-induced cystitis in. rats. European Urology 56, 159-166 (2009).

121. Su, X., Lashinger, E.S., Leon, L.A., Hoffman, B.E., Hieble, J.P., Gardner, S.D., Fries, H.E., Edwards, R.M., Li, J. \& Laping, N.J. An excitatory role for peripheral EP3 receptors in bladder afferent function. American Journal of Physiology. Renal Physiology 295, F585-594 (2008).

122. Wilbraham D., Masuda, T., Deacon, S., Kuwayama, R., \& Vincent, S. Safety, tolerability, and pharmacokinetic of multiple ascending doses of the EP-1 receptor antagonist ONO-8539, a potential new and novel therapy to overactive bladderin healthy young and elderly subjects. European Urology Supplements Vol. 9, 250 (2010).

123. Liu, L., Li, H., Underwood, T., Lloyd, M., David, M., Sperl, G., Pamukcu, R. \& Thompson, W.J. Cyclic GMPdependent protein kinase activation and induction by exisulind and $\mathrm{CP}_{4} 61$ in colon tumor cells. Journal of Pharmacological and Experimental Therapeutics 299, 583-592 (2001). 



\section{Chapter 2 \\ The Role of Prostanoids in Urinary Bladder Physiology}

Nature Reviews Urology. 2012 Mar 13;9(5):283-90

doi: 10.1038/nrurol.2012.33

PMID: 22410675

M.S. Rahnama'i, Ph.E.V. Van Kerrebroeck, S.G.G de Wachter and G.A. van Koeveringe

Department of Urology, Maastricht University Medical Centre (MUMC+)

Maastricht, The Netherlands 


\section{Abstract}

Five primary prostanoids are synthesized by the cyclooxygenase enzymes, $\mathrm{COX}_{1}$ and $\mathrm{COX}_{2}$ : the prostaglandins $P G E_{2}, P G F_{2 a}, P G I_{2}, P G D_{2}$ and thromboxane $A_{2}$. High levels of these signaling molecules have been implicated — in both animal models and human studies -in decreased functional bladder capacity and micturition volume and increased voiding contraction amplitude. Thus, inhibition of prostanoid production or the use of prostanoid receptor antagonists, might be a rational way to treat patients with detrusor muscle overactivity. Similarly, prostanoid receptor agonists, or agents that stimulate their production, might have a function in treating bladder underactivity. Although some promising results have been reported, the adverse effects of nonselective cyclooxygenase inhibitors are a major concern that restricts their use in the treatment of functional bladder disorders. Further preclinical and clinical studies are needed before cyclooxygenase inhibitors, prostanoid receptor agonists and antagonists become worthwhile therapeutic tools in this setting. 


\section{Introduction}

The prostanoids are a subclass of signaling molecules consisting of the prostaglandins, thromboxanes and prostacyclins. Two cyclooxygenase enzyme isoforms- $\mathrm{COX}_{1}$ and $\mathrm{COX}_{2}$ - catalyze the ratelimiting step of prostanoid synthesis, which uses the fatty acid arachidonic acid as the substrate. Both cyclooxygenase isoforms produce labile cyclic endoperoxide, also known as $\mathrm{PGH}_{2}$, which is involved in two pathways of prostanoid synthesis. First, $\mathrm{PGH}_{2}$ is the substrate for the enzymes that produce the other prostaglandins and thromboxane $\mathrm{A}_{2}$ (figure 1). Secondly, $\mathrm{PGH}_{2}$ rapidly undergoes spontaneous rearrangement in aqueous solution to $\mathrm{PGE}_{2}, \mathrm{PGD}_{2}$ and, via ring cleavage, to the seco-prostagladins, which are not discussed further in this article'. Although the exact rates of reaction of each pathway are not known, the seco-prostagladins constitute approximately $20 \%$ of $\mathrm{PGH}_{2}$ products ${ }^{2}$.

The involvement of the prostanoids in bladder physiology first became apparent in the early 1970s, after studies showed that prostaglandins were released upon distension of the bladder ${ }^{3}$ and as a result of mechanical damage to or inflammation of the bladder mucosa ${ }^{4}$. Research over the past several decades has confirmed that prostanoids have a role in controlling mammalian urinary bladder motility, ${ }^{5,6}$. For example, vesical distension and pelvic nerve stimulation cause the release of prostaglandins $\mathrm{PGE}_{2}$ and $\mathrm{PGF}_{2 \alpha}$ into the pelvic venous blood in anesthetized dogs ${ }^{3,7}$. Additionally, intra-arterial administration of $\mathrm{PGE}_{2}$ and $\mathrm{PGF}_{2 \alpha}$ in dogs decreases the threshold micturition volume considerably ${ }^{8}$, which, by contrast, can be increased by the inhibition of prostaglandin production using indomethacin ${ }^{8}$.

In the rabbit bladder, an enhancing role for $\mathrm{PGE}_{2}$ and $\mathrm{PGF}_{2 \alpha}$ has been demonstrated on cholinergic and purinergic contractions generated by electrical field stimulation ${ }^{9,10}$. In the human bladder, ex vivo studies have shown that the detrusor muscle relaxes in response to indomethacin administration and that this muscle produces $\mathrm{PGE}_{2}$ and $\mathrm{PGF}_{2 \alpha}$-like substances" ${ }^{11}$. These data suggest a role for endogenous prostaglandins in the maintenance of baseline muscle tone in the normal human detrusor. Indeed, the high levels of prostanoids expressed in the bladder and their expansive distribution implies organ-specific roles for these signaling molecules in bladder function and, by extension, dysfunction.

A role for prostanoids as biomarkers of disease has also been suggested. For example, urinary levels of $\mathrm{PGE}_{2}$ and $\mathrm{PGF}_{2 \alpha}$ are significantly increased in patients with overactive bladder syndrome compared with control patients ${ }^{12}$. Moreover, an inverse relationship was found between urinary $P G E_{2}$ levels and both the bladder volume at first desire to void and the maximum cystometric capac$i^{12}{ }^{12}$. However, urinary levels of $P G E_{2}$ in a group of patients with detrusor overactivity, increased bladder sensation and interstitial cystitis were not significantly different from those in healthy controls ${ }^{13}$. These conflicting findings illustrate that the role of prostanoid levels in the diagnosis of functional bladder disorders remains controversial and merits further investigation.

In this chapter, we describe the role of prostanoids in bladder physiology, summarize the findings from animal model and human studies and discuss the clinical use of prostanoids in the treatment of functional bladder disorders. 


\section{Prostanoid expression in the bladder}

The five primary prostanoids $\left(\mathrm{PGE}_{2}, \mathrm{PGF}_{2 a^{\prime}}, \mathrm{PGI}_{2}, \mathrm{PGD}_{2}\right.$ and thromboxane $\mathrm{A}_{2}$ ) are all synthesized and released in the bladders of various species during detrusor contraction ${ }^{14-16}$ and under basal physiological conditions ${ }^{17,18}$. For example, in the rabbit, $\mathrm{PGE}_{2}$ is the major prostanoid produced, followed by $\mathrm{PGI}_{2}, \mathrm{PGF}_{2 a}$ and thromboxane $\mathrm{A}_{2}{ }^{19}$. By contrast, $\mathrm{PGI}_{2}$ is the principle prostaglandin in the rat bladder; $P G E_{2}$ and thromboxane $A_{2}$ are produced to a lesser extent ${ }^{20}$ In the human bladder, the major prostanoid is $\mathrm{PGI}_{2}$, followed by $\mathrm{PGE}_{2}, \mathrm{PGF}_{2 \alpha}$ and thromboxane $\mathrm{A}_{2}{ }_{2}^{20}$. As well as these speciesspecific prostanoid expression profiles in the mammalian urinary bladder ${ }^{21}$, marked local differences in prostanoid production are apparent within the bladder wall. For example, the rabbit bladder dome (body) produces considerably higher levels of all the prostanoids than the base ${ }^{19}$. In normal rats, the levels of thromboxane $\mathrm{A}_{2}$ and $\mathrm{PGI}_{2}$ were much greater in urine collected from the bladder than in that collected from the ureters ${ }^{22}$, which suggests that the bladder contributes considerably to the amount of prostanoids present in the urine.

Both $\mathrm{COX}_{1}$ and $\mathrm{COX}_{2}$ are expressed in the bladder ${ }^{23-25}$. Constitutive expression of $\mathrm{COX}_{1}$ is associated with cell somata of the urothelium and with the network of cells running over the smooth muscle bundles of the detrusor ${ }^{24}$. COX 2 expression is induced by various stimuli, including proinflammatory cytokines and growth factors ${ }^{26,27}$. The differences in expression of the two cyclooxygenase isoforms have led to the widely held belief that $\mathrm{COX}_{1}$ produces prostanoids required for the maintenance of homeostasis, whereas those produced by $\mathrm{COX}_{2}$ fulfil a primarily pathophysiological role ${ }^{27}$. Interestingly, increased $\mathrm{COX}_{2}$ expression is apparent immediately after experimentally induced bladder outlet obstruction ${ }^{25}$, which suggests that selective COX 2 inhibitors might alleviate symptoms in patients with overactive bladder. Indeed, in patients with bladder inflammation, inhibiting $\mathrm{COX}_{2}$ could prevent urodynamic changes ${ }^{28}$.

\section{The urothelium}

The bladder urothelium secretes several molecules, such as nitrous oxide, ATP and various prostaglandins, which have cell signaling functionality ${ }^{23,24,29}$. The interstitial cells of the urothelium and suburothelium also express several receptors for these signaling molecules ${ }^{29}$, including prostaglandin receptors ${ }^{30}$.

The expression of COX $\mathrm{X}_{1}$ by the basal layer of the urothelium (and, to a lesser extent, the cells of the intermediate urothelial layer) indicates that prostanoids are active at these sites ${ }^{23,30}$. Indeed, stretching the urothelium can trigger the release of a number of different substances, including prostaglandins ${ }^{24}$. Removal, damage or stimulation (by stretching or administration of muscarinic receptor agonists) of the urothelium and suburothelial layers can change the contractile activity of the underlying tissues, including the smooth muscle ${ }^{31,32}$, which suggests that the prostaglandins are integral to the complex signaling system operating within the urothelium and between the urothelium, suburothelial cells of the lamina propria ${ }^{24,30}$ and the muscle layers ${ }^{31,32}$. Indeed, cells 


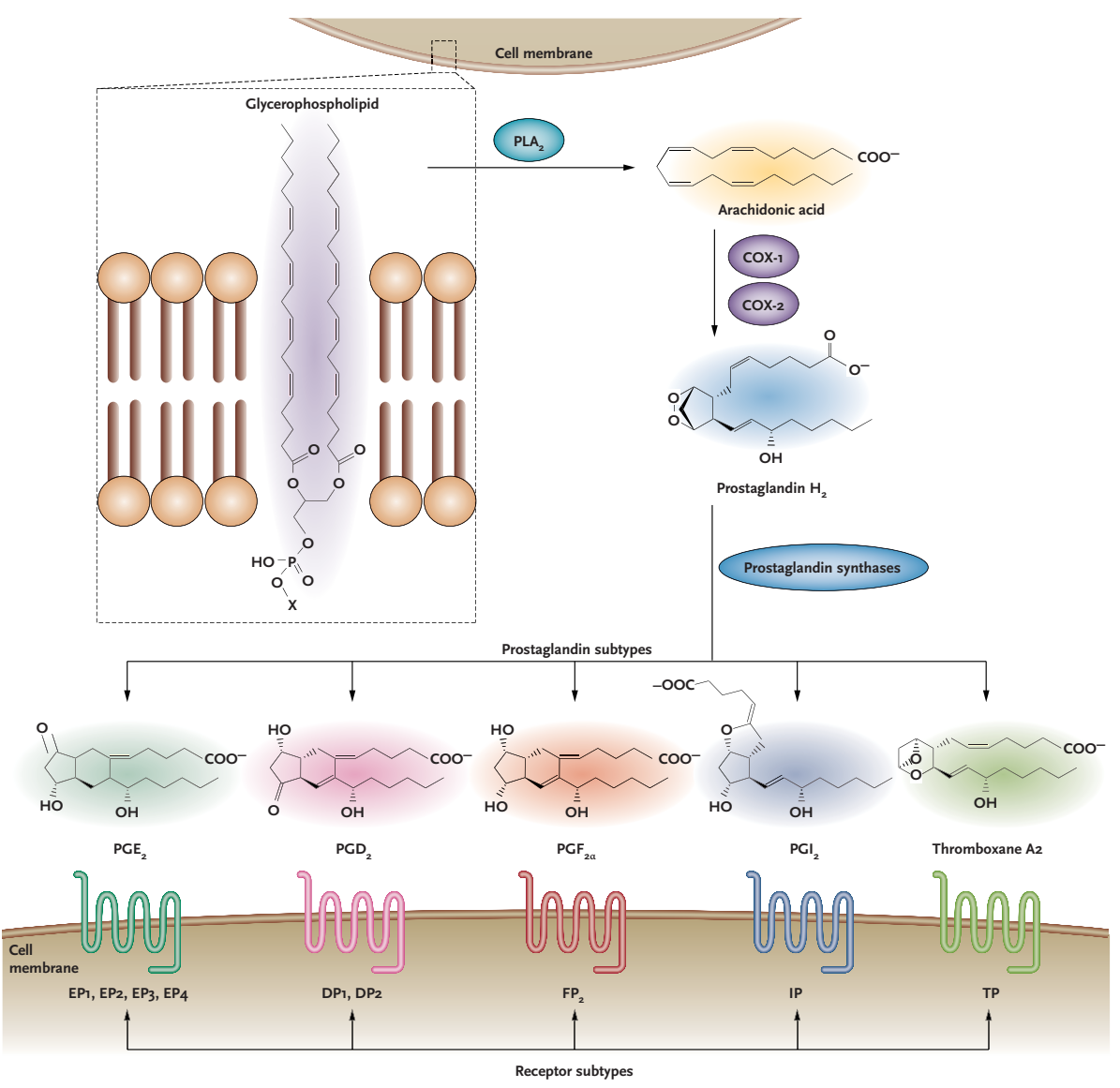

Figure 1. An overview of prostanoid synthesis and prostaglandin receptor affinity. The COX 1 and $C_{1} X_{2}$ enzymes catalyze key steps in the biosynthesis of the labile cyclic endoperoxide prostaglandin $\mathrm{PGH}_{2}$, which is subsequently converted into five structurally related primary prostanoids: the prostaglandins, $P G E_{2}, P G D_{2}, P_{2} F_{2 a}, P G I_{2}$, and thromboxane $A_{2}$. These prostanoids each have their own receptors- $\mathrm{EP}_{1}-4, \mathrm{DP}_{1-2}, \mathrm{FP}_{2}, \mathrm{IP}$ and $\mathrm{TP}$, respectively - which comprise a distinct family of G-protein-coupled receptors. Abbreviations: COX, cyclooxygenase; PLA $_{2}$, phospholipase $A_{2}$. Permission obtained from Nature Publishing Group. Gupta, R. A. \& DuBois, R. N. Nature Reviews Cancer 1, 11-21 (2001).

within these bladder layers express $\mathrm{COX}_{1}$ (at least in the guinea pig bladder) and, hence, are capable of prostaglandin production ${ }^{23,30}$. COX 1 expression predominates within the basal and intermediate layers of the urothelium and within a population of small cells closely associated with a network of vimentin-positive interstitial cells ${ }^{23}$. These interstitial cells form a network throughout the suburothelial space of the lamina propria that extends over the surface of the muscle bundles and invades the inner layers of the bladder wall. Prostanoids are, therefore, produced by cells throughout the bladder wall and its muscle layers ${ }^{23,24,30}$. 


\section{The detrusor muscle}

The cells of the bladder muscle layer express both $\mathrm{COX}_{1}$ and $\mathrm{COX}_{2}$ and, therefore, might also synthesize prostaglandins ${ }^{23-25}$. Indeed, rabbit detrusor muscle strips (free of urothelium) produce $\mathrm{PGE}_{2}^{33}$. Furthermore, detrusor muscle contraction in response to acetylcholine and ATP activation is increased by prostanoid production in various animal models ${ }^{5,34-36}$, which might point to more complex prostanoid involvement in the bladder than was previously thought. Further implicating the prostanoids in detrusor function was the observation that administering indomethacin or other NSAIDs, which inhibit prostanoid synthesis, caused a reduction in tone and loss of spontaneous contractile activity of the isolated bladder; this phenomenon can be reversed by administering prostanoids ${ }^{14}$. In fact, application of exogenous prostaglandins $\left(\mathrm{PGF}_{2 \alpha^{\prime}} \mathrm{PGE}\right.$ and $\left.\mathrm{PGE} \mathrm{E}_{2}\right)$ causes

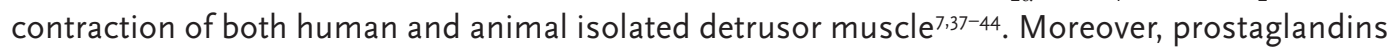
also affect the mammalian urethra ${ }^{7}$ PGF ${ }_{2 \alpha}$ causes it to contract ${ }^{37-40}$, whereas $P G E_{1}$ and $P G E_{2}$ cause relaxation ${ }^{37,42}$. On the basis of these findings, one can envisage a role for agents that act on prostanoid pathways in treating incontinence disorders.

\section{Prostanoid receptors}

Each prostanoid interacts with a specific member of a family of G-protein-coupled receptors (Figure 1). Overall, with the exception of the prostaglandin DP and FP 2 receptors, specific for $\mathrm{PGD}_{2}$ and $P G F_{2 \alpha}$, respectively, all the prostanoid receptors have been shown (directly or indirectly) to be expressed in the bladders of various species (figure 2). Whether these receptors have a function in bladder physiology remains to be determined. One study showed that the prostaglandin $\mathrm{DP}_{1}$ receptor (for $\mathrm{PGD}_{2}$ ) mediates relaxation in human cavernosal tissue and stimulates erectile responses in rats and rabbits ${ }^{45}$. However, no other evidence supports the presence of prostaglandin $\mathrm{DP}_{1}$ and $\mathrm{DP}_{2}$ receptors elsewhere in the urogenital tract. Similarly, no published data support the expression or the role of the prostaglandin $\mathrm{FP}_{2}$ receptor (for $\mathrm{PGF}_{2 a}$ ) in the bladder. The expression and distribution of $\mathrm{PGI}_{2}$ (prostacyclin) receptors in the urinary bladder is also unknown. However, $\mathrm{PGI}_{2}$ is synthesized locally in the bladder in response to bladder distention, injury and inflammation ${ }^{10,46}$, which suggests that its receptor might also be present. This notion is supported by evidence that the $\mathrm{PGI}_{2}$ receptor antagonist $\mathrm{RO}_{3244019}$ was effective in the treatment of neurogenic detrusor overactivity rats with spinal cord injuries ${ }^{47}$. Similarly, no data have been published on thromboxane $A_{2}$ receptor expression or distribution in the bladder. However, thromboxane $A_{2}$ induces contraction of isolated human urinary bladder smooth muscle $4^{8}$. Moreover, two thromboxane $A_{2}$ receptor antagonists inhibit spontaneous, rhythmic contractions of the rabbit bladder, which was free of urothelium, indicating the presence of these receptors in the bladder muscle layer ${ }^{49}$. 


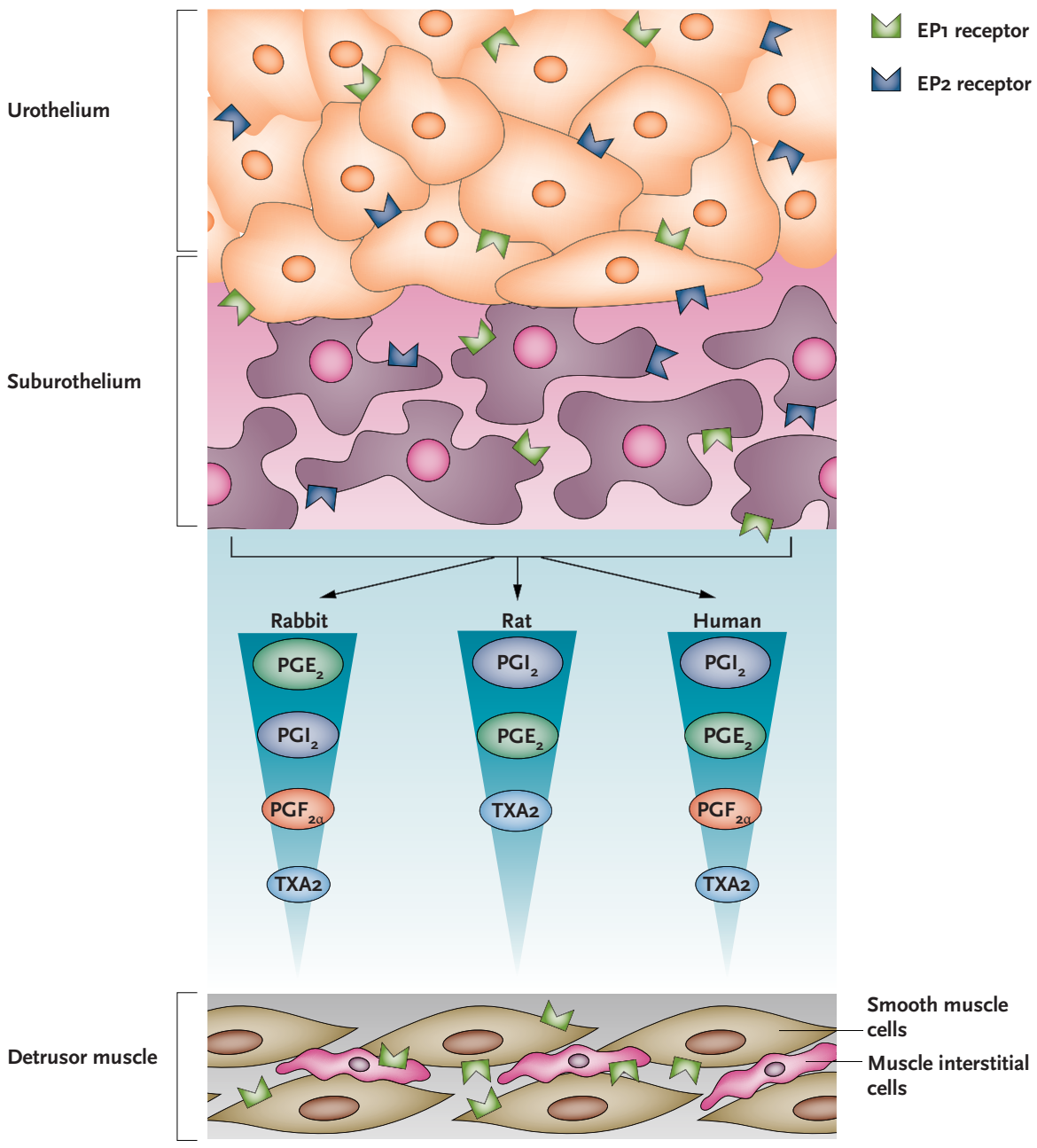

Figure 2. Schematic overview of the distribution of prostanoid receptors in the mammalian bladder. Prostaglandin DP and FP receptors have not yet been identified in the bladder and their role in bladder physiology remains unclear. Expression of IP (the $\mathrm{PGI}_{2}$ receptor) has been indirectly confirmed using an IP-selective antagonist, which reduced detrusor muscle overactivity in a rat model ${ }^{47}$. The $\mathrm{PGE}_{2}$ receptors $E P_{1}$ and $E P_{2}$ are present in the guinea pig urothelium and suburothelial interstitial cells. The EP1 receptor is also expressed in muscle interstitial cells and smooth muscle cells ${ }^{63}$. The EP 3 and EP4 receptors (not shown) have been implicated in rat bladder contraction but their distribution in the bladder has not yet been shown ${ }^{63,65,66}$. Abbreviation: TXA, thromboxane $A_{2}$. 
If the prostanoids do contribute to urinary bladder overactivity, $P G E_{2}$ has been put forward as the most likely candidate. The evidence supporting this hypothesis includes studies in which intravesical instillation of $P G E_{2}$ resulted in diminished bladder capacity ${ }^{41,50-52}$. In addition, local $P G E_{2}$ production is elevated in the bladders of animals with overactive detrusor muscles ${ }^{53,54}$, as well as human patients with overactive bladders ${ }^{12,55}$. The physiological effects of PGE ${ }_{2}$ are mediated by the four prostaglandin EP receptors ${ }^{56}, E_{1}-E P_{4}$, each of which responds to $P G E_{2}$ in a different manner ${ }^{57}$. In general, stimulation of $\mathrm{EP}_{1}$ and $\mathrm{EP}_{3}$ are thought to cause contraction of the bladder smooth muscle, whereas EP2 and EP4 stimulation induces muscle relaxation ${ }^{58,59}$. The molecular characterization of these receptors has led to renewed interest in the development of compounds with activity against specific human prostaglandin receptors, including $\mathrm{EP}_{1}{ }^{60}$.

Initially, the effects of $\mathrm{PGE}_{2}$ on bladder function were thought to be mediated predominantly through $E_{1}$ receptors $^{61}$, because these effects could be inhibited by antagonists of this receptor subtype ${ }^{62}$. In the guinea pig, the EP1 receptor is present in the urothelium, suburothelial interstitial cells, muscle interstitial cells and, to a lesser extent, smooth muscle cells ${ }^{30,63}$. The EP1 receptor is also involved in initiation of the micturition reflex in both normal rats and in animals with bladder outlet obstruction $^{62}$. The EP1 receptor, therefore, is thought to contribute to the initiation of detrusor overactivity after bladder outlet obstruction ${ }^{62}$.

Little information is available on the exact role of the $\mathrm{EP}_{2}$ receptor in the bladder. However, the normal guinea pig bladder expresses EP2 receptors ${ }^{30}$, and the dual EP1 and EP2 receptor antagonist $\mathrm{AH} 6809$ decreases the amplitude of detrusor contraction in the human bladder, as observed in isolated bladder experiments ${ }^{4}$. In rats, pharmacological activation of the EP 3 receptor with the agonist GR63799X was associated with reduced functional bladder capacity, whereas inhibition of this receptor resulted in an enhancement of functional bladder capacity ${ }^{64}$. A diminished response to intravesical instillation of PGE $E_{2}$ was observed in EP3-receptor-knockout mice; these animals also had increased bladder capacity under basal conditions ${ }^{51}$. Furthermore, cystometric studies have provided evidence in support of a role for $\mathrm{EP}_{3}$ receptor activity in urinary bladder activity and regulation of urinary flow ${ }^{64}$. Although its exact role remains to be determined, the $\mathrm{EP}_{3}$ receptor is (at least in this rat model study) a modulator of urinary bladder activity that might regulate urine flow. Despite these findings, the type and localization of cells expressing $\mathrm{EP}_{3}$ receptors in the bladder of any species has not yet been studied.

Expression of the EP4 receptor has been demonstrated in the rat bladder, albeit indirectly via Western blot. EP4 expression can be inhibited by intravesical or intraspinal administration of botulinum toxin $A$ in rats with cyclophosphamide-induced cystitis ${ }^{65}$. A study of rats with bladder outlet obstruction showed that activation of EP4 receptors using the agonist ONO-AE1-329 might suppress detrusor muscle contraction and afferent nerve activity ${ }^{66}$. By contrast, upregulation via increased expression of $\mathrm{EP}_{4}$ receptors exacerbated cyclophosphamide-induced overactive bladder in rats; in this study, treatment with an EP4 receptor antagonist attenuated bladder activity ${ }^{67}$. Blockade of the EP4 receptor mechanism has, therefore, been proposed as a potential treatment for patients with overactive bladder. However, more studies are needed to truly understand the mechanisms underlying EP4 receptor signaling and the implications of its blockade. 


\section{Pharmacological intervention}

Numerous studies in animal models have examined the effects of targeting prostanoids pharmacologically to treat bladder disorders. For example, the level of $\mathrm{PGE}_{2}$ released by bladder strips taken from rats with spinal cord injury was greater than that observed in normal bladders. 68 This finding was confirmed in bladders from human patients with neurogenic overactive bladder or detrusor overactivity owing to spinal cord injury and healthy controls ${ }^{68}$. Moreover, administration of an $E \mathrm{P}_{1}$ receptor antagonist counteracted the increased number and amplitude of nonvoiding bladder contractions resulting from spinal cord injury in rats. This treatment also led to increased micturition volume ${ }^{68}$. In further support of the involvement of $\mathrm{PGE}_{2}$ and $E \mathrm{P}_{1}$ receptors in detrusor activity, normal, conscious rats that received intravesically instilled $\mathrm{PGE}_{2}$ had increased frequency of micturition and increased basal intravesical pressure ${ }^{52}$.

The efficacy of cyclooxygenase inhibitors and prostanoid receptor antagonists for decreasing muscular tone and spontaneous contractile activity of the bladder has been confirmed repeatedly in various animal model studies ${ }^{14,28,69,70}$. For example, intravesical aspirin instillations in partially obstructed rabbit bladders attenuated, albeit not significantly, the contractile response to cholinergic stimulation ${ }^{71}$. The effects of dexketoprofen (a nonselective cyclooxygenase inhibitor) and NS-398 (a selective COX 2 inhibitor) have been studied in normal and inflamed bladder ${ }^{28}$; the results suggest that $\mathrm{COX}_{1}$ might be involved in raising the threshold for activation of the micturition reflex in normal rats and that inhibiting $\mathrm{COX}_{2}$ could prevent the urodynamic changes associated with bladder inflammation ${ }^{28}$. A subsequent study showed that selective $\mathrm{COX}_{2}$ and nonselective cyclooxygenase inhibitors were both effective in suppressing the micturition reflex in rats with bladder overactivity caused by bladder irritation ${ }^{72}$. Similar results were presented by a Japanese research group with regard to the urodynamic effects of the nonselective cyclooxygenase inhibitor indomethacin in rats with xylene-induced cystitis and healthy controls ${ }^{70}$. By contrast, NS-398 (a selective $\mathrm{COX}_{2}$ inhibitor) was a much less potent inhibitor of the micturition reflex than the unselective cyclooxygenase inhibitor dexketoprofen in normal rats ${ }^{28}$. These results suggest that COX 1 might be involved in raising the threshold for activating the micturition reflex in normal rats, whereas $\mathrm{COX}_{2}$ might prevent or reverse the urodynamic changes associated with bladder inflammation induced either by surgery, endotoxins or cyclophosphamide treatment. Few clinical studies have examined pharmacological agents that target prostanoid signaling, despite the increasing evidence from animal models that cyclooxygenase inhibitors might be effective in the treatment of detrusor muscle overactivity. Treatment with the nonselective cyclooxygenase inhibitors flurbiprofen and indomethacin was associated with urodynamic and clinical benefits in a controlled study of 62 patients with urinary symptoms caused by detrusor instability 73,74 . Unfortunately, these two agents produced many adverse effects, including nausea, vomiting, headache and gastrointestinal symptoms ${ }^{73,74}$. The most promising results were reported in a double-blind, placebo-controlled study of the nonselective cyclooxygenase inhibitor ketoprofen (given intravesically for 4 weeks) in 30 women with urodynamically proven detrusor overactivity. Of these patients, 18 were symptom-free after this treatment, and no adverse effects were observed 75 . 
Cyclooxygenase inhibitors are also commonly used to treat postoperative pain ${ }^{76}$; reducing $\mathrm{PGE}_{2}$ levels might, therefore, have a detrimental effect on postoperative voiding function. Unfortunately, no studies have been published on this potentially important relationship. By contrast, $\mathrm{PGE}_{2}$ has been assessed as a treatment for bladder hypocontractility or underactive detrusor syndromes, although little clinical benefit was observed 77,78 . Even in combination with the cholinergic agonist bethanechol chloride, intravesical instillation of $\mathrm{PGE}_{2}$ had only limited therapeutic benefit compared to placebo79. However, intravesical instillation of $\mathrm{PGE}_{2}$ reduces the time to restoration of detrusor function after gynecological surgery ${ }^{80-82}$.

\section{Future perspectives}

The available clearly show that prostanoids are involved in the signaling cascade within the bladder wall. However, their exact role in the bladder is still not fully understood. One hypothesis presented in the literature is that prostanoids, specifically the prostaglandins, act as mediators of the noncholinergic, nonadrenergic control of contraction of the mammalian detrusor ${ }^{83,84}$. Prostaglandins are also thought to induce increased excitability of afferent nerve fibres in several disease states ${ }^{4}$, such as neurogenic bladder, outflow obstruction, idiopathic detrusor instability and interstitial cystitis, as well as in the ageing bladder, which in turn is thought to affect both efferent and afferent neurotransmission. Several different prostaglandin receptors could potentially be involved in this mechanism ${ }^{4,6}$. This hypothesis is further supported by data showing that prostaglandin synthesis is stimulated during the contractile response of the detrusor smooth muscle to release of acetylcholine and $A$ TP $^{34,36}$. Indeed, ATP and PGE $_{2}$ release from the bladder urothelium in rats with overactive detrusor muscles (induced by cerebral infarction) can be suppressed by the antimuscarinic agents imidafenacin and dariferacin. 85 Additional support for the regulatory effect of prostaglandins in the bladder has come from observations that cyclooxygenase inhibitors such as indomethacin exert a mild inhibitory effect on electrically evoked, nerve-mediated contractions of the mammalian detrusor ${ }^{36}$. By contrast, addition of exogenous prostaglandins enhanced the electrically evoked nervemediated contractions of isolated rabbit bladder smooth muscle as well as those evoked by the ATP analogue $\beta, \gamma$-methylene ${ }^{86}$. Spontaneous, rhythmic contractions of the rabbit and mouse detrusor are also thought to be mediated by $P \mathrm{PE}_{2}{ }_{2}^{6,33}$. Both $\mathrm{ATP}$ and $P \mathrm{PE}_{2}$ induce acetylcholine release from the guinea pig bladder urothelium 5 . In addition, some findings indicate that cyclooxygenase inhibitors might suppress ATP release from bladder epithelium by inhibiting production of $P G E_{2} ; E_{1}$ and $E P_{3}$ receptors are thought to be involved in mediating this effect ${ }^{87}$. These observations suggest a strong interplay between the prostaglandins, their receptors and ATP in the control of bladder contractility that might provide a number of potential targets for therapy in bladder contractility disorders. Indeed, some evidence points to an overall modulating influence of $\mathrm{PGE}_{2}$ on nerve excitability, and perhaps on intramural reflexes. However, little evidence exists of any direct effect along the efferent arm of the micturition reflex $x^{4,5,35,38}$. Thus, from a therapeutic perspective, drugs that enhance prostaglandin 
production or bladder sensitivity to these signaling molecules might be suitable for patients with hypocontractile bladder disorders. Emerging evidence indicates that $\mathrm{PGE}_{2}$ causes smooth muscle depolarization, induces intracellular smooth muscle $\mathrm{Ca}^{2+}$ waves and increases the frequency of action potential firing in smooth muscle cells in a manner resistant to neurotransmitter blockade with cyclopentolate ${ }^{6}$. Furthermore, another study revealed that guinea pig bladder smooth muscle cells express the $\mathrm{EP}_{1}$ receptor and the prostaglandin signal is propagated throughout the bladder wall via the interstitial cell network ${ }^{63}$. The implication of this finding is that the motor effect by prostaglandins is not necessarily mediated through nerve fibres but rather through the interstitial cell network.

Cumulatively, these hypotheses can be used to formulate a comprehensive view of the role of the prostanoids in the bladder. Although the urothelium has been historically viewed primarily as a barrier, it is increasingly being recognized as a responsive structure capable of detecting physiological and chemical stimuli, and of releasing a number of signaling molecules $23,24,29,30,87$. Data indicate that bladder urothelial cells display a number of receptors similar to those of sensory neurons, such as nociceptors and mechanoreceptors, and that these cells use diverse signal-transduction mechanisms such as prostaglandins to detect and respond to physiological stimuli ${ }^{88}$. Several substances, including prostanoids, are released from urothelial cells following physical and chemical stimuli24,30. Thus, because prostaglandins are produced by the urothelium and lamina propria ${ }^{18,24,30}$, they are likely to have an effect on the bladder smooth muscle cells and the interstitial cell network ${ }^{24,30}$ and might also have a modulating effect on the nerves ${ }^{38,88}$. This hypothesis provides three possible, coexisting mechanisms of action for prostaglandins on bladder function: a neuromodulatory effect, effects mediated through the interstitial cell network and direct effects on smooth muscle cells.

More research is needed to elucidate the exact role of prostanoids in the bladder. Despite agreement in the literature that prostanoids have an important role in bladder physiology, approaches that target these factors (by modulating prostanoid receptors, inducing prostanoid synthesis or administering exogenous prostanoids) have failed to gain a place in the standard therapeutic arsenal for functional bladder disorders. This failure is partly attributable to the high incidence of adverse effects associated with the medications used and, in some cases, to their poor clinical efficacy ${ }^{73-75,77-79,81,82}$. Despite these setbacks, efforts to find effective prostanoid-based strategies to treat bladder disorders are ongoing. For example, long-acting prostaglandin agonists or cyclooxygenase activators could be beneficial in the treatment of patients with bladder underactivity (figure 3) ${ }^{89}$. ONO 85-39, an $E P_{1}$ receptor antagonist has entered phase I clinical trials in patients with overactive bladder ${ }^{\circ}$. Bladder-specific prostaglandin receptor antagonists or nonselective prostanoid receptor antagonists might also provide an avenue for treating bladder overactivity. In this regard, the EP receptors for PGE ${ }_{2}$ seem to be the most promising targets. Importantly, the various prostaglandin receptors operate through different mechanisms, and their nonselective activation or inhibition might inadvertently result in opposing effects. Thus, combination therapy with specific selective prostaglandin receptor agonist and antagonists of the other receptors is a potentially interesting area worthy of exploration. 


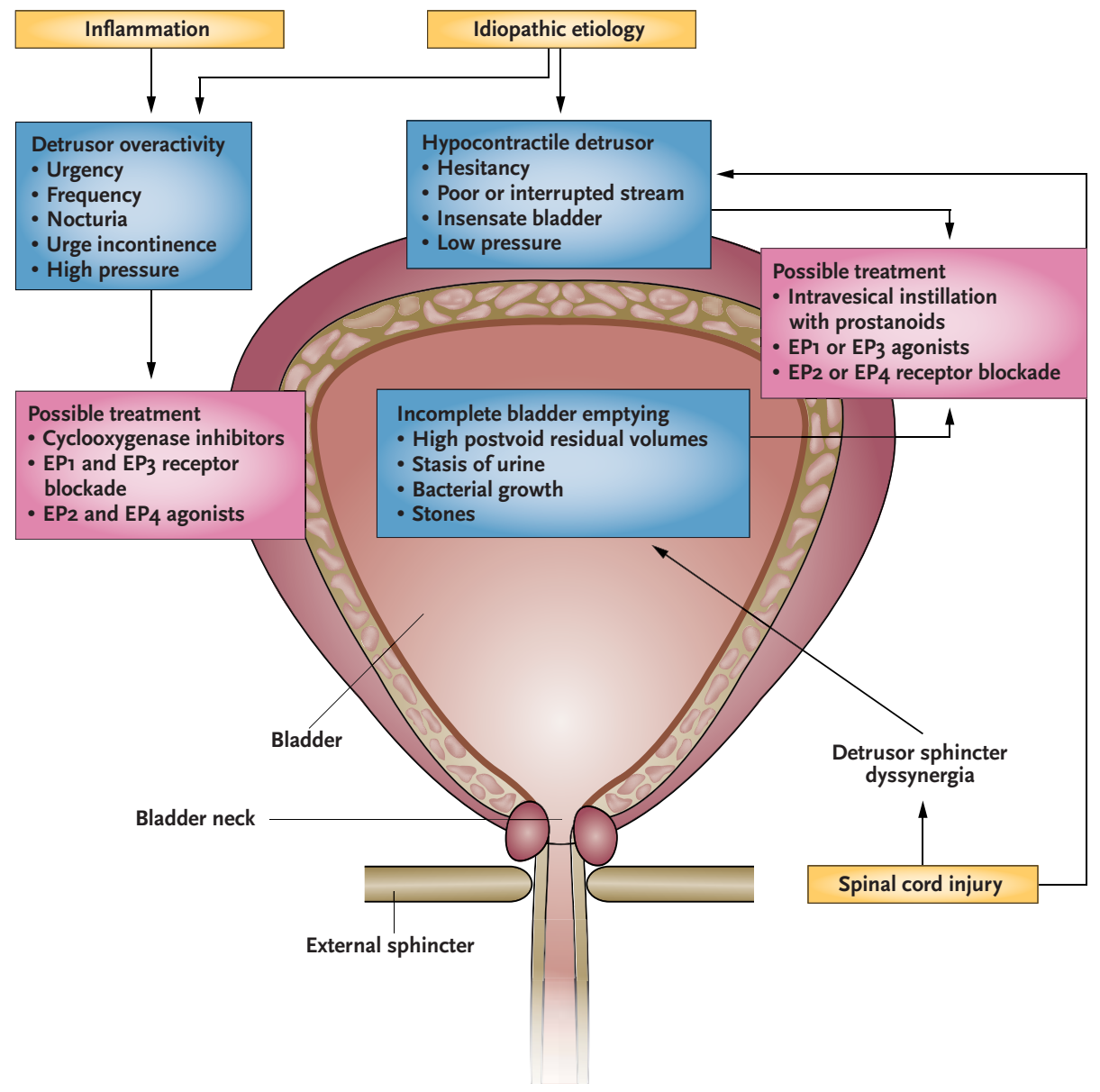

Figure 3. Common pathological states of the urinary bladder.

Prostanoid-related pharmacotherapy might be useful for treating detrusor overactivity or hypocontractility. 


\section{Conclusions}

Prostanoids are produced in the bladder and their receptors are located within the bladder wall. In animal experiments, the administration of prostanoids, specifically the prostaglandins, decreases functional bladder capacity and micturition volume and increases voiding contraction amplitude. This effect has also been demonstrated in a small number of human studies with limited numbers of patients. Inhibition of prostanoid production, or the use of prostanoid receptor antagonists, seems to be a rational method of treating patients with detrusor overactivity. By contrast, prostanoid receptor agonists or agents that stimulate production of prostanoids might have a role in treating bladder underactivity. Although some promising results have been reported, the adverse effects associated with nonselective cyclooxygenase inhibitors present a major obstacle to the general use of prostaglandin-based pharmacotherapy in patients with functional bladder disorders. Further preclinical and clinical studies are needed before prostanoid signaling pathways can become viable targets for pharmacotherapy in functional bladder disorders. 


\section{References}

1. Boutaud, O. Ou, J.J., Chaurand, P., Caprioli, R.M., Montine, T.J. \& Oates, J.A. Prostaglandin $\mathrm{H}_{2}$ (PGH2) accelerates formation of amyloid $\beta 1-42$ oligomers. Journal of Neurochemistry. 82, 1003-1006 (2002).

2. Salomon, R. G., Miller, D. B., Zagorski, M. G. \& Coughlin, D. J. Prostaglandin endoperoxides. 14. Solventinduced fragmentation of prostaglandin endoperoxides. New aldehyde products from $\mathrm{PGH}_{2}$ and a novel intramolecular 1,2-hydride shift during endoperoxide fragmentation in aqueous solution. Journal of American Chemical Society. 106, 6049-6060 (1984).

3. Gilmore, N. J. \& Vane, J. R. Hormones released into the circulation when the urinary bladder of the anaesthetized dog is distended. Clinical Science 41, 69-83 (1971).

4. Andersson, K. E. Overactive bladder-pharmacological aspects. Scandinavian Journal Urology and Nephrology Supplement 210, 72-81 (2002).

5. Nile, C. J. \& Gillespie, J. I. Interactions between cholinergic and prostaglandin signaling elements in the urothelium: role for muscarinic type 2 receptors. Urology 79, 240.e17-23 (2012).

6. Kobayter, S., Young, J. S. \& Brain, K. L. Prostaglandin E2 induces spontaneous rhythmic activity in mouse urinary bladder independently of efferent nerves. British Journal Pharmacology 165, 401-413 (2012).

7. Khalaf, I. M., Lehoux, J. G., Elshawarby, L. A. \& Elhilali, M. M. Release of prostaglandins into the pelvic venous blood of dogs in response to vesical distension and pelvic nerve stimulation. Investigative Urology. 17, 244-247 (1979).

8. Khalaf, I. M., Ghoneim, M. A. \& Elhilali, M. M. The effect of exogenous prostaglandins F2 $\alpha$ and E2 and indomethacin on micturition. British Journal Urology 53, 21-28 (1981).

9. Husted, S., Sjögren, C. \& Andersson, K. E. Role of prostaglandins in the responses of rabbit detrusor to noncholinergic, non-adrenergic nerve stimulation and to ATP. Archives Internationales de Pharmacodynamie et de Therapie. 246, 84-97 (1980).

10. Downie, J. W. \& Karmazyn, M. Mechanical trauma to bladder epithelium liberates prostanoids which modulate neurotransmission in rabbit detrusor muscle. Journal of Pharmacology and Experimental therapeutics. 230, 445-449 (1984).

11. Abrams, P. H., Sykes, J. A., Rose, A. J. \& Rogers, A. F. The synthesis and release of prostaglandins by human urinary bladder muscle in vitro. Investigative Urology 16, 346-348 (1979).

12. Kim, J. C., Park, E. Y., Seo, S. I., Park, Y. H. \& Hwang, T. K. Nerve growth factor and prostaglandins in the urine of female patients with overactive bladder. The Journal of Urology 175, 1773-1776 (2006).

13. Liu, H. T., Tyagi, P., Chancellor, M. B. \& Kuo, H. C. Urinary nerve growth factor but not prostaglandin E2 increases in patients with interstitial cystitis/bladder pain syndrome and detrusor overactivity. British Journal of Urology International 106, 1681-1685 (2010).

14. Bultitude, M. I., Hills, N. H. \& Shuttleworth, K. E. Clinical and experimental studies on the action of prostaglandins and their synthesis inhibitors on detrusor muscle in vitro and in vivo. British Journal of Urology 48, 631-637 (1976).

15. Khalaf, I. M., Rioux, F., Quirion, R. \& Elhilali, M. M. Intravesical prostaglandin: release and effect of bladder instillation on some micturition parameters. British Journal of Urology 52, 351-356 (1980). 
16. Klarskov, P. Influence of prostaglandins and ketoprofen on contractile responses of human and pig detrusor and trigone muscles in vitro. Pharmacology and Toxicology 61, 37-41 (1987).

17. Poggesi, L., Nicita, G., Castellani, S., Selli, C., Galanti, G., Turini, D. \& Masotti, G. The role of prostaglandins in the maintenance of the tone of the rabbit urinary bladder. Investigative Urology. 17, 454-458 (1980).

18. Brown, W. W., Zenser, T. V. \& Davis, B. B. Prostaglandin E2 production by rabbit urinary bladder. American Journal of Physiology 239, F452-F458 (1980).

19. Leslie, C. A., Pavlakis, A. J., Wheeler, J. S. Jr, Siroky, M. B. \& Krane, R. J. Release of arachidonate cascade products by the rabbit bladder: neurophysiological significance? Journal of Urology 132, 376-379 (1984).

20. Jeremy, J. Y., Mikhailidis, D. P. \& Dandona, P. The rat urinary bladder produces prostacyclin as well as other prostaglandins. Prostaglandins Leukotrienes and Medicine 16, 235-248 (1984).

21. Larsson, C. Production and effects of prostaglandins in the detrusor from homo, cat, rabbit, and rat. Advances in Prostaglandin Thromboxane Research 8, 1263-1267 (1980).

22. Reyes, A. A. \& Klahr, S. Bladder contributes to eicosanoids excreted in urine. American Journal of Physiology 259 (5 Pt 2), F859-F861 (1990).

23. de Jongh R., Grol, S., van Koeveringe, G.A., Van Kerrebroeck, Ph.E.V., de Vente, J. \& Gillespie, J.I. The localization of cyclo oxygenase immuno-reactivity (COX I-IR) to the urothelium and to interstitial cells in the bladder wall. Journal of Cellular and Molecular Medicine 13, 3069-3081 (2009).

24. de Jongh R., van Koeveringe, G.A., Van Kerrebroeck, Ph.E.V., Markerink-van Ittersum, M., de Vente, J. \& Gillespie, J.I The effects of exogenous prostaglandins and the identification of constitutive cyclooxygenase I and II immunoreactivity in the normal guinea pig bladder. British Journal of Urology International 100, 419-429 (2007).

25. Park, J. M., Yang, T., Arend, L.J., Smart, A.M., Schnermann, J.B. \& Briggs, J.P. Cyclooxygenase-2 is expressed in bladder during fetal development and stimulated by outlet obstruction. American Journal of Physiology 273 (4 Pt 2), F538-F544 (1997).

26. Vane, J. R., Bakhle, Y. S. \& Botting, R. M. Cyclooxygenases 1 and 2. Annual Review of Pharmacology and Toxicology 38, 97-120 (1998).

27. Rouzer, C. A. \& Marnett, L. J. Cyclooxygenases: structural and functional insights. Journal of Lipid Research 50 (Suppl.), S29-S34 (2009).

28. Lecci, A., Birder, L.A., Meini, S., Catalioto, R.M., Tramontana, M., Giuliani, S., Criscuoli, M., \& Maggi, C.A. Pharmacological evaluation of the role of cyclooxygenase isoenzymes on the micturition reflex following experimental cystitis in rats. British Journal of Pharmacology 130, 331-338 (2000).

29. Birder, L. A. \& de Groat, W. C. Mechanisms of disease: involvement of the urothelium in bladder dysfunction. Nature Clinical Practice Urology 4, 46-54 (2007).

30. Rahnama'i, M. S. van Koeveringe, G.A., Essers, P.B., de Wachter, S.G., de Vente, J., Van Kerrebroeck, Ph.E.V., \& Gillespie, J.I. Prostaglandin receptor EP1 and EP2 site in guinea pig bladder urothelium and lamina propria. The Journal of Urology 183, 1241-1247 (2010).

31. Ikeda, Y. \& Kanai, A. Urotheliogenic modulation of intrinsic activity in spinal cord-transected rat bladders: role of mucosal muscarinic receptors. American Journal of Physiology. Renal Physiology 295, F454-F461 (2008). 
32. Kanai, A., Roppolo, J., Ikeda, Y., Zabbarova, I., Tai, C., Birder, L., Griffiths, D., de Groat, W. \& Fry C. Origin of spontaneous activity in neonatal and adult rat bladders and its enhancement by stretch and muscarinic agonists. American Journal of Physiology. Renal Physiology 292, F1065-F1072 (2007).

33. Klausner, A. P., Johnson, C.M., Stike, A.B., Speich, J.E., Sabarwal, V., Miner, A.S., Cleary, M., Koo, H.P. \& Ratz, P.H. Prostaglandin E2 mediates spontaneous rhythmic contraction in rabbit detrusor muscle. Canadian Journal of Urology 18, 5608-5614 (2011).

34. Anderson, G. F. Evidence for a prostaglandin link in the purinergic activation of rabbit bladder smooth muscle. Journal of Pharmacology and Experimental Therapy 220, 347-352 (1982).

35. Nile, C. J., de Vente, J. \& Gillespie, J. I. Stretch independent regulation of prostaglandin E2 production within the isolated guinea-pig lamina propria. British Journal of Urology International 105, 540-548 (2010).

36. Maggi, C. A., Evangelista, S., Grimaldi, G., Santicioli, P., Giolitti, A. \& Meli, A. Evidence for the involvement of arachidonic acid metabolites in spontaneous and drug-induced contractions of rat urinary bladder. Journal of Pharmacology and Experimental Therapy 230, 500-513 (1984).

37. Andersson, K. E., Ek, A. \& Persson, C. G. Effects of prostaglandins on the isolated human bladder and urethra. Acta Physiologica Scandinavica 100, 165-171 (1977).

38. Andersson, K. E. \& Forman, A. Effects of prostaglandins on the smooth muscle of the urinary tract. Acta Pharmacologica et Toxicologica 43 (Suppl. 2), 90-95 (1978).

39. Khanna, O. P., Barbieri, E. J. \& McMichael, R. Effects of prostaglandins on vesicourethral smooth muscle of rabbit. Therapeutic Implications. Urology 12, 674-681 (1978).

40. Klarskov, P., Gerstenberg, T., Ramirez, D., Christensen, P. \& Hald, T. Prostaglandin type E activity dominates in urinary tract smooth muscle in vitro. The Journal of Urology 129, 1071-1074 (1983).

41. Maggi, C. A., Giuliani, S., Conte, B., Furio, M., Santicioli, P., Meli, P., Gragnani, L. \& Meli, A. Prostanoids modulate reflex micturition by acting through capsaicin-sensitive afferents. European Journal of Pharmacology 145, 105-112 (1988).

42. Ueda, S., Satake, N. \& Shibata, S. a1-and a2-adrenoceptors in the smooth muscle of isolated rabbit urinary bladder and urethra. European Journal of Pharmacology 103, 249-254 (1984).

43. Gotoh, M., Hassouna, M. \& Elhilali, M. M. The mode of action of prostaglandin E2, F2a and prostacyclin on vesicourethral smooth muscle. The Journal of Urology 135, 431-437 (1986).

44. Poli, E., Macaluso, G. \& Pozzoli, C. Actions of two novel prostaglandin analogs, SC-29169 and SC-31391, on guinea pig and human isolated urinary bladder. General Pharmacology 23, 805-809 (1992).

45. Brugger, N., Kim, N. N., Araldi, G. L., Traish, A. M. \& Palmer, S. S. Pharmacological and functional characterization of novel EP and DP receptor agonists: DP1 receptor mediates penile erection in multiple species. Journal of Sexual Medicine 5, 344-356 (2008).

46. Jeremy, J.Y., Tsang, V., Mikhailidis, D.P., Rogers, H., Morgan, R.J. \& Dandona, P. Eicosanoid synthesis by human urinary bladder mucosa: pathological implications. British Journal of Urology 59, 36-39 1987).

47. Khera, M., Boone, T. B., Salas, N., Jett, M. F. \& Somogyi, G. T. The role of the prostacyclin receptor antagonist $\mathrm{RO}_{3244019}$ in treating neurogenic detrusor overactivity after spinal cord injury in rats. British Journal of Urology International 99, 442-446 (2007). 
48. Palea, S., Toson, G., Pietra, C., Trist, D.G., Artibani, W., Romano, O. \& Corsi, M. Pharmacological characterization of thromboxane and prostanoid receptors in human isolated urinary bladder. British Journal of Pharmacology. 124, 865-872 (1998).

49. Collins, C., Klausner, A.P., Herrick, B., Koo, H.P., Miner, A.S., Henderson, S.C. \& Ratz, P.H. Potential for control of detrusor smooth muscle spontaneous rhythmic contraction by cyclooxygenase products released by interstitial cells of Cajal. Journal of Cellular and Molecular Medicine 13, 3236-3250 (2009).

50. Schüssler, B. Comparison of the mode of action of prostaglandin $E_{2}\left(P_{2} E_{2}\right)$ and sulprostone, a PGE ${ }_{2}^{-}$ derivative, on the lower urinary tract in healthy women. A urodynamic study. Urological Research 18, 349-352 (1990).

51. McCafferty, G. P., Misajet, B. A., Laping, N. J., Edwards, R. M. \& Thorneloe, K. S. Enhanced bladder capacity and reduced prostaglandin E2-mediated bladder hyperactivity in $\mathrm{EP}_{3}$ receptor knockout mice. American Journal of Physiology. Renal Physiology 295, F507-F514 (2008).

52. Ishizuka, O., Mattiasson, A. \& Andersson, K. E. Prostaglandin E2-induced bladder hyperactivity in normal, conscious rats: involvement of tachykinins? Journal of Urology 153, 2034-2038 (1995).

53. Park, J. M. Yang, T., Arend, L.J., Schnermann, J.B., Peters, C.A., Freeman, M.R. \& Briggs, J.P. Obstruction stimulates $\mathrm{COX}_{2}$ expression in bladder smooth muscle cells via increased mechanical stretch. American Journal of Physiology 276, F129-F136 (1999).

54. Hu, V. Y., Malley, S., Dattilio, A., Folsom, J.B., Zvara, P., \& Vizzard, M.A. COX2 and prostanoid expression in micturition pathways after cyclophosphamide-induced cystitis in the rat. American Journal of Physiology. Regulatory, Integrative and Comparative Physiology 284, R574-R585 (2003).

55. Kim, J. C. Park, E.Y., Hong, S.H., Seo, S.I., Park, Y.H. \& Hwang, T.K. Changes of urinary nerve growth factor and prostaglandins in male patients with overactive bladder symptom. International Journal of Urology 12 , $875-880$ (2005).

56. Alexander, S. P., Mathie, A. \& Peters, J. A. Guide to Receptors and Channels (GRAC), 3rd edition. British Journal of Pharmacology 153 (Suppl. 2), S1-S209 (2008).

57. Negishi, M., Sugimoto, Y. \& Ichikawa, A. Prostaglandin E receptors. Journal of Lipid Mediators and Cell Signalling 12, 379-391 (1995).

58. Coleman, R. A., Smith, W. L. \& Narumiya, S. International Union of Pharmacology classification of prostanoid receptors: properties, distribution, and structure of the receptors and their subtypes. Pharmacological Reviews 46, 205-229 (1994).

59. Ikeda, M., Kawatani, M., Maruyama, T. \& Ishihama, H. Prostaglandin facilitates afferent nerve activity via EP1 receptors during urinary bladder inflammation in rats. Biomedical Research 27, 49-54 (2006).

6o. Naganawa, A., Matsui T., Saito T., Ima, M., Tatsumi, T., Yamamoto, S., Murota, M., Yamamoto, H., Maruyama, T., Ohuchida, S., Nakai, H., Kondo, K. \& Toda, M.Discovery of heteroaryl sulfonamides as new EP1 receptor selective antagonists. Bioorganic and Medicinal Chemistry 14, 6628-6639 (2006).

61. Schröder, A., Newgreen, D. \& Andersson, K. E. Detrusor responses to prostaglandin E2 and bladder outlet obstruction in wild-type and EP1 receptor knockout mice. The Journal of Urology 172, 1166-1170 (2004). 
62. Lee, T., Hedlund, P., Newgreen, D. \& Andersson, K. E. Urodynamic effects of a novel EP1 receptor antagonist in normal rats and rats with bladder outlet obstruction. The Journal of Urology 177, 1562-1567 (2007).

63. Rahnama'i, M. S., de Wachter, S.G., van Koeveringe G.A., Van Kerrebroeck, Ph.E.V., de Vente, J. \& Gillespie, J.I. The relationship between prostaglandin E receptor 1 and cyclooxygenase I expression in guinea pig bladder interstitial cells: proposition of a signal propagation system. The Journal of Urology 185, 315-322 (2011).

64. Jugus, M. J., Jaworski, J.P., Patra, P.B., Jin, J., Morrow, D.M., Laping, N.J., Edwards, R.M. \& Thorneloe, K.S. Dual modulation of urinary bladder activity and urine flow by prostanoid EP receptors in the conscious rat. British Journal of Pharmacology 158, 372-381 (2009).

65. Chuang, Y.C., Yoshimura, N., Huang, C.C., Wu, M., Chiang, P.H. \& Chancellor, M.B. Intravesical botulinum toxin $\mathrm{A}$ administration inhibits $\mathrm{COX}_{2}$ and EP4 expression and suppresses bladder hyperactivity in cyclophosphamide-induced cystitis in rats. European Urology 56, 159-166 (2009).

66. Beppu, M., Araki, I., Yoshiyama, M., Du, S., Kobayashi, H., Zakoji, H. \& Takeda, M. Bladder outlet obstruction induced expression of prostaglandin $\mathrm{E}_{2}$ receptor subtype $\mathrm{EP}_{4}$ in the rat bladder: a possible counteractive mechanism against detrusor overactivity. The Journal of Urology 186, 2463-2469 (2011).

67. Chuang, Y. C., Yoshimura, N., Huang, C.C., Wu, M., Tyagi, P. \& Chancellor, M.B. Expression of E-series prostaglandin (EP) receptors and urodynamic effects of an EP4 receptor antagonist on cyclophosphamideinduced overactive bladder in rats. British Journal of Urology International 106, 1782-1787 (2010).

68. Masunaga, K., Yoshida, M., Inadome, A., Iwashita, H., Miyamae, K. \& Ueda, S. Prostaglandin E2 release from isolated bladder strips in rats with spinal cord injury. International Journal of Urology 13,271-276. (2006)

69. Andersson, K. E., Chapple, C.R., Cardozo, L., Cruz, F., Hashim, H., Michel, M.C., Tannenbaum, C. \& Wein, A.J. Pharmacological treatment of overactive bladder: report from the International Consultation on Incontinence. Current Opinion in Urology 19, 380-394 (2009).

70. Morikawa, K., Fukuoka, M., Kakiuchi, M., Kato, H., Ito, Y. \& Gomi,Y. Detrusor hyperreflexia induced by intravesical instillation of xylene in conscious rats. Japanes Journal of Pharmacology 52, 587-595 (1990).

71. Kibar, Y., Irkilata, H.C., Yaman, H., Onguru, O., Coguplugil, A.E., Ergin, G., Seyrek, M., Yildiz, O. \& Dayanc, $M$. The effect of intravesical acetylsalicylic acid instillation on tissue prostaglandin levels after partial bladder outlet obstruction in rabbits. Neurourology and Urodynamics 30, 1646-1651 (2011).

72. Angelico, P., Guarneri, L,, Velasco, C., Cova, R., Leonardi, A., Clarke, D.E. \& Testa, R. Effect of cyclooxygenase inhibitors on the micturition reflex in rats: correlation with inhibition of cyclooxygenase isozymes. British Journal of Urology International 97, 837-846 (2006).

73. Cardozo, L. D. \& Stanton, S. L. A comparison between bromocriptine and indomethacin in the treatment of detrusor instability. The Journal of Urology 123, 399-401 (1980).

74. Cardozo, L. D., Stanton, S. L., Robinson, H. \& Hole, D. Evaluation of flurbiprofen in detrusor instability. British Medical Journal 280, 281-282 (1980).

75. Sprem, M., Milicic, D., Oreskovic, S., Ljubojevic, N. \& Kalafatic, D. Intravesically administered ketoprofen in treatment of detrusor instability: cross-over study. Croatian Medical Journal 41, 423-427 (2000). 
76. Zemmel, M. H. The role of $\mathrm{COX}_{2}$ inhibitors in the perioperative setting: efficacy and safety-a systematic review. American Association of Nurse Anesthetists Journal 74, 49-60 (2006).

77. Bergman, A., Mushkat, Y., Gordon, D. \& David, M. P. Prostaglandin for enhancing bladder function after vaginal surgery. Does it work? Journal of Reproductive Medicine 37, 320-322 (1992).

78. Delaere, K. P., Thomas, C. M., Moonen, W. A. \& Debruyne, F. M. The value of intravesical prostaglandin E2 and F2 $\alpha$ in women with abnormalities of bladder emptying. British Journal of Urology 53, 306-309 (1981).

79. Hindley, R. G., Brierly, R. D. \& Thomas, P. J. Prostaglandin E2 and bethanechol in combination for treating detrusor underactivity. British Journal of Urology International 93, 89-92 (2004).

80. Buckley, B. S. \& Lapitan, M. C. Drugs for treatment of urinary retention after surgery in adults. Cochrane Database Systemic Review CDoo8O23 (2010).

81. Bergman, A., Mushket, Y., Gordon, D. \& David, M. P. Prostaglandin prophylaxis and bladder function after vaginal hysterectomy: a prospective randomised study. British Journal of Obstetrics and Gynaecology 100, 69-72 (1993).

82. Koonings, P. P., Bergman, A. \& Ballard, C. A. Prostaglandins for enhancing detrusor function after surgery for stress incontinence in women. Journal of Reproductive Medicine 35, 1-5 (1990).

83. Andersson, K. E. \& Arner, A. Urinary bladder contraction and relaxation: physiology and pathophysiology. Physiological Reviews 84, 935-986 (2004).

84. Maggi, C. A. Prostanoids as local modulators of reflex micturition. Pharmacological Research 25, 13-20 (1992).

85. Yokoyama, O., Tanaka, I., Kusukawa, N., Yamauchi, H., Ito, H., Aoki, Y., Oyama, N., Miwa, Y. \& Akino, H. Antimuscarinics suppress adenosine triphosphate and prostaglandin E2 release from urothelium with potential improvement in detrusor overactivity in rats with cerebral infarction. The Journal of Urology 185 , 2392-2397 (2011).

86. Downie, J. W. \& Larsson, C. Prostaglandin involvement in contractions evoked in rabbit detrusor by field stimulation and by adenosine 5'-triphosphate. Canadian Journal of Physiology and Pharmacology 59, 253-260 (1981).

87. Tanaka, I. Nagase, K., Tanase, K., Aoki, Y., Akino, H., Yokoyama, O., Modulation of stretch evoked adenosine triphosphate release from bladder epithelium by prostaglandin E2. The Journal of Urology 185, 341-346 (2011).

88. Birder, L. Role of the urothelium in bladder function. Scandinavian Journal of Urology and Nephrology Supplements. 215, 48-53 (2004).

89. van Koeveringe, G. A., Vahabi, B., Andersson, K. E., Kirschner-Herrmans, R. \& Oelke, M. Detrusor underactivity: a plea for new approaches to a common bladder dysfunction. Neurourology and Urodynamics 30, 723-728 (2011).

90. Wilbraham, D., Masuda, T., Deacon, S., Kuwayama, T. \& Vincent, S. Safety, tolerability, and pharmacokinetic of multiple ascending doses of the EP-1 receptor antagonist ONO-8539, a potential new and novel therapy to overactive bladder in healthy young and elderly subjects. The Journal of Urology 13, 271-276 (2006). 

Chapter 3

\section{Prostaglandin Receptor EP1 and EP2 Site in \\ Guinea Pig Bladder Urothelium and Lamina Propria}

The Journal of Urology. 2010 Mar; 183(3):1241-7

doi: $10.1016 /$ j.juro.2009.11.004.

PMID: 20096878

M.S. Rahnama' 'i, , G.A. van Koeveringe, ${ }^{1,2}$, P.B. Essers', S.G.G. de Wachter', J. de Vente', Ph.E.V. Van Kerrebroeck ${ }^{1}$ and J.I. Gillespie ${ }^{3}$

' Department of Urology, Maastricht University Medical Centre (MUMC+)

Maastricht, The Netherlands

2 Department of Psychiatry and Neuropsychology, European Graduate School of Neuroscience (EURON) Maastricht University, Maastricht, The Netherlands

3 Uro-physiology Research Group, Institute of Cellular Medicine, Medical School, Newcastle University Newcastle upon Tyne, United Kingdom 


\section{Abstract}

\section{Purpose}

Urothelium has 2 main functions. It is a barrier to urine and has a sensory role. In response to stretch urothelium releases various substances that modulate afferent nerve activity. Recent data on the localization of cyclooxygenase type 1 , the enzyme responsible for prostaglandin production, suggests that prostaglandin may have complex local action.

\section{Materials and Methods}

The bladders of 7 guinea pigs were stained for prostaglandin receptors type 1 and 2 , and costained for vimentin and cyclooxygenase 1 .

\section{Results}

Prostaglandin $\mathrm{E}_{2}$ receptor type 1 staining was seen in urothelial cells and in the suburothelium. Urothelial staining, which was often punctuate and weak, was detected in all urothelial cell layers, including suburothelial cells. In contrast, strong prostaglandin $\mathrm{E}_{2}$ receptor type 2 staining was seen in the urothelium and in suburothelial cells. Cyclooxygenase 1 was absent in interstitial cells and umbrella cells with the highest concentration in the basal cell layer.

\section{Conclusions}

Interstitial cells express prostaglandin receptor types 1 and 2, indicating that they can respond to prostaglandin. Umbrella cells do not express cyclooxygenase 1. Cyclooxygenase 1 was present in basal urothelial cells, making them a possible site of prostaglandin synthesis. Thus, prostaglandin produced by urothelium may target prostaglandin receptor types 1 and 2 in the urothelium and suburothelium. Therefore, prostaglandin is hypothesized to have a role in signal regulation in the bladder wall. 


\section{Introduction}

Arachidonic metabolites, principally PG, are released from the bladder into the general circulation in response to distention ${ }^{1-3}$. Bladder PG originates from urothelial and muscle layers ${ }^{1,2}$. The exact role of this endogenous PG is not known but it is well documented that exogenous PG alters bladder motor activity in vitro and in vivo, and can influence the micturition reflex in humans ${ }^{4-6}$, rats ${ }^{7}$, guinea pigs $^{8}$, rabbits ${ }^{9}$ and monkeys ${ }^{10}$. The main PGs synthesized in the bladder are PGE ${ }_{2}^{1-3}$ and $\mathrm{PGI}_{2}{ }^{11}$. PGs are locally synthesized in bladder muscle and mucosa. Synthesis is initiated by detrusor muscle stretch, bladder nerve stimulation, bladder mucosa damage and inflammation mediators. PGs are involved in the micturition reflex by decreasing thresholds of the stimuli necessary to trigger bladder contraction by activation of the capsaicin sensitive afferent nerves ${ }^{2-4}$. The role of the PG signaling pathway on bladder function and more particularly the role of EP1 on bladder function is the subject of different studies ${ }^{12,13}$. However, to our knowledge prostaglandin receptor cellular localization and expression in the bladder wall remain unknown. This information would help us understand how these receptors are involved in micturition reflex regulation.

Regarding PG actions on smooth muscle, PG may be coreleased with acetylcholine at efferent nerve endings and so directly contribute to muscle excitation ${ }^{\circ}$. Alternatively, PG may act indirectly on presynaptic motor terminals to affect excitatory transmitter release ${ }^{7}$. It may also inhibit acetylcholine esterase $^{6}$ or enhance myogenic bladder activity'${ }^{14}$.

PG related changes in the micturition reflex may act directly on afferent nerves to modulate firing and so trigger micturition at lower bladder volume ${ }^{15}$. Such action could arise anywhere in the bladder wall where PG is synthesized and there are afferent nerves. A specific site is the urothelial and suburothelial layers. PG is released from this region, as mentioned, and could act on suburothelial nerve fibers. This would represent a situation similar to that proposed for urothelial derived ATP and its subsequent afferent nerve activation ${ }^{16}$. To our knowledge whether PG directly affects afferent firing remains to be determined.

In the guinea pig the enzymes $\mathrm{COX}_{1}$ and 2 are located in specific cell types in the lamina propria. $\mathrm{COX}_{1}$ is found in the basal layers of the urothelium and is associated with the distributed network of lamina propria interstitial cells ${ }^{17}$. COX 2 is associated with the nuclei of a population of umbrella cells and SU-IC nuclei ${ }^{18}$. Thus, PG signaling in this bladder wall region may be complex with multiple sites of production and action.

We used antibodies to EP1 and EP2 to explore this complexity by localizing potential cellular targets of PG in the lamina propria. We discuss our observations in terms of possible physiological mechanisms that may occur in this bladder wall region.

\section{Materials and Methods}

Seven male guinea pigs weighing 270 to $300 \mathrm{~g}$ were sacrificed by cervical dislocation. All procedures were done in agreement with Maastricht University ethical committee guidelines. 
The bladder, including the proximal urethra, was removed from each animal and placed in icecold Krebs solution composed of $121.1 \mathrm{mM} \mathrm{NaCl}, 1.87 \mathrm{mM} \mathrm{KCl}, 1.2 \mathrm{mM} \mathrm{CaCl}_{2}, 1.15 \mathrm{mM} \mathrm{MgSO}_{4}, 25$

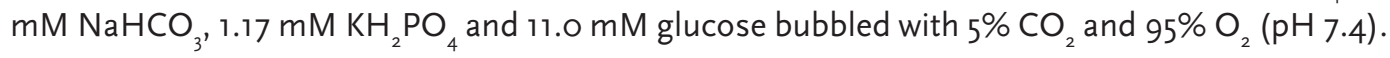
Each bladder was divided into a ventral piece and a dorsal piece, and maintained in Krebs solution containing $1 \mathrm{mM}$ of the nonspecific phosphodiesterase inhibitor isobutyl-methyl-xanthine (SigmaAldrich) at $36^{\circ} \mathrm{C}$ for 30 minutes. Incubation was terminated by immersing bladder pieces in ice-cold fixative solution of $4 \%$ freshly prepared depolymerized paraformaldehyde for 120 minutes at $4{ }^{\circ} \mathrm{C}$. Tissues were fixed in 3 steps of 2 overnight and 1 daytime incubation at $4{ }^{\circ} \mathrm{C}$ in $0.1 \mathrm{M}$ phosphate buffer with 10\%, 20\% and $30 \%$ sucrose, respectively. On day 3 the tissues were placed in Tissue-Tek OCT ${ }^{\mathrm{TM}}$ compound to form a single block, snap frozen in isopentane and cooled in liquid nitrogen. Cryostat sections $(10 \mu \mathrm{m})$ were cut such that each section was perpendicular to the urothelial surface. Sections were thawed on chrome alum-gelatin coated slides and processed for imunocytochemistry.

\section{Immunohistochemistry}

Sections were dried for 20 minutes at room temperature, followed by 3 washes with TBS ( $\mathrm{pH}$ 7.6), and incubated overnight with primary antibodies at $4{ }^{\circ} \mathrm{C}$. To visualize $E P_{1}$ and $E P_{2}$ we used polyclonal antibodies rabbit anti-EP2 and rabbit anti-EP1 (Cayman Chemical, Ann Arbor, Michigan). Mouse antibody against vimentin (Sigma-Aldrich) was diluted 1:5,000. Rabbit antibodies against EP1 and EP2 were diluted 1:100. Ater overnight incubation with primary antibodies diluted in TBS-T sections were washed in TBS, TBS-T and TBS. Each wash step was 15 minutes in duration. Rabbit primary antibody was visualized using Alexa Fluor 488 donkey anti-rabbit lgG $(\mathrm{H}+\mathrm{L}$ ) conjugate (Molecular Probes $($ ) ) diluted 1:100 in TBS-T. Mouse primary antibodies were visualized with Alexa Fluor 488

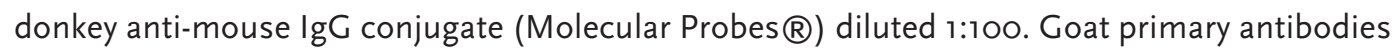
were visualized with Alexa Fluor 594 donkey anti-goat IgG conjugate (Molecular Probes $®$ )) Sections were incubated with secondary antibodies for 60 minutes at room temperature in the dark. After washing with TBS-T and TBS sections were mounted with TBS-glycerol. All staining was done in duplicate and repeated on at least 2 separate days. Multiple sections were observed. Presented images are representative sections showing $\mathrm{EP}_{1}$ and $\mathrm{EP}_{2}$ distribution.

Sections were partly analysed and photographed using an AX70 microscope (Olympus, Center Valley, Pennsylvania) using 4x, 10x, 20x and 40x objectives. To detect Alexa 488 and 594 fluorescence a narrow band pass MNIBA filter and a narrow excitation band U-M41007A filter were used, respectively (Chroma Technology, Rockingham, Vermont). Images were stored digitally as 16-bit images using analySIS, version 3.0.

For confocal laser scanning microscopy fluorescent samples were imaged using an MRC600 confocal microscope (Bio-Rad) equipped with an air cooled argon-krypton mixed gas laser and mounted on an Axiophote Microscope using an oil immersion objective (40,NA1/4 3D1.3 or 63 , $\mathrm{NA}^{1} 1 / 43 \mathrm{D} 1.4$ ). The laser scanning microscope was used in dual wavelength excitation at 488 and 568 $\mathrm{nm}$. Optical sections were recorded in the Kalman filtering mode using 4 to 8 scans per picture. 


\section{$E P_{1}$ and EP 2 Antibodies}

To determine antibody specificity we performed a pre-absorption test and characterized the antibodies by Western blotting. Pre-absorption was done by overnight incubation of anti-EP 1 and anti-EP2 antibodies (1:100) with or without $10 \mu \mathrm{g} / \mathrm{ml}$ of the peptide against which the antibody was raised. Antibody solution or antibody plus peptide solution was then applied to the sections. Bladder homogenate of 2 guinea pig bladders were prepared for Western blotting. Bladders were cut into approximately $1 \mathrm{~mm}^{2}$ squares and homogenized with an Ultra-Turrax homogenizer at $4{ }^{\circ} \mathrm{C}$ in $1 \times$ radio-immunoprecipitation assay buffer composed of $1 \%$ Triton-X-100, $137 \mathrm{mM} \mathrm{NaCl}, 20 \mathrm{mM}$ tris- $\mathrm{HCl}, 2 \mathrm{mM}$ ethylenediaminetetraacetic acid, $10 \%$ glycerol, $1 \mathrm{mM}$ sodium orthovanadate, $10 \mathrm{mM}$ $\mathrm{NaF}, 1 \times$ protease inhibitor cocktails and $1 \mathrm{mM}$ phenylmethylsulfonyl fluoride. Homogenates were centrifuged at $13,000 \times$ gravity for 20 minutes at $4{ }^{\circ} \mathrm{C}$. The pellet was discarded and supernatant was stored at $-80^{\circ} \mathrm{C}$. Protein was measured using bovine albumin serum dilutions with the Bio-Rad protein measurement system according to manufacturer instructions.

Blot analysis was done under reducing conditions according to standard procedures using the Odyssey Infrared Imaging System. Primary antibodies for Western blotting were rabbit anti-EP1 and rabbit anti-EP2 antibody, diluted 1:100. Staining was also confirmed by blocking peptide on the Western blot using pre-absorption with anti-EP1 and anti-EP2 antibody, diluted 1:100. The secondary antibody was donkey anti-rabbit IRdye ${ }^{\mathrm{TM}} 800$.

\section{Results}

Figure $1, A, C$ and $E$ shows the characterization of $E P_{1}$, and figure $1, B, D$ and $F$ shows the characterization of EP2. Figure $1, A$ and $B$ shows that guinea pig urothelial and suburothelial walls stained positive with $\mathrm{EP}_{1}$ and $\mathrm{EP}_{2}$ antibodies, respectively. An approach to confirm that this was specific staining is to pre-incubate the antibody with the peptide to which it was raised (blocking peptide) to eliminate the antibody specific reactive site. When this was done, all observed staining was removed (figures 1, C and D). The camera gain was the same (figures 1, A to D). Figure 1 insets shows an enhanced view of tissue morphology. Figure 1, E and $\mathrm{F}$ shows Western blots of bladder protein exposed by EP1 and EP2 antibodies, respectively. A single protein band was seen of the predicted molecular weight of $\mathrm{EP}_{1}$ and $\mathrm{EP}_{2}$ protein. This band was also removed by pre-absorbing the antibody with the blocking peptide. Thus, these antibodies for EP1 and EP2 may be used with a high degree of certainty that they will specifically detect $E P_{1}$ and EP2 in the guinea pig bladder.

Figure 2 shows a section stained with $E P_{1}$ antibody as green areas and an antibody to vimentin as red areas. Staining was noted in urothelial cells and in the suburothelium. Urothelial staining appeared weak and was detected in all urothelial cell layers. This EP1 staining was often punctuate (figure 2, $B$ ). EP1 staining was also associated with SU-ICs. It was relatively weak and not present in all cells (figure. $2, C)$. Thus, although $\mathrm{EP}_{1}$ was present in this bladder wall region, staining was not pronounced. In contrast, strong EP2 staining was seen in the urothelium and in SU-ICs (figures 3 to 5). 

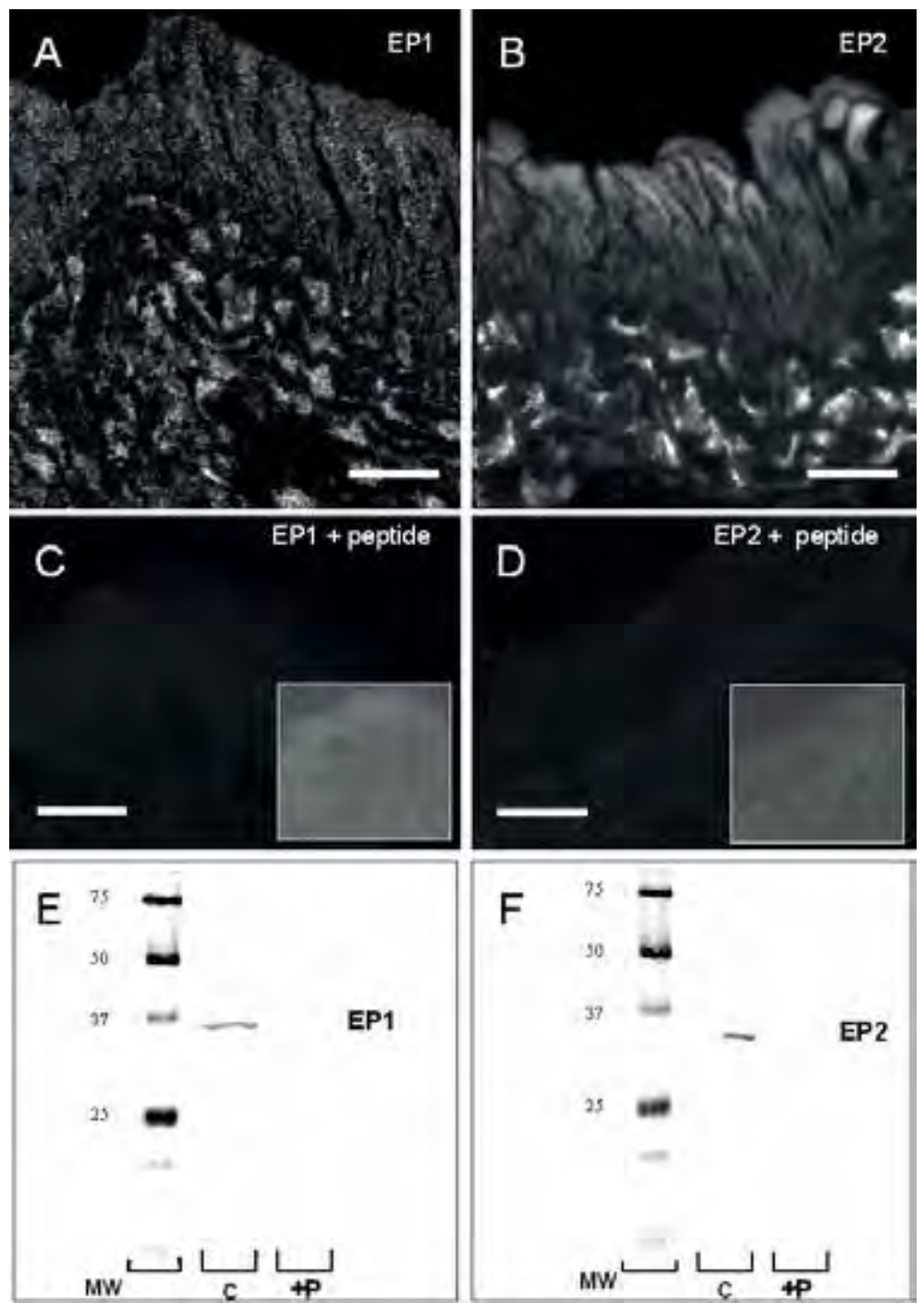

Figure 1. Characterization of $\mathrm{EP}_{1}$ and $\mathrm{EP}_{2}$ antibodies. $A, C$ and $E, \mathrm{EP}_{1} . B, D$ and $F, \mathrm{EP}_{2}$. $A$ and $B$, low magnification of bladder wall shows staining in urothelium and suburothelium. Scale bars indicate $20 \mu \mathrm{m}$. $C$ and $D$, images obtained at same camera gain reveal staining with same antibody concentration but with pre-incubation with blocking peptide to which antibody was raised. Scale bars indicate $10 \mu \mathrm{m}$. Insets, enhanced images show section morphology. $E$ and $F$, Western blots show antibody characterization. MW, molecular weight calibration. $C$, native protein stained with $\mathrm{EP}_{1}$ or $\mathrm{EP}_{2}$ antibody. $+P$, native protein exposed to antibody plus appropriate blocking peptide. 

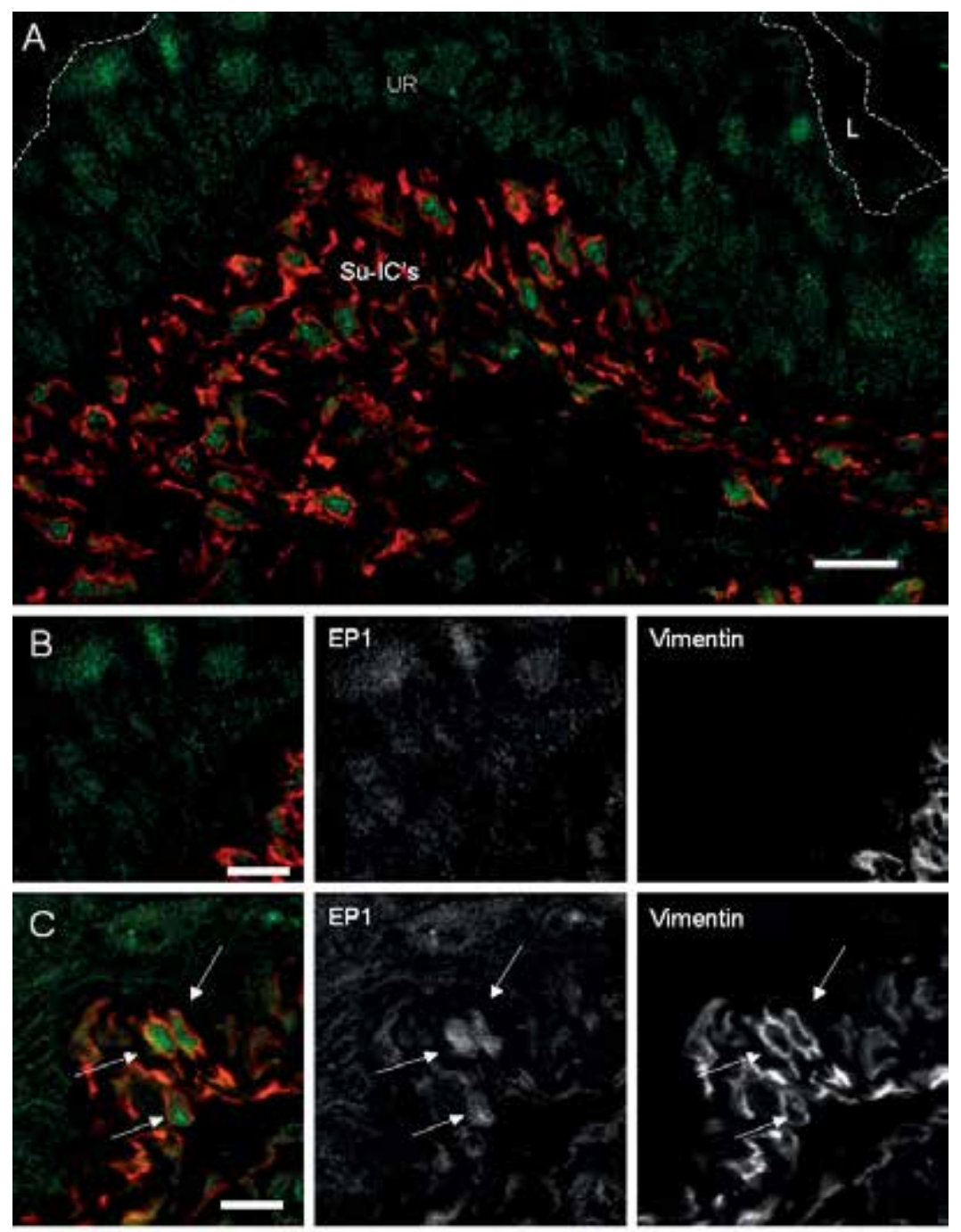

Figure 2. EP1 in urothelium and lamina propria of guinea pig bladder lateral wall. $A$, section of urothelium (UR) and suburothelium stained with antibody for EP1 (green areas) and vimentin (red areas). L, bladder lumen. Calibration bars: $50 \mu \mathrm{m}$. B, higher magnification shows weak staining in urothelium with appearance of highly localized fluorescent foci. Calibration bars: $20 \mu \mathrm{m}$. C, some SU-ICs colocalized with EP1 and vimentin (arrows). Others were vimentin positive but did not express $\mathrm{EP}$. Calibration bars: $20 \mu \mathrm{m}$. 

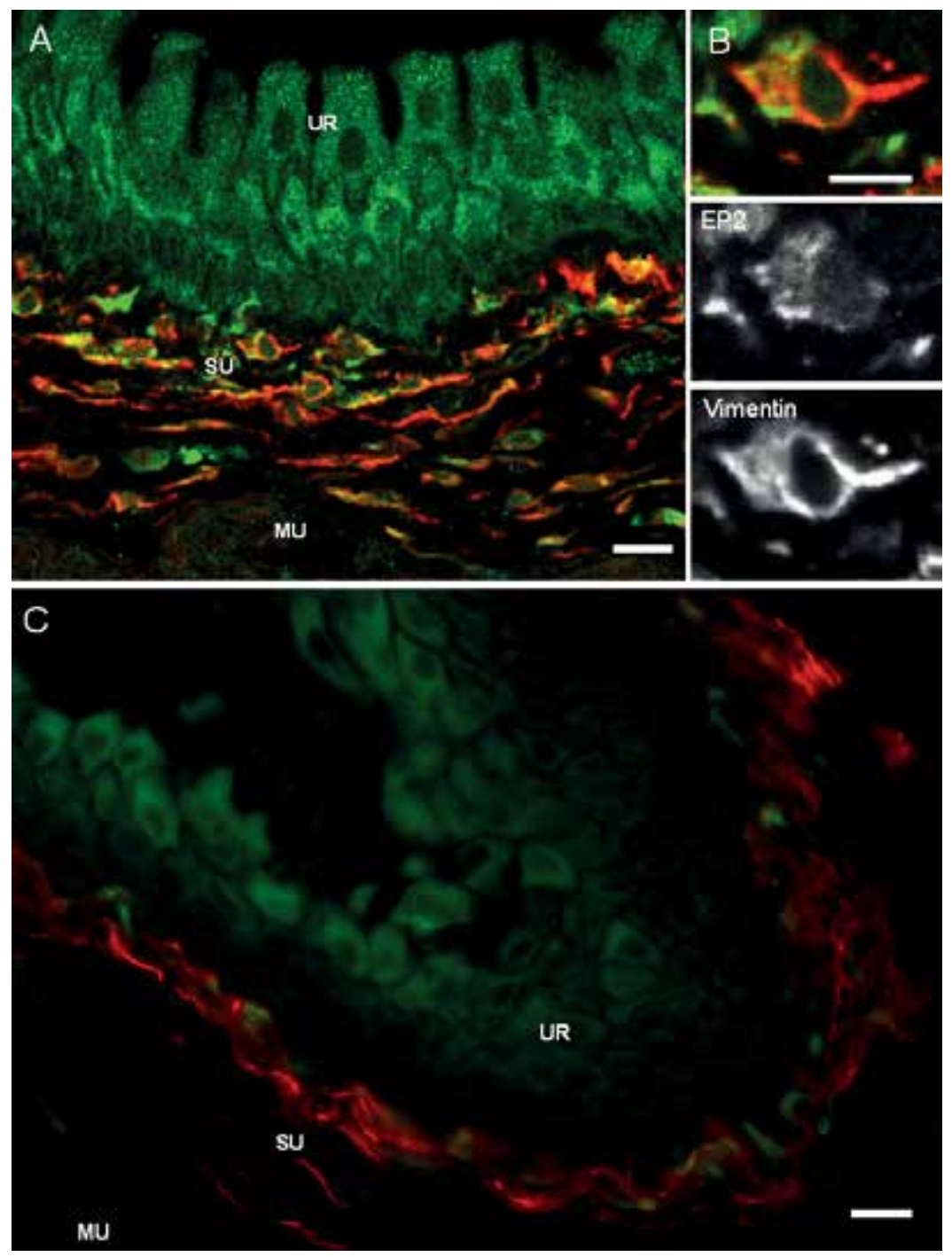

Figure 3. EP2 in urothelium and lamina propria of guinea pig bladder lateral wall. $A$, laser scan microscopy reveals overview of EP2 (green areas) and vimentin (red areas). UR, urothelium. SU, suburothelium. MU, muscle layer. Calibration bars: $20 \mu \mathrm{m}$. B, confocal enlargement of SU-IC shows vimentin and EP2 co-localization. Calibration bars: $10 \mu \mathrm{m} . \mathrm{C}, \mathrm{EP} 2$ in urothelium of another part of lateral wall was most expressed in outer layer with most expression in intermediate urothelial layer. Calibration bars: $20 \mu \mathrm{m}$. 
Figure 3 shows 2 sections from 2 regions in the lateral guinea pig bladder wall. The term lateral wall indicates the part of the bladder between the bladder dome and the bladder base lateral and cranial to the ureteral orifices. Each section stained with EP2 (green areas) and vimentin (red areas) at the same concentration. There were clearly 2 distinct patterns of EP2 staining in the urothelial cell layers. Figure 3, A shows a representative region where the most pronounced staining was located in intermediate urothelial cells, which stained stronger than umbrella cells. Figure 3, C shows a different region of the lateral wall where the most intense staining occurred in the outer layer of umbrella cells with staining absent in the intermediate urothelial cell layer. Figure 4 shows different EP2 expression in the urothelium.

Figure 4. EP2 (green areas) and vimentin (red areas) positive cells in guinea pig lamina propria. $A$, site of umbrella cell layer $(u)$, intermediate cell layer (il), basal layer $(b l)$, SU-ICS and major lamina propria space $(I p)$. Calibration bars: $100 \mu \mathrm{m}$. B, similar section of different bladder shows dense intermediate layer staining (pound sign) (\#) and weak staining in umbrella cells (plus sign) $(+)$. Note strong vimentin but relatively weak EP2 staining in this region of SU-IC layer. Asterisk (*) indicates near absence of staining in basal layer. Calibration bars: $25 \mu \mathrm{m}$. C, laser scan microscopy reveals urothelium (UR), suburothelium (SU) and muscle layer $(M U)$ with EP2 expression on vimentin positive SU-ICS clearly visible. Calibration bars: $25 \mu \mathrm{m}$.

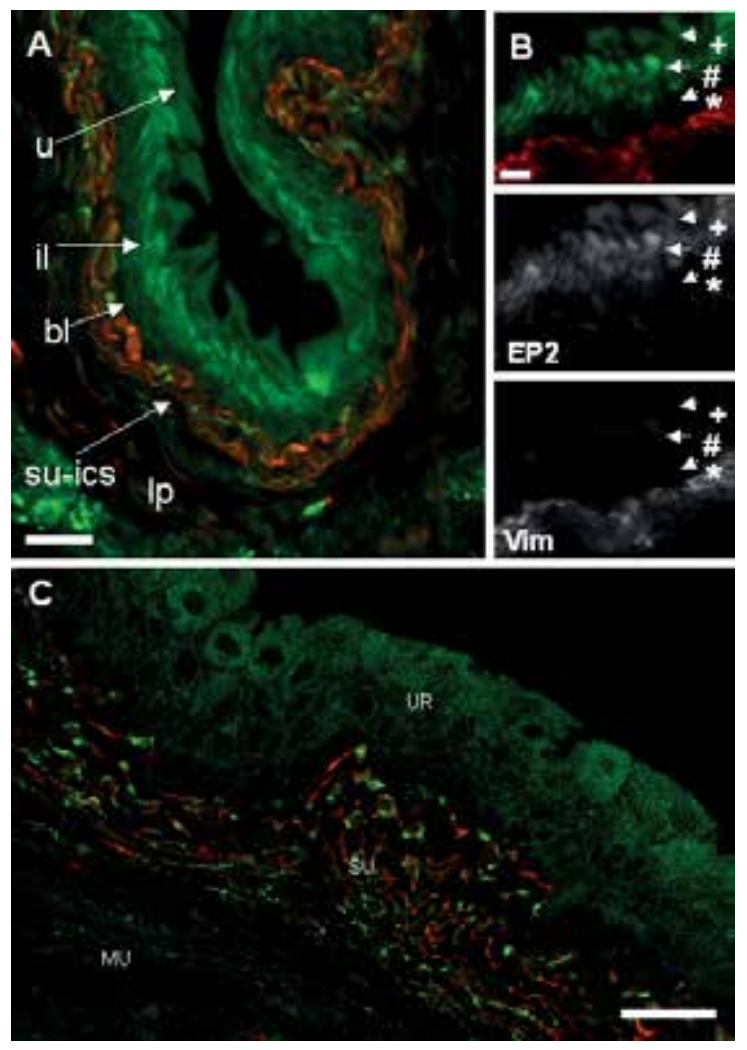



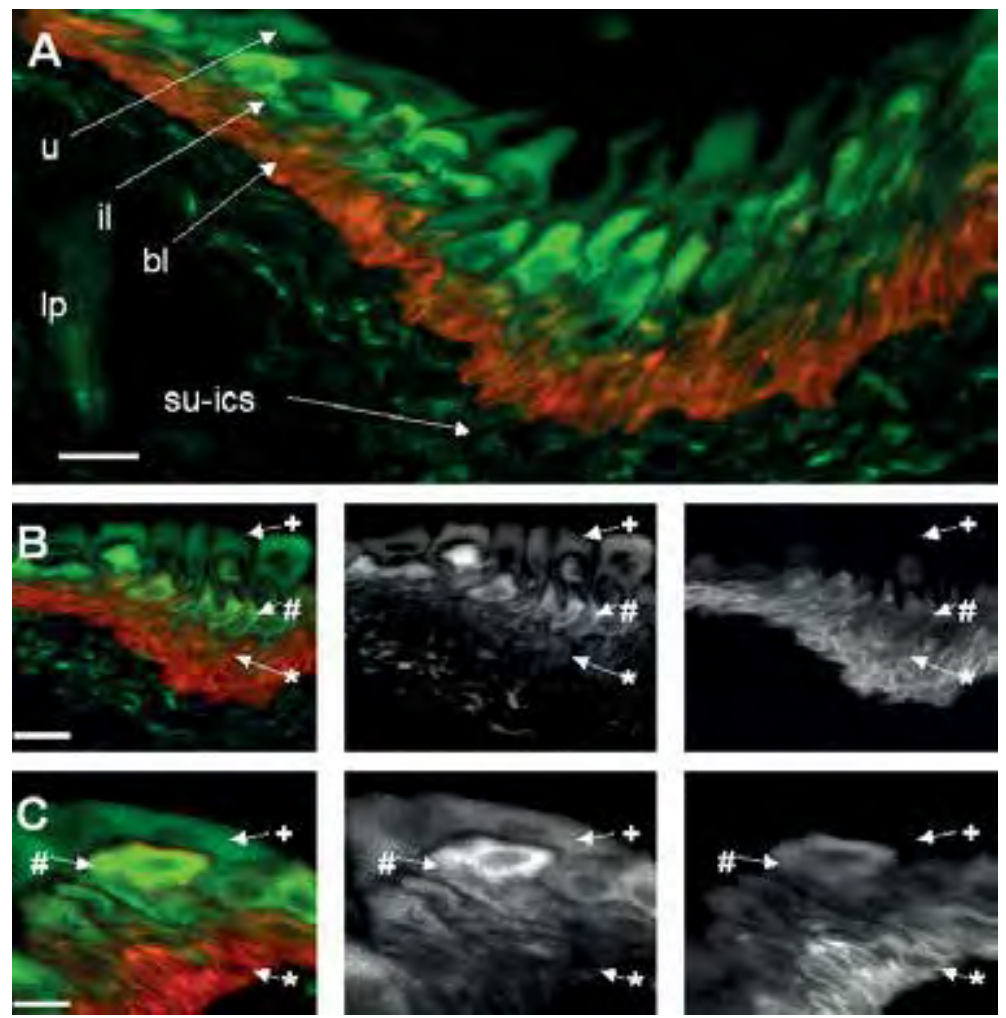

Figure 5. EP2 (green areas) and $\mathrm{COX}_{1}$ (red areas) antibody staining in different guinea pig bladder urothelial layers. $A$, urothelium and suburothelium show preponderance of COX 1 staining in basal and internal intermediate cell layers, and dense EP2 staining of outer intermediate cell layer. Note small distinct spots of EP2 staining in SU-ICs. u, umbrella cell layer. II intermediate cell layers. $b$, basal layer. Ip, lamina propria. Calibration bars: $50 \mu \mathrm{m}$. $B$ and $C$, further details of similar staining in sections of other bladders. $B$, clear $C O_{1}$ immunoreactivity in basal layers (asterisk) $(*)$, strongly reactive EP2 cells in intermediate layer (pound sign) (\#) and low EP2 staining in umbrella cells (plus sign) (+). Calibration bars: $30 \mu \mathrm{m}$. C, some cells in intermediate urothelial layers expressed EP2 and COX1. Asterisk indicates $\operatorname{COX}_{1}$ positive umbrella cells. Plus sign indicates $\mathrm{COX}_{1}$ positive basal urothelial cells. Calibration bars: $15 \mu \mathrm{m}$.

Urothelial EP2 staining was seen in all 7 guinea pigs examined (figures $3, A$ and $C$ ). Figure 3, $C$ shows the pattern that was seen more often with the most intense staining in the outer layer of umbrella cells. Thus, guinea pig urothelium showed a different staining pattern for EP 2 in different parts of its lateral wall. To our knowledge the meaning of this heterogeneity of EP2 expression in the urothelium remains to be understood. A remarkable observation was EP2 in vimentin positive 

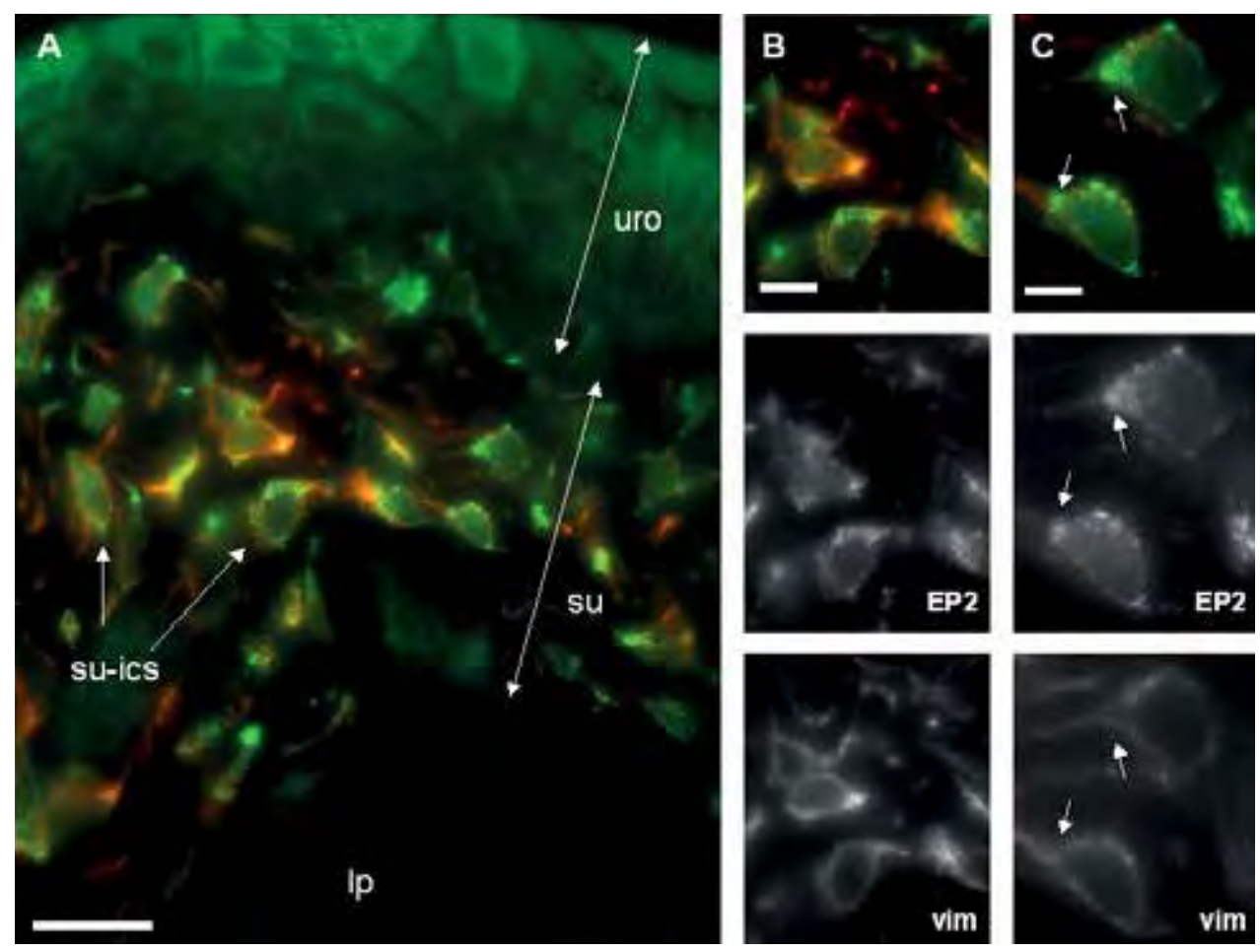

Figure 6. EP2 expression in SU-IC layer. A, lamina propria (Ip) region with basal urothelium (uro) and SU-ICs. EP2 positive cells (green areas) were clearly seen in urothelial layer (uro) and associated with SU-ICs. Section also stained for vimentin (red areas) with only SU-ICs vimentin positive.

Calibration bars: $40 \mu \mathrm{m}$. $B$ and $C$, individual SU-ICs separating EP2 and vimentin stains. C, EP2 and vimentin colocalization (arrow). Calibration bars: $20(B)$ and $15(C) \mu \mathrm{m}$.

SU-ICs (figure 6). COX 1 expressing cells, located primarily in the basal layers, did not strongly express EP2 (figures 4 and 5).

These results suggest that when $\mathrm{COX}_{1}$ is active, there appears to be a close signaling system in the urothelium with basal cells signaling to the intermediate and outer layers. The implied complexity of this system was further noted using a more quantitative approach. Figure 6 shows EP2 staining in SU-ICs. This section stained for EP2 as green areas and for vimentin as red areas. The suburothelial layer was marked and individual interstitial cells were identified. Figure $6, B$ and $C$ shows examples of individual SU-ICs that clearly express EP2 and vimentin.

Figure $7, A$ shows the cellular location of $\mathrm{COX}_{1}, \mathrm{EP}_{1}$ and $\mathrm{EP}_{2}$ in the lamina propria layer of the guinea pig bladder wall. 


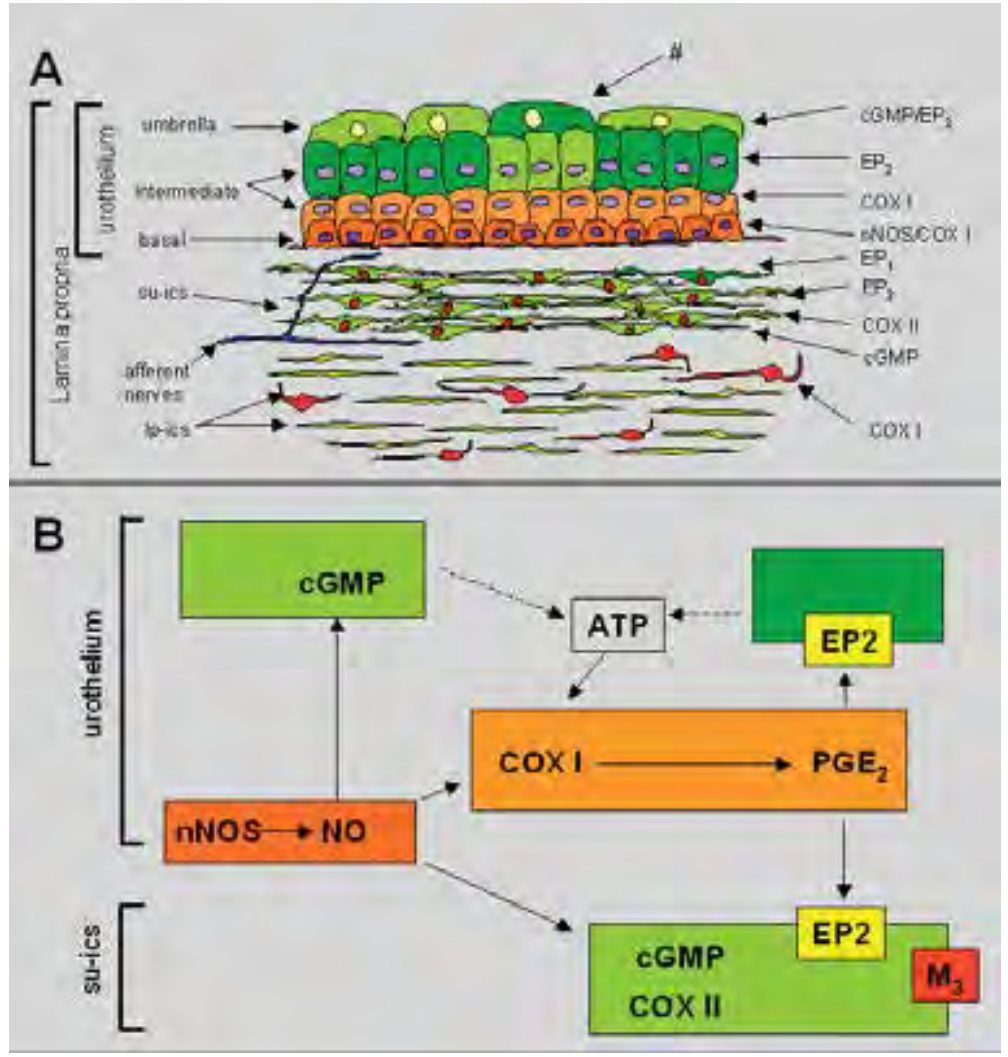

Figure 7. Guinea pig lamina propria cells expressing EP2, and $C_{2} O_{1}$ and 2. $A$, overview of lamina propria structures and receptors. Pound sign (\#) indicates EP2 alternative distribution in urothelium in some parts of bladder lateral wall. cGMP, cyclic guanosine monophosphate. nNOS, neuronal nitric oxide synthase. Ip-ics, lamina propria suburothelial interstitial cells. $M_{3}$, type 3 muscarinic receptor. $B$, possible interactions between substances produced by different cells.

\section{Discussion}

$P G$ receptors ( $E P_{1}$ and $E P_{2}$ ) are expressed in interstitial cells, indicating that they respond to $P G E_{2}$. Umbrella cells do not express $\mathrm{COX}_{1}$. However, $\mathrm{COX}_{1}$ was detected in basal urothelial cells, making these cells a possible site of PG synthesis. When urothelium is stretched, it releases different substances, including $\mathrm{PG}^{19,20}, \mathrm{ATP}^{21}, \mathrm{NO}^{21}$ and acetylcholine ${ }^{22}$. However, to our knowledge it is not known which cells in the urothelium or lamina propria are responsible for producing and releasing these signals, and which physiological systems they involve. A great 
deal of study has focused on the idea that the release of these substances is an integral part of a sensory system assessing bladder volume ${ }^{23,24}$. Upon stretch ATP, acetylcholine and NO are released from the urothelium and then act directly or indirectly on suburothelial afferent nerves. Direct evidence shows a direct modulation of afferent nerve activity by ATP ${ }^{25}$ and indirect NO action $^{26}$. This sensory model involving urothelial signaling was recently described in detail24,27. Many observations underpinning these ideas are derived from rat bladder studies. In that species the urothelium is relatively simple, comprising 2 or 3 cell layers. To our knowledge no study to date has examined the possibility of functional heterogeneity between the different layers.

In regard to the suburothelial space little is known about the cell types present other than to describe presumptive sensory nerves ${ }^{28}$. The suburothelial innervation is sparse with the highest density of urothelial innervation at the base $\mathrm{e}^{24-27}$. Our study in the guinea pig model shows that lateral wall urothelium and lamina propria have a high degree of structural complexity and potential for signaling despite relatively low nerve density. These data on the guinea pig bladder suggest that possibly complex signaling systems operate in the urothelium, and between the urothelium and lamina propria SU-ICs.

The basal urothelial cell layer and to a lesser extent the intermediate layer express COX 1 . Thus, this layer is capable of generating PG. In the normal healthy guinea pig bladder COX2 expression is much less abundant than $\mathrm{COX}_{1}$ expression and, thus, we do not discuss it. However, the basic mechanistic features may apply to PGs generated by COX2. Our data suggest that local cellular targets for this PG are most probably the intermediate layers and the umbrella cells of the urothelium, and SU-ICs. We hypothesize that this close spatial arrangement of signaling and responding cells could reflect some functional specialization involving interaction between the basal and outer urothelial cell layers.

Recently it was reported that guinea pig SU-ICs express type 3 muscarinic receptor ${ }^{29}$. Since the urothelium may synthesize and release acetylcholine ${ }^{30}$, this raises the possibility that SU-ICs receive multiple inputs. Our observations show that these cells also express EP2, indicating that they respond to PG. In the intact animal a major source of PGs acting on these cells may be derived from the basal and intermediate urothelial layers. Thus, SU-ICs may be a site of integration of different signals. If some signals such as PG are also under complex regulation by other urothelial signals (ATP and NO), the physiology of this bladder wall region is particularly complex. Figure 7 shows this complexity, including the different cell types and layers of the urothelium and suburothelium along with the signals and receptors present, and the emerging picture of urothelial derived signals and their interactions. 
Prostaglandins and Phosphodiesterases in the Urinary Bladder Wall

\section{Conclusions}

To unravel the role and the importance of this system we need more data, particularly to identify other signals and interactions. Our hypotheses must be explored by physiological and pharmacological in vivo and ex vivo experiments to integrate the micro-anatomical data presented with functional data. Thus, the hypothesis can be tested and better understanding of bladder physiology may be achieved. 


\section{References}

1. Masunaga, K., Yoshida, M., Inadome, A., Iwashita, H., Miyamae, K. \& Ueda, S. Prostaglandin E2 release from isolated bladder strips in rats with spinal cord injury. International Journal of Urology 13, 271-276 (2006).

2. Park, J.M., Yang, T., Arend, L.J., Schnermann, J.B., Peters, C.A., Freeman, M.R. \& Briggs, J.P. Obstruction stimulates $\mathrm{COX}_{2}$ expression in bladder smooth muscle cells via increased mechanical stretch. American Journal of Physiology 276, F129-136 (1999).

3. Pinna, C., Zanardo, R. \& Puglisi, L. Prostaglandin-release impairment in the bladder epithelium of streptozotocin-induced diabetic rats. European Journal of Pharmacology. 388, 267-273 (2000).

4. Andersson, K.E., A. \& Persson, C.G. Effects of prostaglandins on the isolated human bladder and urethra. Acta Physiologica Scandinavica 100, 165-171 (1977).

5. Bultitude, M.I., Hills, N.H. \& Shuttleworth, K.E. Clinical and experimental studies on the action of prostaglandins and their synthesis inhibitors on detrusor muscle in vitro and in vivo. British Journal of Urology 48, 631-637 (1976).

6. Borda, E., Contreras-Ortiz, N., Gutnisky, R. \& Gimeno, M.F. In vitro effect of acetylcholine and bethanechol on the contractions of the human detrusor muscle. Influence of prostaglandins. Archa Internayonales de Pharmacodynamie et de Therapie 259, 31-39 (1982).

7. Choo, L.K. \& Mitchelson, F. The effect of indomethacin and adenosine 5'-triphosphate on the excitatory innervation of the rate urinary bladder. Canadian Journal of Physiology and Pharmacology 58, 1042-1048 (1980).

8. Burnstock, G., Cocks, T., Crowe, R. \& Kasakov, L. Purinergic innervation of the guinea-pig urinary bladder. British Journal of Pharmacology 63, 125-138 (1978).

9. Downie, J.W. \& Larsson, C. Prostaglandin involvement in contractions evoked in rabbit detrusor by field stimulation and by adenosine 5'-triphosphate. Canadian Journal of Physiology and Pharmacology 59, 253$260(1981)$.

10. Johns, A. \& Paton, D.M. Effect of indomethacin on atropine-resistant transmission in rabbit and monkey urinary bladder: evidence for involvement of prostaglandins in transmission. Prostaglandins 13, 245-254 (1977).

11. Jeremy, J.Y., Mikhailidis, D.P. \& Dandona, P. The rat urinary bladder produces prostacyclin as well as other prostaglandins. Prostaglandins, Leukotrienes, and Medicine 16, 235-248 (1984).

12. Ikeda, M., Kawatani, M., Maruyama, T. \& Ishihama, H. Prostaglandin facilitates afferent nerve activity via EP1 receptors during urinary bladder inflammation in rats. Biomedical research (Tokyo, Japan) 27, 49-54 (2006).

13. Ishizuka, O., Mattiasson, A. \& Andersson, K.E. Prostaglandin E2-induced bladder hyperactivity in normal, conscious rats: involvement of tachykinins? The Journal of Urology 153, 2034-2038 (1995).

14. Andersson, K.E. \& Sjogren, C. Aspects on the physiology and pharmacology of the bladder and urethra. Progress in Neurobiology 19, 71-89 (1982).

15. Andersson, K.E. Current concepts in the treatment of disorders of micturition. Drugs 35, 477-494 (1988). 
16. Burnstock, G. Purinergic cotransmission. Experimental Physiology 94, 20-24 (2009).

17. de Jongh, R., Grol, S., Van Koeveringe, G.A., Van Kerrebroeck, Ph.E.V., de Vente, J., \& Gillespie, J.I. The localisation of cyclo oxygenase immuno-reactivity (COX $1-I R)$ to the urothelium and to interstitial cells in the bladder wall. Journal of Cellular and Molecular Medicine 13(9B), 3069-3081 (2009).

18. de Jongh, R., Van Koeveringe, G.A., Van Kerrebroeck, Ph.E.V., Markerink-van Ittersum, M., de Vente, J. \& Gillespie, J.I. The effects of exogenous prostaglandins and the identification of constitutive cyclooxygenase I and II immunoreactivity in the normal guinea pig bladder. British Journal of Urology International 100, 419-429 (2007).

19. Mikhailidis, D.P., Jeremy, J.Y. \& Dandona, P. Urinary bladder prostanoids--their synthesis, function and possible role in the pathogenesis and treatment of disease. The Journal of Urology 137, 577-582 (1987).

20. Jeremy, J.Y., Tsang, V., Mikhailidis, D,P., Rogers, H., Morgan, R.J., Dandona, P. Eicosanoid synthesis by human urinary bladder mucosa: pathological implications. British Journal of Urology 59, 36-39 (1987).

21. Ferguson, D.R., Kennedy, I. \& Burton, T.J. ATP is released from rabbit urinary bladder epithelial cells by hydrostatic pressure changes--a possible sensory mechanism? The Journal of Physiology 505 ( Pt 2), 503-511 (1997).

22. Hanna-Mitchell, A.T., Beckel, J.M., Barbadora, S., Kanai, A.J., de Groat, W.C. \& Birder, L.A. Non-neuronal acetylcholine and urinary bladder urothelium. Life Sciences 80, 2298-2302 (2007).

23. de Groat, W.C. The urothelium in overactive bladder: passive bystander or active participant? Urology 64 , 7-11 (2004).

24. Fowler, C.J., Griffiths, D. \& de Groat, W.C. The neural control of micturition. Nature Reviews 9, 453-466 (2008).

25. Rong, W., Spyer, K.M. \& Burnstock, G. Activation and sensitisation of low and high threshold afferent fibres mediated by $\mathrm{P}_{2} \mathrm{X}$ receptors in the mouse urinary bladder. Journal of Physiology 541, 591-600 (2002).

26. Persson, K., Igawa, Y., Mattiasson, A. \& Andersson, K.E. Effects of inhibition of the L-arginine/nitric oxide pathway in the rat lower urinary tract in vivo and in vitro. British Journal of Pharmacology 107, 178-184 (1992).

27. Birder, L.A. \& de Groat, W.C. Mechanisms of disease: involvement of the urothelium in bladder dysfunction. Nature Clinical Practice 4, 46-54 (2007).

28. Birder, L. Role of the urothelium in bladder function. Scandinavian Journal of Urology and Nephrology 48-53 (2004).

29. Grol, S., Essers, P.B., van Koeveringe, G.A., Martinez-Martinez, P., de Vente, J. \& Gillespie J.I.M (3) muscarinic receptor expression on suburothelial interstitial cells. British Journal of Urology International 104(3):398-405 (2009).

30. Lips, K.S., Wunsch, J., Zarghooni, S., Bschleipfer, T., Schukowski, K., Weidner, W., Wessler, I., Schwantes, U., Koepsell, H. \& Kummer, W. Acetylcholine and molecular components of its synthesis and release machinery in the urothelium. European Urology 51, 1042-1053 (2007). 


Chapter 4

\section{The Relationship Between Prostaglandin E Receptor Type 1 (EP1) and Cyclooxygenase 1 Expression in Guinea Pig Bladder Interstitial Cells Proposition of a Signal Propagation System}

The Journal of Urology. 2011 Jan;185(1):315-22

doi: 10.1016/j.juro.2010.09.005

PMID: 21075388

M.S. Rahnama'i', , S.G.G. de Wachter', G.A. van Koeveringe ${ }^{1,2}$ Ph.E.V. Van Kerrebroeck' , J. de Vente', and J.I. Gillespie ${ }^{3}$

' Department of Urology, Maastricht University Medical Centre (MUMC+)

Maastricht, The Netherlands

${ }^{2}$ Department of Psychiatry and Neuropsychology, European Graduate School of Neuroscience (EURON) Maastricht University, Maastricht, The Netherlands

${ }_{3}^{3}$ Uro-physiology Research Group, Institute of Cellular Medicine, Medical School, Newcastle University, Newcastle upon Tyne, United Kingdom 


\section{Abstract}

\section{Purpose}

We explored the structural relationship between enzymes producing prostaglandin (cyclooxygenase 1) and one of the receptor families that respond to prostaglandin (prostaglandin E receptor 1 ) in the bladder muscle.

\section{Materials and Methods}

Nine male guinea pigs were sacrificed by cervical dislocation. Bladders were removed and fixed in $4 \%$ paraformaldehyde in phosphate buffered saline. Frozen sections (10 $\mu \mathrm{m})$ were cut and stained with antibodies to prostaglandin E receptor type 1, cyclooxygenase 1 and vimentin.

\section{Results}

Prostaglandin $\mathrm{E}_{2}$ receptor type 1 was identified on smooth muscle cells, and vimentin positive surface muscle and intramuscular interstitial cells. Muscle staining was less intense than on interstitial cells and had a punctuate appearance. Prostaglandin $\mathrm{E}_{2}$ receptor type 1 expression on interstitial cells was highly localized. Discrete regions of intense staining were noted on interstitial cell processes. Cyclooxygenase 1 was also expressed in muscle interstitial cells. Cyclooxygenase 1 positive interstitial cells were more prevalent in the muscle bundles of the inner muscle than in the outer muscle layers. Cyclooxygenase 1 staining was noted on discrete regions of the cell or cell processes. Double staining with prostaglandin E receptor 1 and cyclooxygenase 1 suggested that cell regions expressing the former are different from those expressing the latter.

\section{Conclusions}

The discovered arrangement of Prostaglandin $\mathrm{E}_{2}$ receptor type 1 and cyclooxygenase 1 may have the potential to facilitate the propagation of signals in the interstitial cell network. Such a signaling system may have a role in coordinating events, as in bladder pathology, facilitating the global coordinated changes associated with bladder wall remodelling. 


\section{Introduction}

Prostaglandin is generated in the bladder wall in the lamina propria and muscle layers ${ }^{1-3}$. Production is stimulated by stretch or receptor mediated processes ${ }^{1-3}$ and involves de novo synthesis via 1 of 2 enzymes ( $\mathrm{COX}_{1}$ or 2$)^{4,5}$. The physiological role of prostaglandin (PG) in any region of the bladder wall remains controversial.

PG is released in the muscle layers ${ }^{6}$. Application of exogenous PG induces contractile activity in bladder smooth muscle in different species, including humans ${ }^{7-9}$, rats $^{10}$, guinea pigs ${ }^{11}$, rabbits $^{12}$ and monkeys ${ }^{13}$. In vivo these actions may be brought about directly or indirectly. For example, direct actions of PG may occur if PGs were coreleased with acetylcholine at efferent nerve endings to directly affect smooth muscle ${ }^{13}$. Alternatively it may act presynaptically to affect the release of excitatory transmitters ${ }^{10}$ or inhibit acetylcholine esterase ${ }^{9}$. However, COX 1 and 2 are rarely if ever associated with nerves. They are found in specific populations of muscle layer interstitial cells ${ }^{14}$. $\operatorname{COX}_{1}$ is found predominantly in interstitial cells on the surface of the muscle bundles of the inner layers but not on outer muscle bundles ${ }^{14,15}$. This led to the suggestion that PGs may be involved in the interplay between interstitial cells and smooth muscle, resulting in coordinated complex contractile activity ${ }^{14}, 15$.

Exogenous PG can increase autonomous activity in the isolated bladder ${ }^{14}, 15$. In animal studies intravesical PG increased voiding frequency, decreased bladder capacity and enhanced nonvoiding activity. When PG was placed in the human bladder lumen, it increased urge sensations and decreased bladder capacity ${ }^{7,16}$. This suggested that 1 action of PG in the bladder may be to enhance the motor component of a motor/sensory system and so increase bladder sensation ${ }^{14,15}$. In this way PGs may have a role in the pathological development of clinical sensory conditions such as urge. Clearly PG production and PG signaling are an integral part of the physiology of different regions of the bladder wall. Despite this generalization we have little detailed insight into signaling processes. We explored the relationship between $C_{1} O X_{1}$ and $P G$ receptors $\left(E P_{1}\right)$ in the muscle layers. Data showed that $\mathrm{COX}_{1}$ and $\mathrm{EP}_{1}$ are associated predominantly with muscle layer interstitial cells. Enzyme and receptor expression did not coincide in any interstitial cell, giving the appearance of regional distribution. To our knowledge the physiological significance of this arrangement is not known but it is consistent with a system that would facilitate the propagation of prostanoid signals in an interstitial cell network.

\section{Materials and Methods}

Nine male guinea pigs weighing 270 to $300 \mathrm{~g}$ were sacrificed by cervical dislocation. All procedures were done in agreement with Maastricht University ethical committee guidelines. Tissues were prepared as we previously described ${ }^{17}$. 


\section{Immunohistochemistry}

Sections were dried for 20 minutes at room temperature, followed by 3 washes with TBS $(\mathrm{pH}$ 7.6), and incubated overnight with primary antibodies at $4{ }^{\circ} \mathrm{C}$. To visualize $\left.E P\right\urcorner$ we used polyclonal antibody rabbit anti-EP1 (No. 101740, Cayman Chemical, Ann Arbor, Michigan) (1:100). The enzyme COX$_{1}$ was visualized using goat polyclonal antibody to COX 1 (Santa Cruz Biotechnology, Santa Cruz, California) (1:2,000). Mouse antibody against vimentin (No. V 5355, Sigma-Aldrich) was also used (1:5,000). Rabbit primary antibody was visualized using Alexa Fluor 488 donkey anti-rabbit $\lg \mathrm{G}(\mathrm{H}+\mathrm{L})$ conjugate (1:100 in TBS-T). The mouse primary antibody was visualized with Alexa Fluor 488 donkey anti-mouse IgG conjugate (Molecular Probes) (1:100). Goat primary antibody was visualized with Alexa Fluor 594 donkey anti-goat IgG conjugate (Molecular Probes). Sections were incubated with secondary antibodies for 60 minutes at room temperature in the dark. After 3 wash steps the sections were incubated at room temperature for 10 minutes with the nuclear marker Hoechst 33342 (Sigma-Aldrich) and mounted with TBS-glycerol.

All staining was done in all animals, and duplicated and repeated on at least 2 separate days. We accumulated observations from different slides and different bladders.

\section{Microscopy}

Most sections were analysed and photographed with an Olympus AX70 microscope using a $\times 4$, $\times 10, \times 20$ or $\times 40$ objective. To detect Alexa 488 fluorescence we used a narrow band pass MNIBA filter and for Alexa 594 we used a narrow excitation band U-M41007A filter (Chroma Technology, Bellows Falls, Vermont).

We performed confocal laser scanning microscopy fluorescent imaging in the samples using a Bio-Rad MRC60o confocal microscope equipped with an air cooled argon-krypton mixed gas laser and mounted on an Axiophot microscope (Carl Zeiss), using oil immersion objectives. The laser scanning microscope was used in dual wavelength excitation at 488 and $568 \mathrm{~nm}$. Optical sections were recorded in Kalman filtering mode using 4 to 8 scans per picture. We generated $Z$ series by collecting a stack of optical sections using a step size of between 0.18 and $0.46 \mu \mathrm{m}$ in the $Z$ direction.

We also obtained confocal triple staining images with an Stereo Investigator Confocal Spinning Disk (SI-SD) system (MBF Bioscience, Williston, Vermont), consisting of a modified BX 51 fluorescence microscope with UPlanSApo objectives and a customized DSU spinning disk unit (Olympus). We previously characterized the EP1 antibody used'? 


\section{Results}

\section{Vimentin and $E P_{1}$}

Figure 1 shows key study observations. Sections of guinea pig bladder wall stained for $\mathrm{EP}_{1}$ revealed the receptor on detrusor smooth muscle cells and vimentin positive muscle interstitial cells.

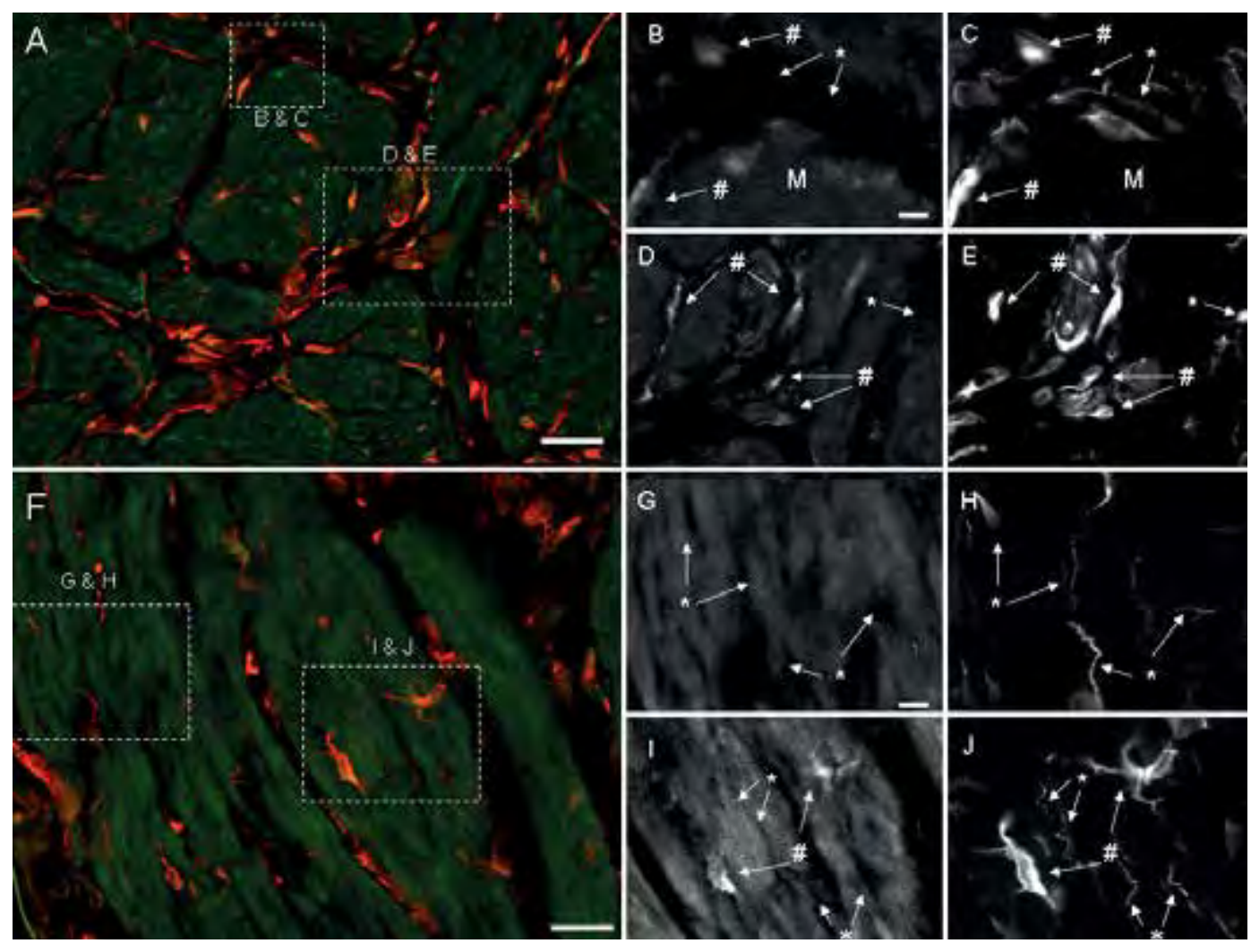

Figure 1. EP1 and vimentin in inner and outer muscle layers of guinea pig bladder lateral wall. $A$, inner muscle layer section stained with $\mathrm{EP}_{1}$ (green areas) and vimentin (red areas) antibodies. Calibration bars: $50 \mu \mathrm{m}$. Insets $B \& C, D \& E$ are ROIs. $B$ and $D$, higher magnification shows individual EP1 staining. Note cells (arrows) expressing vimentin as well as EP1. $M$, muscle. Asterisk (*) indicates vimentin staining structures. Pound sign (\#) indicates EP1 staining structures. Calibration bars: 10 $\mu \mathrm{m} . C$ and $E$, higher magnification shows individual vimentin staining. $B$ to $E$, Calibration bars: $10 \mu \mathrm{m}$. $F$, section of outer muscle layers stained with EP1 and vimentin antibodies. Calibration bars: $50 \mu \mathrm{m}$. Insets $G \& H$, and $I \& J$ are ROIs. $G$ and $I$, higher magnification shows individual EP1 staining. $H$ and J, higher magnification shows individual vimentin staining. $G$ to J, Calibration bars: $10 \mu \mathrm{m}$. 
Prostaglandins and Phosphodiesterases in the Urinary Bladder Wall

Muscle staining was less intense than interstitial cell staining and had a punctuate appearance, suggesting localized receptor expression regions (figure 2 and 3 ).

We found 2 types of vimentin positive interstitial cells in the inner and outer muscle, including sm-ics and intramuscular interstitial cells (figure 1). Many interstitial cells clearly expressed EP1 receptors and some did not. EP1 expression was not uniform throughout the cell and appeared to be localized to discrete regions (figures $1, G$ to $)$ ).
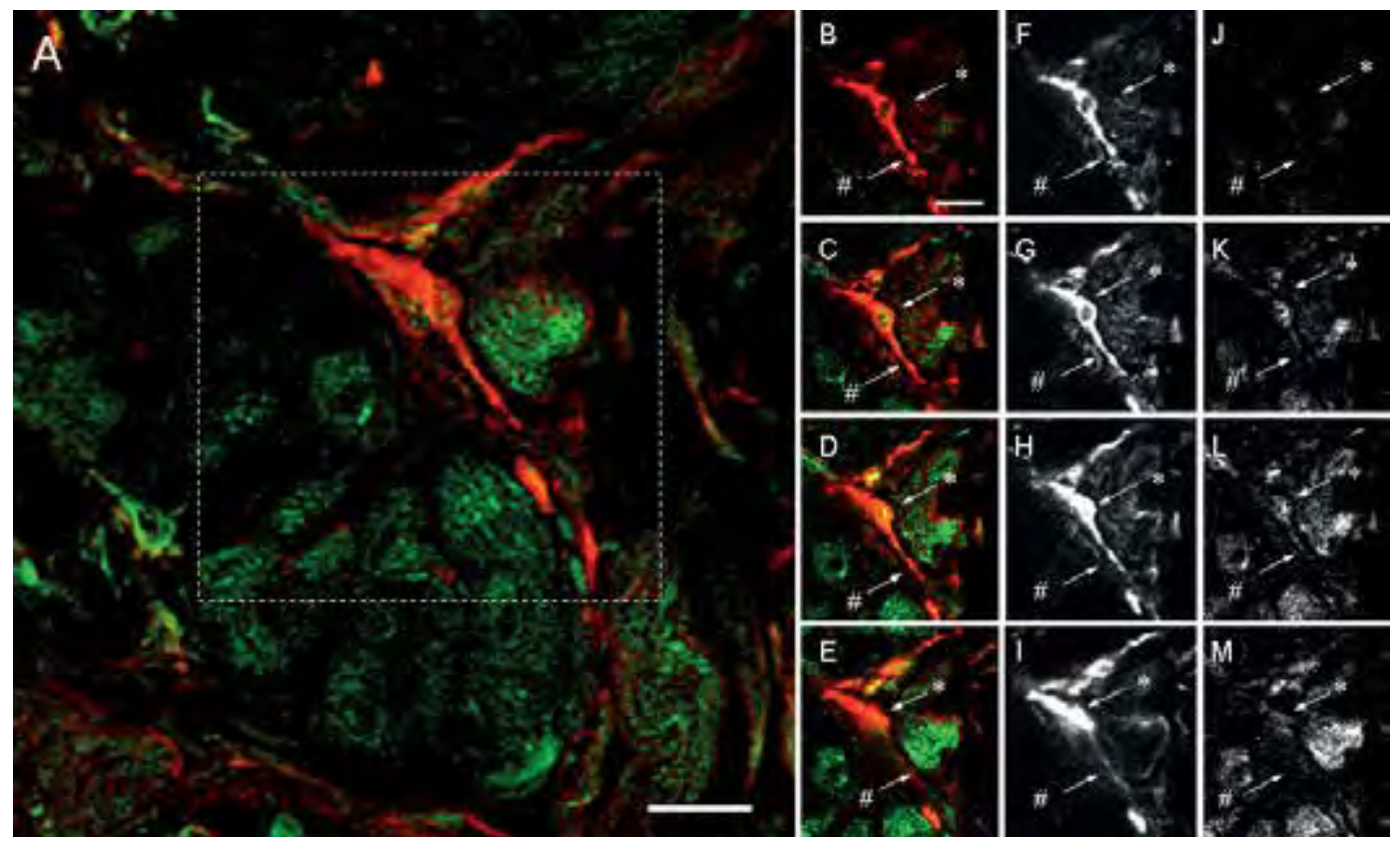

Figure 2. Confocal images reveal EP1 and vimentin in outer muscle layer of guinea pig bladder lateral wall. $A, Z$ projection stained with antibody for $\mathrm{EP}_{1}$ (green areas) and vimentin (red areas). Inset, ROIs ( $B$ to $E$ ). Calibration bars: $10 \mu \mathrm{m}$. $B$ to $E$, individual ROIs at different confocal stack planes. Slices were separated by $1.5 \mu \mathrm{m}$. $F$ to $I$, individual vimentin staining. $J$ to $M$, individual EP1 staining. $B$ to $M$, Calibration bars: $20 \mu \mathrm{m}$. 


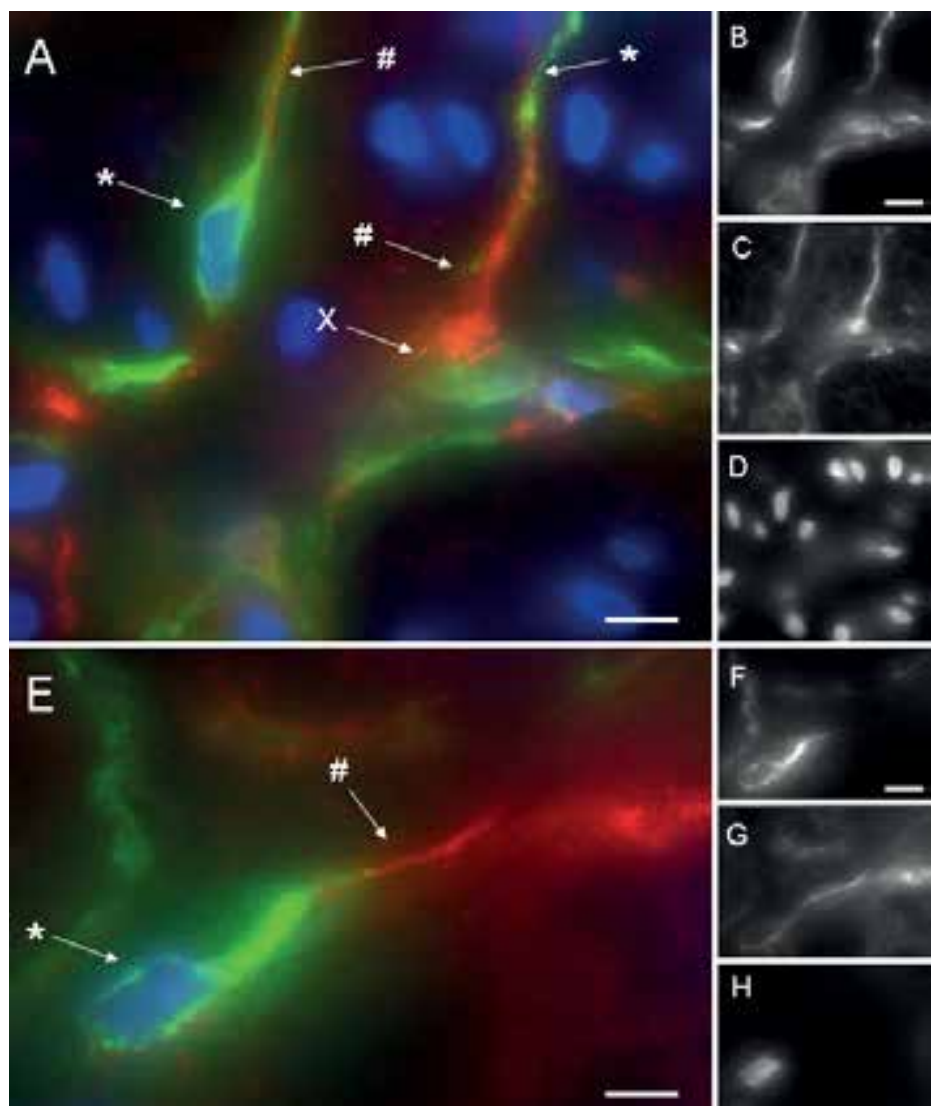

Figure 3. EP1 and vimentin in interstitial cells of outer muscle layer of guinea pig bladder lateral wall. $A$, confocal image projections stained with antibody for EP1 (green areas), vimentin (red areas) and Hoechst (blue areas). Interstitial cell shows intense vimentin and EP1 staining. Same cell expresses vimentin and EP1 but not at same site. Note single process with high EP1 density at 1 site. Asterisk (**) indicates vimentin staining structures. Pound sign (\#) indicates EP1 staining structures. Scale bar indicates $10 \mu \mathrm{m}$. B, individual vimentin (vim) images. C, individual EP1 staining. D, individual Hoechst (hoe) nuclei staining images. $B$ to $H$, scale bar indicates $10 \mu \mathrm{m}$. E, confocal image projections stained with antibody for $\mathrm{EP}_{1}$, vimentin and Hoechst. Interstitial cell shows intense vimentin and EP1 staining. Same cell expresses vimentin and EP1 but not at same site. Note interstitial cell with EP1 expression in highly localized region of cell process. Calibration bars: $10 \mu \mathrm{m}$. 


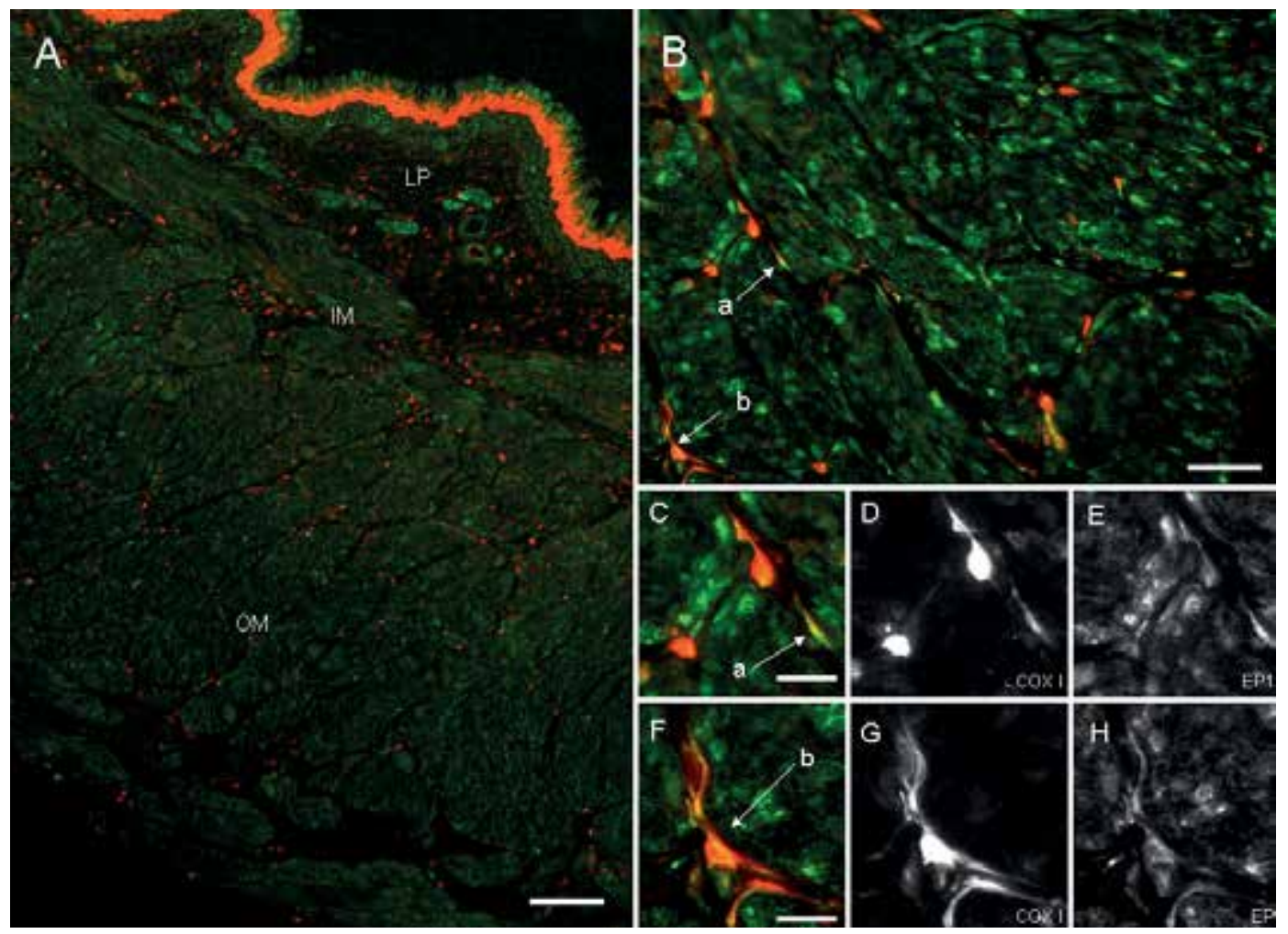

Figure 4. $\mathrm{EP}_{1}$ and $\mathrm{COX}_{1}$ in guinea pig bladder lateral wall. $A$, full-thickness bladder wall section. Green areas indicate staining for $E_{1}$. Red areas indicate staining for $C_{1} X_{1}$. LP, lamina propria. IM, inner muscle. OM, outer muscle. Calibration bars: $200 \mu \mathrm{m} . B$, inner muscle layer region. Arrows indicate surface muscle interstitial cells $(a$ and $b)$ as COX 1 and EP1 expression regions that did not colocalize. Calibration bars: $100 \mu \mathrm{m}$. $C$ to $E$, higher magnification of surface muscle interstitial cell as expression region that did not colocalize $(B, a)$. $D$ and $E$, individual $C O X_{1}$ and $E P I$ staining, respectively, of noncolocalized region $(B, a)$. $F$ to $H$, higher magnification of surface muscle interstitial cell as expression region that did not colocalize $(B$, b). $G$ and $H$, individual $C O X_{1}$ and $E P I$ staining, respectively, of noncolocalized region $(B, b)$. $C$ to $H$, Calibration bars: $20 \mu m$.

Figure 2 shows this observation of regional EP1 expression using confocal microscopy. Figure 2, $A$ shows a projection of the confocal stack. Punctate EP1 expression on the muscle was clearly visible as green areas. In the identified region of interest a sm-ic was noted. Figure 2, $B$ to $M$ show separate images of this region from the confocal stack. The vimentin positive sm-ic is apparent running through the stack. Colour images showed vimentin as red areas. Some section planes showed hot spots of yellow, indicating EP1 expression and its colocalization with vimentin structures. They were also apparent in EP1 single images (figures 2, J to $M$ ). Thus, discrete regions in a single SM-IC expressed EP1 receptors. 
Figure 3 shows such regions at higher magnification. Remarkably we identified localized EP1 expression on a single process of an interstitial cell in close proximity to an adjacent interstitial cell (figure $3, A$ ). Figure 3, B shows another example of a single process of an interstitial cell with highly regionalized $\mathrm{EP}_{1}$ expression.

\section{EP1 and $\mathrm{COX}_{1}$}

Figure 4 shows a full-thickness section of the bladder wall stained for $C_{1} O X_{1}$ as red areas and EP 1 as green areas. $\mathrm{COX}_{1}$ expression was clear in the urothelial basal and intermediate layers. $\mathrm{COX}_{1}$ was also apparent on lamina propria interstitial cells and on muscle interstitial cells on the inner muscle layers ${ }^{14,17}$. COX 1 positive interstitial cells were less prominent in the outer muscle layers ${ }^{14}$. Figure $4, B$ shows a region of the inner muscle layer at higher magnification. We identified 2 regions of interest that stained for $\mathrm{COX}_{1}$ and $\mathrm{EP}_{1}$ (figure $4, B$ to $H$ ). Some interstitial cells were noted to express $\mathrm{COX}_{1}$ as well as $\mathrm{EP}_{1}$ (figure 4 , arrows). Hot spots shown as yellow areas indicated cell regions with $\mathrm{EP}_{1}$ and $\mathrm{COX}_{1}$ in close proximity. As with $\mathrm{EP}_{1}$ (figure 1-3), localized $\mathrm{COX}_{1}$ expression to processes of muscle interstitial cells was identified using vimentin to identify interstitial cell processes (figure 5 ). Figure 6 further reveals punctate $\mathrm{EP}_{1}$ and $\mathrm{COX}_{1}$ distribution. Regional $\mathrm{COX}_{1}$ and $\mathrm{EP}_{1}$ expression was observed on the same interstitial cell. 


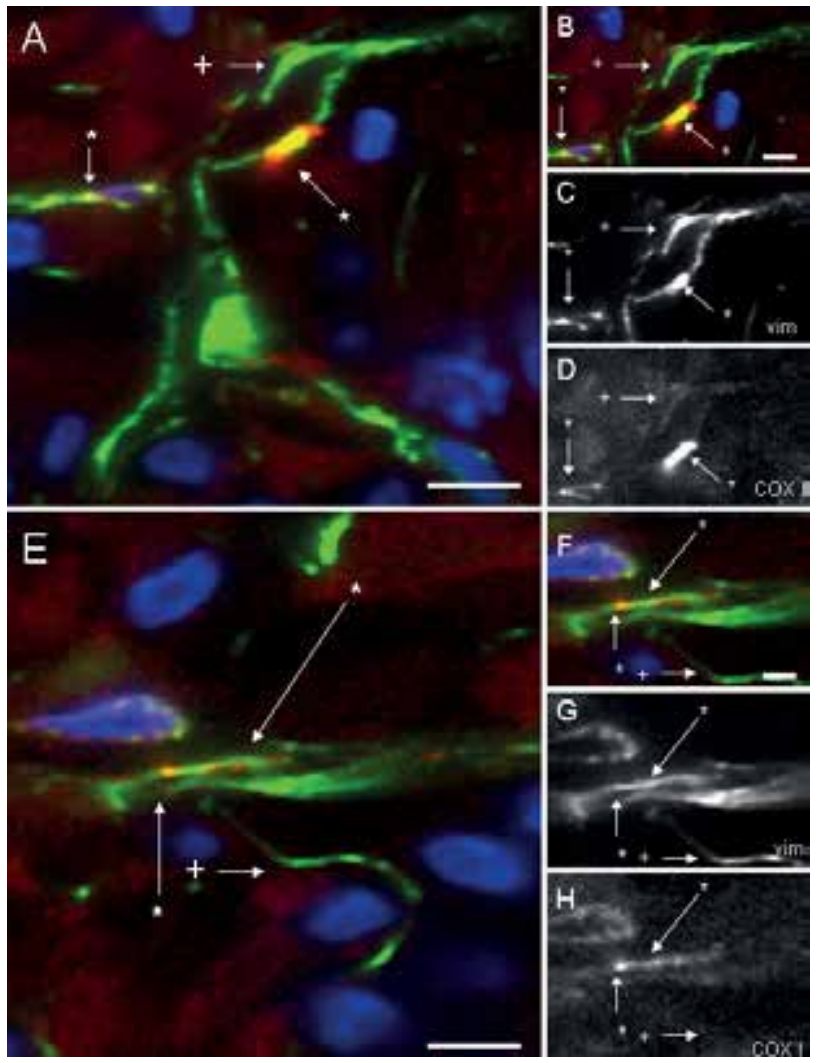

Figure 5. $\mathrm{COX}_{1}$ and vimentin in interstitial cells of inner muscle layer guinea pig bladder lateral wall. $A$, interstitial cell processes (arrows). One process (asterisk) (*) shows intense COX 1 staining (red areas). Green areas (plus sign) (+) indicate vimentin staining. Blue areas indicate Hoechst staining. Calibration bars: $10 \mu \mathrm{m}$. $B$, ROI $(A)$. $C$, individual vimentin (vim) staining $(A) . D$, individual $C_{1}$ staining $(A) . B$ to $D$, Calibration bars: $10 \mu \mathrm{m}$. $E$, another example of regional $\mathrm{COX}_{1}$ expression in interstitial cell process. $C O X 1$ regions are adjacent to vimentin positive interstitial cells not expressing COX $\mathrm{X}_{1}$. Calibration bars: $10 \mu \mathrm{m}$. $F, \mathrm{ROI}(E)$. $G, \mathrm{ROI}$ individual vimentin staining $(E) . H, \mathrm{ROI}$ individual $\mathrm{COX}_{1}$ staining (E). F to $H$, Calibration bars: $10 \mu \mathrm{m}$. 
Chapter 4 - The Relationship Between EP1 and COX Expression in Guinea Pig Bladder IC's
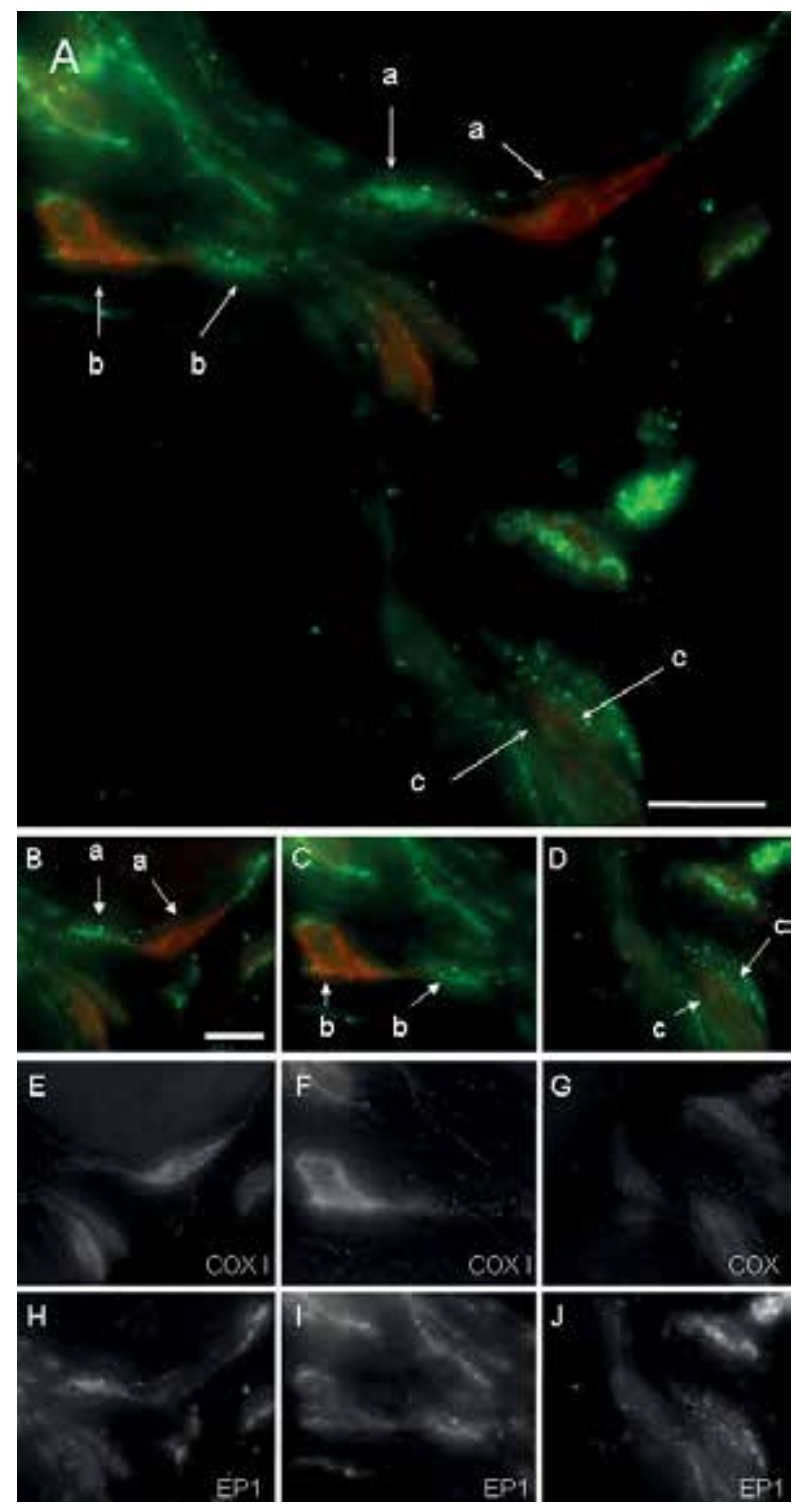

Figure 6. Regional $\mathrm{COX}_{1}$ and $\mathrm{EP}_{1}$ expression in single surface muscle interstitial cells. $A$, region where $\mathrm{EP}_{1}$ (green areas) and $\mathrm{COX}_{1}$ (red areas) are easily seen. $a$ and $b$, individual interstitial cells expressing $\mathrm{COX}_{1}$ and $\mathrm{EP}_{1}$. $c$, cell with $\mathrm{COX}_{1}$ but no $\mathrm{EP}_{1}$ expression region and adjacent cell with EP1 but no COX 1 expression. Calibration bars: 20 $\mu \mathrm{m} . B, E$ and $H, \mathrm{ROI}(A, a) . C, F$ and $I, \mathrm{ROI}(A, b) . D, G$ and $J$, ROI (A, c). $E$ to $G$, individual COX 1 staining. $H$ to J, individual EP1 staining. $B$ to J, Calibration bars: $10 \mu \mathrm{m}$. 


\section{Discussion}

We focused on the expression of $E P 1$, which is 1 of the 4 PG receptor subtypes. These receptors are found in many tissues in which intracellular signals are generated in response to $P G$, involving diacylglycerol and 1,4,5-triphosphate ${ }^{18}$. In such systems EP1 is involved in regulating intracellular $\mathrm{Ca}^{2+}$ and cell excitability. The presence of EP1 receptor on bladder interstitial cells suggests that they may also be excitable. This idea was put forward in relation to the coordination of localized contractions in the bladder wall (autonomous activity) as part of a motor/sensory system regulating bladder afferent activity ${ }^{19,20}$. Experimental evidence shows that bladder interstitial cells are excitable ${ }^{21}$ and activating these cells can initiate smooth muscle contraction, possibly via direct electrical coupling through gap junctions ${ }^{22}$. Also, in the isolated bladder exogenous PG produces coordinated phasic contractions in the bladder wall'14. The idea is now put forward that bladder interstitial cells could form a communication network, similar to interstitial cells of Cajal in the gut. This network could be more effective than smooth muscle bundles, which are relatively uncoupled. Thus, signal transduction through these coupled interstitial cells would be more rapid than via the spread of electrical or $\mathrm{Ca}^{2+}$ signals. Hence, such coordinated contractions are more likely to be mediated via EP1 receptors on interstitial cells than on muscle since by local PG release random activation of the latter would result in random uncoordinated activity. Thus, the EP1 stimulation of muscle interstitial cells may be involved in the rapid generation of coordinated contractile responses.

$E P_{1}$ receptors respond to PG. Therefore, a key question is where the PG used to activate these receptors comes from. PG is generated in the lamina propria and muscle layers ${ }^{6}$. However, to our knowledge the precise cell types responsible have not been investigated. Recently it was reported that in the guinea pig bladder the basal and intermediate layers of the urothelium strongly express 1 of the PG synthesizing enzymes, $\operatorname{COX}_{1}{ }^{14}$, suggesting that this is the site of PG synthesis in the lamina propria. $\mathrm{EP}_{1}$ and $\mathrm{EP}_{2}$ receptors were localized to urothelium and suburothelial interstitial cells, suggesting that these cells are the target of urothelial derived $P \mathrm{C}^{17}$.

The physiological role of this system is not fully understood. However, ideas are now being put forward that suggest involvement in regulating early physiological responses involved in bladder inflammation ${ }^{23}$.

Muscle interstitial cells were identified as a potential source of PG in the muscle layers ${ }^{14}$, which was confirmed in the current study. Our data reveal an unusual, interesting micro-anatomical arrangement in interstitial cells, that is localized expression of EP1 receptors and sites of PG production (COX expression). The PG production site in a cell is different from the site that expresses the receptors. Figure $7, A$ shows this micro-anatomical specialization. The arrangement of a cell that produces a signal and has receptors to that signal is a classic autocrine arrangement. This may also be the case in the bladder. However, the specialization of discrete signal producing regions and signal responsive regions suggests a further degree of complexity. Figure $7, B$ shows an idea. We propose that the system operates to facilitate signal propagation in the interstitial cell network. Cell activation would stimulate $\mathrm{COX}_{1}$ and local PG release, which would then activate an 


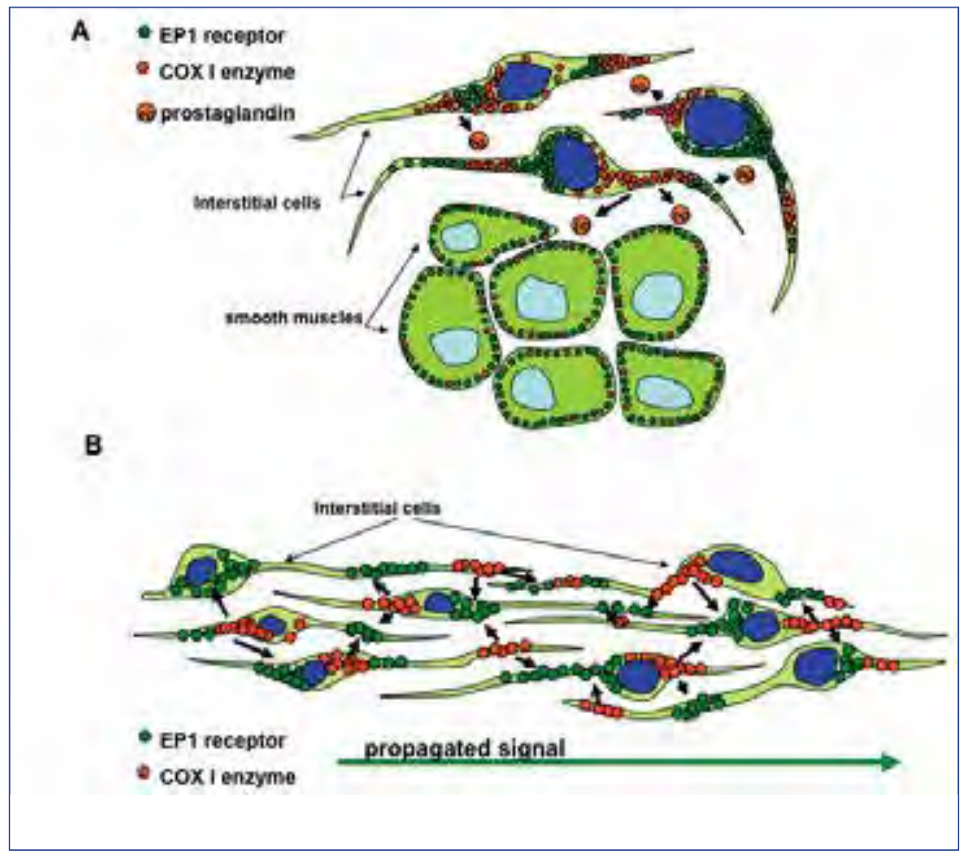

Figure 7. EP1 (green dots) and COX1 (red dots) distribution pattern on interstitial and smooth muscle cells of guinea pig detrusor, and proposed signal propagation system. $A, C_{1} X_{1}$ and $E_{1}$ regional sites on surface muscle interstitial cells and colocalization of 2 markers in smooth muscle. $C_{1} X_{1}$ muscle staining intensity was considerably lower than on interstitial cells. $B$, surface muscle interstitial cell network with $\mathrm{COX}_{1}$ and $\mathrm{EP}_{1}$ expression regions. Hypothesis is that this arrangement allows signal propagation along and throughout network. PG produced by $\mathrm{COX}_{1}$ exits cells and acts on adjacent cells expressing EP1. After activation these cells then release $P G$ from their $C_{1} O X_{1}$ sites. Adjacent cells with $E_{1}$ receptors are then activated and so on. Net result is possible propagation of $\mathrm{COX}_{1} / \mathrm{PG}_{\mathrm{E}} \mathrm{EP}_{1}$ signal throughout network.

adjacent cell via its EP1 receptor region. After it is activated this cell would release PG to activate neighbouring cells. In this way activation would spread throughout the network as an avalanche effect. The propagation of such a chemical signal may be somewhat slower than electrical activity moving from cell to cell via gap junctions.

The physiological consequence of this structural finding needs further exploration. It is known that signals propagate throughout the bladder wall. In the rat urothelial stimulation can trigger a $\mathrm{Ca}^{2+}$ signal that travels deep into the muscle layer ${ }^{24}$. To our knowledge how this signal is generated is not known but it may occur as described via the interstitial cell network. Based on micro-anatomical evidence it can be suggested that the network of suburothelial, lamina propria and muscle 
interstitial cells may form a communicating network ${ }^{14}$. Recent data on an isolated lamina propria preparation revealed that signals released from urothelium are targeted at the suburothelial cell layer ${ }^{23}$. Thus, the activation of propagated signals in the suburothelial network may originate from the urothelium.

Also, the number of lamina propria and muscle interstitial cells is increased in the bladder of animals with experimentally induced partial bladder outflow obstruction ${ }^{25}$. Bladders from animals with partial bladder outlet obstruction have increased excitability (sensitivity to exogenous acetylcholine) and enhanced autonomous activity. Such changes are linked to changes in the interstitial cell network ${ }^{25}$. Our observations may provide further evidence for an explanation of this process. Activation of the interstitial cell network using the COX $/ \mathrm{PG}_{1} / \mathrm{PP}_{1}$ system may trigger changes in cell excitability and, presumably in view of the latter finding, proliferation.

\section{Conclusions}

The localized presence of $\mathrm{COX}_{1}$ in interstitial cells suggest the localized production and release of PG. The proximity of $\mathrm{EP}_{1}$ receptors suggests that they may be a possible target of this PG. Such an arrangement in the muscle interstitial cell network has the potential to propagate signals throughout the entire bladder wall. Activation of this network could result in increased excitability and be associated with triggering cell proliferation. These findings suggest that the PG system may have a role in the structural pathological bladder changes, for example those after partial bladder outlet obstruction. As a consequence, these structural changes may be inhibited by pharmacological agents targeting the PG system. More functional experiments are needed to investigate these hypotheses. 


\section{References}

1. Gilmore, N.J. \& Vane, J.R. Hormones released into the circulation when the urinary bladder of the anaesthetized dog is distended. Clinical Science 41, 69-83 (1971).

2. Ghoneim, M.A., Fretin J,A., Gagnon, D.J., Lebel, E., Van Lier, J., Arsenault, A. \& Susset, J.G.The influence of vesical distension on the urethral resistance to flow: a possible role for prostaglandins? The Journal of Urology 116, 739-743 (1976).

3. Poggesi, L., Nicita, G., Castellani, S., Selli, C., Galanti, G., Turini, D. \& Masotti, G. The role of prostaglandins in the maintenance of the tone of the rabbit urinary bladder. Investigative Urology 17, 454-458 (1980).

4. Vane, J.R., Bakhle, Y.S. \& Botting, R.M. Cyclooxygenases 1 and 2. Annual review of Pharmacology and Toxicology 38, 97-120 (1998).

5. Nile, C.J., de Vente, J. \& Gillespie, J.I. Stretch independent regulation of prostaglandin E production within the isolated guinea-pig lamina propria. British Journal of Urology International (2009).

6. Maggi, C.A. Prostanoids as local modulators of reflex micturition. Pharmacological Research 25, 13-20 (1992).

7. Andersson, K.E., Ek, A. \& Persson, C.G. Effects of prostaglandins on the isolated human bladder and urethra. Acta Physiologica Scandinavica 100, 165-171 (1977).

8. Bultitude, M.I., Hills, N.H. \& Shuttleworth, K.E. Clinical and experimental studies on the action of prostaglandins and their synthesis inhibitors on detrusor muscle in vitro and in vivo. British Journal of Urology 48, 631-637 (1976).

9. Borda, E., Contreras-Ortiz, N., Gutnisky, R. \& Gimeno, M.F. In vitro effect of acetylcholine and bethanechol on the contractions of the human detrusor muscle. Influence of prostaglandins. Archives Internationales de Pharmacodynamie et de Therapie 259, 31-39 (1982).

10. Choo, L.K. \& Mitchelson, F. The effect of indomethacin and adenosine 5'-triphosphate on the excitatory innervation of the rate urinary bladder. Canadian Journal of Physiology and Pharmacology 58, 1042-1048 (1980).

11. Burnstock, G., Cocks, T., Crowe, R. \& Kasakov, L. Purinergic innervation of the guinea-pig urinary bladder. British Journal of Pharmacology 63, 125-138 (1978).

12. Downie, J.W. \& Larsson, C. Prostaglandin involvement in contractions evoked in rabbit detrusor by field stimulation and by adenosine 5'-triphosphate. Canadian Journal of Physiology and Pharmacology 59, 253-260 (1981).

13. Johns, A. \& Paton, D.M. Effect of indomethacin on atropine-resistant transmission in rabbit and monkey urinary bladder: evidence for involvement of prostaglandins in transmission. Prostaglandins 13, 245-254 (1977).

14. de Jongh, R., Grol, S., van Koeveringe, G.A., Van Kerrebroeck, Ph.E.V., de Vente, J., \& Gillespie, J.I. The localisation of cyclo oxygenase immuno-reactivity (COX $\mathrm{CIR}$ ) to the urothelium and to interstitial cells in the bladder wall. Journal of Cellular and Molecular Medicine 13(9B),3069-3081 (2009).

15. de Jongh, R., van Koeveringe, G.A., Van Kerrebroeck, Ph.E.V., Markerink-van Ittersum, M., de Vente, J. \& Gillespie, J.I. The effects of exogenous prostaglandins and the identification of constitutive cyclooxygenase I and II immunoreactivity in the normal guinea pig bladder. British Journal of Urology International 100, 419-429 (2007). 
16. Andersson, K.E. \& Forman, A. Effects of prostaglandins on the smooth muscle of the urinary tract. Acta Pharmacologica et Toxicologica 43 Suppl 2, 90-95 (1978).

17. Rahnama'i, M. S., van Koeveringe, G.A., Essers, P.B., de Wachter, S.G., de Vente, J., Van Kerrebroeck, Ph.E.V., \& Gillespie, J.I. Prostaglandin receptor EP1 and EP2 site in guinea pig bladder urothelium and lamina propria. The Journal of Urology 183, 1241-1247 (2010).

18. Breyer, M.D., Jacobson, H.R. \& Breyer, R.M. Functional and molecular aspects of renal prostaglandin receptors. Journal of American Society of Nephrology 7, 8-17 (1996).

19. Gillespie, J.I. The autonomous bladder: a view of the origin of bladder overactivity and sensory urge. British Journal of Urology International 93, 478-483 (2004).

20. Gillespie, J.I., van Koeveringe, G.A., de Wachter, S.G. \& de Vente, J. On the origins of the sensory output from the bladder: the concept of afferent noise. British Journal of Urology International 103, 1324-1333 (2009).

21. McCloskey, K.D. Interstitial cells in the urinary bladder--localization and function. Neurourology and Urodynamics 29, 82-87 (2010).

22. Hashitani, H., Yanai, Y. \& Suzuki, H. Role of interstitial cells and gap junctions in the transmission of spontaneous Ca2+ signals in detrusor smooth muscles of the guinea-pig urinary bladder. The Journal of Physiology 559, 567-581 (2004).

23. Nile, C.J., de Vente, J. \& Gillespie, J.I. Stretch independent regulation of prostaglandin E(2) production within the isolated guinea-pig lamina propria. British Journal of Urology International 105, 540-548 (2009).

24. Kanai, A., Roppolo, J., Ikeda, Y., Zabbarova, I., Tai, C., Birder, L., Griffiths, D., de Groat, W. \& Fry C. Origin of spontaneous activity in neonatal and adult rat bladders and its enhancement by stretch and muscarinic agonists. American Journal of Physiology 292, F1065-1072 (2007).

25. de Jongh, R., van Koeveringe, G.A., Van Kerrebroeck, Ph.E.V., Markerink-van Ittersum, M., de Vente, J. \& Gillespie, J.I. Alterations to network of NO/cGMP-responsive interstitial cells induced by outlet obstruction in guinea-pig bladder. Cell and Tissue Research 330, 147-160 (2007). 




\section{Chapter 5}

\section{The Distribution of the Prostaglandin E Receptor Type 2 (EP2) in the Detrusor of the Guinea Pig}

Prostaglandins and Other Lipid Mediators. 2012 Dec;99(3-4):107-15

doi: 10.1016/j.prostaglandins. 2012.08.005

PMID: 22960431

M.S. Rahnama'i, B.T. Biallosterski, S.G.G. de Wachter, Ph.E.V. Van Kerrebroeck and G.A. van Koeveringe 


\section{Abstract}

\section{Purpose}

To explore the distribution of prostaglandin E receptor type $2\left(E_{2}\right)$ in the bladder muscle layers and its spatial relationship to cyclo oxygenase type 1 (COXI).

\section{Materials and methods:}

Twelve male guinea pigs were killed by cervical dislocation, the bladders removed and fixed in $4 \%$ paraformaldehyde in PBS. Frozen sections of $10 \mu \mathrm{m}$ were cut and stained with antibodies to EP2, $\mathrm{COX}_{1}$ and vimentin.

\section{Results}

EP2 receptor immunoreactivity is located on the smooth muscle cells as well as on vimentin positive surface muscle and intramuscular interstitial cells. EP2 expression on interstitial cells is highly localized. Discrete regions of intense staining were observed on the interstitial cell processes. $\mathrm{COX}_{1}$ is expressed in the muscle interstitial cells and was found to be located on discrete regions of the cell and cell processes. Double staining with $\mathrm{EP}_{2}$ and $\mathrm{COX}_{1}$ suggests that the regions of a cell expressing $\mathrm{EP}_{2}$ are different from those expressing $\mathrm{COX}_{1}$.

\section{Conclusions}

The presence of $\mathrm{COX}_{1}$, prostaglandin $\mathrm{E}$ receptor type $2\left(\mathrm{EP}_{2}\right)$ immune-reactivity in the network of interstitial cells suggests a role of this network in the propagation of signals. Due to a cAMP coupling of the EP2 receptor in many other tissues and a lower dissociation constant of EP2, it is suggested that a rise in PG levels may gradually push the balance from a relaxant $\mathrm{EP}_{2}$ effect towards a contractile effect. Hence, PG could have a modulatory role on the non-voiding bladder contractions by changing the threshold level for excitability of the interstitial cell network. 


\section{Introduction}

It is now generally accepted that prostaglandin (PG) plays a role in the control of mammalian urinary bladder motility ${ }^{1,2}$. In the bladder, both the lamina propria and the muscle layers can produce Prostaglandins ${ }^{3-6}$. Prostaglandin E2 $\left(\mathrm{PGE}_{2}\right)$ is known to be the predominant PG in the urinary bladder of most mammals ${ }^{7}$ and the receptors for $P G E_{2}$ are classified into four types: $E P_{1}$, $E P_{2}, E_{3}$ and $E_{4}{ }^{8}$. $P_{E_{2}}$ is an agonist at EP receptors, ${ }^{1-4}$ all G-protein coupled, which mediate its physiological effects ${ }^{9}$. $P G E_{2}$ is the main $\mathrm{PG}$ suggested to be involved in the pathophysiology of detrusor overactivity (DO) and overactive bladder syndrome $(O A B)^{9,10}$. This involvement is based on three observations. Firstly, the ability of $\mathrm{PGE}_{2}$ infused into the bladder to induce DO in humans and animals. Secondly, the increased PGE ${ }_{2}$ production in DO models and thirdly, the high concentrations of $\mathrm{PGE}_{2}$ that have been detected in the urine of patients with $\mathrm{OAB}^{9}$. It has also been shown that upon stretch, $\mathrm{PGE}_{2}$ is released by the urothelium " and that this release is regulated by a complex interaction of signals through ATP and NO'. the literature contains substantial data that the wall of the mammalian urinary bladder contains several sub-populations of cells in the interstitial space, called interstitial cells (ICs) after the interstitial cells of Cajal in the gut ${ }^{12}$. These interstitial cells are located in the lamina propria and within the detrusor and have been suggested to form a network called the interstitial cell network ${ }^{3,13-15}$. The expression of prostaglandin E receptor type $1\left(E_{1}\right)$ in the guinea pig muscle interstitial cell network has been studied recently3.

Moreover, it has been shown that the cyclo oxygenase 1 (COX 1 ) enzymes are located within specific cell types within the lamina propria of the guinea pig bladder ${ }^{16}$. In addition, $C_{1} O X_{1}$ is found in the basal layers of the urothelium and associated with the distributed network of lamina propria interstitial cells ${ }^{16}$. It has also been suggested that the arrangement of EP1 and COX 1 might have the potential to facilitate the propagation of signals in the interstitial cell network ${ }^{3}$. Such a signalling system is thought to have a role in coordinating events in the normal bladder ${ }^{17}$ and might be defective in bladder pathology'3. It might also have a function in facilitating the global coordinated changes associated with bladder wall remodelling 3,18 . PG receptors $\mathrm{EP}_{1}$ and $\mathrm{EP}_{2}$ have been shown to be expressed in the ICs in the lamina propria indicating that this part of the bladder wall can respond to $\mathrm{PGE}_{2}{ }^{4}$. There is hardly any literature about the exact role of the EP2 receptor in the bladder. However, it is known that the normal guinea pig urothelium does express EP2 receptors ${ }^{4}$ and that the combined $\mathrm{EP}_{1} / \mathrm{EP}_{2}$ receptor antagonist $\mathrm{AH} 6809$ decreases detrusor contraction in isolated human bladder experiments ${ }^{19}$. Unlike $\mathrm{EP}^{13}$, the cellular localization and the expression of $E P 2$ receptor in the muscle layers of the bladder have not been studied before. In the present study, we have used antibodies to EP2 in order to study the distribution of this receptor in the muscle layers of the guinea pig urinary bladder. Our results are discussed in terms of possible physiological mechanisms, which might be occurring in this region of the bladder wall. 


\section{Materials and methods}

Guinea pigs ( 12 male, weight range $260-300 \mathrm{~g}$ ) were killed by cervical dislocation. All procedures were carried out in agreement with the guidelines of the Maastricht University Ethical Committee. The tissue workup of the lateral wall of the guinea pig bladders as well as freezing and the cutting of the sections are as described in our previous paper 4 .

\section{Tissue preparation}

The bladder, including the proximal urethra, was removed from each animal and placed in ice-cold Krebs solution composed of $121.1 \mathrm{mM} \mathrm{NaCl}, 1.87 \mathrm{mM} \mathrm{KCl}, 1.2 \mathrm{mM} \mathrm{CaCl}_{2}, 1.15 \mathrm{mM} \mathrm{MgSO}_{4}, 25 \mathrm{mM}$ $\mathrm{NaHCO}_{3}, 1.17 \mathrm{mM} \mathrm{KH}_{2} \mathrm{PO}_{4}$ and $11.0 \mathrm{mM}$ glucose bubbled with $5 \% \mathrm{CO}_{2}$ and $95 \% \mathrm{O}_{2}(\mathrm{pH} 7.4)$. Each bladder was divided into a ventral piece and a dorsal piece, while maintained in Krebs solution. Then, the bladder pieces were immersed in ice-cold fixative solution of $4 \%$ freshly prepared depolymerized paraformaldehyde for $120 \mathrm{~min}$ at $4{ }^{\circ} \mathrm{C}$. Tissues were fixed in 3 steps of 2 overnight and 1 daytime incubation at $4{ }^{\circ} \mathrm{C}$ in $0.1 \mathrm{M}$ phosphate buffer with $10 \%, 20 \%$ and $30 \%$ sucrose, respectively. On day 3 the tissues were placed in Tissue-Tek OCT ${ }^{\mathrm{TM}}$ compound to form a single block, snap frozen in isopentane and cooled in liquid nitrogen. Cryostat sections $(10 \mu \mathrm{m})$ were cut such that each section was perpendicular to the urothelial surface. Sections were thawed on chrome alum-gelatin coated slides and processed for immunocytochemistry.

\section{Characterization of the EP2 antibody}

In order to gain insight in the specificity of our antibody, we conducted a pre-absorption test and characterized the antibodies by Western blotting as described in our previous paper 4 . In short, preabsorption was done by overnight incubation of the anti-EP2 antibody (1:100 by Cayman Chemical, Catalogue No. 301740) with or without $10 \mu \mathrm{g} / \mathrm{ml}$ of the peptide against which the antibody was raised. Thereafter the antibody solution or antibody plus peptide solution was applied to the sections. Bladder homogenate of guinea pig bladders $(\mathrm{N}=2)$ was prepared for Western blotting. Bladders were cut into squares of approximately $1 \mathrm{~mm} 2$ and homogenized using an UltraTurrax homogenizer (Janke \& Kunkel, Ika Labortechnik, Staufen, Germany) at $4{ }^{\circ} \mathrm{C}$ in $1 \times$ radio-immunoprecipitation assay buffer ( $1 \%$ Triton-X-100, $137 \mathrm{mM} \mathrm{NaCl}, 20 \mathrm{mM}$ Tris- $\mathrm{HCl}, 2 \mathrm{mM}$ EDTA, $10 \%$ glycerol, $1 \mathrm{mM}$ sodium orthovanadate, $10 \mathrm{mM} \mathrm{NaF}, 1 \times$ protease inhibitor cocktails, $1 \mathrm{mM}$ phenylmethylsulphonyl fluoride). Subsequently the homogenates were centrifuged at $13,000 \times \mathrm{g}$ for $20 \mathrm{~min}$ at $4{ }^{\circ} \mathrm{C}$. The pellet was discarded and the supernatant was stored at $-80^{\circ} \mathrm{C}$. Protein measurements were done using bovine albumin serum dilutions with the Biorad protein measurement system (Bio-Rad Laboratories, Inc., Hertfordshire, CA, USA) according to the manufacturer's instructions. The blot analysis was performed under reducing conditions following standard procedures and using the Odyssey infrared imaging system (Licor Biosciences, USA). Primary antibody used for Western blotting was rabbit anti-EP2 antibody (Cayman Chemicals) used in a dilution of 1:100. The staining was also confirmed by a blocking 
peptide on the Western blot using pre-absorption with anti-EP2 antibody in a dilution of 1:100 (Cayman Catalogue Nos. 301750 and 301740). The secondary antibody used was donkey antirabbit IRdye800 (Rockland, 611-732-127).

\section{Immunohistochemistry}

Sections were dried for 20 min at room temperature followed by three washes with Tris-buffered saline (TBS; $\mathrm{pH} 7.6$ ), and thereafter incubated overnight with primary antibodies at $4{ }^{\circ} \mathrm{C}$. To visualize the prostaglandin receptor EP2, we used a polyclonal antibody rabbit anti-EP2 (Cayman Chemical, Catalogue No. 101750) which was diluted 1:100. The COX 1 enzyme was visualized using an optimized concentration of goat polyclonal antibody to COX 1 (1:2000; Santa Cruz Biotech, Catalogue No. sc-1752). Furthermore, a mouse antibody against vimentin (Sigma-Aldrich, Catalogue No. V 5355) was used at a dilution of 1:5000. The rabbit primary antibody was visualized using Alexa Fluor 488 donkey anti-rabbit $\operatorname{lgG}(\mathrm{H}+\mathrm{L})$ conjugate (Molecular Probes), diluted 1:100 in TBS-T. The mouse primary antibody was visualized with Alexa Fluor 594 donkey antimouse IgG conjugate (Molecular Probes), diluted 1:100. The goat primary antibody was visualized with Alexa Fluor 594 donkey antigoat IgG conjugate (Molecular Probes). Sections were incubated with the secondary antibodies for $60 \mathrm{~min}$ at room temperature in the dark. After three wash steps the sections were incubated at room temperature for 10 min with a nuclei marker, HOECHST 33342 (Sigma, Zwijndrecht, The Netherlands) and mounted with TBS-glycerol. All stainings were done in all the animals and duplicated and repeated on at least 2 separate days. All results were confirmed with negative control stainings, without application of the primary antibody. Observations were accumulated from the different slides and from the different bladder specimens of all 12 animals. A representative section of all animal bladders was studied.

\section{Microscopy}

The majority of the sections was analysed and photographed using an Olympus AX70 microscope using a 10X, 20x and 40X objective. For the detection of Alexa 488 fluorescence, a narrow bandpass MNIBA-filter and for Alexa 594 a narrow excitation band U-M41007A filter was used (both from Chroma Technologies). Confocal laser scanning microscopy fluorescent imaging was done on the samples using a Bio-Rad MRC6oo confocal microscope (Bio-Rad Laboratories Ltd., Hemel Hempstead, UK) equipped with an air-cooled Argon-Krypton mixed gas laser and mounted onto an Axiophotemicroscope (Zeiss), using oil-immersion objectives (4O, NA1/4 3D1.3 or 63, NA1/4 3D1.4). The laser-scanning microscope was used in dual wavelength excitation at 488 and $568 \mathrm{~nm}$.

Optical sections were recorded in the Kalman filtering mode using 4-8 scans for each picture. Z-series were generated by collecting a stack consisting of optical sections using a step size between 0.18 and $0.46 \mathrm{~mm}$ in the $z$-direction. 


\section{Results}

Figure 1 shows the characterization of the EP2 antibody used in this study. This characterization was described in our previous paper 4 . There were two approaches chosen to confirm that this is specific staining. Firstly, the antibody was pre-incubated with the peptide to which it was raised (blocking peptide) and the antibod-ies specific reactive site was eliminated. Where this was done, all of the observed staining was removed (panel A). In order to see the tissue morphology, an enhanced (overexposed) image is shown in the inset. Panel B shows a Western blot of bladder protein exposed EP2 antibody (middle lane). A single protein band of the predicted molecular weight of the EP2 protein was seen. This band was also removed by pre-absorbing the antibody with the blocking peptide. Thus, this antibody for $\mathrm{EP}_{2}$ can be used with a high degree of certainty that they will detect specifically the EP2 receptors in the guinea pig bladder.

The $E P 2$ receptor is present on both the detrusor smooth muscle cells as well as on vimentin positive muscle interstitial cells (figure 2). The vast majority of interstitial cells clearly express EP2 receptors. More detail about the EP2 expression is shown in figures 2,5 and 6 where it can be noted that the EP2 expression is not equal throughout the cell and appears to be localized in discrete regions.

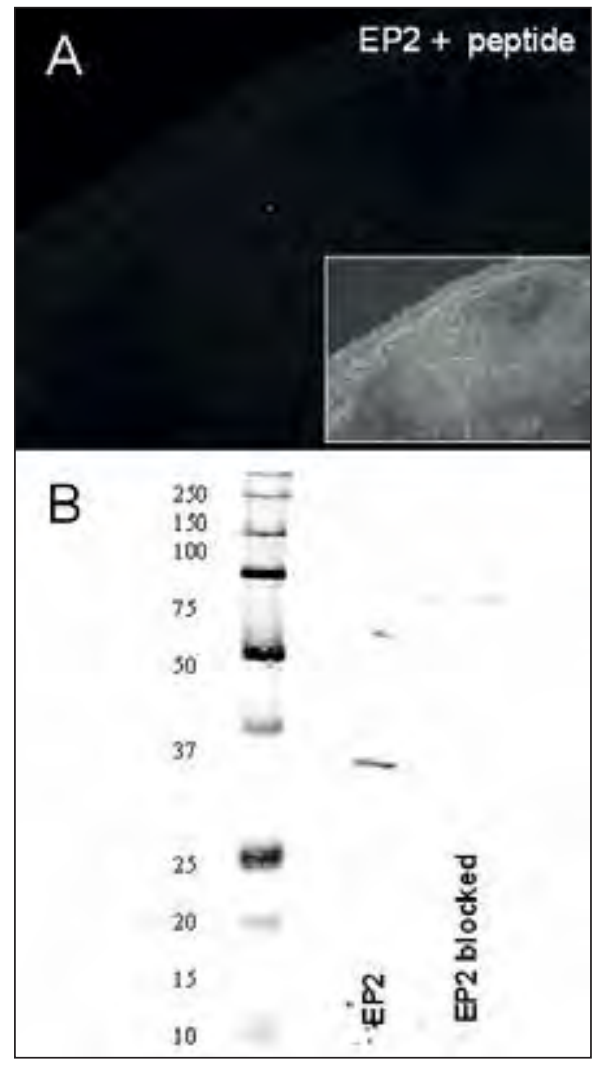

Figure 1. Characterization of the EP2 antibody. Panel A illustrates the staining observed with the same concentration of antibody as used in all the stainings of other figures, but with pre-incubation with the blocking peptide to which the antibody was raised. (The inset shows an enhanced image showing the section morphology.) Panel B shows a characterization of the antibodies using Western blotting. Three lanes are shown: the molecular weight calibration bands, the native protein stained with the EP2 antibody and the native protein but exposed to antibody plus appropriate blocking peptide. 


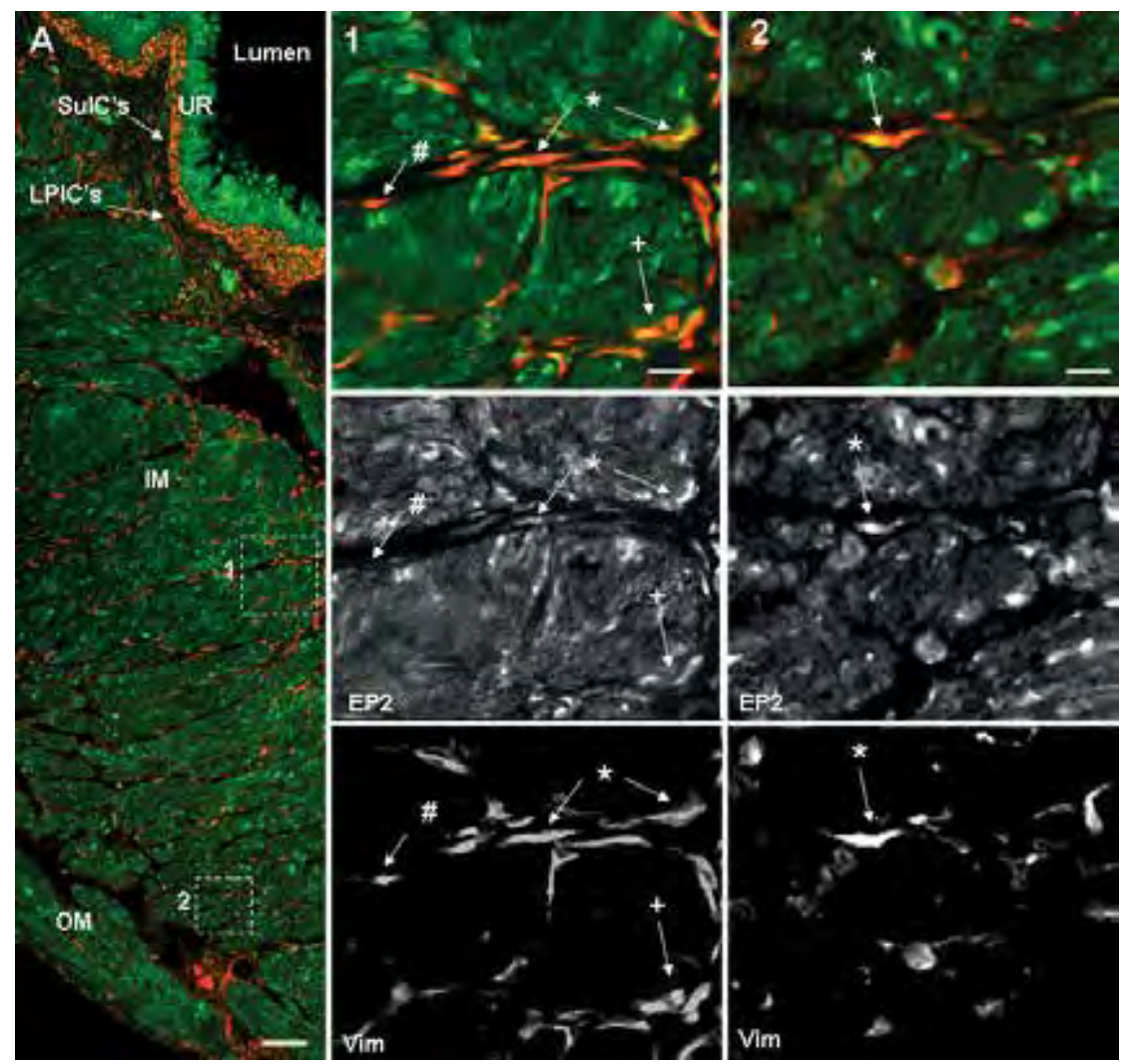

Figure 2. The distribution of EP2 and vimentin in the inner- and outer-muscle layers of the lateral wall of the guinea pig bladder. Panels show an image of the guinea pig bladder stained with the antibody for EP2 (green) and vimentin (red). In panel A, a low magnification image of a full thickness guinea pig bladder section is shown. The bladder lumen, the urothelium (UR), suburothelial interstitial cells (SuIC's), the lamina propria interstitial cells (LPICs), inner muscle (IM) and outer muscle layer $(\mathrm{OM})$ are marked. In the right panels, regions of interest of the inner (1) and the outer muscle layer (2) are shown in a larger magnification. Interstitial cells co-expressing vimentin and EP2 receptor are marked with asterisk (*) and those vimentin positive interstitial cells not expressing EP2 are marked with pound sign (\#). Calibration bars: $100 \mu \mathrm{m}$ in A and $20 \mu \mathrm{m}$ in the insets 1 and 2. 
In figure 3, vimentin positive (red) processes of intramuscular interstitial cells (IM-ICs) are clearly visible. These fibres also express EP2 (green). The EP2 staining on the muscle cells is less intense and has a punctuate appearance. The EP2 expression in the outer muscle layer is shown in figure 4. In the middle of the muscle bundles, IM-ICs can be seen in which the EP2 (green) and vimentin (red) co-localization is visible by the yellow colour. Thus, the vimentin positive interstitial cells seem to express the EP2 receptor. In this outer muscle region, the muscle is positive for EP2 with a less intense punctuate staining. On the upper edge of the panel, muscle coat interstitial cells are visible. Black and white panels on the right show clearly that only some of the muscle coat vimentin positive interstitial cells express EP2. Distinct groups of vimentin positive interstitial cells are seen between the muscle bundles.

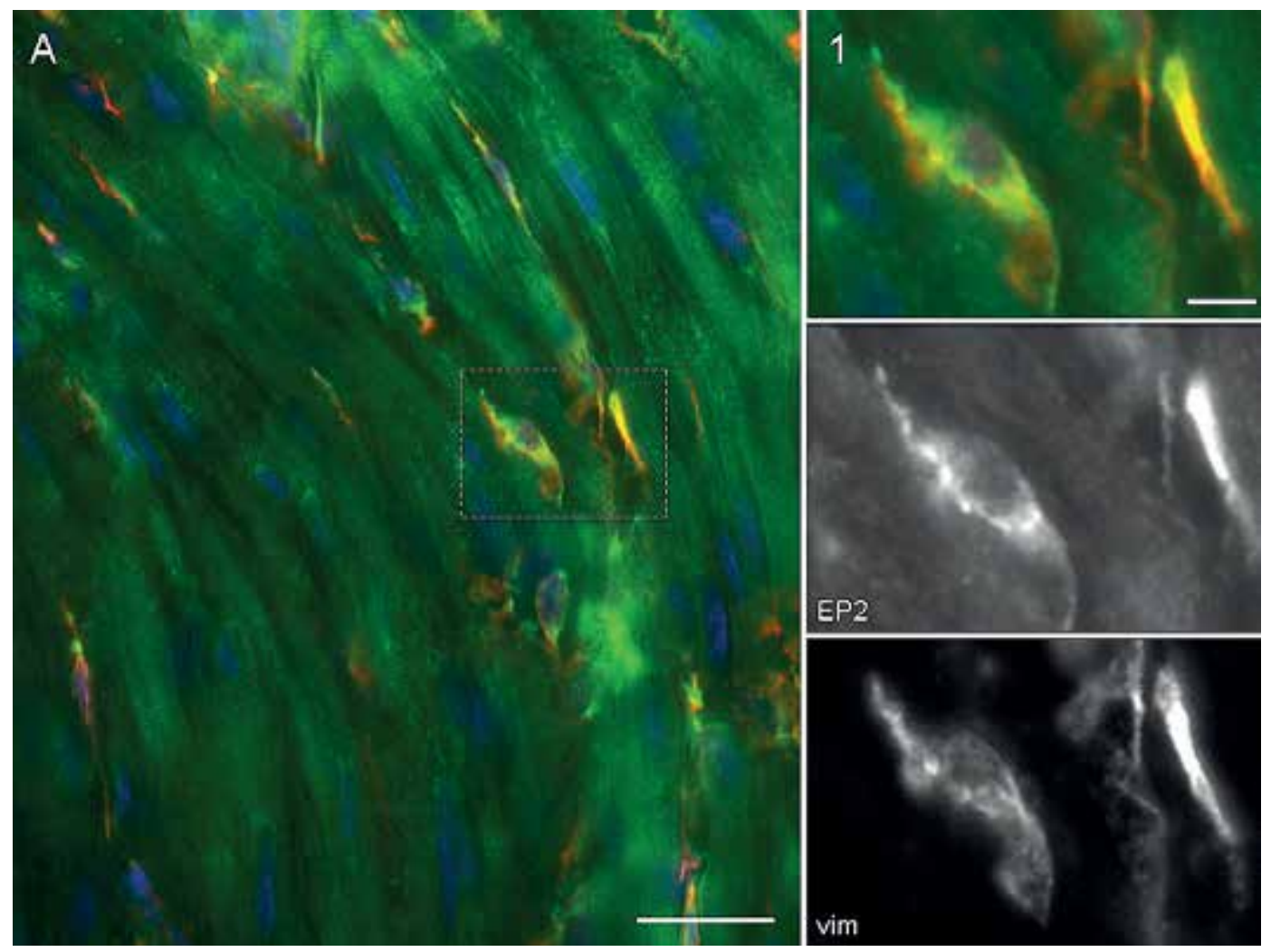

Figure 3. The distribution of EP2 and vimentin in the inner muscle layer of the lateral wall of the guinea pig bladder. An image taken from a confocal stack of the inner muscle layer of the guinea pig bladder stained with the antibody for EP2 (green) and, vimentin (red) is shown. The nuclei of the IM-ICs are visualized by a HOECHST nuclei staining (blue). A region of interest is enlarged in inset 1 . The black and white insets show the individual EP2 and vimentin staining.

Calibration bars: $40 \mu \mathrm{m}$ in $\mathrm{A}$ and $10 \mu \mathrm{m}$ in 1 . 


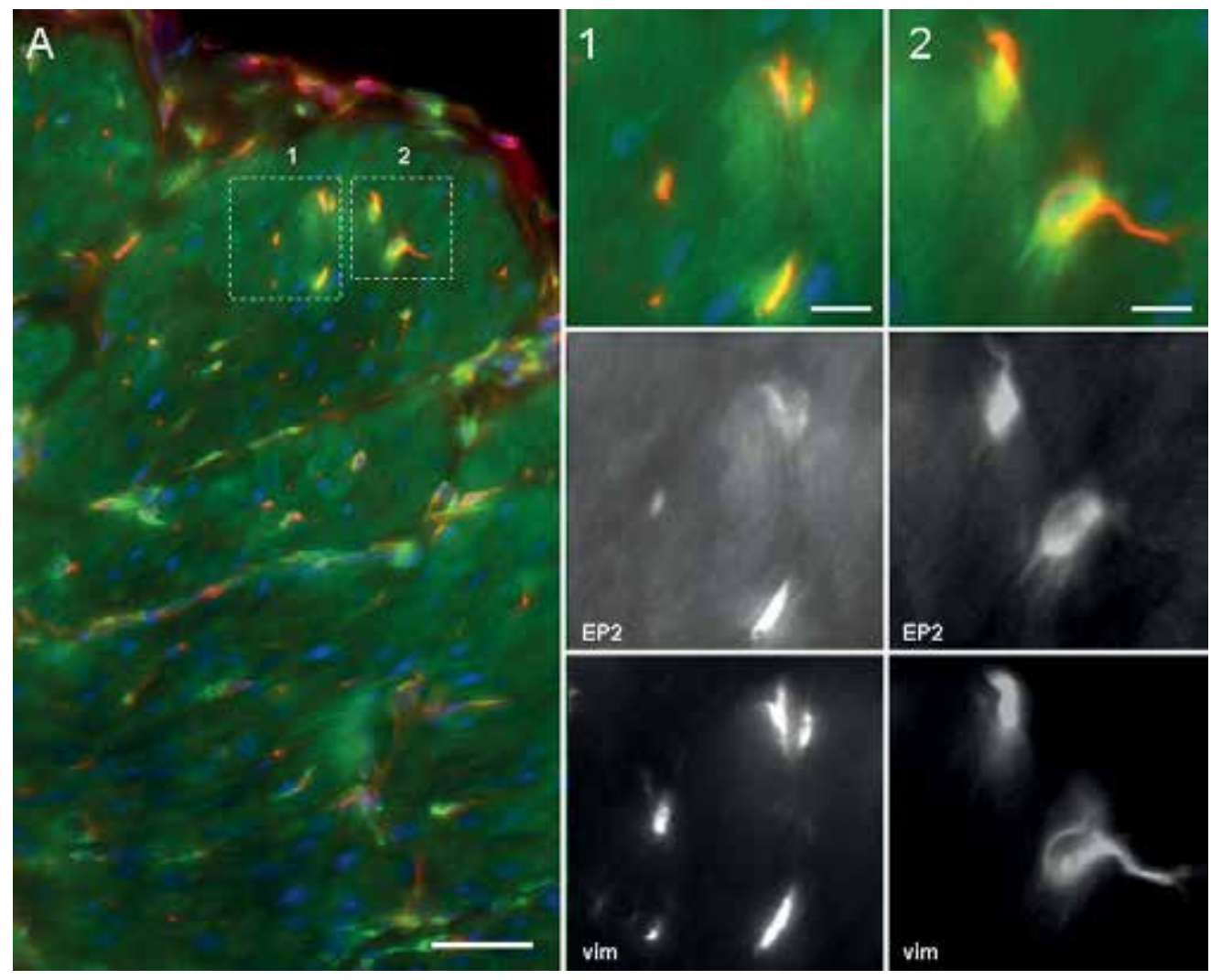

Figure 4. The distribution of EP2 and vimentin in the outer muscle layer of the lateral wall of the guinea pig bladder. An image taken from a confocal stack of the outer muscle layer of the guinea pig bladder stained with the antibody for EP2 (green) and vimentin (red) is shown. The nuclei of the IM-ICs are visualized by a HOECHST nuclei staining (blue). Two regions of interest from panel A are enlarged as panels 1 and 2 . The black and white insets show the individual EP2 and vimentin staining. Calibration bars: $100 \mu \mathrm{m}$ in $\mathrm{A}$ and $10 \mu \mathrm{m}$ in 1 and 2.

In figure 5, a number of ICs are shown in the vicinity of each other. The fibres of these cells are noted as red fibres (vimentin positive) running through and in between the muscle bundles. Many of these ICs co-express vimentin and EP2 causing the yellow co-staining. In figure 5, the expression of EP2 in an IM-IC in the lateral wall is shown. The processes of these cells are visible as vimentin positive fibres (red) running on the surface of the muscle bundles. Spots of EP2 expression (green) are also visible on these fibres. Moreover, the punctuate expression of EP2 on the muscle bundles can be seen in figure 6 . 


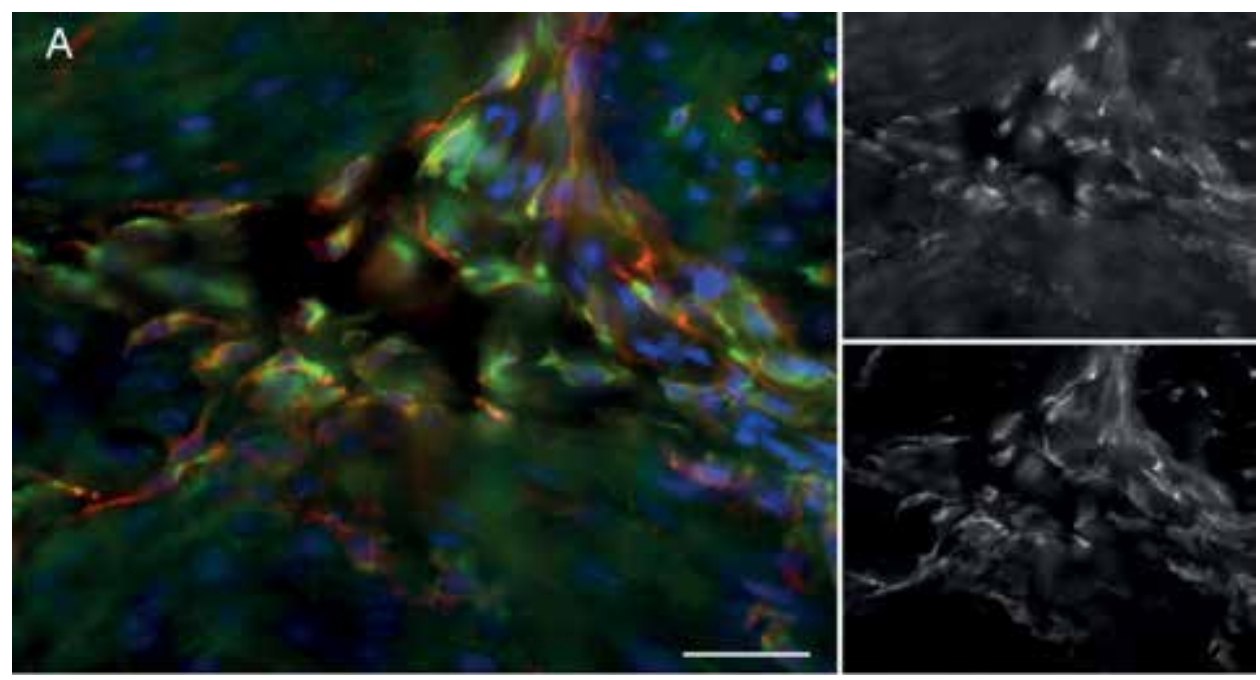

Figure 5. The expression of EP2 in a group of nearby intramuscular interstitial cells in the lateral wall of the guinea pig bladder. An image of the outer muscle layer of the guinea pig bladder stained with the antibody for EP2 (green) and vimentin (red) is shown. The nuclei of the cells are visualized by a HOECHST nuclei staining (blue). The black and white insets show the individual $\mathrm{EP}_{2}$ and vimentin staining. Calibration bar: $20 \mu \mathrm{m}$.

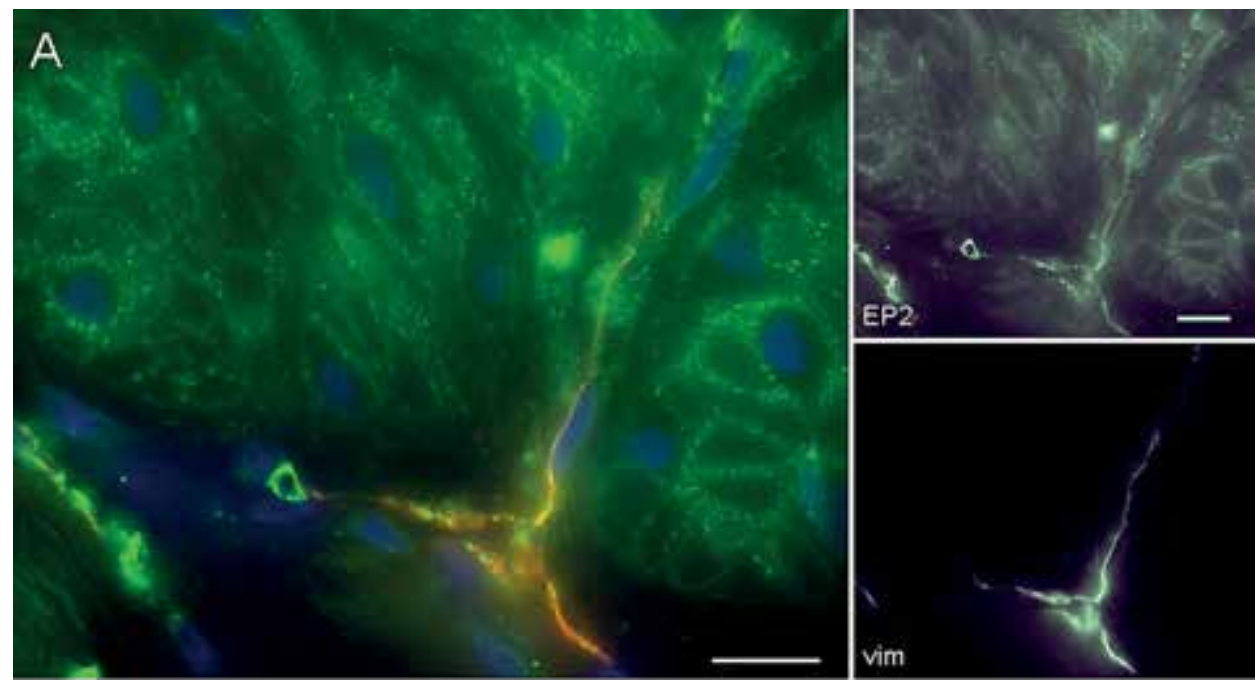

Figure 6. The expression of EP2 in an intramuscular interstitial cell in the lateral wall of the guinea pig bladder. An image taken from a confocal stack of the outer muscle layer of the guinea pig bladder stained with the antibody for EP2 (green) and vimentin (red) is shown. The nuclei of the cells are visualized by a HOECHST nuclei staining (blue). The black and white insets show the individual EP2 and vimentin staining. Calibration bars: $20 \mu \mathrm{m}$. 
The EP2 staining (green) is especially located on the membrane of muscle cells. The punctuate expression of EP2 on the muscle bundles (green) is further displayed in figure 7. It can be noted that some COX 1 positive interstitial cells (red) are in close proximity of EP2 positive interstitial cells and $E P_{2}$ receptors on the near by muscle bundles. Another remarkable observation was that some cells expressing EP2 co-express COX 1 . This phenomena was seen in about one third of all interstitial cells expressing COX $\mathrm{CO}_{1}$. A low power image of the guinea pig bladder stained for EP2 (green) and COX (red) is shown in fig.ure 8. It can be noted that beside the urothelium, many interstitial cells throughout the muscle layer express COX 1 . Both COX 1 positive IM-ICs as well as SM-ICs can be noted.

The findings on EP2 expression within the muscle layers of the guinea pig urinary bladder are summarized in a cartoon shown in figure 9, which was adapted from our previously published cartoon ${ }^{4}$. In this cartoon it is demonstrated that $C_{1} O X_{1}$ and the EP2 receptor are expressed on the intramuscular interstitial cells as well as on the muscle bundles. Furthermore, the suggested propagation of the PG signal from the urothelium to the muscle layers is visualized.

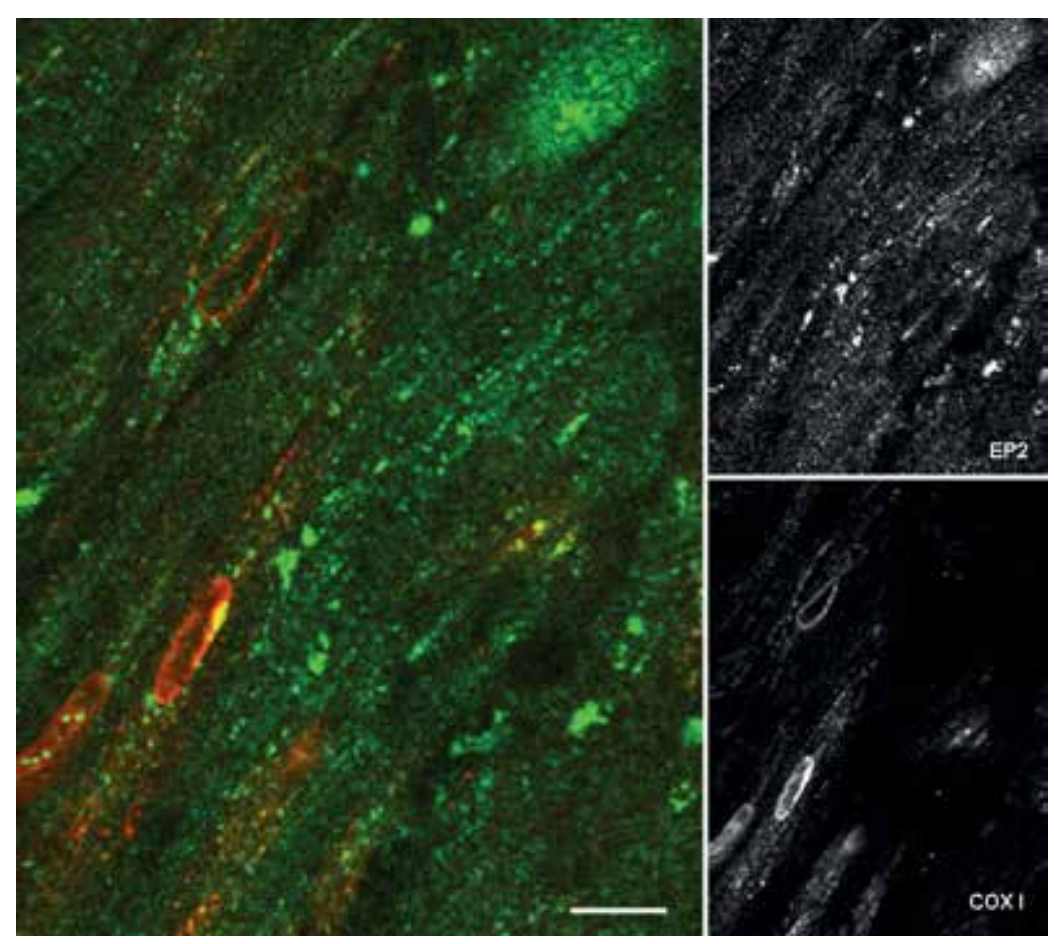

Figure 7. The expression of EP2 and COX1 on the muscle bundles of the lateral wall of the guinea pig bladder. An image of the outer muscle layer of the guinea pig bladder stained with the antibody for $\mathrm{EP}_{2}$ (green) and $\mathrm{COX}_{1}$ (red) is shown. The black and white insets show the individual $\mathrm{EP}_{2}$ and $\mathrm{COX}_{1}$ staining. Calibration bar: $20 \mu \mathrm{m}$. 


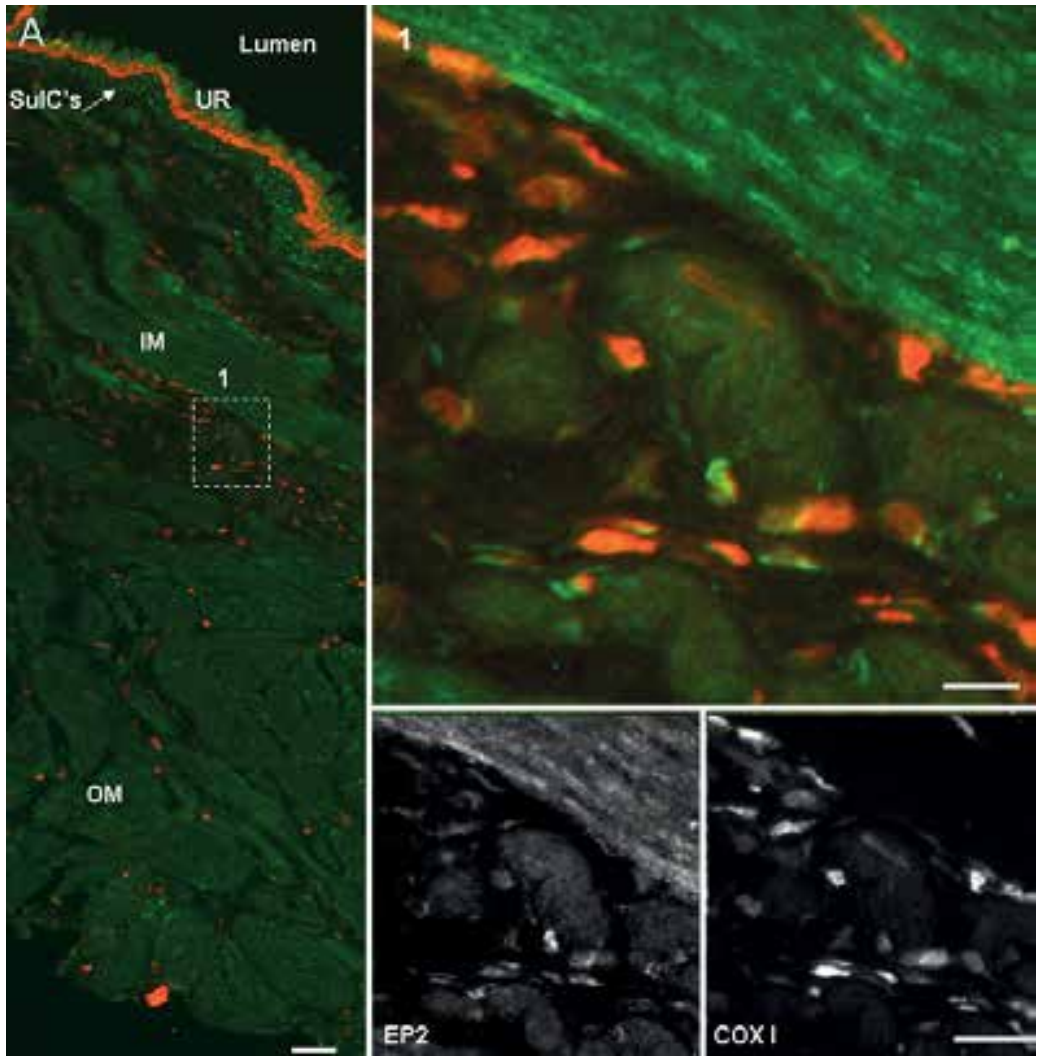

Figure 8. The expression of EP2 and $\mathrm{COX}_{1}$ on the muscle bundles of the lateral wall of the guinea pig bladder. A low power image of the guinea pig bladder stained with the antibody for $\mathrm{EP}_{2}$ (green) and $\mathrm{COX}_{1}$ (red) is shown in panel A. A region of interest is indicated in panel $\mathrm{A}$ and enlarged in the inset 1 . The black and white insets show the individual EP2 and $C O X_{1}$ staining. Calibration bars: $100 \mu \mathrm{m}$ in $\mathrm{A}$ and $20 \mu \mathrm{m}$ in 1 .

\section{Discussion}

Cyclo oxygenase inhibiting drugs, have been shown to alter normal voiding function in rats as well as bladder hyperactivityinduced by chemical irritation of the lower urinary tract $\mathrm{t}^{20}$. Furthermore, it is known that intra-arterial administration of $\mathrm{PGE}_{2}$ to the urinary bladder enhances the micturition refle ${ }^{21}$. Therefore, it has been suggested that PG might act at various sites to regulate or modulate voiding itself and non-voiding activity as well as voiding sensation. Very recently, it was demonstrated that both ATP and $\mathrm{PGE}_{2}$ can induce acetylcholine release from the bladder urothelium'. Therefore, the stretch-induced acetylcholine release, previously described in the bladder ${ }^{22}$, is suggested to be a part of the result of a more complex series of signalling interactions 
within the urothelium. This complexity is increased because acetylcholine can also modulate PGE ${ }_{2}$ release. This mechanism is suggested to provide a rapid amplification of urothelial signal output'. In the present study we have focused on EP2 expression in the muscle layers of the guinea pig bladder. EP2 receptor presence on umbrella cells and the suburothelial interstitial cells (SU-ICs) has previously been demonstrated ${ }^{4}$. The present study shows that EP2 receptors are further expressed on intramuscular interstitial cells (IM-ICs) and surface muscle interstitial cells (SM-ICs) of the innerand the outer-muscle layer. Moreover, our stainings show a punctuate low intensity expression of EP2 in guinea pig detrusor muscle bundles. This punctuate appearance deserves more future attention as to whether this might be due to certain areas serving a specific function for example in cell to cell contacts. In the muscle, each of the EP receptors is known to act through different intracellular pathways that involve calcium transport and the stimulation or inhibition of adenylate cyclase to elicit muscle contraction or relaxation depending on the EP subtypes (figure 7$)^{23}$. In general, $E P_{1}$ and $E_{3}$ are thought to cause contraction of the smooth muscle, whereas $\mathrm{EP}_{2}$ and $\mathrm{EP}_{4}$ are thought to cause relaxation ${ }^{24,25}$. Each receptor uses a different G-protein coupled transduction system $^{24,25}$. This difference in response of the muscle to each of the EP receptors has been shown for uterine smooth muscle where indeed, activation of $\mathrm{EP}_{1}$ and $\mathrm{EP}_{3}$ causes muscle contraction and stimulation of EP2 and EP4 leads to relaxation ${ }^{26}$. Earlier observations showed networks of ICs with short and long processes, running from the urothelium and suburothelium through the muscle layers and form connections with other ICs nodes (figure 8). There is a clear COX 1 expression in the basal urothelial layer as also reported by earlier papers ${ }^{3,4}$, suggesting the possibility that a PG signal presumably mediated and enhanced by ATP release from the urothelium can be picked up by EP1 receptors and be spread further via the IC network ${ }^{3,4}$. Furthermore, these data showed that some $C_{1} X_{1}$ positive interstitial cells are in very close proximity of $\mathrm{EP}_{1}$ positive interstitial cells and EP1 receptors on the nearby muscle bundles. It was described that, PG can be produced in close vicinity, or even within the same cell containing the EP1 receptor, which suggested the possibility for a PG signal to be further spread and maybe even augmented ${ }^{3,4}$. Our present data show similar global configurations for the EP2 as was previously shown for the EP1 receptor ${ }^{4}$. For $\mathrm{EP}_{2}, \mathrm{COX}_{1}$ and $\mathrm{EP}_{2}$ immuno-reactivity was in close proximity or even co-expressed in the same cell. Further research is necessary in order to determine the physiological role of this $\mathrm{EP}_{2}$ receptor configuration. However, a spread and augmentation of a signal mediated by $P G$ via EP2 is unlikely as in most smooth muscle preparations, other than the urinary bladder, $E P 2$ has been shown to cause muscle relaxation. ${ }^{24}$ In several tissues, EP2 receptors have been shown to couple to a G-protein (G_s), resulting in increased formation of cAMP. In the smooth muscle of different organs, this rise in CAMP through EP2 leads then to muscle relaxation ${ }^{27}$. It is unknown whether this is the predominant effect of EP2 in the detrusor muscle. In several recent reports $\mathrm{EP}_{2}$ action has been shown to be coupled to immune responses or secretion of specific agents, which might also suggest an activation instead of an inhibition ${ }^{8,29}$. The cyclic nucleotide mono-phosphates, CAMP and CGMP, are now generally accepted to be important intracellular 
regulators of several physiological processes, including smooth muscle function ${ }^{30}$. Rat bladder studies have suggested that beta-adrenoceptor-mediated relaxation is mainly attributed to cAMPdependent mechanism ${ }^{31,32}$. Moreover, the phosphodiesterase (PDE) type 1 inhibitor vinpocetine has been shown to have a relaxant effect on human detrusor. This relaxing effect was paralleled by an increase in tissue levels of CAMP and CGMP $^{33}$. There is also some clinical support for the involvement of CAMP in human detrusor control. A randomized double-blind placebo-controlled study, showed that treatment with PDE1 inhibitors which lead to a rise in CAMP levels in patients with urgency and urge incontinence was superior to placebo with regard to the clinical outcome parameters micturition frequency, bladder volume at first sensation, bladder volume at voiding desire, maximum detrusor pressure, and voided volume ${ }^{34}$. Moreover, an influence on the above mentioned parameters also suggests a coupling to the bladder sensory system. It can be concluded from these findings that the CAMP-pathway might be of functional significance in the control of detrusor smooth muscle and indeed have a relaxant effect. The question to be answered now is the possible physiological meaning of the shown EP2 arrangement in relation to the previously shown $E P_{1}$ distribution in the bladder muscle layers. It is known that $P G E_{2}$, may have multiple and at times apparently opposing functional effects on a given target tissue such asvascular smooth muscle ${ }^{35,36}$. Although no functional experiment was included in this study, some possible hypothesis could be put forward. These hypotheses are not based on data and need to be confirmed in future functional studies. One possible explanation could be based on differences in affinity of EP2 and EP1 for PG. In fact, it has been shown that the rat EP2 receptor signal transduction pathway is approximately 20-fold more sensitive for $P G E_{2}$ than for $E_{1}$, as the concentration of $P_{G} E_{2}$ required to produce a half-maximal response was $37 \mathrm{nM}$ for $\mathrm{EP}_{2}$ against $2.1 \mathrm{nM}$ for $\mathrm{EP}_{13}{ }^{37}$. Furthermore, in order to determine the affinity of $\mathrm{PGE}_{2}$ for $\mathrm{EP}_{1}$ and $\mathrm{EP}_{2}$, saturation analysis has been done showing $K D$ values of $P \mathrm{PE}_{2}$ for $\mathrm{EP}_{1}$ and $\mathrm{EP}_{2}$ be around 24 and $5 \mathrm{nM}$, respectively37. Therefore, it can be hypothesized that under normal conditions, $\mathrm{PGE}_{2}$ levels in the detrusor might be such, that the inhibiting EP2 effect predominates the activating EP1 effect, which might result in a stabilization of the muscle layer. Under certain circumstances, the $\mathrm{PGE}_{2}$ levels may increase above a certain threshold level in which case the contractile EP1 effect becomes more predominant. Small sub-threshold increases of $P G E_{2}$ might, in such a case, be due to subtitle bladder wall irritation, inflammation or stretch. The exact role of the EP2 receptor in the bladder wall remains to be determined by future analysis of the activation, signal propagation and bladder sensory pathways by functional studies. The PGE ${ }_{2}$ signal is suggested to be spread out through suburothelial and intramuscular interstitial cells expressing $E P_{1}$. The narrow balance between the contractile $E P_{1}$ and the possible relaxant $E P_{2}$ effect might be a system that modulates the autonomous, non-voiding contractions and relaxation which can become disrupted when $\mathrm{PGE}_{2}$ levels reach certain higher levels. This idea is supported by earlier studies showing that frequency and amplitude of the non-voiding activity is reduced by stimulation of an adrenergic/cAMP-linked mechanism ${ }^{38}$. 


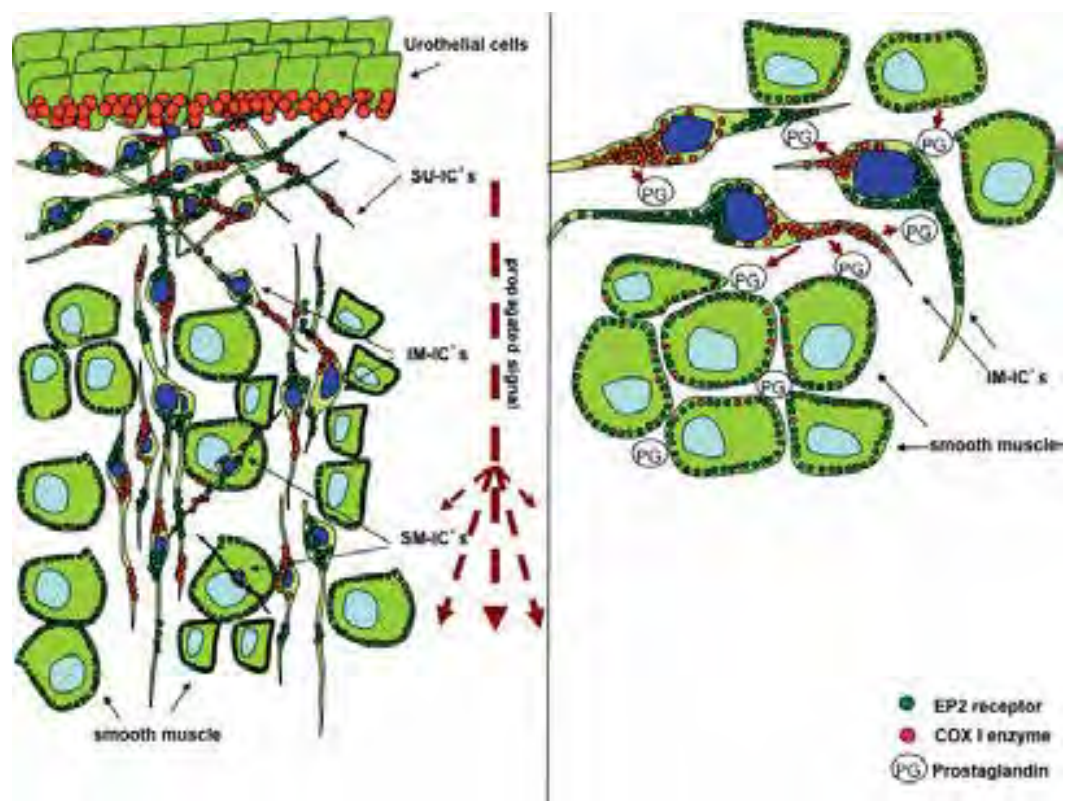

Figure 9. Cartoon of the expression of EP2 and COX1 in the muscle bundles. A schematic overview of the lateral wall of the guinea pig bladder and the proposed PG signal transduction.

\section{Conclusion}

This morphological study indicates that the EP2 receptor is expressed on muscle interstitial cells and on muscle bundles. The proximity of the $\mathrm{COX}_{1}$ positive interstitial cells to EP2 positive cells suggests that PG targeting these EP2 receptors can be produced locally. It is hypothesized that the $\mathrm{PGE}_{2}$ concentration in the tissue might be responsible for the threshold level setting of interstitial cell excitability. However, functional experiments are needed in order to confirm this hypothesis and the physiological significance of the $E P_{1}$ and $E P_{2}$ receptors in the bladder. 


\section{References}

1. Nile, C.J. \& Gillespie, J.I. Interactions between cholinergic and prostaglandin signaling elements in the urothelium: role for muscarinic type 2 receptors. Urology 79, 240 e217-223 (2012).

2. Kobayter, S., Young, J. \& Brain, K. Prostaglandin E(2) induces spontaneous rhythmic activity in mouse urinary bladder independently of efferent nerves. British Journal of Pharmacology 165, 401-413 (2012).

3. Rahnama'i, M. S., de Wachter, S.G., van Koeveringe G.A., Van Kerrebroeck, Ph.E.V., de Vente, J. \& Gillespie, J.I. The relationship between prostaglandin E receptor 1 and cyclooxygenase I expression in guinea pig bladder interstitial cells: proposition of a signal propagation system. The Journal of Urology 185, 315-322 (2011).

4. Rahnama'i, M. S., van Koeveringe, G.A., Essers, P.B., de Wachter, S.G., de Vente, J., Van Kerrebroeck, Ph.E.V., \& Gillespie, J.I. Prostaglandin receptor EP1 and EP2 site in guinea pig bladder urothelium and lamina propria. The Journal of Urology 183, 1241-1247 (2010).

5. Maggi, C.A., Evangelista, S., Grimaldi, G., Santicioli, P., Giolitti, A. \& Meli, A. Evidence for the involvement of arachidonic acid metabolites in spontaneous and drug-induced contractions of rat urinary bladder. Journal of Pharmacological and Experimental Therapy 230, 500-513 (1984).

6. de Jongh, R., Grol, S., van Koeveringe, G.A., Van Kerrebroeck, Ph.E.V., de Vente, J., \& Gillespie, J.I. The localisation of cyclo oxygenase immuno-reactivity (COX $\mathrm{COX}_{1-\mathrm{IR})}$ to the urothelium and to interstitial cells in the bladder wall. Journal of Cellular and Molecular Medicine 13(9B),3069-3081 (2009).

7. Mikhailidis, D.P., Jeremy, J.Y. \& Dandona, P. Urinary bladder prostanoids--their synthesis, function and possible role in the pathogenesis and treatment of disease. The Journal of Urology 137, 577-582 (1987).

8. Narumiya, S., Sugimoto, Y. \& Ushikubi, F. Prostanoid receptors: structures, properties, and functions. Physiological Reviews 79, 1193-1226 (1999).

9. McCafferty, G.P., Misajet, B.A., Laping, N.J., Edwards, R.M. \& Thorneloe, K.S. Enhanced bladder capacity and reduced prostaglandin $\mathrm{E}_{2}$-mediated bladder hyperactivity in $\mathrm{EP}_{3}$ receptor knockout mice. American Journal of Physiology. Renal Physiology 295, F507-514 (2008).

10. Andersson, K.E. \& Forman, A. Effects of prostaglandins on the smooth muscle of the urinary tract. Acta Pharmacologica et Toxicologica 43 Suppl 2, 90-95 (1978).

11. Birder, L.A. Urinary bladder urothelium: molecular sensors of chemical/thermal/mechanical stimuli. Vascular Pharmacology 45, 221-226 (2006).

12. McCloskey, K.D. Interstitial cells in the urinary bladder--localization and function. Neurourology and Urodynamics 29, 82-87 (2010).

13. de Jongh, R., van Koeveringe, G.A., Van Kerrebroeck, Ph.E.V., Markerink-van Ittersum, M., de Vente, J. \& Gillespie, J.I. Alterations to network of NO/cGMP-responsive interstitial cells induced by outlet obstruction in guinea-pig bladder. Cell and Tissue Research 330, 147-160 (2007)

14. Gillespie, J.I., Markerink-van Ittersum, M. \& De Vente, J. Endogenous nitric oxide/cGMP signalling in the guinea pig bladder: evidence for distinct populations of suburothelial interstitial cells. Cell and Tissue Research 325, 325-332 (2006).

15. Gillespie, J.I., Markerink-van Ittersum, M. \& De Vente, J. Interstitial cells and cholinergic signalling in the outer muscle layers of the guinea-pig bladder. British Journal of Urology International 97, 379-385 (2006). 
16. de Jongh, R., van Koeveringe, G.A., Van Kerrebroeck, Ph.E.V., Markerink-van Ittersum, M., de Vente, J. \& Gillespie, J.I. The effects of exogenous prostaglandins and the identification of constitutive cyclooxygenase I and II immunoreactivity in the normal guinea pig bladder. British Journal of Urology International 100, 419429 (2007).

17. Gillespie, J.I., Harvey, I.J. \& Drake, M.J. Agonist- and nerve-induced phasic activity in the isolated whole bladder of the guinea pig: evidence for two types of bladder activity. Experimental physiology 88, 343-357 (2003).

18. Grol, S., Essers, P.B., van Koeveringe, G.A., de Vente, J. \& Gillespie, J.I. Ubiquitin hydrolase (protein gene product 9.5) in the obstructed bladder: evidence for tissue remodelling involving a subset of interstitial cells. British Journal of Urology International 104, 698-706 (2009).

19. Palea, S., Toson, G., Pietra, C., Trist, D.G., Artibani, W., Romano, O. \& Corsi M. Pharmacological characterization of thromboxane and prostanoid receptors in human isolated urinary bladder. British Journal of Pharmacology 124, 865-872 (1998).

20. de Groat, W.C. \& Yoshimura, N. Pharmacology of the lower urinary tract. Annual Review of Pharmacology and Toxicology 41, 691-721 (2001).

21. Ishizuka, O., Mattiasson, A. \& Andersson, K.E. Prostaglandin E2-induced bladder hyperactivity in normal, conscious rats: involvement of tachykinins? The Journal of Urology 153, 2034-2038 (1995).

22. Yoshida, M., Masunaga, K., Satoji, Y., Maeda, Y., Nagata, T. \& Inadome, A. Non-neuronal cholinergic system in human bladder urothelium. Urology 67, 425-430 (2006).

23. Ponglowhapan, S., Church, D.B. \& Khalid, M. Expression of prostaglandin E receptor subtypes in the canine lower urinary tract varies according to the gonadal status and gender. Theriogenology 74, 14501466 (2010).

24. Coleman, R.A., Smith, W.L. \& Narumiya, S. International Union of Pharmacology classification of prostanoid receptors: properties, distribution, and structure of the receptors and their subtypes. Pharmacological Reviews 46, 205-229 (1994).

25. Ikeda, M., Kawatani, M., Maruyama, T. \& Ishihama, H. Prostaglandin facilitates afferent nerve activity via EP1 receptors during urinary bladder inflammation in rats. Biomedical Research 27, 49-54 (2006).

26. Astle, S., Thornton, S. \& Slater, D.M. Identification and localization of prostaglandin $\mathrm{E}_{2}$ receptors in upper and lower segment human myometrium during pregnancy. Molecular Human Reproduction 11, 279-287 (2005).

27. Breyer, R.M., Bagdassarian, C.K., Myers, S.A. \& Breyer, M.D. Prostanoid receptors: subtypes and signaling. Annual Review of Pharmacology and Toxicology 41, 661-690 (2001).

28. Fedyk, E.R. \& Phipps, R.P. Prostaglandin $\mathrm{E}_{2}$ receptors of the EP2 and EP4 subtypes regulate activation and differentiation of mouse B lymphocytes to IgE-secreting cells. Procedings of National Acadamic Science USA 93, 10978-10983 (1996).

29. Harizi, H., Limem, I. \& Gualde, N. CD40 engagement on dendritic cells induces cyclooxygenase-2 and EP2 receptor via p38 and ERK MAPKs. Immunology and Cellular Biology 89, 275-282 (2011).

30. Antoni, F.A. Molecular diversity of cyclic AMP signalling. Frontiers in Neuroendocrinology 21, 103-132 (2000). 
31. Uchida, H., Shishido, K., Nomiya, M. \& Yamaguchi, O. Involvement of cyclic AMP-dependent and -independent mechanisms in the relaxation of rat detrusor muscle via beta-adrenoceptors. European Journal of Pharmacology 518, 195-202 (2005).

32. Yamaguchi, O.\& Chapple, C.R. Betaz-adrenoceptors in urinary bladder. Neurourology and Urodynamics 26, $752-756$ (2007).

33. Truss, M.C., Uckert, S., Stief, C.G., Kuczyk, M. \& Jonas, U. Cyclic nucleotide phosphodiesterase (PDE) isoenzymes in the human detrusor smooth muscle. I. Identification and characterization. Urological Research 24, 123-128 (1996).

34. Truss, M.C., Stief, C.G., Uckerts, S., Becker, A.J., Wefer, J., Schultheiss, D. \& Jonas, U. Phosphodiesterase 1 inhibition in the treatment of lower urinary tract dysfunction: from bench to bedside. World Journal of Urology 19, 344-350 (2001).

35. Bonvalet, J.P., Pradelles, P. \& Farman, N. Segmental synthesis and actions of prostaglandins along the nephron. American Journal of Physiology 253, F377-387 (1987).

36. Smith, W.L. Prostanoid biosynthesis and mechanisms of action. American Journal of Physiology 263, F181191 (1992).

37. Boie, Y., Stocco, R., Sawyer, N., Slipetz, D.M., Ungrin, M.D., Neuschäfer-Rube, F., Püschel, G.P., Metters, K.M. \& Abramovitz, M. Molecular cloning and characterization of the four rat prostaglandin E2 prostanoid receptor subtypes. European Journal of Pharmacology 340, 227-241 (1997).

38. Gillespie, J.I. Noradernaline inhibits autonoumous activity in the isolated guinea pig bladder British Journal of Urology International feb, 401-409 (2004). 




\section{Chapter 6 \\ The Effect of Indomethacin on the Muscarinic Induced Contractions in the Isolated Normal Guinea Pig Urinary Bladder}

BioMed Central Urology. 2013 Feb 7;13:8

doi: 10.1186/1471-2490-13-8.

PMID: 23388044

M.S. Rahnama' $i^{1,2}$, G.A. van Koeveringe ${ }^{1,2}$, Ph.E.V. Van Kerrebroeck ${ }^{1,2}$, and S.G.G. de Wachter

' Department of Urology, Maastricht University Medical Centre (MUMC+)

Maastricht, The Netherlands

${ }^{2}$ Department of Psychiatry and Neuropsychology, European Graduate School of Neuroscience (EURON)

Maastricht University, Maastricht, The Netherlands 


\section{Abstract}

\section{Purpose}

To investigate the effect of prostaglandin depletion by means of COX-inhibition on cholinergic enhanced spontaneous contractions.

\section{Methods}

The urethra and bladder of 9 male guinea pigs (weight 270-300 g) were removed and placed in an organ bath with Krebs' solution. A catheter was passed through the urethra through which the intravesical pressure was measured. The muscarinic agonist arecaidine, the non-selective COX inhibitor indomethacin, and $\mathrm{PGE}_{2}$ were subsequently added to the organ bath. The initial average frequency and amplitude of spontaneous contractions in the first 2 minutes after arecaidine application were labelled $\mathrm{F}_{\text {ini }}$ and $\mathrm{P}_{\text {ini }}$, respectively. The steady state frequency $\left(\mathrm{F}_{\text {steady }}\right)$ and amplitude $\left(P_{\text {steady }}\right)$ were defined as the average frequency and amplitude during the 5 minutes before the next wash out.

\section{Results}

Application of $1 \mu \mathrm{M}$ PGE $E_{2}$ increased the amplitude of spontaneous contractions without affecting frequency. $10 \mu \mathrm{M}$ of indomethacin reduced amplitude but not frequency. The addition of indomethacin did not alter $F_{i n i}$ after the first application $(p=0.7665)$. However, after the second wash, $F_{\text {ini }}$ was decreased $(p=0.0005) . F_{\text {steady }}, P_{\text {steady }}$ and $P_{\text {ini }}$ were not significantly different in any of the conditions. These effects of indomethacin were reversible by $\mathrm{PGE}_{2}$ addition.

\section{Conclusions}

Blocking PG synthesis decreased the cholinergically stimulated autonomous contractions in the isolated bladder. This suggests that PG could modify normal cholinergically evoked response. A combination of drugs inhibiting muscarinic receptors and PG function or production can then become an interesting focus of research on a treatment for overactive bladder syndrome. 


\section{Introduction}

The overactive bladder syndrome $(O A B)$ is defined as urinary urgency with or without urgency incontinence, urinary frequency and nocturia. These symptoms still present a therapeutic challenge. Currently, antimuscarinic drugs are first-line treatment for OAB. How their beneficial action is achieved is still a matter of discussion. Depending on the studied compound, antimuscarinic drugs often have only moderate response rates when compared to placebo'. However, adverse effects and decreasing efficacy cause long-term compliance problems ${ }^{2}$. Therefore, it is desirable that alternative treatment methods are developed and made available. The lower urinary tract has two basic functions: to store urine for most of the time at low pressure and expel it at a socially convenient time and place. Therefore, it is equipped with an extensive relay network to transmit information on bladder fullness to the brain ${ }^{3}$. One of the proposed mechano-transduction mechanisms is stretch dependent urothelial release of mediators such as acetylcholine, Nitric oxide, ATP and prostaglandin $(P G)^{4}$. $P G E_{2}$ appears o be the main PG involved in the regulation of the bladder ${ }^{5}$ and exert its effect through the endoprostanoid receptors, of which four subtypes (EP1, EP2, EP3, and EP4) have been described ${ }^{6,7}$. In the bladder, $P G$ release depends on de novo synthesis rather than release from pre-formed stores ${ }^{8}$. Cyclooxygenase type 1 and 2 ( $\mathrm{COX}_{1}$ and $\mathrm{COX}_{2}$ ) are the central enzymes in the production of $\mathrm{PG}^{9}$. $\mathrm{COX}_{1}$ is a constitutive form, whereas $\mathrm{COX}_{2}$ an inducible form in the bladder. Its expression is regulated by various stimuli, including pro-inflammatory cytokines and growth factors ${ }^{9}$. An increased expression of $\mathrm{COX}_{2}$ has been described immediately after experimentally induced bladder outlet obstruction ${ }^{10}$. There is an increasing amount of data available pointing to a role of PG in the regulation of non-voiding contractions and afferent activity ${ }^{10.13}$. The isolated whole bladder shows autonomous small contractions, which resemble non-voiding contractions that increase in amplitude and/or frequency by muscarinic agonists ${ }^{14,15}$ and $\mathrm{PG}^{10}$. Similarly, intravesical PG administration in vivo increases nonvoiding contractions during bladder filling and decreases the inter-micturition interval ${ }^{16}$, whereas $E P 1$ and $\mathrm{EP}_{3}$ knockout mice show an increased micturition threshold. Moreover, in these animals, the PGE induced hyperactivity is decreased $^{16}$. How PG exerts its effect is not well understood. However, involvement of capsaicin sensitive afferents and autonomous ganglia has been suggested. ${ }^{12}$ An interaction or crosslink between the cholinergic and prostanoid pathway has been suggested before ${ }^{17}$ and may be another mechanism of action. This idea is supported by the fact that muscarinic agonists can induce production of $\mathrm{PGE}_{2}{ }_{2}^{18}$. The current study aims to further investigate the crosslink between the cholinergic and prostanoid pathway in order to explore a possible new treatment modality through COX inhibition for OAB. Therefore, the non-specific COX inhibitor indomethacin was used to investigate the effect of prostaglandin depletion on cholinergic enhanced spontaneous contractions. 


\section{Material and Methods}

\section{Animals}

A total of 9 male guinea pigs (weight 270-300 g) were killed by cervical dislocation, followed by exsanguination. Male guinea pigs were used because of the favourable urethral length, which made catheterization of the isolated bladder easier. All procedures were carried out with the approval of guidelines of the animal ethics committee of the University of Maastricht and were in line with European Community guidelines.

\section{Pressure recordings}

The urinary bladder and proximal urethra were excised immediately after cervical dislocation of the animal and placed in Krebs' solution (mM: NaCl 121.1; $\mathrm{KCl} 1.87 ; \mathrm{CaCl}_{2} 1.2 ; \mathrm{MgSO}_{4} 1.15 ; \mathrm{NaHCO}_{3}$ $25 ; \mathrm{KH}_{2} \mathrm{PO}_{4}$ 1.17; glucose 11.0), bubbled with $5 \% \mathrm{CO}_{2}$ and $95 \% \mathrm{O}_{2}\left(\mathrm{pH} 7.4,34^{\circ} \mathrm{C}\right)$. The urethra was cannulated with a flexible plastic cannula ( $2 \mathrm{~mm}$ diameter) secured using a fine ligature. The bladder was then transferred to a heated organ bath $\left(40 \mathrm{~mL}, 33-36^{\circ} \mathrm{C}\right)$ containing constantly gassed Krebs' solution, and the cannula was connected through a fluid filled tube containing three-way connector to a pressure transducer (DTX Plus, Becton Dickinson, Franklin Lakes, NJ, USA). The bladder was allowed to empty. Subsequently, the bladder was filled to $2 \mathrm{ml}$ in approximately 30 seconds. The transducer output was amplified, digitized at $20 \mathrm{~Hz}$ and recorded using a data capture system (MP100 with AcqKnowledge 3.7.3 software, BIOPAC systems inc, California). The pressure range of this apparatus was $0.02-180 \mathrm{cmH}_{2} \mathrm{O}$. The transducer was calibrated before each experiment. Recordings started 30 minutes after the animal was sacrificed. The timeline of the experiments is given in figure 1 . The pressure recordings started with cholinergic stimulation with $1 \mu \mathrm{M}$ of the cholinergic agonist, arecaidine $(t=0)$. This was followed by empting the organ bath and washing the bladder twice with fresh Krebs' solution, 15 minutes after arecaidine stimulation $(t=15)$. In order to investigate the effect of inhibition of PG production on the arecaidine response, the nonselective COX inhibitor, indomethacin was applied to the bladder For this purpose, after another 15 minutes, $10 \mu \mathrm{M}$ of the nonspecific COX inhibitor indomethacin was added to the Krebs' solution in the organ bath $(t=30)$, followed by a second stimulation with $1 \mu \mathrm{M}$ arecaidine, given 15 minutes later $(t=45)$. After another 15 minutes, a wash step was conducted $(t=60)$. This was then followed by an arecaidine stimulation $(t=75)$, followed by a wash step, 15 minutes later $(t=90)$. At this point, in 4 experiments, $1 \mu \mathrm{M} \mathrm{PGE}_{2}$ was added to the organ bath after 10 minutes in order to check the reversibility of the indomethacin effect by $\mathrm{PGE}_{2} .(t=105)$. Again this was followed by arecaidine stimulation 30 minutes later $(t=135)$. At the end another wash step was conducted $(t=150)$.

\section{Drugs}

Concentrated drug solutions were added directly to the bath to achieve the required final dilution. All drugs were added to the solution bathing the serosal surface. The non selective COX inhibitor, 


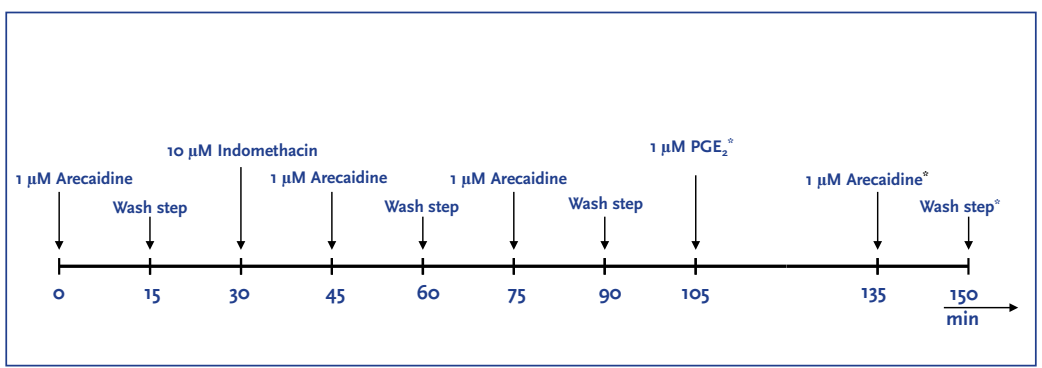

Figure 1. The timeline of the experiments. Pressure recordings started with stimulation of the guinea pig bladder by adding the cholinergic agonist arecaidine to the organ bath with Krebs' solution in which the isolated guinea pig bladder was kept. After 15 minutes the Krebs' solution is renewed (wash step). The COX inhibitor indomethacin was added 15 minutes after the first wash step. This was then followed by two sets of arecaidine stimulation and wash steps each separated by 15 minutes. In four experiments $P G E_{2}$ was added to the organ 15 minutes after the third wash step which was then followed by a set of arecaidine stimulation and wash step, 30 minutes later.

indomethacin (Sigma, St Louis, Missouri) was used in a concentration of $10 \mu \mathrm{M}$. As muscarinic agonist, a $1 \mu \mathrm{M}$ concentration of arecaidine but-2-ynyl ester tosylate (Tocris, Avonmouth, UK) was used 14 . PGE ${ }_{2}$ (Sigma, St Louis, Missouri) was used in a concentration of $1 \mu M 19$.

\section{Definitions}

In figure 2 the different defined phases of the bladder contraction amplitude and frequency are marked. The baseline activity $($ base $)$ is defined as spontaneous baseline contractions before arecaidine stimulation. The initial phase $\left(_{\text {ini }}\right)$ is defined as the first 2 minutes after arecaidine application and is characterized by average frequency $\left(\mathrm{F}_{\mathrm{ini}}\right)$ and amplitude $\left(\mathrm{P}_{\text {ini }}\right)$ of spontaneous contractions. The steady state (steady) is defined as the 5 minutes before the next wash out, and is characterized by frequency $\left(\mathrm{F}_{\text {steady }}\right)$ and amplitude $\left(\mathrm{P}_{\text {steady }}\right)$. Instantaneous frequency plot The raw pressure at the peak of every contraction was acquired from the measurement system along with the exact time of the contractions. The frequencies were then calculated and plotted as demonstrated in the figures.

\section{Statistical analysis}

The analysis of the data was done, by conducting a double sided, paired t-test using the SPSS software.

\section{Results}

The figures displayed represent raw experimental data conducted in different animals on different days. 


\section{Response to muscarinic stimulation}

The isolated bladder response to the non-selective muscarinic agonist, arecaidine, is shown in figure 2 (arrow). The initial phase was characterized by a rapid rise in basal pressure, followed by high-frequency bladder contractions. Frequency declined within 5 minutes after which contraction

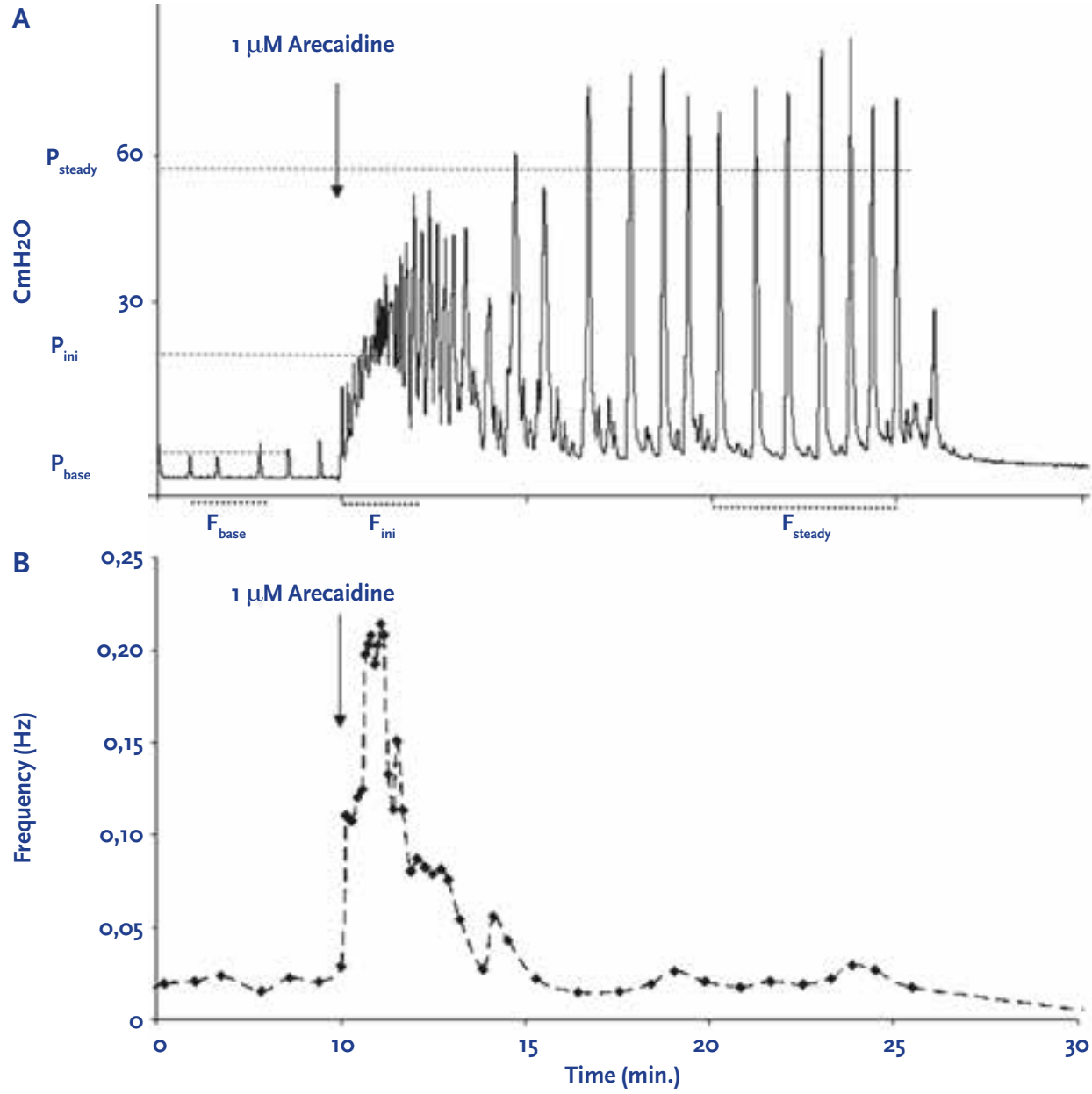

Figure 2. Pressure changes and instantaneous frequency plot of an isolated guinea pig bladder induced by arecaidine. A. Pressure changes of an isolated guinea pig bladder induced by $1 \mu \mathrm{M}$ arecaidine. The average frequency in the initial phase, defined as the first 2 minutes after arecaidine application, is labelled $F_{\text {ini }}$. The steady state frequency $\left(\mathrm{F}_{\text {steady }}\right)$ is defined as the average frequency over a 5 minutes period prior to the wash out. B. Instantaneous frequency plot of an isolated guinea pig bladder. The time of stimulation with $1 \mu \mathrm{M}$ arecaidine is indicated with an arrow. The frequency of the autonomous contractions initially increases and then return back to a lower steady level after approximately 5 minutes. 
amplitude increased, eventually reaching a steady state. These findings are consistent with previous observations ${ }^{15,20}$.

\section{Effect of prostaglandin and COX inhibition on the baseline activity}

The effects of $\mathrm{PGE}_{2}$ and indomethacin on the baseline transients are shown in figure $3 . \mathrm{P}_{\text {base }}$ increased about 2-fold in the presence of $1 \mu \mathrm{M} \mathrm{PGE}$ (control $8.0 \pm 4.6 \mathrm{cmH}_{2} \mathrm{O}$ vs. $\mathrm{PGE}_{2} 17.1 \pm 7.5$ $\mathrm{cmH}_{2} \mathrm{O} ; \mathrm{p}=0.01 ; \mathrm{n}=5$ ). $\mathrm{F}_{\text {base }}$ was not affected by $\mathrm{PGE}_{2}$ (control $0.026 \pm 0.01 \mathrm{~Hz}$ vs. $\mathrm{PGE}_{2} 0.039 \pm$ $0.02 \mathrm{~Hz} ; \mathrm{p}=0.26 ; n=5)$. Application of $10 \mu \mathrm{M}$ of indomethacin decreased $\mathrm{P}_{\text {base }}$ (control $13.2 \pm 6.2$ $\mathrm{cmH}_{2} \mathrm{O}$ vs. indomethacin $\left.11.6 \pm 5.9 \mathrm{cmH}_{2} \mathrm{O} ; \mathrm{p}=0.03 ; \mathrm{n}=6\right) . \mathrm{F}_{\text {base }}$ was not affected by indomethacin (control $0.028 \pm 0.0066 \mathrm{~Hz}$ vs. indomethacin $0.030 \pm 0.0051 \mathrm{~Hz} ; \mathrm{p}=0.32 ; \mathrm{n}=6$ ).

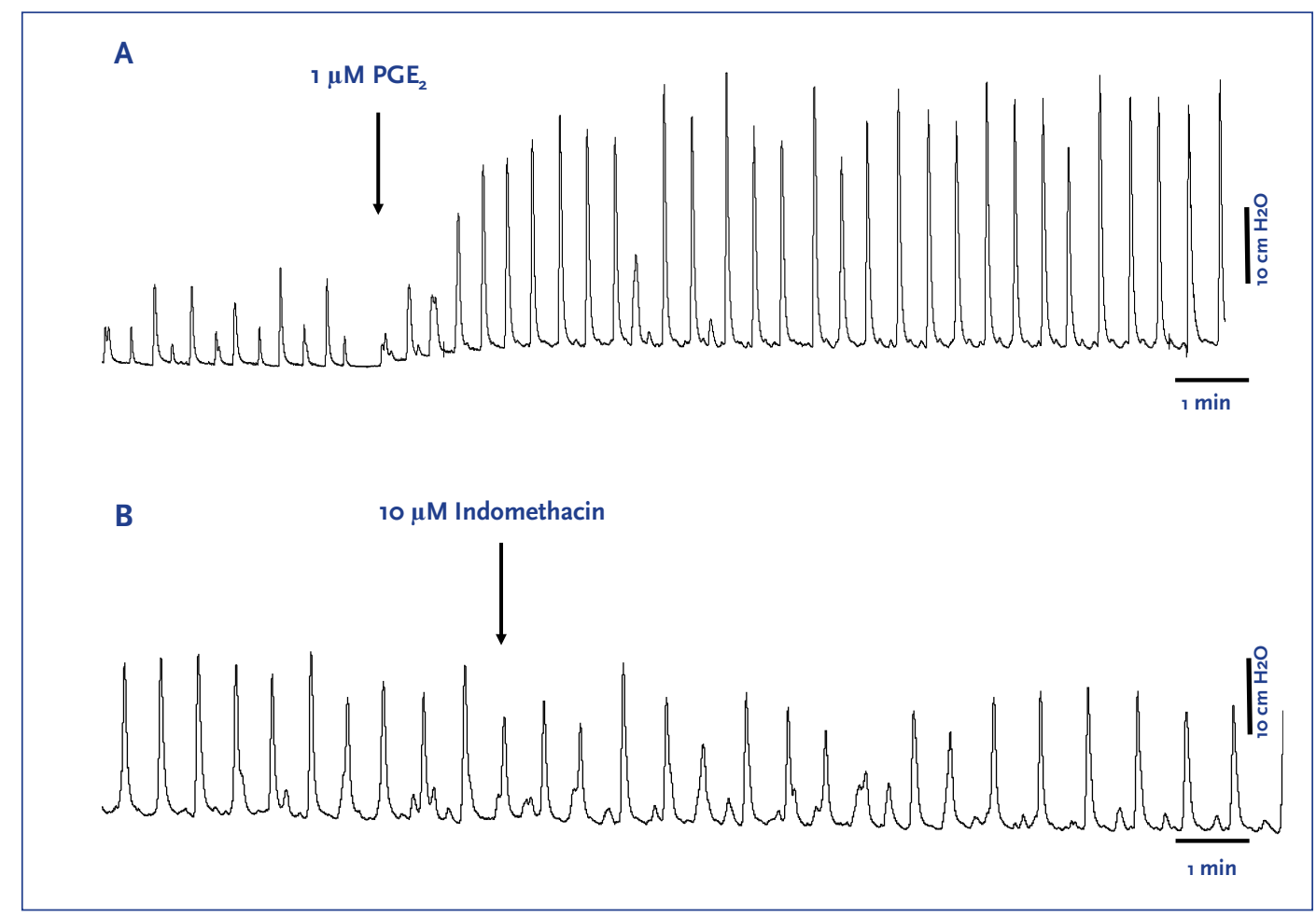

Figure 3. Spontaneous activity of the isolated guinea pig bladder after administration of $\mathrm{PGE}_{2}$ and indomethacin. A. Spontaneous activity of the isolated guinea pig bladder. The arrow indicates when $1 \mu \mathrm{M}$ of $\mathrm{PGE}_{2}$ is added. The amplitude of the contractions is significantly increased. B. Spontaneous activity of the isolated guinea pig bladder. The arrow indicates when $10 \mu \mathrm{M}$ indomethacin is added. The amplitude of the contractions is slightly decreased by indomethacin. However, the frequency of contractions is not affected. 


\section{Effect of indomethacin and $P G E_{2}$ on the muscarinic response}

The recordings of an experiment with COX inhibitor indomethacin are shown in figure 4. At $t=30$ indomethacin was added to the bath. The bladder response on arecaidine stimulation in the presence of indomethacin $(t=45)$ was not different from the response to arecaidine stimulation in the absence of indomethacin $(t=0)$, for any of the parameters $P_{\text {ini }}(p=0.081), F_{\text {ini }}(p=0.77)$, $P_{\text {steady }}(p=0.19), F_{\text {steady }}(p=0.32)$. However, after a wash step and a the second stimulation, with arecaidine $(t=75), F_{\text {ini }}$ was significantly decreased $(p=0.0005)$, whereas $P_{\text {ini }}(p=0.086), F_{\text {steady }}$ $(P=0.32)$ and $P_{\text {steady }}(p=0.33)$ remained unchanged. To check the reversibility of the described indomethacin effect after the wash step, by prostaglandin, $\mathrm{PGE}_{2}$ was given exogenously at $t=105$ in four animals. One of these recordings is shown in figure 5. After adding $P G E_{2}$ a strong response, i.e. high amplitude contractions, were observed as shown in figure 5 . In order to achieve a steady state before adding arecaidine, arecaidine was added 30 minutes later instead of 15 minutes. Data of all four experiments show that, compared to arecaidine stimulation after indomethacin exposure $(t=45$ and $T=75), F_{\text {ini }}$ was increased $(p=0.014)$, so the indomethacin effect on $F_{i n i}$ was reversed by PGE $E_{2}$. There were no changes noted in $P_{\text {ini }}(0.38)$, neither $F_{\text {steady }}(0.27)$ nor $P_{\text {steady }}(0.19) . F_{\text {ini }}$ at $t=135$ was not significantly changed when compared to the initial arecaidine stimulation $(t=0)(p=0.06)$.

\section{Discussion}

Presence of PG receptors in the bladder and involvement of PG in the bladder physiology has been demonstrated before ${ }^{6,13,21,22}$. The urothelium is shown to release acetylcholine, ATP, Nitric Oxide and prostaglandin ${ }^{4,6}$. The physiological role of these signals is poorly understood and a possible interaction between them has not widely been considered. The link between PG and cholinergic effects in the bladder has been suggested before. In a study in rat detrusor it was shown that indomethacin suppressed frequency of muscarinic-induced contractions but only in strips of certain orientation and with urothelium intact ${ }^{23}$. Furthermore, in another study in rat bladders studied in an organ bath model it was shown that $P G E_{2}$ release could be antagonized by indomethacin and concluded that COX inhibitors suppress ATP release from bladder epithelium via decreasing $\mathrm{PGE}_{2}$. In addition, $\mathrm{EP}_{1}$ and/or $\mathrm{EP}_{3}$ receptors were suggested to participate in this effect $^{24}$. In a study in rabbit detrusor strips it was shown that both indomethacin and ibuprofen suppress spontaneous contractions ${ }^{25}$. In addition, it has been suggested that endogenous PGs in isolated human detrusor facilitate the action of acetylcholine ${ }^{17}$. This effect was thought to be through an increase in the concentration of the cholinergic neurotransmitter probably via an inhibition of the acetylcholinesterase activity ${ }^{17}$. Moreover, PG has been suggested to have a modulatory role in the release of acetylcholine and ATP in the guinea pig bladder ${ }^{26}$. The aim of our study was to further investigate the link between the prostaglandin and the cholinergic system and explore the possibility of COX inhibition as a treatment modality for OAB. It has been demonstrated that that there is a basal acetylcholine release in human detrusor muscle in vitro ${ }^{27}$. This release was resistant to nerve 


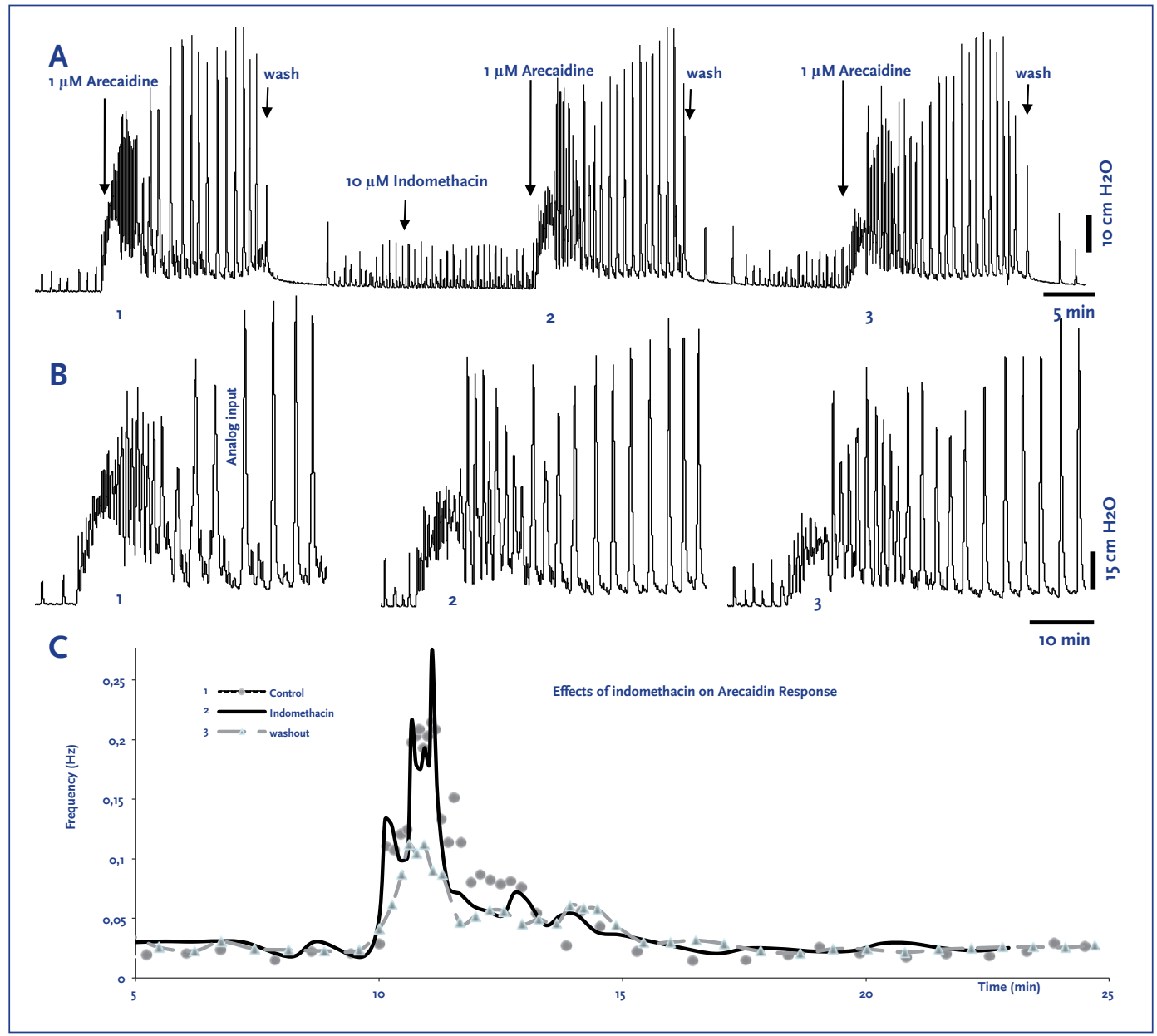

Figure 4. Timeline, pressure changes and instantaneous frequency plot of an isolated guinea pig bladder pre-exposed to indomethacin before stimulation with arecaidine. A. an outline of the experiment. After the first $1 \mu \mathrm{M}$ arecaidine simulation (enlarged in panel B as 1), the organ bath is washed to remove the arecaidine. After 15 minutes, $10 \mu \mathrm{M}$ indomethacin is added followed by a second stimulation of arecaidine (enlarged in panel B as 2). After a wash step, a third arecaidine stimulation is performed (enlarged in panel B as 3). B. Parts of panel A in an expanded scale. C. Instantaneous frequency plot comparing the three conditions described in panel $\mathrm{A}$. 


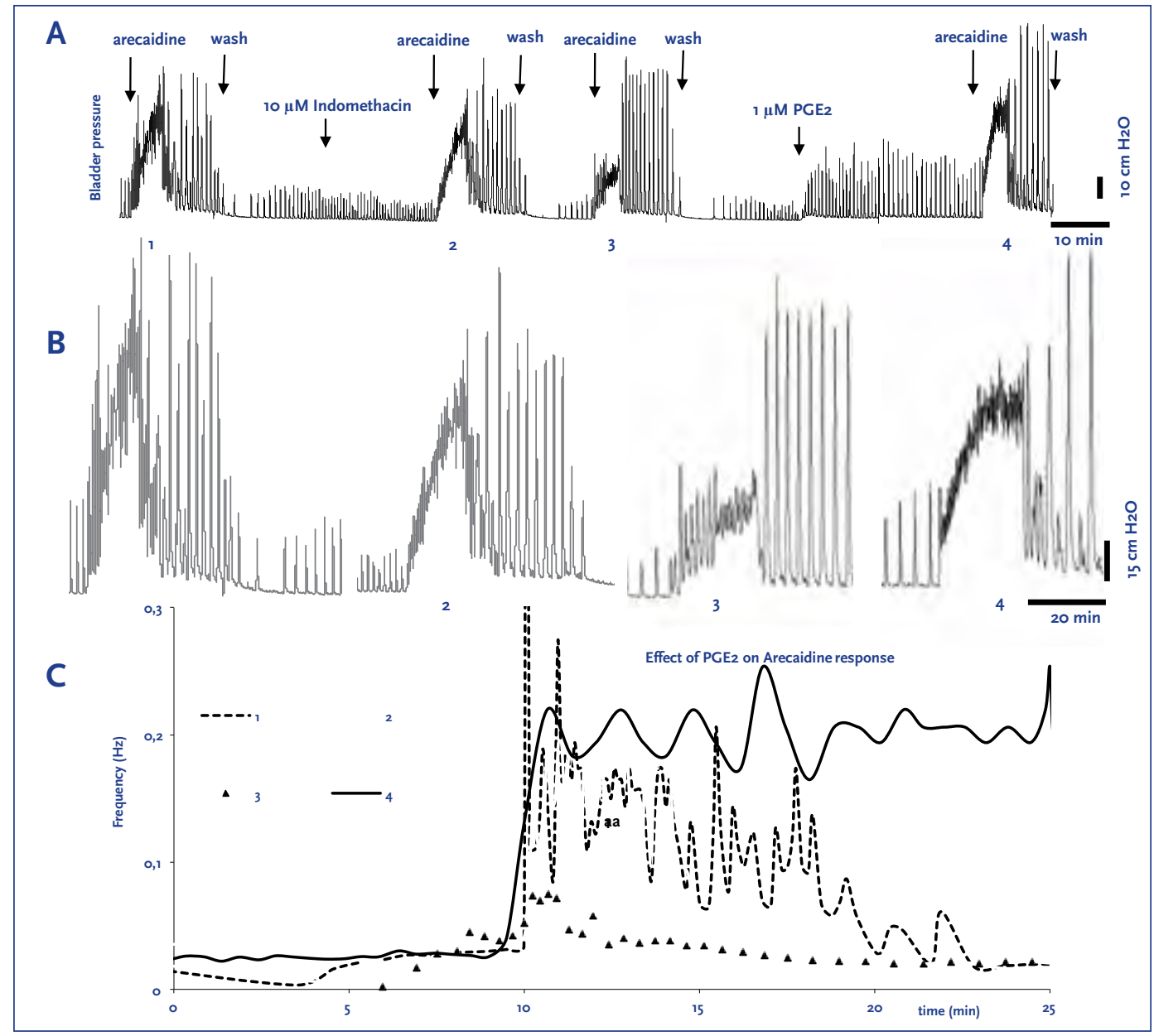

Figure 5. Timeline, pressure changes and instantaneous frequency plot of an isolated guinea pig bladder after stimulation with arecaidine showing the reversibility of the indomethacin effect by $\mathrm{PGE}_{2}$. $\mathrm{A}$. an outline of another typical experiment. The same protocol as described in Figure 3 was followed. To check the reversibility, at the end of the experiment, $1 \mu \mathrm{M} \mathrm{PGE}_{2}$ is added in to the organ bath and a last arecaidine stimulation is conducted. The first arecaidine stimulation is marked as (1) followed by the stimulation with presence of indomethacin (2) followed by stimulation after a wash step (3). At the end an arecaidine stimulation is shown after adding $P G E_{2}$ to the system (4). B. Each of the arecaidine responses shown in panel $A$ in an enlarged scale, starting from the left, the first trace shows the basic arecaidine response (1), the second trace shows the previously shown effect of the inhibition of PG production (2). The third trace shows the effect of washing the organ bath with fresh Krebs' before stimulation with arecaidine (3). The last trace from the right shows the effect of addition of exogenous $\mathrm{PGE}_{2}(4)$. C. Instantaneous frequency plot comparing the four conditions described in panel A. 
blocker tetrodotoxin, and considerably reduced when the urothelium was removed, suggesting that the released acetylcholine was of non-neuronal origin and, at least partly, generated by the urothelium. Stretch of the muscle increased the release.

There are thus reasons to believe that acetylcholine can be generated by nonneuronal structures within the bladder, and it may be speculated that urothelially derived acetylcholine can excite suburothelial afferent nerves and that this contributes to OAB. During filling of the bladder, there is no activity in the parasympathetic nerves innervating the bladder, and direct evidence for spontaneous release of acetylcholine from nerves during the filling phase of the bladder has so far been lacking ${ }^{28}$. However, it has been shown that there is a spontaneous tetrodotoxinresistant release of acetylcholine from autonomic cholinergic nerves in guinea pig and rat bladders under both in vitro and in vivo conditions ${ }^{29}$. This release was shown to significantly affect bladder contractility (autonomous activity) ${ }^{29}$. These findings provide further support for the hypothesis that antimuscarinic drugs can act also by inhibiting a myogenic afferent pathway during the filling phase ${ }^{28}$. Thus, during the storage phase, acetylcholine may be released from both neuronal and non-neuronal sources, and directly or indirectly excite afferent nerves suburothelially and within the detrusor. It is has been shown that an isolated bladder in an organ bath shows spontaneous rhythmical contractions ${ }^{14,15}$. The frequency of this baseline activity was shown to be unaffected by $P G E_{2}$ and the COX-inhibitor indomethacin (figure 3). Although $\mathrm{F}_{\text {base }}$ was not significantly affected by $\mathrm{PGE}_{2}$ (control $0.026 \pm 0.01 \mathrm{~Hz}$ vs. $\mathrm{PGE}_{2} 0.039 \pm 0.02 \mathrm{~Hz} ; \mathrm{p}=0.26 ; n=5$ ) there was an increase of about $50 \%$. Therefore, this might be due to a lack of power in our study and might become significant if more animals were tested. On the other hand, the amplitude of the baseline contractions was significantly raised by $\mathrm{PGE}_{2}$ and decreased by indomethacin, indicating that $\mathrm{PG}$ is needed for and has a stimulating effect on the amplitude of these baseline contractions. The nonselective muscarinic agonist, arecaidine induces a rapid rise in basal pressure with high-frequency bladder contractions which declined within 5 minutes. After this, contraction amplitude increased, eventually reaching a steady state. These findings are consistent with previous observations ${ }^{15,20}$ and represent a typical response by the isolated bladder to arecaidine as shown in figure 2 . Furthermore, data presented in this paper show that inhibition of PG production by indomethacin diminished the average frequency of the initial burst of transients of the isolated guinea pig bladder, in the first 2 minutes after of the application of the muscarinic agonist, arecaidine $\left(F_{i n i}\right)$. As explained in figure $2 \mathrm{~B}$, indomethacin by itself, i.e. in the absence of arecaidine, did not change baseline contraction frequency but slightly reduced contraction baseline amplitude. However, arecaidine stimulation after COX inhibition by indomethacin application, lead to a significantly less outspoken response, after the second arecaidine stimulation. The explanation of this delayed effect of indomethacin on $\mathrm{F}_{\text {ini }}$ could simply be due to a longer incubation time needed for indomethacin to exert its effect. Indomethacin is still believed to be present in the organ bath since the recordings after the second wash step are not the same as control. This can be clearly seen in figures 4 and 5 , especially at the 
diagram at the bottom of the figures. The difference in 1 (control) and 3 (after second wash step) is only in the addition of indomethacin and since these two recordings are persistently different in all experiments we assume that indomethacin is still present in the system. Furthermore, the conducted control experiments (data not included) have ruled out that this effect is simply due to time or a repeated wash step. However, another plausible explanation may be that the second wash step, applied after the second arecaidine stimulation, could have caused a further washout of the previously produced PG. Since de novo production of the PG is inhibited by indomethacin, there is no new PG production in the isolated bladder. The delayed effect may therefore also be explained by the small amount of previously produced PG, which might still be present and active in the system during the first arecaidine stimulation. Therefore, the initial burst induced by arecaidine is not affected the first time. We hypothesize that after the addition of indomethacin followed by the second wash step, there is practically no PG left in the organ bath and the tissue. Therefore, there is a significantly less outspoken response to arecaidine. Thus, inhibition of PG production seems to reduce $F_{i n i}$ of the muscarinic response and it can be suggested that PG is necessary for the normal increase in autonomous activity following cholinergic stimulation, i.e. the arecaidine response. In line with this, an exogenous dose of $P G E_{2}$ increases the initial burst frequency after arecaidine stimulation, to levels even higher than the control (figure 4). PG has been suggested to be linked to acetylcholine before. In a study conducted in another species and It has been shown that patients with the overactive bladder syndrome (OAB) have an increased urinary $\mathrm{PG}^{38,39}$ which is thought to affect bladder activity directly by effects on smooth muscle and/or indirectly via effects on neurotransmission ${ }^{40}$.

\section{Conclusions}

In summary, our data show that inhibition of PG production has an influence on the cholinergically induced bladder response in the isolated bladder. In order to evaluate the effect of PG on the autonomous activity in the presence of local reflex loops and control by the central nervous system, these experiments should be performed in vivo. By this, a combination of drugs inhibiting both muscarinic receptors and PG function or production can become an interesting focus of research in the quest for a better treatment for OAB. In order to gain a full understanding of the PG effect shown on the cholinergically induced bladder response, more studies need to be conducted using selective EP blockers in vitro and in vivo. 


\section{References}

1. Michel, M.C. \& de la Rosette, J.J. Role of muscarinic receptor antagonists in urgency and nocturia. British Journal of Urology International 96 Suppl 1, 37-42 (2005).

2. Andersson, K.E. Drugs and future candidates. Canadian Urological Association Journal 5, S131-133 (2011).

3. Griffiths, D. \& Tadic, S.D. Bladder control, urgency, and urge incontinence: evidence from functional brain imaging. Neurourology and Urodynamics 27, 466-474 (2008).

4. Birder, L. Role of the urothelium in bladder function. Scandinavian Journal of Urology and Nephrology 48-53 (2004).

5. Pinna, C., Zanardo, R. \& Puglisi, L. Prostaglandin-release impairment in the bladder epithelium of streptozotocin-induced diabetic rats. European Journal of Pharmacology 388, 267-273 (2000).

6. Rahnama'i, M.S., Van Kerrebroeck, Ph.E.V., de Wachter, S.G. \& van Koeveringe, G.A. The role of prostanoids in urinary bladder physiology. Nature Reviews Urology 9, 283-290 (2012).

7. Narumiya, S., Sugimoto, Y. \& Ushikubi, F. Prostanoid receptors: structures, properties, and functions. Physiological Reviews 79, 1193-1226 (1999).

8. Piper, P. \& Vane, J. The release of prostaglandins from lung and other tissues. Annals of New York Academy of Science 180, 363-385 (1971).

9. Vane, J.R., Bakhle, Y.S. \& Botting, R.M. Cyclooxygenases 1 and 2. Annual Review of Pharmacology and Toxicology 38, 97-120 (1998).

10. de Jongh, R., van Koeveringe, G.A., Van Kerrebroeck, Ph.E.V., Markerink-van Ittersum, M., de Vente, J. \& Gillespie, J.I. The effects of exogenous prostaglandins and the identification of constitutive cyclooxygenase I and II immunoreactivity in the normal guinea pig bladder. British Journal of Urology International 10o, 419-429 (2007).

11. Maggi, C.A. Prostanoids as local modulators of reflex micturition. Pharmacological Research 25, 13-20 (1992).

12. Maggi, C.A., Giuliani, S., Conte, B., Furio, M., Santicioli, P., Meli, P., Gragnani, L. \& Meli, A.Prostanoids modulate reflex micturition by acting through capsaicin-sensitive afferents. European Journal of Pharmacology 145, 105-112 (1988).

13. Nile, C.J., de Vente, J. \& Gillespie, J.I. Stretch independent regulation of prostaglandin E production within the isolated guinea-pig lamina propria. British Journal of Urology International (2009).

14. Gillespie, J.I., Harvey, I.J. \& Drake, M.J. Agonist- and nerve-induced phasic activity in the isolated whole bladder of the guinea pig: evidence for two types of bladder activity. Experimental Physiology 88, 343-357 (2003).

15. Finney, S.M., Stewart, L.H. \& Gillespie, J.I. Cholinergic activation of phasic activity in the isolated bladder: possible evidence for $\mathrm{M}_{3}$ - and $\mathrm{M}_{2}$-dependent components of a motor/sensory system. British Journal of Urology International 100, 668-678 (2007).

16. McCafferty, G.P., Misajet, B.A., Laping, N.J., Edwards, R.M. \& Thorneloe, K.S. Enhanced bladder capacity and reduced prostaglandin E2-mediated bladder hyperactivity in $\mathrm{EP}_{3}$ receptor knockout mice. American Journal of Physiology. Renal Physiology 295, F507-514 (2008). 
17. Borda, E., Contreras-Ortiz, N., Gutnisky, R. \& Gimeno, M.F. In vitro effect of acetylcholine and bethanechol on the contractions of the human detrusor muscle. Influence of prostaglandins. Arcives Internationales de Pharmacodynamie et de Therapie 259, 31-39 (1982).

18. Jeremy, J.Y., Mikhailidis, D.P. \& Dandona, P. Prostanoid synthesis by the rat urinary bladder: evidence for stimulation through muscarine receptor-linked calcium channels. Naunyn Schmiedebergs Arcives of Pharmacology 334, 463-467 (1986).

19. Ishizuka, O., Mattiasson, A. \& Andersson, K.E. Prostaglandin E2-induced bladder hyperactivity in normal, conscious rats: involvement of tachykinins? The Journal of Urology 153, 2034-2038 (1995).

20. de Jongh, R., van Koeveringe, G,A., Van Kerrebroeck, Ph.E.V., Markerink-van Ittersum, M., de Vente, J. \& Gillespie, J.I. Damage to the bladder neck alters autonomous activity and its sensitivity to cholinergic agonists. British Journal of Urology International 100, 919-929 (2007).

21. Rahnama'i, M. S., van Koeveringe, G.A., Essers, P.B., de Wachter, S.G., de Vente, J., Van Kerrebroeck, Ph.E.V., \& Gillespie, J.I. Prostaglandin receptor EP1 and EP2 site in guinea pig bladder urothelium and lamina propria. The Journal of Urology 183, 1241-1247 (2010).

22. Rahnama'i, M. S., de Wachter, S.G., van Koeveringe G.A., Van Kerrebroeck, Ph.E.V., de Vente, J. \& Gillespie, J.I. The relationship between prostaglandin E receptor 1 and cyclooxygenase I expression in guinea pig bladder interstitial cells: proposition of a signal propagation system. The Journal of Urology 185, 315$322(2011)$.

23. Santoso, A.G., Lo, W.N. \& Liang, W. Urothelium-dependent and urothelium-independent detrusor contractility mediated by nitric oxide synthase and cyclooxygenase inhibition. Neurourology and Urodynamics 30, 619-625 (2011).

24. Tanaka, I., Nagase, K., Tanase, K., Aoki, Y., Akino, H., \& Yokoyama, O. Modulation of stretch evoked adenosine triphosphate release from bladder epithelium by prostaglandin $\mathrm{E}(2)$. The Journal of Urology 185 , 341-346 (2011).

25. Collins, C., Klausner, A,P., Herrick, B., Koo, H.P., Miner, A.S., Henderson, S.C. \& Ratz, P.H. Potential for control of detrusor smooth muscle spontaneous rhythmic contraction by cyclooxygenase products released by interstitial cells of Cajal. Journal of Cellular and Molecular Medicine 13, 3236-3250 (2009).

26. Alkondon, M. \& Ganguly, D.K. Release of prostaglandin E from the isolated urinary bladder of the guineapig. British Journal of Pharmacology 69, 573-577 (1980).

27. Yoshida, M., Masunaga, K., Satoji, Y., Maeda, Y., Nagata, T. \& Inadome, A. Basic and clinical aspects of non-neuronal acetylcholine: expression of non-neuronal acetylcholine in urothelium and its clinical significance. Journal of Pharmacological Science 106, 193-198 (2008).

28. Andersson, K.E. Words of wisdom. Re: Spontaneous release of acetylcholine from autonomic nerves in the bladder. European Urology 57, 171-172 (2010).

29. Zagorodnyuk, V.P., Gregory, S., Costa, M., Brookes, S.J., Tramontana, M., Giuliani, S. \& Maggi, C.A. Spontaneous release of acetylcholine from autonomic nerves in the bladder. British Journal of Pharmacology 157, 607-619 (2009). 
30. Koshita, M., Hidaka, K., Ueno, H., Yamamoto, Y. \& Suzuki, H. Properties of acetylcholine-induced hyperpolarization in smooth muscle cells of the mouse mesenteric artery. Journal of Smooth Muscle Research = Nihon Heikatsukin Gakkai kikanshi 43, 219-227 (2007).

31. Finney, S.M., Andersson, K.E., Gillespie, J.I. \& Stewart, L.H. Antimuscarinic drugs in detrusor overactivity and the overactive bladder syndrome: motor or sensory actions? British Journal of Urology International 98, 503-507 (2006).

32. Andersson, K.E. \& Yoshida, M. Antimuscarinics and the overactive detrusor--which is the main mechanism of action? European Urology 43, 1-5 (2003).

33. de Groat, W.C. The urothelium in overactive bladder: passive bystander or active participant? Urology 64 , 7-11 (2004).

34. Fry, C.H., Ikeda, Y., Harvey, R., Wu, C. \& Sui, G.P. Control of bladder function by peripheral nerves: avenues for novel drug targets. Urology 63, 24-31 (2004).

35. Gillespie, J.I. Inhibitory actions of calcitonin gene-related peptide and capsaicin: evidence for local axonal reflexes in the bladder wall. British Journal of Urology International 95, 149-156 (2005).

36. de Jongh, R., Grol, S., van Koeveringe, G.A., Van Kerrebroeck, Ph.E.V., de Vente, J., \& Gillespie, J.I. The localisation of cyclo oxygenase immuno-reactivity ( $\left.\mathrm{COX}_{1-I R}\right)$ to the urothelium and to interstitial cells in the bladder wall. Journal of Cellular and Molecular Medicine 13(9B),3069-3081 (2009).

37. Drake, M.)., Harvey, I.)., Gillespie, J.I. \& Van Duyl, W.A. Localized contractions in the normal human bladder and in urinary urgency. British Journal of Urology International 95, 1002-1005 (2005).

38. Kim, J.C., Park, E.Y., Seo, S.I., Park, Y.H. \& Hwang, T.K. Nerve growth factor and prostaglandins in the urine of female patients with overactive bladder. The Journal of Urology 175, 1773-1776; discussion 1776 (2006).

39. Kim, J.C., Park, E,Y., Hong, S.H., Seo, S.I., Park, Y.H. \& Hwang, T.K. Changes of urinary nerve growth factor and prostaglandins in male patients with overactive bladder symptom. International Journal of Urology 12 , 875-880 (2005).

40. Andersson, K.E. Bladder activation: afferent mechanisms. Urology 59, 43-50 (2002). 



\section{Chapter 7 \\ The Role of Phosphodiesterases in Bladder Pathophysiology}

Nature Reviews Urology. 2013

doi: $10.1038 /$ nrurol.2013.101

PMID: 23670184

M.S. Rahnama'i', S. Ückert², R. Hohnen ${ }^{3}$ and G.A. van Koeveringe'

' Department of Urology, Maastricht University Medical Centre (MUMC+)

Maastricht, The Netherlands

${ }^{2}$ Department of Urology \& Urological Oncology

Hannover Medical School, Division of Surgery

Hannover, Germany

3 Department of Psychiatry and Neuropsychology, European Graduate School of Neuroscience (EURON) Maastricht University, Maastricht, The Netherlands 


\begin{abstract}
Nitric oxide and the cyclic nucleotide monophosphates CAMP and CGMP have a role in control of the micturition process and hence, are suggested to be involved in the pathophysiology of storage and voiding disorders. Phosphodiesterase enzymes (PDEs) hydrolyse cAMP and cGMP. Inhibition of PDEs increases CAMP and CGMP levels and relaxes urinary bladder smooth musculature. Although many preclinical studies have been conducted, to date, only PDE1 and PDE5 inhibitors have been tested clinically for the management of storage and voiding disorders. Treatment with PDE1 inhibitors might improve micturition frequency in patients with overactive bladder, whereas inhibition of PDE5 improves lower urinary tract symptoms in men, either with or without benign prostatic hyperplasia and erectile dysfunction. Furthermore, the combination of a PDE5 inhibitor and an $\alpha$-adrenoceptor antagonist has superior efficacy to monotherapy with either agent. However, the role of PDE5 inhibitors in the treatment of women with detrusor overactivity remains unclear. The clinical application of agents that inhibit other PDEs, including PDE4, also certainly merits scientific attention. PDE inhibitors seem likely to become a valuable alternative treatment for patients with storage and voiding disorders in the future. Phosphodiesterases (PDEs) hydrolyse CAMP and CGMP, and are thought to have a crucial role in
\end{abstract}




\section{Introduction}

Many families of enzymes can break phosphodiester bonds, including phospholipases C and D, autotaxin, sphingomyelin phosphodiesterase, DNases, RNases, and restriction endonucleases, among others. However, in most circumstances, the term phosphodiesterase (PDE) refers to the cyclic nucleotide PDEs, which break down the second-messenger molecules CAMP and cGMP that are important endogenous mediators of many cellular processes, including smooth muscle motility'-3. PDE inhibitors block breakdown of these molecules and consequently elevate intracellular levels of cAMP, cGMP, or both.

cAMP is synthesized by adenylyl cyclases either in the cytoplasm or associated with G-protein-coupled receptors in the plasma membrane, termed soluble and particulate adenylate cyclases, respectively. Although these enzymes have different subcellular localizations and respond differently to various regulators, they share a conserved catalytic domain architecture and function via a common catalytic mechanism ${ }^{4}$. Eight of the nine particulate adenylyl cyclase isoforms (the exception being adenylate cyclase type 9 ) are activated by GTP-bound $\mathrm{G}_{\mathrm{s}} \alpha$ (stimulatory $\mathrm{G}$ protein subunit $\alpha$ ) and forskolin 5 . Soluble adenylate cyclases, by contrast, are regulated by bicarbonate and calcium ions, and are insensitive to both forskolin and activated $\mathrm{G}_{\mathrm{s}} \alpha^{4}$. cGMP is synthesized by guanylyl cyclases, again located either in the cytoplasm or plasma membrane. Particulate guanylyl cyclases are activated by extracellular natriuretic peptides, whereas soluble guanylyl cyclases are triggered by nitric oxide (figure 1$)^{6}$.

In the lower urinary tract, nitric oxide is an important nonadrenergic, noncholinergic neurotransmitter that acts alongside the classical adrenergic and cholinergic systems to regulate micturition ${ }^{7.8}$. Nitric oxide is thought to inhibit efferent neurotransmission in the urethra and to modulate afferent neurotransmission in the bladder, as well as related reflex pathways in the spinal cord ${ }^{7-9}$. Nitric oxide released from nerve endings and endothelium diffuses into smooth muscle cells, where it stimulates cGMP synthesis, which subsequently leads to their relaxation ${ }^{10}$. cGMP is hydrolysed to inactive 5' GMP by PDEs". cAMP and CGMP are also generally accepted to be involved in the control of micturition, and hence to have a role in the pathophysiology of storage and voiding disorders ${ }^{9,11-16}$.

In vitro studies indicate that human detrusor smooth muscle is relatively inert to the nitric-oxideproducing agent, sodium nitroprusside, and to activation or inhibition of targets acting via the cGMP system ${ }^{17}$. Animal studies, however, suggest that nitrinergic nerves innervate the bladder stroma and suburothelium, and that the urothelial layer both expresses nitric oxide synthase and can release nitric oxide ${ }^{8,18-20}$. In turn, nitric oxide may exert a cGMP-mediated inhibitory effect on bladder sensory afferent nerves ${ }^{21,22}$. Although little guanylyl cyclase activity can be detected in detrusor smooth muscle, and nitric oxide and PDE5 inhibitors have an insignificant effect on bladder relaxation (during filling) or contraction (during emptying), considerable amounts of guanylyl cyclase are present in bladder afferent nerves and interstitial cells. Excitation of bladder sensory nerves, caused by distention during bladder filling, inflammation or irritation, is a key trigger of the micturition reflex. Increased activity in these nerves can, therefore, contribute to bladder 
overactivity. Inhibition of PDE 5 increases CGMP or cGMP-binding protein kinase (PKG) activity in afferent nerves, and directly decreases neuropeptide release, thereby resulting in decreased afferent nerve signalling. In interstitial cells, increasing cGMP or PKG activity can decrease cytosolic $\mathrm{Ca}^{2+}$ via several mechanisms of action (figure 1$)^{23}$.

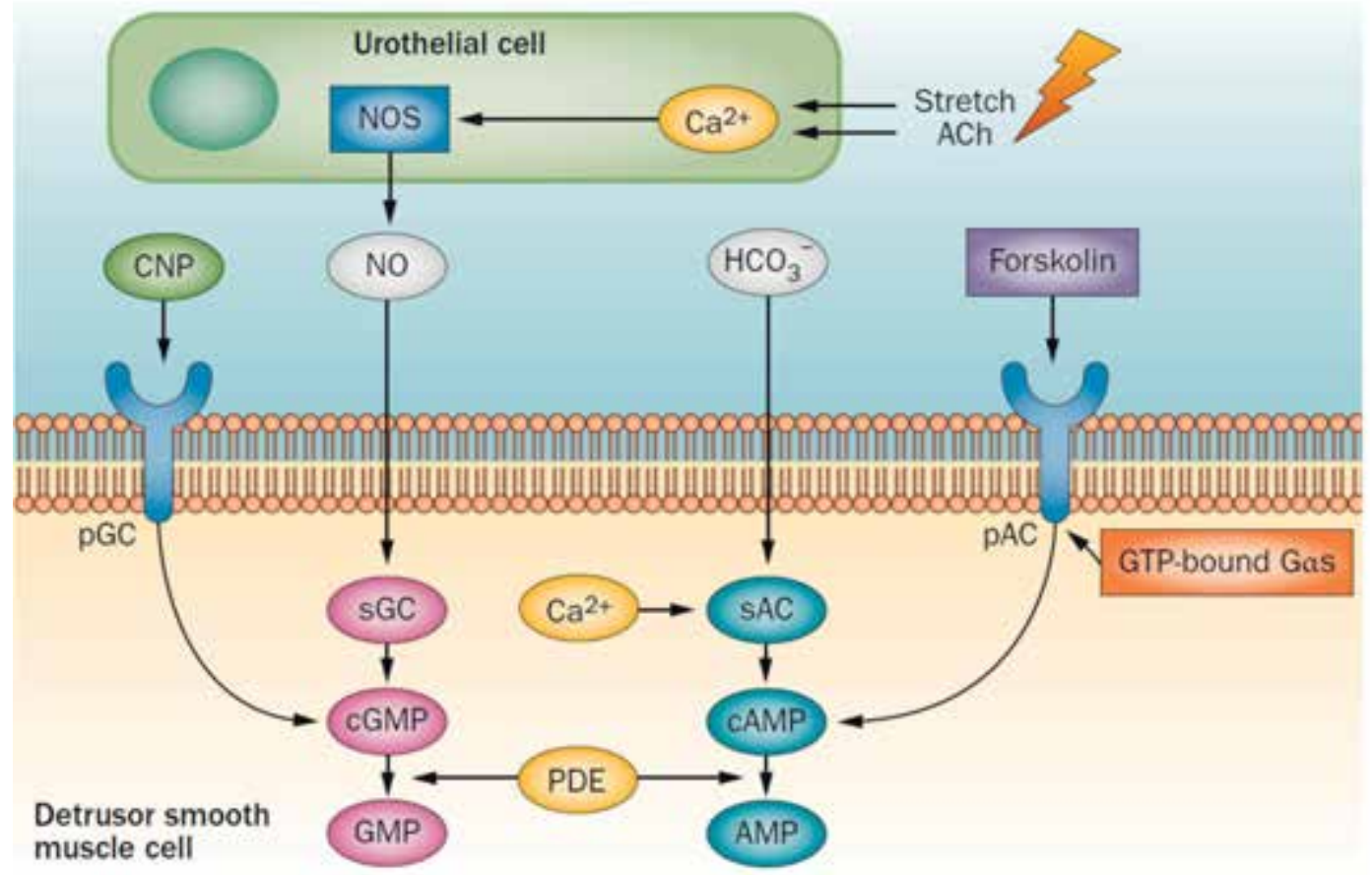

Figure 1. Schematic diagram of the cyclic nucleotide signalling pathways. Stretch stimuli, or acetylcholine release increase internal $\mathrm{Ca}^{2+}$ levels in NOS-expressing urothelial cells. NOS produces nitric oxide, which signals to detrusor smooth muscle cells. NO is thought to have a modulatory role in the lower urinary tract, including the relaxation of urethral smooth muscle, modulation of neurotransmitter release from efferent nerves, regulation of urothelial permeability, and modulation of afferent nerve activity. Moreover, a pathophysiological role of NO has been suggested because injury or chronic inflammation can upregulate the expression of inducible NOS. Guanylyl cyclases located in the cytoplasm or plasma membrane synthesize CGMP in response to NO or CNP. cAMP is synthesized by adenylyl cyclases, either associated with G proteincoupled receptors in the plasma membrane, or in the cytoplasm. Membrane-associated adenylyl cyclases are activated by GTP-bound $\mathrm{G}_{s} \alpha$ and forskolin, whereas cytoplasmic adenylyl cyclases are regulated by $\mathrm{HCO}_{3}^{-}$and $\mathrm{Ca}^{2+}$, but insensitive to forskolin or activated $\mathrm{G}_{\mathrm{s}}$ a. cAMP and cGMP are hydrolysed to AMP and GMP, respectively, by phosphodiesterases (PDEs). Abbreviations: NOS, nitric oxide synthase; CNP, C-like natriuretic peptide; pGC, particulate (plasma membrane) guanylyl cyclase; sGC, soluble guanylyl cyclase; pAC, particulate (plasma membrane) adenyl cyclase; sAC, soluble (cytoplasmic) adenyl cyclase; PDE, phosphodiesterase. 
PDE isoenzymes are classified according to their preferences for either CAMP and/or cGMP, kinetic parameters of hydrolysis, sensitivity to inhibition by various compounds, allosteric regulation by other molecules and biochemical behaviour on anion exchange columns ${ }^{24}$. The PDE superfamily now includes more than 50 distinct isoforms, divided into 14 subtypes $^{25}$. So far, 11 PDEs have been identified (figure 2), and three further isoenzymes are thought to exist, but have yet to be characterized $^{26-28}$. The expression, distribution and function of the various PDE isoenzymes can vary in different tissues. Selective PDE inhibitors, therefore, have the potential to exert specific effects on a given target tissue ${ }^{25,29}$. Several selective PDE inhibitors have already been approved for clinical use and others are under investigation in ongoing clinical trials. To date, six PDEs (PDEs $1-5$ and 11) have been proven to be of pathophysiological importance in different clinical conditions ${ }^{30}$. In this Review, we summarize current understanding of the distribution and physiological roles of PDEs in the urinary bladder. We also discuss the effects and clinical use of PDE inhibitors in the treatment of functional bladder disorders, including lower urinary tract symptoms (LUTS), overactive bladder (OAB) and detrusor overactivity (defined in Box 1).

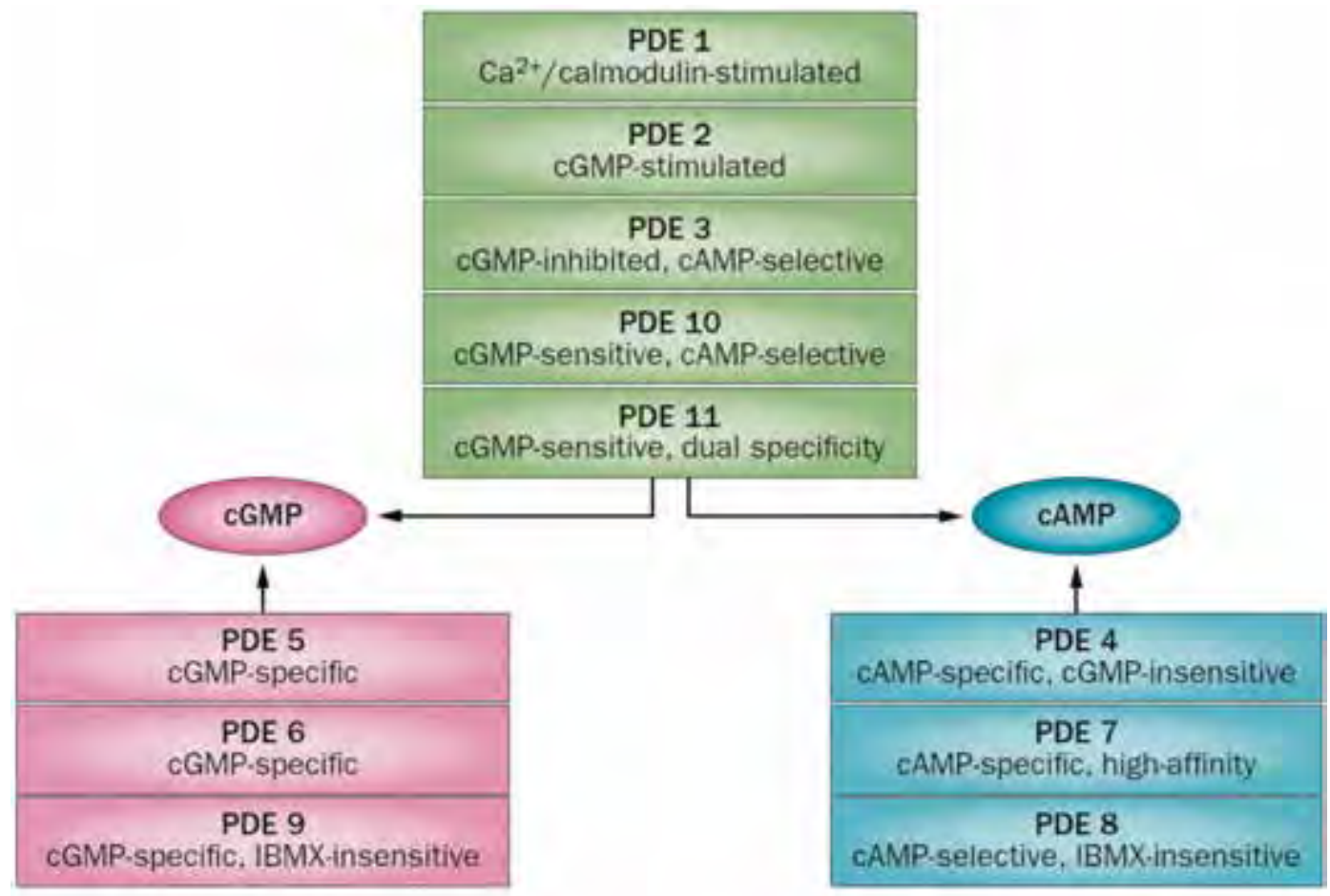

Figure 2. A schematic overview of the different PDE isoenzymes and some of their characteristics, including affinity for cAMP and/or cGMP. PDEs 1-3, 10 and 11 hydrolyse both cAMP and cGMP. PDEs 5, 6 and 9 only hydrolyse cGMP. PDEs 4, 7 and 8 only hydrolyse cAMP. Abbreviations: IBMX, 3-isobutyl-1-methylxanthine (a non-selective, competitive phosphodiesterase inhibitor); PDE, phosphodiesterase. 
Prostaglandins and Phosphodiesterases in the Urinary Bladder Wall

Table 1. PDEs, their major substrates, inhibitors and their expression in the urinary bladder. ${ }^{11,16,34,36,37,90,10,102}$

\begin{tabular}{|c|c|c|c|}
\hline Isoenzyme & Major substrate(s) & Inhibitor(s) [Ki] & Expression in human bladder* \\
\hline $\mathrm{PDE}_{1}$ & cAMP \& cGMP & $\begin{array}{l}\text { Vinpocetine, N (6-aminohexyl) } \\
\text { 5-chloro 1-naphthalenesulphonamide, } \\
\text { 8-methoxy mixture }\end{array}$ & $\begin{array}{l}\text { Protein: IHC, }{ }^{33,34} \text {, activity90 } \\
\text { mRNA: RT PCR }{ }^{36}\end{array}$ \\
\hline PDE2 & cAMP \& cGMP & Erythro 9-(2-hydroxy 3-nonyl)adenine & $\begin{array}{l}\text { Protein: activity }{ }^{\circ} \\
\text { mRNA: RT PCR }\end{array}$ \\
\hline $\mathrm{PDE}_{3}$ & cAMP \& cGMP & $\begin{array}{l}\text { Cilostamide, milrinone, zardaverine, } \\
\text { olprinone, cilostazol, quazinone, } \\
\text { siguazodan }\end{array}$ & $\begin{array}{l}\text { Protein: activity }{ }^{90} \\
\text { mRNA: RT PCR }\end{array}$ \\
\hline $\mathrm{PDE}_{4}$ & cAMP & $\begin{array}{l}\text { Rolipram, Ro } 20 \text { 1724, piclamilast, } \\
\text { zardaverine, cilomilast, roflumilast }\end{array}$ & $\begin{array}{l}\text { Protein: activity }{ }^{\circ} \\
\text { mRNA: RT PCR }{ }^{36}\end{array}$ \\
\hline $\mathrm{PDE}_{5}$ & cGMP & $\begin{array}{l}\text { Zaprinast [130 nM], sildenafil, } \\
\text { vardenafil, tadalafil, E4O21, } \\
\text { morpholinosulphonyl-prazolopyrimidine, } \\
\text { dipyridamole }\end{array}$ & $\begin{array}{l}\text { Protein: IHC, }{ }^{103,32} \text { activity, }{ }^{90} \mathrm{WB}^{104} \\
\text { mRNA: RT PCR, }, 36,103,104 \mathrm{NB}^{37}\end{array}$ \\
\hline PDE6 & cGMP & $\begin{array}{l}\text { Zaprinast [400 nM], dipyridamole } \\
{[125 \mathrm{nM}] \text {, sildenafil }}\end{array}$ & Not determined \\
\hline PDE7 & cAMP & MIX, dipyridamole [6oo nM] & mRNA: RT PCR ${ }^{36}$ \\
\hline PDE8 & cAMP & Dipyridamole $[9 \mu \mathrm{M}]$ & mRNA: RT PCR ${ }^{36}$ \\
\hline PDEg & cGMP & Zaprinast [35 $\mu \mathrm{M}]$ & $\begin{array}{l}\text { Protein: } \text { IHC }^{35} \\
\text { mRNA: RT PCR }\end{array}$ \\
\hline PDE10 & cAMP \& cGMP & Dipyridamole [1 $\mu \mathrm{M}]$ & Not determined \\
\hline PDE11 & cAMP \& cGMP & $\begin{array}{l}\text { Zaprinast [12 } \mu \mathrm{M}] \text {, dipyridamole } \\
{[400 \mathrm{nM}] \text {, tadalafil }}\end{array}$ & Not determined \\
\hline
\end{tabular}

*mRNA was identified by either NB or RT PCR. Protein was identified by measuring enzyme activity (degradation of cyclic nucleotides), WB or IHC. IBMX-insensitive.

Abbreviations: IBMX, 3 isobutyl 1-methylxanthine (a non-selective competitive PDE inhibitor); IHC, immunohistochemistry; Ki, inhibitor binding activity (if known); NB, northern blot; PDE, phosphodiesterase; RT PCR, reverse transcription polymerase chain reaction; WB, western blot. 


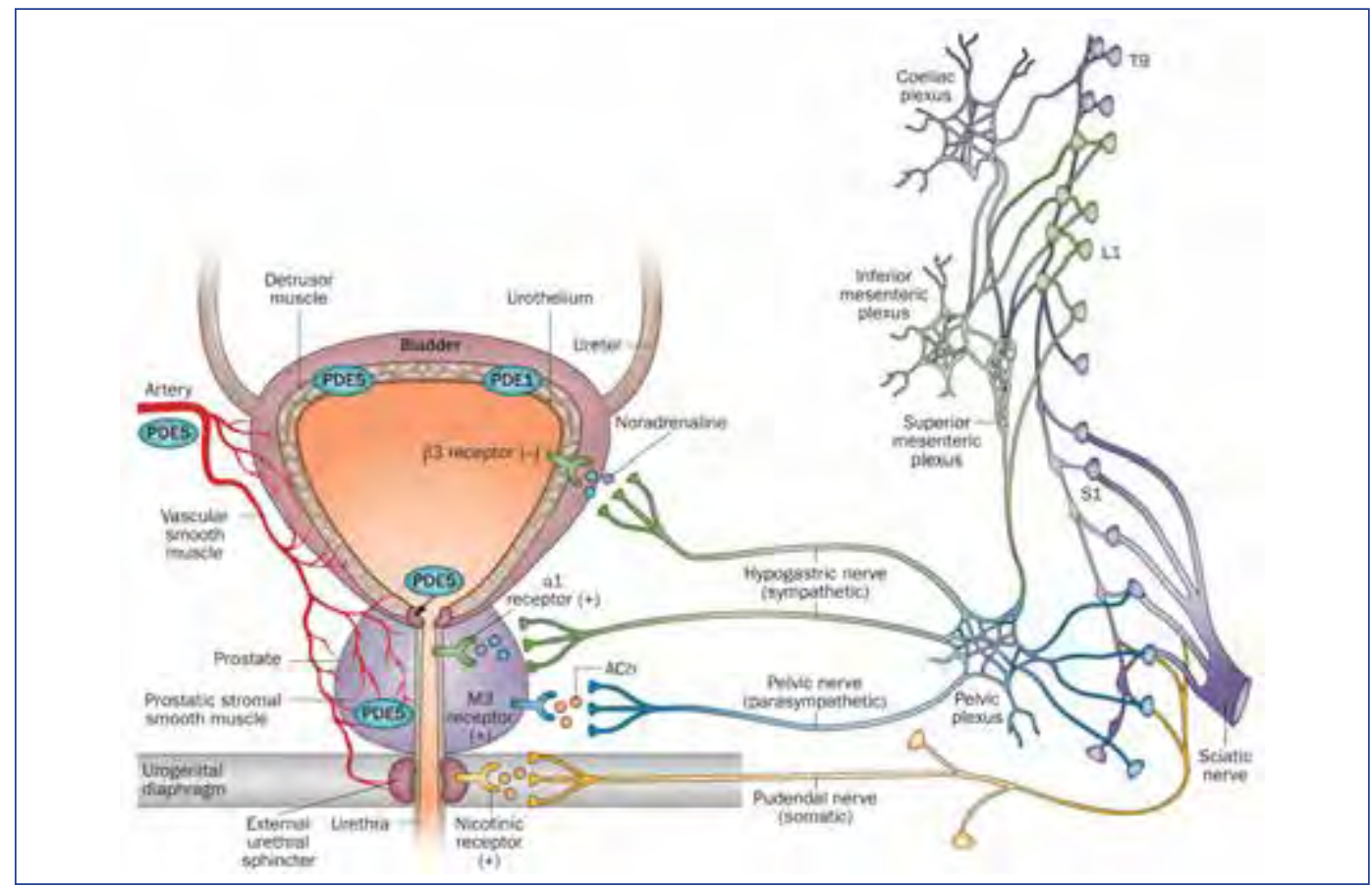

Figure 3. Phosphodiesterases and innervation in the male lower urinary tract. Sympathetic fibres (blue) originate in T11-L2 and extend through the inferior mesenteric ganglia and hypogastric nerve or the paravertebral chain to enter the pelvic nerves at the base of the bladder and urethra. Parasympathetic preganglionic fibres (green) originating in $\mathrm{S}_{2}-\mathrm{S}_{4}$ extend through the pelvic nerves to ganglia in the pelvic plexus and bladder wall, where the postganglionic nerves that supply parasympathetic innervation to the bladder arise. Somatic motor nerves (yellow) supplying the striated muscle of the external urethral sphincter arise from $\mathrm{S}_{2}-\mathrm{S}_{4}$ motor neurons that extend through the pudendal nerve. Parasympathetic postganglionic axons in the pelvic nerve release acetylcholine, which produces bladder contractions by stimulating $\mathrm{M}_{3}$ muscarinic receptors in bladder smooth muscle. Sympathetic postganglionic neurons release noradrenaline, which activates $\beta_{3}$ adrenergic receptors to relax bladder smooth muscle and activates $\alpha_{1}$ adrenergic receptors to contract urethral smooth muscle. Somatic axons in the pudendal nerve also release acetylcholine, which contracts the external sphincter striated muscle by activating nicotinic cholinergic receptors. Parasympathetic postganglionic nerves also release ATP, which excites bladder smooth muscle, and nitric oxide, which relaxes urethral smooth muscle (not shown). The distribution of PDE1 and PDE5 enzyme in the lower urinary tract is indicated. Abbreviations: IMP, inferior mesenteric plexus; L, lumbar root; S, sacral root; SHP, superior hypogastric plexus; SN, sciatic nerve; T, thoracic root.

Permission obtained from Nature Publishing Group (C) C.J. Fowler et al. The neural control of micturition. Nat. Rev. Neurosci. 9, 453-466 (2008). 


\section{PDE expression in the bladder}

Various PDE subtypes have been identified in both animal and human bladders. PDE5 is expressed in the rat bladder, where its expression and activity are both thought to be regulated by testosterone. ${ }^{31}$ PDE5 is also present in guinea pig urothelium, suburothelial interstitial cells and bladder blood vessels, as demonstrated in studies that revealed these tissues (rather than bladder nerve fibres) to be the site of action of the PDE5 inhibitor, vardenafili32. In rabbits and humans, detrusor smooth muscle in the dome and lateral walls of the bladder express PDEs 1-533-35. Furthermore, mRNAs encoding PDEs 7-9 and 15 are detectable by RT-PCR in the human bladder, and PDE1 and PDEg are expressed in human urothelium. Finally, the presence and activity of PDEs $1-5$ have also been demonstrated in the human bladder by biochemical assays and immunohistochemistry (table 1$)^{34-37}$.

\section{Urological effects of PDE inhibitors}

The effects of several PDE inhibitors have been studied in many preclinical and clinical contexts, both in vitro and in vivo. However, to date, no published functional studies using isolated urinary bladder tissue have assessed inhibitors of PDE3 or PDEs 6-11.

\section{Preclinical studies}

\section{PDE1 inhibition}

The PDE inhibitor vinpocetine (the only such agent currently approved for clinical use) elicits relaxation of rabbit detrusor muscle, despite producing no detectable changes in CAMP or CGMP levels ${ }^{38}$. However, a subsequent study showed that PDE 1 inhibition with 8-methoxymethyl-3-isobutyl1-methylxanthine relaxes guinea pig detrusor smooth muscle by raising cellular cAMP level ${ }^{39}$. In vitro studies using pig detrusor smooth muscle also suggest that PDE1 (which is stimulated by $\mathrm{Ca}^{2+}$ and calmodulin) has major functional importance in regulating hydrolysis of cAMP. ${ }^{40}$ Moreover, isolated human detrusor strips contracted by carbachol, an antagonist of muscarinic acetylcholine receptors, relax in the presence of either papaverine, a nonspecific PDE inhibitor, or vinpocetine. Relaxation was accompanied by an increase in tissue cAMP and cGMP levels ${ }^{41}$.

\section{PDE2 inhibition}

PDE2 inhibition has only been studied in the context of the bladder in amphibians. Blocking PDE2 activity using erythro-9-[2-hydroxy-3-nonyl]adenine had no effect on nitric-oxide-mediated inhibition of an arginine-vasotocin-induced increase in the osmotic water permeability of excised frog bladders, showing that PDE2 is present ${ }^{42}$. 


\section{PDE4 inhibition}

$\mathrm{PDE}_{4}$ is thought to be involved in the degradation of intracellular CAMP, which mediates phasic contractions in the bladder ${ }^{22}$. In rabbit detrusor muscles, cAMP levels rose significantly in response to PDE4 inhibition using rolipram, but this agent only elicited a moderate relaxation effect ${ }^{38}$. In human detrusor strips, however, PDE4 inhibition has a moderate relaxing effect on carbachol-induced contraction. This effect was increased in strips that were not devoid of urothelium, where nitric oxide is produced, suggesting that nitric oxide signalling potentiates this effect of PDE 4 inhibition. An enhancement of this bladder-relaxing effect of rolipram was also seen in response to administration of the adenylyl cyclase activator, forskolin, which increases intracellular CAMP levels ${ }^{43}$.

In a rat urethral ligation model of bladder outlet obstruction (BOO), PDE4 inhibition with IC486051 decreased the frequency and amplitude of nonvoiding contractions and suppressed bladder overactivity ${ }^{44}$. urthermore, PDE4 inhibition with YM976 attenuated the development of cyclophosphamide-induced haemorrhagic cystitis ${ }^{45}$. Treatment with this agent also improved voiding behaviour and reduced histological damage in rats with cystitis (induced by instillation of hydrochloric acid) ${ }^{45}$. Additionally, inhibition of PDE4 with rolipram decreased the amplitude, frequency and strength (represented by the area under the time-contraction amplitude curve) of nonvoiding contractions in cyclophosphamide-treated rats, at doses that had no effect on carbachol-induced phasic bladder contractions and cystometric parameters ${ }^{46}$. In guinea pig studies, bladder strips contracted by electrical-field stimulation could be relaxed by treatment with rolipram, which also suppressed the contractile response to low concentrations of carbachol and potentiated the contractile response to high concentrations of this agent ${ }^{47}$. The mechanism underlying this potentiating effect of rolipram on bladder contractions induced by high-dose carbachol is not currently known. Furthermore, cAMP decreased mechanisms that influence the frequency of agonist-induced phasic activity in isolated guinea pig bladders ${ }^{47}$. Overall, these observations suggest that PDE4 inhibition has a moderate muscle-relaxing effect in the bladder.

\section{PDE5 inhibition}

The most widely studied PDE inhibitors in bladder pathophysiology are those that target CGMPspecific PDE5. Vardenafil increases nitric oxide signalling, potentiates bladder relaxation and inhibits bladder smooth muscle proliferation, as well as decreasing nonvoiding contractions in rats with $\mathrm{BOO}^{31}$. Vardenafil also attenuated the contractions induced by carbachol as well as those induced by electrical-field stimulation in detrusor preparations with and without urothelium..$^{8}$ Similar effects were seen in full-thickness bladder-wall preparations (which included urothelium) from rats with a partial urethral obstruction ${ }^{48}$.

Intra-arterial administration of udenafil to rats prolonged both bladder intercontraction intervals and the duration of urethral relaxation observed during high-frequency oscillations in urethral contractions ${ }^{49}$. $n$ anaesthetized, decerebrated rats with neurogenic detrusor overactivity resulting from spinal cord injury, vardenafil attenuated the increase in bladder afferent nerve firing and also 
reduced the frequency of nonvoiding contractions ${ }^{50}$. Once-daily vardenafil treatment reduces detrusor overactivity ${ }^{51}$ and significantly reduces the expression of hypoxia markers ${ }^{52}$ in the bladders of spontaneously hypersensitive rats (a model of $O A B$ ). These findings suggest that in addition to relaxation of bladder muscle, PDE5 inhibition can increase blood perfusion of the bladder ${ }^{52}$. By contrast, chronic vardenafil treatment increased the contractile force exerted in isolated strips of muscle from normal rat bladders ${ }^{53}$. In spontaneously hypertensive rats, the inhibitory effect of vardenafil on increased bladder contractility is thought to be partially mediated by cGMP-dependent inhibition of RhoA-Rho kinase signalling54.

Nitric oxide-cGMP signalling is presumed to predominantly activate sensory rather than motor components of the micturition reflex ${ }^{55}$. Indeed, systemic administration of the PDE5 inhibitor, tadalafil, reduced the activity of mechanosensitive afferent $A \delta$ and $C$ fibres elicited by mechanical distention of rat bladder in vivo. Another study demonstrated that tadalafil inhibits the increase in activities of both $A \delta$ and $C$ fibres induced by intravesical instillation of the irritant, acrolein ${ }^{56}$. In isolated guinea pig detrusor muscle tissue, sildenafil inhibited spontaneous contractions in multiple-bundle preparations, but not in single-bundle preparations. This observation suggests that the contraction-inhibiting effect of PDE5 inhibition is due to a decrease in synchronicity between functional units of muscle bundles rather than the direct inhibition of smooth muscle contractility ${ }^{57}$. In addition, the researchers showed that nitric oxide enhanced the spontaneous contractions observed in isolated guinea pig detrusor smooth muscle. The mechanism underlying enhancement of spontaneous contractions by nitric oxide is thought to be cGMP-independent, and possibly $\mathrm{Ca}^{2+}$-related (fgure 1) ${ }^{57}$. Chronic treatment with a high dose of vardenafil protected rat bladders from BOO-induced contractile dysfunction, as shown by attenuation of the stimulatory effect of carbachol ${ }^{8}$. In a rat model of benign prostatic hyperplasia (BPH), treatment with udenafil decreased urethral pressure ${ }^{59}$. Sildenafil decreases detrusor overactivity in a mouse model of $\mathrm{BOO}$, and urodynamic as well as histological differences were seen between treated and untreated animals ${ }^{60}$. Furthermore, sildenafil treatment induced the relaxation of bladder neck smooth muscle in vitro, suggesting that this agent might be useful for improving LUTS associated with $\mathrm{BPH}^{61}$.

A different PDE5 inhibitor, zaprinast, had no effect on the contractile response of guinea-pig bladder strips to electrical-field stimulation, ATP or potassium chloride. However, zaprinast did suppress the contractile response to low concentrations of carbachol, and potentiated the response to a high concentration in bladder strips (as was also observed with the PDE4 inhibitor, rolipram, noted above $)^{47}$. In strips of rabbit detrusor, sildenafil increased cGMP levels and had a relaxation effect on carbachol-contracted muscle ${ }^{38}$, similarly, treatment with udenafil reversed (in a dosedependent manner, such that the relaxation effect increased with increasing udenafil dose) the tonic contraction of isolated rabbit bladder and urethra strip preparations ${ }^{49}$.

In vitro data describing the effects of PDE 5 inhibition on human bladder tissue are scarce. However, sildenafil relaxed carbachol-contracted detrusor strips obtained from patients without OAB who underwent cystatectomy for bladder cancer ${ }^{62}$. This effect was not altered by the presence of nitric 
oxide donors, but was significantly attenuated by inhibition of either guanylyl or adenylyl cyclases ${ }^{62}$. In another study, exposure of isolated human detrusor smooth muscle to low concentrations of the nitric oxide donor, sodium nitroprusside, significantly increased the mean attenuation of muscle contraction induced by the PDE 5 inhibitor MY 5,445, as well as that induced by the PDE1 inhibitor vinpocetine and the PDE4 inhibitor rolipram ${ }^{63}$. An enhancement in the potency of all three drugs was also registered in the presence of sodium nitroprusside ${ }^{63}$. Interestingly, however, sodium nitroprusside did not significantly affect the maximum attenuation of muscle contraction brought about by sildenafil in this study ${ }^{63}$. The researchers concluded from these findings that relaxation of human detrusor smooth muscle strips in response to PDE5 inhibition is mediated by both cGMP and cAMP signalling pathways ${ }^{62,63}$. However, the contribution of nitric oxide to this mechanism remains to be elucidated. Overall, we can conclude that PDE 5 inhibition has a relaxing effect on the bladder.

\section{Clinical data}

Currently, PDE1 and PDE 5 inhibitors are the only two families of agents used in the management of storage and voiding disorders in humans (table 2).

\section{PDE1 inhibitors}

Initial data from a randomized, double-blind, placebo-controlled trial of vinpocetine in patients with various forms of voiding dysfunction who had not responded to standard antimuscarinic therapy indicate a possible role for this agent in the treatment of urgency and urge incontinence (and, possibly, poor bladder compliance as well as interstitial cystitis) in both men and women ${ }^{64,65}$. Results from a large randomized, double-blind, placebo-controlled, multicentre trial of vinpocetine show a trend towards superiority of vinpocetine over placebo, although a statistically significant result has been documented only for one parameter, namely micturition frequency ${ }^{65}$. This lack of positive results might be due to the low dose of vinpocetine used ( $20 \mathrm{mg}$ once daily) and limited number of participants (62 patients) ${ }^{65}$.

\section{PDE5 inhibitors}

No studies have been conducted on the use of PDE5 inhibitors in women with or without LUTS. However, a number of trials have assessed the effects of PDE 5 inhibitors in men with erectile dysfunction accompanied by LUTS. PDE 5 inhibitors are widely used in the treatment of erectile dysfunction, and have been suggested to be of potential utility in the preservation of penile smooth muscle and rehabilitation of erectile function after radical prostatectomy ${ }^{66,67}$. Moreover, PDE inhibitors might also counteract ejaculatory delay arising as an adverse effect of antidepressant therapy with a 5-hydroxytryptamine reuptake inhibitor ${ }^{17}$. In the search for new treatment options to improve symptoms related to storage and voiding disorders, including LUTS, OAB and detrusor overactivity, the clinical effects of PDE inhibition on urinary symptoms have gained increasing 
interest ${ }^{68,69}$. Many studies have demonstrated a positive effect of PDE5 inhibitors on mild to moderate LUTS in men ${ }^{70-83}$. The pathophysiology of LUTS is complex and likely to be influenced by multiple factors; increasing the activity of the nitric oxide-cGMP pathway through PDE5 inhibition might, therefore, affect various pathological mechanisms (figure 3 ). The effects of PDE5 inhibition are presumed (although not yet proven) to be mediated through relaxation of smooth muscle in the bladder neck and/or prostate. In many studies, treatment with $\mathrm{PDE}_{5}$ inhibitors is associated with enhanced smooth muscle relaxation, proliferation of endothelial and smooth muscle cells, and increased nerve activity and tissue perfusion, and all these factors could have a beneficial effect on LUTS in men ${ }^{70}$. The use of individual agents is discussed in more detail below.

\section{Sildenafil}

Sildenafil monotherapy significantly improves international prostate symptom scores (IPSSs) and quality of life (QoL) scores in men with both erectile dysfunction and LUTS ${ }^{72}$. In total, IPSSs improved in $60 \%$ of patients, and $35 \%$ had an IPSS improvement of at least four points ${ }^{72}$. Another group reported that LUTS scores significantly improved in all 189 men with erectile dysfunction and moderate to severe LUTS due to $\mathrm{BPH}$ who were receiving sildenafil, and this improvement was independent of baseline BMI ${ }^{71}$. Moreover, the improvement in IPSS observed with sildenafil treatment was greater in men with severe LUTS than in men with moderate LUTS ${ }^{71}$. The same researchers also confirmed the positive effect of 12 weeks of treatment with sildenafil on both LUTS and erectile dysfunction ${ }^{74}$. Finally, in a further randomized study, men with previously untreated LUTS and erectile dysfunction received the $\alpha_{1}$ receptor antagonist alfuzosin, sildenafil, or a combination of both compounds for 12 weeks. Patients in all three groups experienced a significant improvement in IPSS, but the effect was most pronounced in the combination-therapy group ${ }^{78}$.

\section{Tadalafil}

A single oral dose of tadalafil can exert significant positive effects on urodynamic parameters in patients with neurogenic bladder dysfunction associated with suprasacral spinal cord injury ${ }^{81}$. A placebo-controlled, double-blind trial of tadalafil in 281 men with erectile dysfunction and LUTS provided evidence that this agent is also effective in the treatment of LUTS secondary to BPH; however, the treated patients did not show significant changes in uroflowmetry findings ${ }^{73}$. In addition, a multicentre trial in 200 men with LUTS and BPH, both with and without BOO, compared tadalafil $20 \mathrm{mg}$ once daily to placebo. After 12 weeks of treatment, no significant changes in bladder function (detrusor pressure at maximum urinary flow rate) or any other urodynamic parameter were seen. Interestingly, however, the men receiving tadalafil still had significant improvements in IPSS ${ }^{84}$. A few trials have also compared the effectiveness of PDE 5 inhibitors with that of $\alpha$-blockers or antimuscarinic agents, or a combination of the two. In patients with erectile dysfunction and urinary storage symptoms after surgical treatment for LUTS due to BPH, a $5 \mathrm{mg}$ dose of tadalafil given once daily for 12 weeks improved IPSSs, and this benefit was equivalent to that seen in men treated with the 
antimuscarinic agent solifenacin ( $5 \mathrm{mg}$, given for the same period of time) ${ }^{77}$. A crossover study of 30 men aged $>50$ years with LUTS secondary to $\mathrm{BPH}$ also demonstrated that tadalafil given in combination with the $\alpha$-blocker tamsulosin was superior to tamsulosin treatment alone ${ }^{79}$. The long-term benefits of tadalafil treatment were also investigated in a 1-year open-label study in men with LUTS due to BPH, which showed that $5 \mathrm{mg}$ of tadalafil once daily was well tolerated, and that the efficacy of this treatment was maintained ${ }^{85}$. Following these studies, once-daily $5 \mathrm{mg}$ tadalafil was approved by the FDA for use in men with LUTS secondary to BPH (with or without erectile dysfunction).

\section{Vardenafil}

Vardenafil also improves LUTS in men. A study conducted in 39 patients with prostate cancer who had undergone bilateral nerve-sparing radical prostatectomy demonstrated that vardenafil treatment was associated with improved continence recovery compared with placebo ${ }^{86}$. Moreover, vardenafil significantly improved LUTS, erectile dysfunction and QoL in a cohort of 222 men with BPH and LUTS, and these improvements occurred as early as 8 weeks after initiation of this treatment ${ }^{75}$. The efficacy of a single dose of vardenafil was also assessed in a trial of 25 male patients with micturition disorders secondary to spinal cord injury, who were also taking the anticholinergic and antimuscarinic agent, oxybutynin. Vardenafil significantly decreased maximum detrusor pressure, improved maximum cystometric capacity, and increased bladder volume at first detection of detrusor overactivity ${ }^{77}$. As for tadalafil, the effect of a combination of vardenafil and the $\alpha$-blocker tamsulosin was superior to that of tamsulosin alone ${ }^{80}$.

\section{UK-369,003}

In 418 men with LUTS and BPH, 12 weeks of treatment with UK-369,003 resulted in a significant improvement in IPSS from baseline, compared to placebo. The researchers noted that increasing the drug dose from $100 \mathrm{mg}$ to $400 \mathrm{mg}$ increased the efficacy of this treatment ${ }^{82}$. The use of PDE5 inhibitors to treat patients with OAB has only been studied in a single multicentre trial of UK-369,003 in 310 consecutive male patients. This treatment improved the patients' IPSSs, and improvements in the voiding and storage subscores of the IPSS were similar to those in overall IPSSs. However, no significant alterations were seen in voiding frequency, mean voided volume, urgency episode frequency or nocturia frequency in this study, at any dose of UK-369,003 (10 mg, $25 \mathrm{mg}, 50 \mathrm{mg}$ or $100 \mathrm{mg})^{83}$.

\section{Interpretation of the clinical data}

Increases in CAMP levels in the smooth muscles of the lower urinary tract are thought to have an important role in bladder relaxation. The results of studies of several agents that target the CAMPproducing adenylyl cyclases show that relaxation of bladder smooth muscle correlated with an

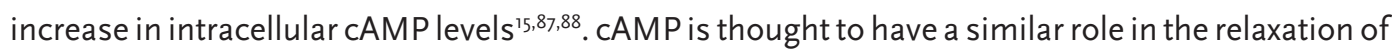
human detrusor smooth muscle, which suggests that the cAMP signalling pathway might be of the 
utmost importance in the regulation of detrusor muscle tone ${ }^{65}$. Specific regulation of intracellular signalling pathways that utilize cAMP and cGMP seems to offer a promising route to achieve selective modulation of urinary function, through modulation of either bladder afferent (sensory) signals or the contraction and relaxation of urinary bladder smooth musculature. Moreover, the use of selective inhibitors of the PDE isoenzymes present in the bladder might ensure a degree of organ selectivity, as both the distribution and function of PDE isoenzymes vary'5,89.

The available data indicate that PDE 1 and PDE 5 represent interesting potential targets in lower urinary tract pathology. Firstly, $\mathrm{PDE} 1$ is expressed and functionally active in human urinary bladder tissue and, in vitro, the $\mathrm{PDE} 1$ inhibitor vinpocetine can reverse the contraction of bladder strips induced by muscarinic signalling. Relaxation was associated with an increase in tissue levels of both cAMP and CGMP in these studies $33,34,36,41,90$. Both preclinical and clinical studies show that PDE1 inhibition relaxes detrusor smooth muscle and benefits patients with $\mathrm{OAB}$ and poor bladder compliance ${ }^{64,65}$. However, to date, only one study of PDE 1 inhibition has been conducted, in a limited number of male patients, although it did report positive findings, as discussed above ${ }^{65}$. The identification of appropriate, individualized treatment strategies for $O A B$ in both men and women is, however, impeded by the apparent heterogeneity of its underlying pathophysiology. It is difficult, if not impossible, to subdivide the $O A B$ population into categories of either disease or patient characteristics to determine which subgroups are most likely to derive benefit from any given treatment ${ }^{23}$.

Secondly, inhibition of the PDE 5 isoenzyme induces relaxation of human detrusor smooth muscle ${ }^{62}$. Although functional studies in human bladders are limited, animal studies and clinical trials indicate that increasing CGMP levels by means of PDE 5 inhibition might be beneficial in the treatment of patients with conditions such as LUTS, OAB and detrusor overactivity. 15,92 Numerous clinical trials in male patients with LUTS secondary to $\mathrm{BPH}$ have investigated the safety and efficacy of the PDE 5 inhibitors sildenafil, ${ }^{71-74,78,92}$ tadalafil73,77,81 and vardenafil, 75 both alone and in combination with the $\alpha$-adrenoceptor antagonists tamsolusin and alfuzosin ${ }^{78}$. Overall, treatment with these three PDE5 inhibitors resulted in a significant improvement in LUTS, expressed as increases in IPSS and QoL scores. Although some studies did not report any changes in urodynamic parameters associated with PDE5-inhibitor therapy, others demonstrated increased maximum urine flow rate during the treatment period $23,73,84,93-95$. Moreover, no differences were noted between placebo and treatment groups when assessing storage symptoms and voiding parameters, namely sensory perception, poor bladder compliance, voided volume and postvoid residual volume ${ }^{23}$. Thus, although PDE5 inhibitors improve LUTS, we currently don't know how exactly they work. On the basis of current evidence, however, $\mathrm{PDE}_{5}$ inhibitors seem to be a promising alternative (or at least, an adjunct) to treatment with $\alpha$-blockers to relieve the symptoms of storage and voiding dysfunction, particularly in men with $\mathrm{BPH}$ (with or without erectile dysfunction). A meta-analysis of 107 articles also concluded that PDE5 inhibition significantly improves both LUTS and erectile dysfunction in men with $\mathrm{BPH}^{96}$. 
Table 2. Clinical trials evaluating the efficacy of selective PDE inhibitors in the treatment of storage and voiding dysfunction.

\begin{tabular}{|c|c|c|c|c|c|c|}
\hline Study & Study design & Inhibitor* & Comparator group & $n t$ & T-duration & Clinical effects \\
\hline Truss et al. $(2001)^{65}$ & Double-blind RCT & Vinpocetine & Placebo & 68 & 4 weeks & $\begin{array}{l}\text { Reduced micturition } \\
\text { frequency }\end{array}$ \\
\hline Mulhall et al. $(2006)^{72}$ & $\begin{array}{l}\text { Comparative } \\
\text { questionnaire }\end{array}$ & Sildenafil & $\begin{array}{l}\text { Pretreatment versus } \\
\text { post-treatment }\end{array}$ & 48 & 3 months & $\begin{array}{l}\text { Improved IPSS } \\
\text { and QoL }\end{array}$ \\
\hline McVary et al. $(2007)^{71,74}$ & Double-blind RCT & Sildenafil & Placebo & $189^{5}$ & 12 weeks & Improved IPSS \\
\hline Kaplan et al. $(2007)^{78}$ & $\begin{array}{l}\text { Randomized } \\
\text { parallel group }\end{array}$ & $\begin{array}{l}\text { Alfuzosin + } \\
\text { sildenafil }\end{array}$ & Alfuzosin & 41 & 12 weeks & Improved IPSS \\
\hline McVary et al. $(2007)^{73}$ & $\begin{array}{l}\text { Placebo-controlled, } \\
\text { double-blind }\end{array}$ & Tadalafil & Placebo & 281 & 12 weeks & Improved IPSS \\
\hline $\begin{array}{l}\text { Dmochowski et al. } \\
(2010)^{84}\end{array}$ & $\begin{array}{l}\text { Muticentre double- } \\
\text { blind RCT }\end{array}$ & Tadalafil & Placebo & 200 & 12 weeks & $\begin{array}{l}\text { Improved IPSS } \\
\text { No effect on MVP }\end{array}$ \\
\hline Taie et al. $(2010)^{81}$ & Cohort study & Tadalafil & $\begin{array}{l}\text { Urodynamics pre- } \\
\text { and post treatment }\end{array}$ & 20 & Single dose & $\begin{array}{l}\text { Improved bladder } \\
\text { compliance, MBC, } \\
\text { MVP and MFP }\end{array}$ \\
\hline Maselli, et al. $(2011)^{77}$ & Parallel-group & Tadalafil & Solifenacin & 25 & 12 weeks & $\begin{array}{l}\text { Similar IPSS } \\
\text { improvements in } \\
\text { both groups }\end{array}$ \\
\hline Donatucci et al. $(2011)^{85}$ & $\begin{array}{l}\text { Open-label, extension } \\
\text { of dose-finding study }\end{array}$ & Tadalafil & None & 427 & 1 year & $\begin{array}{l}\text { Safety and sustained } \\
\text { improvements in } \\
\text { IPSS, QoL }\end{array}$ \\
\hline Bechara et al. $(2008)^{79}$ & $\begin{array}{l}\text { Double-blind, } \\
\text { randomized } \\
\text { crossover }\end{array}$ & $\begin{array}{l}\text { Tadalafil } \\
+ \text { tamsolusin }\end{array}$ & Tamsolusin & 27 & 45 days & $\begin{array}{l}\text { Improved IPSSQmax, } \\
\text { QoL, and reduced } \\
\text { post residual volume }\end{array}$ \\
\hline Gacci et al. $(2007)^{76}$ & $\begin{array}{l}\text { Single-centre, } \\
\text { double-blind RCT }\end{array}$ & Vardenafil & Placebo & 25 & Single dose & Improved MFP, MBC \\
\hline Stief et al. $(2008)^{75}$ & $\begin{array}{l}\text { Placebo-controlled } \\
\text { RCT }\end{array}$ & Vardenafil & Placebo & 222 & 8 weeks & $\begin{array}{l}\text { Improved IPSS, } \\
\text { erectile dysfunction } \\
\text { and QoL }\end{array}$ \\
\hline Gacci et al. $(2012)^{80}$ & $\begin{array}{l}\text { Placebo controlled } \\
\text { RCT }\end{array}$ & $\begin{array}{l}\text { Vardenafil } \\
+ \text { tamsolusin }\end{array}$ & Tamsolusin & 60 & 12 weeks & $\begin{array}{l}\text { Improved IPSS } \\
\text { and Qmax }\end{array}$ \\
\hline Giuliano et al. $(2010)^{83}$ & $\begin{array}{l}\text { Multicentre, } \\
\text { double-blind, } \\
\text { placebo-controlled, } \\
\text { parallel-group }\end{array}$ & UK 369,003 & $\begin{array}{l}10,25,50 \mathrm{mg} \\
\text { or } 100 \mathrm{mg} \\
\text { versus placebo }\end{array}$ & 310 & 12 weeks & No significant effects \\
\hline Tamimi et al. $(2010)^{82}$ & $\begin{array}{l}\text { Multicentre, } \\
\text { double-blind, } \\
\text { placebo controlled }\end{array}$ & UK $_{3} 69,003$ & $\begin{array}{l}10,25,50 \text { or } \\
100 \mathrm{mg} \text {, versus } \\
40 \mathrm{mg} \text { immediate- } \\
\text { release tamsulosin } \\
0.4 \mathrm{mg} \text { or placebo }\end{array}$ & 418 & 12 weeks & $\begin{array}{l}\text { Improved IPSS, which } \\
\text { increased with } \\
\text { increasing dose }\end{array}$ \\
\hline
\end{tabular}

*All agents listed are PDE5 inhibitors, except for vinpocetine, which is a PDE1 inhibitor. except where noted. \$Number who received PDE inhibitors. Abbreviations: IPSS, international prostate symptom score; MBC, maximum bladder capacity; MFP, maximum filling pressure; MVP, maximum voiding pressure; $n$, number of patients; Qmax, maximum urinary flow rate; $\mathrm{Q} o \mathrm{~L}$, quality of life; RCT, randomized controlled trial; T-duration, Treatment Duration. 


\section{Future perspectives}

Additional, large-scale, well-designed trials are needed to assess whether PDE1 inhibitors might be useful in the future as a standard therapy for LUTS or OAB in both male and female patients. On the basis of results from preclinical studies, PDE4 inhibitors might also be an interesting tool to treat storage and voiding symptoms in humans ${ }^{38,43-47,97,98}$. Some PDE4 inhibitors, such as rolipram and roflumilast, are already being investigated in clinical trials, as treatments for mental health disorders and pulmonary diseases. In the case of PDE 5 inhibitors, although some evidence suggests that these agents are safe and effective in male patients with LUTS ${ }^{14,70-83,85,99,100}$, their use in women with storage and voiding symptoms (specifically urgency, urgency incontinence and $O A B$ ) remains to be explored. In the meantime, the promising results for combinations of PDE 5 inhibitors with either $\alpha$-blockers or anticholinergic agents in patients with OAB might in the future add to the current armamentarium of drug treatments for such individuals.

\section{Conclusions}

The importance of the CGMP and cAMP pathways in the control of bladder function has been demonstrated in many in vitro and in vivo studies. PDEs hydrolyse CAMP and CGMP, and PDEs 7-9 and 15 are expressed in the human urinary bladder. Consequently, a number of selective PDE inhibitors have been investigated for use in the management of patients with LUTS and OAB. To date, however, only inhibitors of PDE1 and PDE5 have been studied in a clinical setting for the treatment of storage and voiding disorders. Such studies provided only limited evidence that PDE1 inhibition could improve the symptoms of $O A B$, whereas PDE 5 inhibition has been clearly shown to alleviate LUTS in male patients with and without BPH. Moreover, the combination of a PDE5 inhibitor and an $\alpha$-blocking agent had superior efficacy compared to monotherapy with either agent in this setting.

The role of PDE5 inhibitors in the management of $O A B$, however, remains to be investigated in adequate detail. Despite favourable findings in preclinical and clinical studies, a pivotal role for nitric oxide and CGMP-mediated and CAMP-mediated signalling in the control of urinary bladder function has yet to be convincingly demonstrated, and specifically which PDE (PDE1, PDE5 or a further, as yet uncharacterized, isoenzyme) is the most relevant to the regulation of bladder smooth muscle tone remains to be elucidated. In the current quest for improved treatment options for $O A B$, the available data point towards an important role for PDE inhibition in the pharmacological management of functional bladder disorders. 


\section{Box 1. Definitions of storage and voiding disorders}

\section{Lower urinary tract symptoms}

Defined as the subjective indicator of a disease or change in condition perceived by the patient, caregiver or partner that might lead them to seek help from health care professionals. Symptoms can either be volunteered or described during the patient interview, are usually qualitative, and cannot be used to make a definitive diagnosis. Symptoms can be divided into three groups:

- Storage symptoms - frequency, nocturia, urgency, urinary incontinence, stress incontinence, urge incontinence

- Voiding symptoms-slow stream, splitting or spraying, intermittent stream, hesitancy, straining

- Post micturition symptoms - feeling of incomplete emptying, postmicturition dribble

\section{Detrusor overactivity}

Defined as uncontrolled contractions of the detrusor muscle during bladder filling, seen on urodynamic measurements

\section{Overactive bladder syndrome}

Defined by symptoms of urge, with or without urge urinary incontinence, usually with frequency and nocturia. ${ }^{105}$ In about half of patients with $O A B$, detrusor overactivity can also be demonstrated; however, up to $50 \%$ of patients with detrusor overactivity do not report relevant clinical symptoms. ${ }^{106}$ 


\section{References}

1. Beavo, J.A. Cyclic nucleotide phosphodiesterases: functional implications of multiple isoforms. Physiological Reviews 75, 725-748 (1995).

2. Rybalkin, S.D., Yan, C., Bornfeldt, K.E. \& Beavo, J.A. Cyclic GMP phosphodiesterases and regulation of smooth muscle function. Circulation Research 93, 280-291 (2003).

3. Maurice, D.H., Palmer, D., Tilley, D.G., Dunkerley, H.A., Netherton, S.J., Raymond, D.R., Elbatarny, H.S. \& Jimmo, S.L. Cyclic nucleotide phosphodiesterase activity, expression, and targeting in cells of the cardiovascular system. Molecular Pharmacology 64, 533-546 (2003).

4. Kamenetsky, M., Middelhaufe, S., Bank, E.M., Levin, L.R., Buck, J. \& Steegborn, C. Molecular details of cAMP generation in mammalian cells: a tale of two systems. Journal of Molecular Biology 362, 623-639 (2006).

5. Dessauer, C.W. Adenylyl cyclase--A-kinase anchoring protein complexes: the next dimension in cAMP signaling. Molecular Pharmacology 76, 935-941 (2009).

6. Lucas, K.A., Pitari, G.M., Kazerounian, S., Ruiz-Stewart, I., Park, J., Schulz, S., Chepenik, K.P. \& Waldman, S.A.Guanylyl cyclases and signaling by cyclic GMP. Pharmacological Reviews 52, 375-414 (2000).

7. Moncada, S., Palmer, R.M. \& Higgs, E.A. Nitric oxide: physiology, pathophysiology, and pharmacology. Pharmacological Reviews 43, 109-142 (1991).

8. Andersson, K.E. \& Persson, K. Nitric oxide synthase and nitric oxide-mediated effects in lower urinary tract smooth muscles. World Journal of Urology 12, 274-280 (1994).

9. Andersson, K. E. \& Persson, K. Nitric oxide synthase and the lower urinary tract: possible implications for physiology and pathophysiology. Scandinavian Journal of Urology. Nephrology Supplement 175, 43-53 (1995).

10. Carvajal, J.A., Germain, A.M., Huidobro-Toro, J.P. \& Weiner, C.P. Molecular mechanism of cGMPmediated smooth muscle relaxation. Journal of Cellular Physiology 184, 409-420 (2000).

11. Uckert, S., Hedlund, P., Andersson, K.E., Truss, M.C., Jonas, U. \& Stief, C.G. Update on phosphodiesterase (PDE) isoenzymes as pharmacologic targets in urology: present and future. European Urology 50, 11941207; discussion 1207 (2006).

12. Gillespie, J.I. Phosphodiesterase-linked inhibition of non-micturition activity in the isolated bladder. British Journal of Urology International 93, 1325-1332 (2004).

13. Hanna-Mitchell, A.T. \& Birder, L.A. New insights into the pharmacology of the bladder. Current Opinion in Urology 18, 347-352 (2008).

14. Kedia, G.T., Uckert, S., Jonas, U., Kuczyk, M.A. \& Burchardt, M. The nitric oxide pathway in the human prostate: clinical implications in men with lower urinary tract symptoms. World Journal of Urology 26, 603-609 (2008).

15. Andersson, K.E., Uckert, S., Stief, C. \& Hedlund, P. Phosphodiesterases (PDEs) and PDE inhibitors for treatment of LUTS. Neurourology and Urodynamics 26, 928-933 (2007).

16. Uckert, S. \& Kuczyk, M.A. Cyclic nucleotide metabolism including nitric oxide and phosphodiesteraserelated targets in the lower urinary tract. Handbook of Experimental Pharmacology, 527-542 (2011). 
17. Montorsi, F., Corbin, J. \& Phillips, S. Review of phosphodiesterases in the urogenital system: new directions for therapeutic intervention. Journal of Sexual Medicine 1, 322-336 (2004).

18. Alm, P., Larsson, B., Ekblad, E., Sundler, F. \& Andersson, K.E. Immunohistochemical localization of peripheral nitric oxide synthase-containing nerves using antibodies raised against synthesized $\mathrm{C}$ - and $\mathrm{N}$-terminal fragments of a cloned enzyme from rat brain. Acta Physiologica Scandinavica 148, 421-429 (1993).

19. Birder, L.A., Apodaca, G., De Groat, W.C. \& Kanai, A.J. Adrenergic- and capsaicin-evoked nitric oxide release from urothelium and afferent nerves in urinary bladder. American Journal of Physiology 275, F226229 (1998).

20. Persson, K., Poljakovic, M., Johansson, K. \& Larsson, B. Morphological and biochemical investigation of nitric oxide synthase and related enzymes in the rat and pig urothelium. Journal of Histochemistry and Cytochemistry 47, 739-750 (1999).

21. Fujiwara, M., Andersson, K. \& Persson, K. Nitric oxide-induced cGMP accumulation in the mouse bladder is not related to smooth muscle relaxation. European Journal of Pharmacology 401, 241-250 (2000).

22. Persson, K., Pandita, R.K., Aszòdi, A., Ahmad, M., Pfeifer, A., Fässler, R. \& Andersson, K.E. Functional characteristics of urinary tract smooth muscles in mice lacking cGMP protein kinase type I. American Journal of Physiology. Regulatory, Integrative and Comparative Physiology 279, R1112-1120 (2000).

23. Kanai, A., Zabbarova, I., Oefelein, M., Radziszewski, P., Ikeda, Y. \& Andersson, K.E. Mechanisms of action of botulinum neurotoxins, beta3-adrenergic receptor agonists, and PDE5 inhibitors in modulating detrusor function in overactive bladders: ICI-RS 2011. Neurourology and Urodynamics 31, 300-308 (2012).

24. Uckert, S. \& Oelke, M. Phosphodiesterase (PDE) inhibitors in the treatment of lower urinary tract dysfunction. British Journal of Clinical Pharmacology 72, 197-204 (2011).

25. Essayan, D.M. Cyclic nucleotide phosphodiesterases. Journal of Allergy and Clinical Immunology 108, 671$680(2001)$.

26. Essayan, D.M. Cyclic nucleotide phosphodiesterase (PDE) inhibitors and immunomodulation. Biochemical Pharmacology 57, 965-973 (1999).

27. Soderling, S.H., Bayuga, S.J. \& Beavo, J.A. Cloning and characterization of a cAMP-specific cyclic nucleotide phosphodiesterase. Proceedings of National Academy of Science USA 95, 8991-8996 (1998).

28. Soderling, S.H., Bayuga, S.J. \& Beavo, J.A. Identification and characterization of a novel family of cyclic nucleotide phosphodiesterases. Journal of Biological Chemistry 273, 15553-15558 (1998).

29. Conti, M. \& Jin, S.L. The molecular biology of cyclic nucleotide phosphodiesterases. Progress in Nucleic Acid Research \& Molecular Biology 63, 1-38(1999).

30. Gupta, R., Kumar, G. \& Kumar, R.S. An update on cyclic nucleotide phosphodiesterase (PDE) inhibitors: phosphodiesterases and drug selectivity. Methods and Findings in Expeimental a Clinical Pharmacology 27, 101-118 (2005).

31. Filippi, S., Morelli, A., Sandner, P., Fibbi, B., Mancina, R., Marini, M., Gacci, M., Vignozzi, L., Vannelli, G.B., Carini, M., Forti, G., Maggi, M. Characterization and functional role of androgen-dependent PDE5 activity in the bladder. Endocrinology 148, 1019-1029 (2007). 
32. Rahnama'i, M. S., van Koeveringe, G.A., Hohnen, R., Ona, S., Van Kerrebroeck, Ph.E.V. \& de Wachter, S.G. Distribution of phosphodiesterase type $5\left(\mathrm{PDE}_{5}\right)$ in the lateral wall of the guinea pig urinary bladder. British Journal of Urology International http://dx.doi.org/10.1111/bju.12031 (2013).

33. Uckert, S., Sigl, K., Waldkirch, E,S., Sandner, P., Ulbrich, E., Oelke, M., Stief, C.G., Kuczyk, M.A. Significance of phosphodiesterase isoenzymes in the control of human detrusor smooth muscle function. An immunohistochemical and functional study. Urologe A 48, 764-769 (2009).

34. Morley, D.J., et al. Distribution of phosphodiesterase I in normal human tissues. Journal of Histochemistry and Cytochemistry 35, 75-82 (1987).

35. Nagasaki, S., Nakano, Y., Masuda, M., Ono, K., Miki, Y., Shibahara, Y. \& Sasano, H. Phosphodiesterase type 9 (PDE9) in the human lower urinary tract: an immunohistochemical study. British Journal of Urology International 109, 934-940 (2012).

36. Uckert, S., Kuthe, A., Jonas, U.\& Stief, C.G. Characterization and functional relevance of cyclic nucleotide phosphodiesterase isoenzymes of the human prostate. The Journal of Urology 166, 2484-2490 (2001).

37. Kuthe, A., Mägert, H., Uckert, S., Forssmann, W.G., Stief, C.G. \& Jonas, U. Gene expression of the phosphodiesterases 3A and 5 A in human corpus cavernosum penis. European Urology 38, 108-114 (2000).

38. Qiu, Y., Kraft, P., Craig, E.C., Liu, X. \& Haynes-Johnson, D. Cyclic nucleotide phosphodiesterases in rabbit detrusor smooth muscle. Urology 59, 145-149 (2002).

39. Xin, W., Soder, R.P., Cheng, Q., Rovner, E.S. \& Petkov, G.V. Selective inhibition of phosphodiesterase 1 relaxes urinary bladder smooth muscle: role for ryanodine receptor mediated BK channel activation. American Journal of Pysiology. Cell Physiology (2012).

40. Truss, M.C., Uckert, S., Stief, C.G., Kuczyk, M., Schulz-Knappe, P., Forssmann, W.G., \& Jonas U. Effects of various phosphodiesterase-inhibitors, forskolin, and sodium nitroprusside on porcine detrusor smooth muscle tonic responses to muscarinergic stimulation and cyclic nucleotide levels in vitro. Neurourology and Urodynamics 15, 59-70 (1996).

41. Truss, M.C., Uckert, S., Stief, C.G., Forssmann, W.G. \& Jonas, U. Cyclic nucleotide phosphodiesterase (PDE) isoenzymes in the human detrusor smooth muscle. II. Effect of various PDE inhibitors on smooth muscle tone and cyclic nucleotide levels in vitro. Urological Research 24, 129-134 (1996).

42. Fock, E.M., Lavrova, E.A., Bachteeva, V.T., Chernigovskaya, E.V. \& Parnova, R.G. Nitric oxide inhibits arginine-vasotocin-induced increase of water osmotic permeability in frog urinary bladder. Pflugers Archives 448, 197-203 (2004).

43. Oger, S., Behr-Roussel, D., Gorny, D., Denys, P., Lebret, T., Alexandre, L., \& Giuliano, F. Relaxation of phasic contractile activity of human detrusor strips by cyclic nucleotide phosphodiesterase type 4 inhibition. European Urology 51, 772-780; discussion 780-771 (2007).

44. Nishiguchi, J., Kwon, D.D., Kaiho, Y., Chancellor, M.B., Kumon, H., Snyder, P.B. \& Yoshimura, N. Suppression of detrusor overactivity in rats with bladder outlet obstruction by a type 4 phosphodiesterase inhibitor. British Journal of Urology International 99, 680-686 (2007).

45. Kitta, T., Tanaka, H., Mitsui, T., Moriya, K. \& Nonomura, K. Type 4 phosphodiesterase inhibitor suppresses experimental bladder inflammation. British Journal of Urology International 102, 1472-1476 (2008). 
46. Buyuknacar, H.S., Kumcu, E.K., Gocmen, C. \& Onder, S. Effect of phosphodiesterase type 4 inhibitor rolipram on cyclophosphamide-induced cystitis in rats. European Journal of Pharmacology 586, 293-299 (2008).

47. Longhurst, P.A., Briscoe, J.A., Rosenberg, D.J. \& Leggett, R.E. The role of cyclic nucleotides in guinea-pig bladder contractility. British Journal of Pharmacology 121, 1665-1672 (1997).

48. Werkstrom, V., Hedlund, P., Lee, T. \& Andersson, K.E. Vardenafil-induced relaxation and cyclic nucleotide levels in normal and obstructed rat urinary bladder. British Journal of Urology International 104, 1740-1745 (2009).

49. Lee, J.G., Moon, G., Kang, S.H., Cho, D.Y., Park, H.S \& Bae, J.H. Relaxation effect of phosphodiesterase-5 inhibitor on the animal bladder and prostatic urethra: in vitro and in vivo study. Urologica Internationales 84, 231-235 (2010).

50. Behr-Roussel, D., Oger, S., Caisey, S., Sandner, P., Bernabé, J., Alexandre, L., Giuliano, F. Vardenafil decreases bladder afferent nerve activity in unanesthetized, decerebrate, spinal cord-injured rats. European Urology 59, 272-279 (2011).

51. Chen, H.D., Ye, X.T., Weng, Z.L. \& Li, C.D. Effects and mechanisms of phosphodiesterase type 5 inhibitors on rats with overactive bladder. Zhonghua Yi Xue Za Zhi 91, 2001-2005.

52. Morelli, A., Filippi, S., Comeglio, P., Sarchielli, E., Chavalmane, A.K., Vignozzi, L., Fibbi, B., Silvestrini, E., Sandner, P., Gacci, M., Carini, M., Vannelli, G.B., \& Maggi, M. Acute vardenafil administration improves bladder oxygenation in spontaneously hypertensive rats. Journal of Sexual Medicine 7 , 107-120 (2010).

53. Matsumoto, S., Hanai, T. \& Uemura, H. Chronic treatment with a PDE5 inhibitor increases contractile force of normal bladder in rats. International Journal of Urology and Nephrology 42, 53-56 (2010).

54. Morelli, A., Filippi, S., Sandner, P., Fibbi, B., Chavalmane, A.K., Silvestrini, E., Sarchielli, E., Vignozzi, L., Gacci, M., Carini, M.,Vannelli, G.B., \& Maggi, M. Vardenafil modulates bladder contractility through cGMP-mediated inhibition of RhoA/Rho kinase signaling pathway in spontaneously hypertensive rats. Journal of Sexual Medicine 6, 1594-1608 (2009).

55. Caremel, R., Oger-Roussel, S., Behr-Roussel, D., Grise, P. \& Giuliano, F.A. Nitric oxide/cyclic guanosine monophosphate signalling mediates an inhibitory action on sensory pathways of the micturition reflex in the rat. European Urology 58, 616-625 (2010).

56. Minagawa, T., Aizawa, N., Igawa, Y. \& Wyndaele, J.J. Inhibitory effects of phosphodiesterase 5 inhibitor, tadalafil, on mechanosensitive bladder afferent nerve activities of the rat, and on acrolein-induced hyperactivity of these nerves. British Journal of Urology International (2012).

57. Yanai, Y., Hashitani, H., Hayase, M., Sasaki, S., Suzuki, H. \& Kohri, K. Role of nitric oxide/cyclic GMP pathway in regulating spontaneous excitations in detrusor smooth muscle of the guinea-pig bladder. Neurourology and Urodynamics 27, 446-453 (2008).

58. Matsumoto, S., Hanai, T., Uemura, H. \& Levin, R.M. Effects of chronic treatment with vardenafil, a phosphodiesterase 5 inhibitor, on female rat bladder in a partial bladder outlet obstruction model. British Journal of Urology International 103, 987-990 (2009). 
59. Kang, K.K., Kim, J.M., Yu, J.Y., Ahn, B.O., Yoo, M. \& Kim, Y.C. Effects of phosphodiesterase type 5 inhibitor on the contractility of prostate tissues and urethral pressure responses in a rat model of benign prostate hyperplasia. International Journal of Urology 14, 946-951; discussion 951 (2007).

6o. Beamon, C.R., Mazar, C., Salkini, M.W., Phull, H.S. \& Comiter, C.V. The effect of sildenafil citrate on bladder outlet obstruction: a mouse model. British Journal of Urology International 104, 252-256 (2009).

61. Bittencourt, J.A., Tano, T., Gajar, S.A., Resende, A.C., de Lemos Neto, M,, Damião, R., Criddle, D.N., de Bem, G.F., \& de Moura, R.S. Relaxant effects of sildenafil on the human isolated bladder neck. Urology 73, 427-430 (2009).

62. Oger, S., Behr-Roussel, D., Gorny, D., Lebret, T., Validire, P., Cathelineau, X., Alexandre, L. \& Giuliano, F.Signalling pathways involved in sildenafil-induced relaxation of human bladder dome smooth muscle. British Journal of Pharmacology 160, 1135-1143 (2010).

63. Kedia, G.T., Bodmann, F., Kuczyk, M.A. \& Ückert, S. Stimulation of the cyclic AMP/cyclic GMP signalling enhances the relaxation exerted by phosphodiesterase (PDE) inhibitors of isolated human detrusor smooth muscle. European Urology Supplements 1 (2012).

64. Truss, M.C., Stief, C.G., Uckert, S., Becker, A.J., Schultheiss, D., Machtens, S. \& Jonas, U. Initial clinical experience with the selective phosphodiesterase-I isoenzyme inhibitor vinpocetine in the treatment of urge incontinence and low compliance bladder. World Journal of Urology 18, 439-443 (2000).

65. Truss, M.C., Stief, C.G., Uckert, S., Becker, A,J., Wefer, J., Schultheiss, D. \& Jonas, U. Phosphodiesterase 1 inhibition in the treatment of lower urinary tract dysfunction: from bench to bedside. World Journal of Urology 19, 344-350 (2001).

66. Hatzimouratidis, K. Sildenafil in the treatment of erectile dysfunction: an overview of the clinical evidence. Clinical Interventions in Aging 1, 403-414 (2006).

67. Qaseem, A., Snow, V., Denberg, T.D., Casey, D.E. Jr., Forciea, M.A., Owens, D.K. \& Shekelle, P. Hormonal testing and pharmacologic treatment of erectile dysfunction: a clinical practice guideline from the American College of Physicians. Annals of Internal Medicine 151, 639-649 (2009).

68. Sairam, K., Kulinskaya, E., McNicholas, T.A., Boustead, G.B. \& Hanbury, D.C. Sildenafil influences lower urinary tract symptoms. British Journal of Urology International 90, 836-839 (2002).

69. Liu, L., Li, H., Underwood, T., Lloyd, M., David, M., Sperl, G., Pamukcu, R. \& Thompson, W.J. Cyclic GMPdependent protein kinase activation and induction by exisulind and $\mathrm{CP}_{46} 6 \mathrm{r}$ in colon tumor cells. Journal of Pharmacology and Experimental Therapy 299, 583-592 (2001).

70. Andersson, K.E., de Groat, W.C., McVary, K.T., Lue, T.F., Maggi, M., Roehrborn, C.G., Wyndaele, J.J., Melby, T. \& Viktrup, L. Tadalafil for the treatment of lower urinary tract symptoms secondary to benign prostatic hyperplasia: pathophysiology and mechanism(s) of action. Neurourology and Urodynamics zo, 292-301 (2011).

71. McVary, K.T., Siegel, R.L. \& Carlsson, M. Sildenafil citrate improves erectile function and lower urinary tract symptoms independent of baseline body mass index or LUTS severity. Urology 72, 575-579 (2008).

72. Mulhall, J.P., Guhring, P., Parker, M. \& Hopps, C. Assessment of the impact of sildenafil citrate on lower urinary tract symptoms in men with erectile dysfunction. Journal of Sexual Medicine 3, 662-667 (2006). 
73. McVary, K.T., Roehrborn, C.G., Kaminetsky, J.C., Auerbach, S.M., Wachs, B., Young, J.M., Esler, A., Sides, G.D., Denes, B.S.Tadalafil relieves lower urinary tract symptoms secondary to benign prostatic hyperplasia. The Journal of Urology 177, 1401-1407 (2007).

74. McVary, K.T., Monnig, W., Camps, J.L. Jr., Young, J.M., Tseng, L.J. \& van den Ende G. Sildenafil citrate improves erectile function and urinary symptoms in men with erectile dysfunction and lower urinary tract symptoms associated with benign prostatic hyperplasia: a randomized, double-blind trial. The Journal of Urology 177, 1071-1077 (2007).

75. Stief, C.G., Porst, H., Neuser, D., Beneke, M. \& Ulbrich, E. A randomised, placebo-controlled study to assess the efficacy of twice-daily vardenafil in the treatment of lower urinary tract symptoms secondary to benign prostatic hyperplasia. European Urology 53, 1236-1244 (2008).

76. Gacci, M., Del Popolo, G., Macchiarella, A., Celso, M., Vittori, G., Lapini, A., Serni, S., Sandner, P., Maggi, M. \& Carini, M. Vardenafil improves urodynamic parameters in men with spinal cord injury: results from a single dose, pilot study. The Journal of Urology 178, 2040-2043; discussion 2044 (2007).

77. Maselli, G., Bergamasco, L., Silvestri, V., Gualà, L., Pace, G., \& Vicentini, C. Tadalafil versus solifenacin for persistent storage symptoms after prostate surgery in patients with erectile dysfunction: a prospective randomized study. International Journal of Urology 18, 515-520 (2011).

78. Kaplan, S.A., Gonzalez, R.R. \& Te, A.E. Combination of alfuzosin and sildenafil is superior to monotherapy in treating lower urinary tract symptoms and erectile dysfunction. European Urology 51, 1717-1723 (2007).

79. Bechara, A., Romano, S., Casabé, A., Haime, S., Dedola, P., Hernández, C. \& Rey, H. Comparative efficacy assessment of tamsulosin vs. tamsulosin plus tadalafil in the treatment of LUTS/ BPH. Pilot study. Journal of Sexual Medicine 5, 2170-2178 (2008).

8o. Gacci, M., Vittori G., Tosi, N., Siena, G., Rossetti, M.A., Lapini, A., Vignozzi, L., Serni, S. Maggi, M. \& Carini, M. A Randomized, Placebo-Controlled Study to Assess Safety and Efficacy of Vardenafil $10 \mathrm{mg}$ and Tamsulosin $0.4 \mathrm{mg}$ vs. Tamsulosin $0.4 \mathrm{mg}$ Alone in the Treatment of Lower Urinary Tract Symptoms Secondary to Benign Prostatic Hyperplasia. Journal of Sexual Medicine 9, 1624-1633 (2012).

81. Taie, K., Moombeini, H., Khazaeli, D. \& Salari Panah Firouzabadi, M. Improvement of urodynamic indices by single dose oral tadalafil in men with supra sacral spinal cord injury. Urology Journal 7, 249-253 (2010).

82. Tamimi, N.A., Mincik, I., Haughie, S., Lamb, J., Crossland, A., \& Ellis, P. A placebo-controlled study investigating the efficacy and safety of the phosphodiesterase type 5 inhibitor UK-369,003 for the treatment of men with lower urinary tract symptoms associated with clinical benign prostatic hyperplasia. British Journal of Urology International 106, 674-680 (2010).

83. Giuliano, F.A., Lamb, J., Crossland, A., Haughie, S., Ellis, P., \& Tamimi, N.A. A placebo-controlled exploratory study investigating the efficacy and safety of the phosphodiesterase type 5 inhibitor UK369,003 for the treatment of men with storage lower urinary tract symptoms associated with a clinical diagnosis of overactive bladder. British Journal of Urology International 106, 666-673 (2010).

84. Dmochowski, R., Roehrborn, C., Klise, S., Xu, L., Kaminetsky, J. \& Kraus, S. Urodynamic effects of once daily tadalafil in men with lower urinary tract symptoms secondary to clinical benign prostatic hyperplasia: a randomized, placebo controlled 12-week clinical trial. The Journal of Urology 183, 1092-1097 (2010). 
85. Donatucci, C.F., Brock, G.B., Goldfischer, E.R., Pommerville, P.J., Elion-Mboussa, A., Kissel, J.D. \& Viktrup, L. Tadalafil administered once daily for lower urinary tract symptoms secondary to benign prostatic hyperplasia: a 1-year, open-label extension study. British Journal of Urology International International 107, 1110-1116 (2011).

86. Gacci, M., Ierardi, A., Rose A.D.,Tazzioli, S., Scapaticci, E., Filippi, S., Maggi, M., Nicita, G., Carini, M. \& Montorsi, F. Vardenafil can improve continence recovery after bilateral nerve sparing prostatectomy: results of a randomized, double blind, placebo-controlled pilot study. Journal of Sexual Medicine 7, 234243 (2010).

87. Sunahara, R.K. \& Taussig, R. Isoforms of mammalian adenylyl cyclase: multiplicities of signaling. Molecular Interventions 2, 168-184 (2002).

88. Cooper, D.M. \& Crossthwaite, A.J. Higher-order organization and regulation of adenylyl cyclases. Trends in Pharmacological Science 27, 426-431 (2006).

89. Uckert, S., Stief, C.G., Mayer, M., Jonas, U. \& Hedlund, P. Distribution and functional significance of phosphodiesterase isoenzymes in the human lower urinary tract. World Journal of Urology 23, 368-373 (2005).

90. Truss, M.C., Uckert, S., Stief, C.G., Kuczyk, M. \& Jonas, U. Cyclic nucleotide phosphodiesterase (PDE) isoenzymes in the human detrusor smooth muscle. I. Identification and characterization. Urological Research 24, 123-128 (1996).

91. Andersson, K.E., Chapple, C. \& Wein, A. The basis for drug treatment of the overactive bladder. World Journal of Urology 19, 294-298 (2001).

92. Gales, B.J. \& Gales, M.A. Phosphodiesterase-5 inhibitors for lower urinary tract symptoms in men. Annals of Pharmacotherapy 42, 111-115 (2008).

93. Gomelsky, A. \& Dmochowski, R.R. Urodynamic effects of once-daily tadalafil in men with LUTS secondary to clinical BPH. Current Urology Reports 11, 254-260 (2010).

94. Kraus, S.R., Dmochowski, R., Albo, M.E., Xu, L., Klise, S.R. \& Roehrborn, C.G. Urodynamic standardization in a large-scale, multicenter clinical trial examining the effects of daily tadalafil in men with lower urinary tract symptoms with or without benign prostatic obstruction. Neurourology and Urodynamics 29, 741-747 (2010).

95. Oelke, M., Giuliano, F., Mirone, V., Xu, L., Cox, D. \& Viktrup. L. Monotherapy with tadalafil or tamsulosin similarly improved lower urinary tract symptoms suggestive of benign prostatic hyperplasia in an international, randomised, parallel, placebo-controlled clinical trial. European Urology 61, 917-925 (2012).

96. Gacci, M., Corona, G., Salvi, M., Vignozzi, L., McVary, K.T., Kaplan, S.A., Roehrborn, C.G., Serni, S., Mirone, V., Carini, M.\& Maggi, M.A systematic review and meta-analysis on the use of phosphodiesterase 5 inhibitors alone or in combination with $\alpha$-blockers for lower urinary tract symptoms due to benign prostatic hyperplasia. European Urology 61, 994-1003 (2012).

97. Kaiho, Y., Nishiguchi, J., Kwon, D.D., Chancellor, M.B., Arai, Y., Snyder, P.B., \& Yoshimura, N. The effects of a type 4 phosphodiesterase inhibitor and the muscarinic cholinergic antagonist tolterodine tartrate on detrusor overactivity in female rats with bladder outlet obstruction. British Journal of Urology International 101, 615-620 (2008). 
98. Sakura, M., Masuda, H., Matsuoka, Y., Yokoyama, M., Kawakami, S. \& Kihara, K., Rolipram, a specific type-4 phosphodiesterase inhibitor, inhibits cyclophosphamide-induced haemorrhagic cystitis in rats. British Journal of Urology International 103, 264-269 (2009).

99. Shapiro, E., Hartanto, V. \& Lepor, H. The response to alpha blockade in benign prostatic hyperplasia is related to the percent area density of prostate smooth muscle. Prostate 21, 297-307 (1992).

100. Uckert, S., Mayer, M.E., Stief, C.G. \& Jonas, U. The future of the oral pharmacotherapy of male erectile dysfunction: things to come. Expert Opinion on Emerging Drugs 12, 219-228 (2007).

101. Kuthe, A., Eckel, H., Stief, C.G., Uckert, S., Forssmann, W.G., Jonas, U. \& Mägert, H.J. Molecular biological characterization of phosphodiesterase $3 \mathrm{~A}$ from human corpus cavernosum. Chemico-biological Interactions 119-120, 593-598 (1999).

102. Wheeler, M.A., Ayyagari, R.R., Wheeler, G.L. \& Weiss, R.M. Regulation of cyclic nucleotides in the urinary tract. Journal of Smooth Muscle Research 41, 1-21 (2005).

103. Fibbi, B., Morelli, A., Vignozzi, L., Filippi, S., Chavalmane, A., De Vita, G., Marini, M., Gacci, M., Vannelli, G.B., Sandner, P. \& Maggi, M. Characterization of phosphodiesterase type 5 expression and functional activity in the human male lower urinary tract. Journal of Sexual Medicine 7, 59-69 (2010).

104. Morelli, A., Filippi, S., Mancina, R., Luconi, M., Vignozzi, L., Marini, M., Orlando, C., Vannelli, G.B., Aversa, A., Natali, A., Forti, G., Giorgi, M., Jannini, E.A., Ledda, F. \& Maggi, M. Androgens regulate phosphodiesterase type 5 expression and functional activity in corpora cavernosa. Endocrinology $\mathbf{1 4 5}$, 2253-2263 (2004).

105. Abrams, P., Cardozo, L., Fall, M., Griffiths, D., Rosier, P., Ulmsten, U., Van Kerrebroeck, Ph.E.V., Victor, A. \& Wein, A. The standardisation of terminology in lower urinary tract function: report from the standardisation sub-committee of the International Continence Society. Urology 61, 37-49 (2003).

106. Abrams, P., et al. Fourth International Consultation on Incontinence Recommendations of the International Scientific Committee: Evaluation and treatment of urinary incontinence, pelvic organ prolapse, and fecal incontinence. Neurourology and Urodynamics 29, 213-240 (2010). 

Chapter 8

\section{Distribution of Phosphodiesterase Type 5 (PDE5) in the Lateral Wall of the Guinea Pig Urinary Bladder}

British Journal of Urology International 2013 Mar 4 doi: $10.1111 /$ bju.12031

PMID: 23452226

M.S. Rahnama' ${ }^{1,2}$, G.A. van Koeveringe ${ }^{1,2}$, R. Hohnen ${ }^{2}$, S. Ona ${ }^{3}$, Ph. E.V. Van Kerrebroeck, ${ }^{1,2}$ and S.G.G. de Wachter'

' Department of Urology, Maastricht University Medical Centre (MUMC+)

Maastricht, The Netherlands

${ }^{2}$ Department of Psychiatry and Neuropsychology, European Graduate School of Neuroscience (EURON) Maastricht University, Maastricht, The Netherlands ${ }^{3}$ Lehman College of The City University of New York New York, NY, USA 


\section{Abstract}

\section{Purpose}

To study PDE5 localisation by visualising the product of phosphodiesterase type 5 (PDE5) inhibition, namely cGMP, to determine the site of action of inhibitors in the urinary bladder.

\section{Materials and Methods}

Bladders of nine male guinea pigs were dissected and treated in wells containing $2 \mathrm{~mL}$ Krebs' solution and $1 \mathrm{mM}$ of the specific PDE 5 inhibitor vardenafil at $36^{\circ} \mathrm{C}$ for $30 \mathrm{~min}$. After stimulating tissues with $100 \mathrm{mM}$ of the nitric oxide (NO) donor diethylamine-NONOate for $10 \mathrm{~min}$, the tissues were snapfrozen and 9-10 $\mathrm{mm}$ sections were cut. Sections were examined for cGMP immunoreactivity and also stained for vimentin, a marker for interstitial cells and the neuromarkers protein gene product 9.5 (PGP9.5), synaptic vesicle protein 2 (SV2), neurofilament (NF) and calcitonin gene-related peptide (CGRP), using the two-step indirect immunohistochemistry technique.

\section{Results}

After PDE5 inhibition, $\mathrm{CGMP}_{5}$ was found to be present in the urothelium, suburothelial interstitial cells and endothelium of blood vessels. CGMP was not expressed in nerves positive for CGRP, NF and $\mathrm{SV}_{2}$, and was expressed only in very few efferent nerves positive for PGP9.5.

\section{Conclusion}

Our data show that the possible sites of action of PDE 5 inhibition in the bladder are the urothelium, suburothelial interstitial cells and blood vessels, rather than the bladder nerve fibres. 


\section{Introduction}

Phosphodiesterases (PDEs) are a class of enzymes, consisting of 14 subtypes and more than 50 distinct isoforms', that break down phosphodiester bonds. Usually, when speaking of PDE, one is referring to cyclic nucleotide PDEs, which have great clinical significance. In the present paper, we concentrate on a specific PDE subtype, the PDE type 5 (PDE5), which is selective for the degradation of the intracellular second messenger cGMP. The cGMP molecule is produced by soluble guanylate cyclase after stimulation by nitric oxide (NO) and is involved in important signalling cascades ${ }^{2}$. The inhibition of PDE5 slows the breakdown of the cyclic nucleotide CGMP, leading to an accumulation of $\mathrm{CGMP}^{3}$. Inhibitors targeting the different subtypes of PDE are widely used as therapeutic agents. Perhaps the most well known application of PDE inhibitors is in urology where PDE5 inhibitors are well known, extensively studied and prescribed in the treatment of erectile dysfunction ${ }^{4}$. Interestingly, recent clinical studies on PDE5 inhibitors in patients with erectile dysfunction, also showed a reduction in LUTS in these patients ${ }^{5-8}$. This clinical observation on LUTS was subsequently confirmed in placebo controlled studies in patients with LUTS and BPH with PDE5-inhibitors such as sildenafil 9 and vardenafil ${ }^{\circ}$. Furthermore, functional proteins of the $\mathrm{NO} / \mathrm{CGMP}$ signalling pathway have been identified in the human lower urinary tract, which might suggest a role for PDEs in the control of bladder function". The exact mechanism and site of action of PDE 5 inhibition in the bladder of patients with LUTS is currently unknown. In the present study, immunohistochemistry techniques are applied to investigate the site of action of a commonly used PDE5 inhibitor, vardenafil, within the lateral wall of male guinea pig bladder. There are no reliable and specific $\mathrm{PDE} 5$ antibodies available, therefore, the localisation of the PDE5 enzyme was indirectly visualised using antibodies against intracellular CGMP on bladder tissue pre-incubated with the PDE5 inhibitor, vardenafil.

\section{Materials and Methods}

Nine male guinea pigs (weighing 220-300 g) were killed by cervical dislocation. The bladders were immediately removed from each animal and placed in ice-cold Krebs solution $(121.1 \mathrm{mM} \mathrm{NaCl}, 1.87$ $\mathrm{mM} \mathrm{KCl}, 1.2 \mathrm{mM} \mathrm{CaCl}_{2}, 1.15 \mathrm{mM} \mathrm{MgSO}_{4}, 25 \mathrm{mM} \mathrm{NaHCO}_{3}, 1.17 \mathrm{mM} \mathrm{KH}_{2} \mathrm{PO}_{4}$ and $11.0 \mathrm{mM}$ glucose) that was bubbled with $5 \% \mathrm{CO}_{2}$ and $95 \% \mathrm{O}_{2}(\mathrm{pH} 7.4)$. Strips were cut from the lateral wall, and divided into two groups. One group was maintained in Krebs' solution. The second group was maintained in a Krebs' solution containing $1 \mathrm{mM}$ of the PDE 5 inhibitor vardenafil at $36^{\circ} \mathrm{C}$ for $30 \mathrm{~min}$. To stimulate the production of CGMP, all tissues of both groups were incubated with a $100 \mathrm{mM}$ solution of the NO donor diethylamine-NONOate for $10 \mathrm{~min}$. Incubation was terminated by immersing bladder pieces in ice-cold fixative solution of $4 \%$ freshly prepared depolymerized paraformaldehyde for 120 $\min$ at $4{ }^{\circ} \mathrm{C}$. Tissues were then fixed in three steps of two overnight and one daytime incubation at $4^{\circ} \mathrm{C}$ in $0.1 \mathrm{M}$ phosphate buffer with 10,20 and $30 \%$ sucrose, respectively. On day 3 , the tissues were placed in Tissue-Tek OCT $^{\mathrm{TM}}$ compound (Sakura Finetek, Torrance, CA, USA) to form a single 
block, snap-frozen in isopentane and cooled in liquid nitrogen. Cryostat sections (9-10 mm) were cut such that each section was perpendicular to the urothelial surface. Sections were thawed on chrome alum-gelatin coated slides and processed for immunohistochemistry using the two-step indirect method. All procedures were performed in agreement with Maastricht University ethical committee guidelines.

\section{Antibodies}

Six different primary antibodies were used to study the PDE 5 location in the bladder wall. Sheep anti-formaldehyde fixed cGMP (1:4000) was used to detect PDE5, as described by de Jongh et al. ${ }^{12}$ In order to stain the nerves in the tissue, the sections were co-stained with the antibodies polyclonal rabbit against protein gene product 9.5 ( PGP9.5 1:4000; Bioconnect, Huissen, The Netherlands), mouse antibody against synaptic vesicle protein 2 ( SV2 1:500; DS Hybridoma Bank, University of lowa, lowa City, USA), monoclonal anti-vimentin (1:1000, Biogenex, Fremont, CA, USA), monoclonal rabbit antibody against neurofilament ( NF 1:1000; Epitomics, Burlingame, CA, USA) and polyclonal rabbit antibody against calcitonin gene-related peptide ( CGRP 1:1000; Caliochem, EMD Chemicals, San Diego, CA, USA).

\section{Immunohistochemistry}

The sections were prepared for two-step indirect immunohistochemistry as described in our previous paper'3. In short, the sections were prepared for two-step indirect immunohistochemistry by drying for $20 \mathrm{~min}$ at room temperature followed by three washes with TBS ( $\mathrm{pH} 7.4)$. The slides were then incubated overnight with primary antibodies at $4{ }^{\circ} \mathrm{C}$. The primary antibodies were diluted in TBS containing $0.3 \%(\mathrm{v} / \mathrm{v})$ TBS-T. After the overnight incubation with the primaries, sections were washed in TBS-T, and TBS and TBS-T; each wash step lasted $15 \mathrm{~min}$. Rabbit primary antibodies were visualised using Alexa Fluor 488 donkey anti-rabbit IgG $(\mathrm{H}+\mathrm{L})$ conjugate (Molecular Probes, Invitrogen Ltd, Paisley, UK), diluted 1:100 in TBS-T. Mouse primary antibodies were visualised with Alexa Fluor 488 donkey anti-mouse IgG conjugate (Invitrogen), diluted 1:100 in TBS-T. Sheep primary antibodies were visualised with two different antibodies, Alexa Fluor 594 donkey anti-sheep IgG conjugate (Invitrogen) and Alexa Fluor 546 donkey anti-sheep, and both diluted 1:100 in TBS-T. Thereafter, sections were incubated with the secondary antibodies for $60 \mathrm{~min}$ at room temperature in the dark. After washing with TBS-T, cell nuclei were visualised by Hoechst staining with a dilution of 1:1000 in TBS-T and incubated for $10 \mathrm{~min}$ at room temperature. After washing with TBS-T and then TBS, sections were mounted with TBS-glycerol. Then, cover slits were placed on top of tissues. Sections were analysed and photographed using an Olympus $\mathrm{X}_{70}$ microscope using $\mathrm{X}_{10} \mathrm{X}_{20}$, $\mathrm{X}_{40} \mathrm{O}$ and $\mathrm{X}_{100}$ objectives. For the detection of Alexa 488 fluorescence and the detection of Alexa594 and 546, a narrow band-pass MNIBA-filter and a filter with a narrow excitation band, the U-M41007A filter (both filters from Chroma Technologies, Rockingham, VT, USA) were used, respectively. The microscope was equipped with a cooled CCD Olympus Digital video camera F-view. Images were 
stored digitally as 8-bit images and analysed using Image-J software. All sections were checked under the microscope and estimations of the prevalence of a certain staining pattern were made visually using a $1 X_{1} \mathrm{~mm}$ matrix field and by visually counting the observation in each field. This was then repeated in sections of all animals and with different stainings.
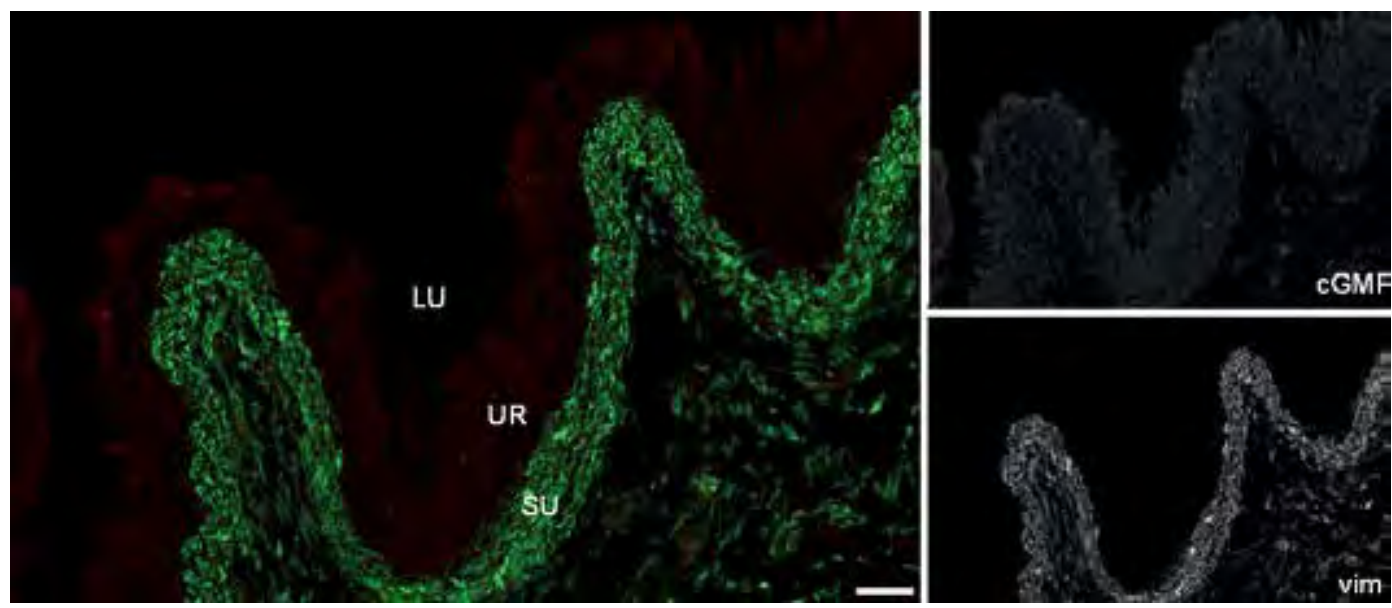

Figure 1. Negative control of the distribution of cGMP and vimentin in the urothelium of the lateral wall of the guinea pig bladder. The coloured panel shows a high power image of the urothelium of the lateral wall of a guinea pig bladder, stained with the antibody to CGMP (red) and vimentin (green). The bladder lumen (LU), the urothelium (UR) and the suburothelial layer (SU) are marked. The black and white panels show the individual images of cGMP and vimentin. Calibration bar: $50 \mu \mathrm{m}$.

\section{Results}

The data were obtained by taking pictures of all nine guinea pig bladders from several stainings conducted on several days. Images were analysed for the presence of cGMP as well as other markers. Typical images are shown in figures 1-8. A negative control of the urothelium and suburothelium, i.e. without pre-inhibition of PDE5, is shown in figure 1. There is a weak expression of CGMP in the urothelium, showing a low basal level of cGMP after NO stimulation and without any PDE inhibition. A section of the lateral bladder wall after PDE5 inhibition is shown in figure $2 A$. The tissue was stained for cGMP (red) and the interstitial cell marker vimentin ${ }^{14}$ (green). The umbrella cells of the urothelium were stained strongly positive (red) for CGMP, whereas the intermediate and basal layer urothelial cells exhibited a cGMP expression which was clearly less than the umbrella cells. This is shown in figure $2 \mathrm{~A}$ in more detail. This finding is in agreement with previous studies on the location of cGMP'5. A large population of vimentin-positive interstitial cells (green) were also cGMP-positive (red). A more detailed image of the urothelium of the lateral wall of a guinea pig bladder, stained with the antibody to cGMP (red), vimentin (green) and the nuclei staining Hoechst 
(blue) is shown in figure $2 \mathrm{~B}$. Details of this staining are shown in panel $\mathrm{A}$. It can be noted that the suburothelial interstitial cells were stained positive for CGMP (red) indicating PDE5 activity. The red signal for cGMP can be seen in both the processes of these suburothelial interstitial cells as well as their cytoplasm.
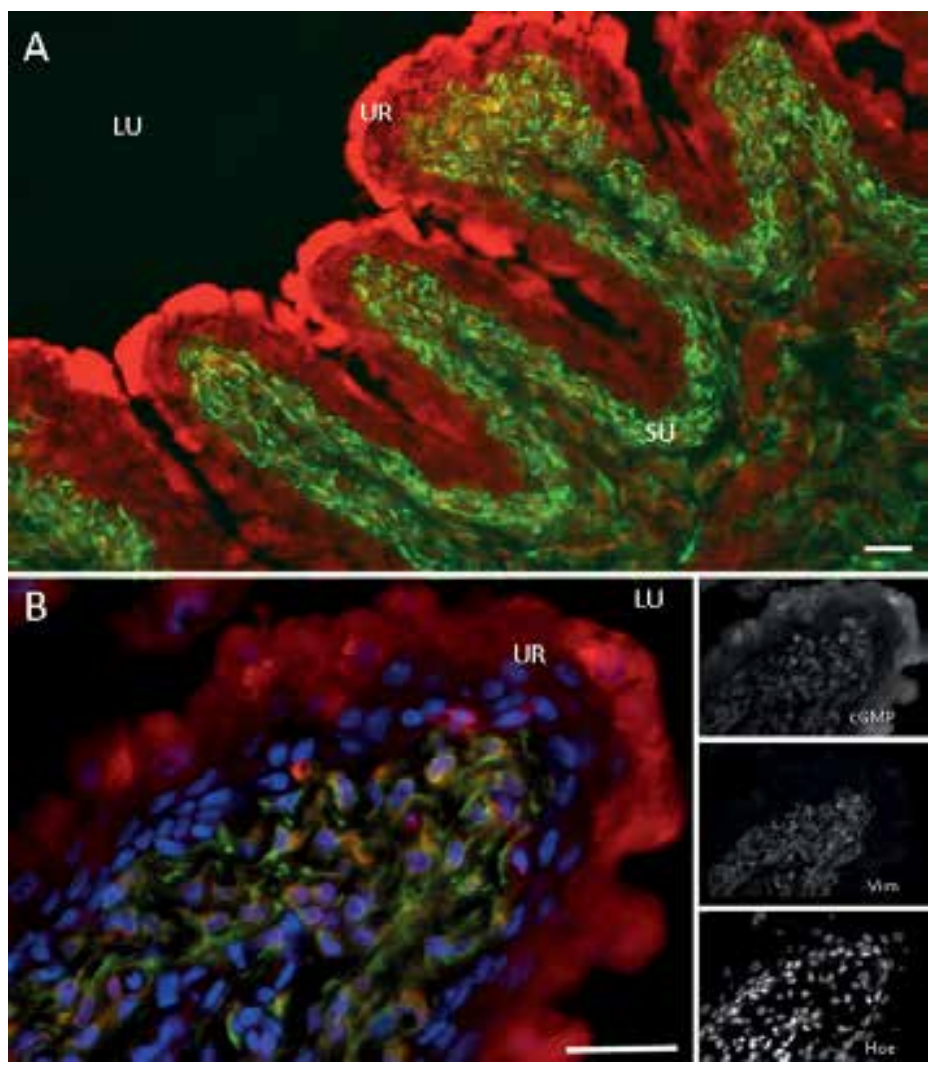

Figure 2. The distribution of $\mathrm{CGMP}$ and vimentin after PDE5 inhibition in the urothelium of the lateral wall of the guinea pig bladder. (A) shows a low power image of the urothelium of the lateral wall of a guinea pig bladder, stained with antibodies to CGMP (red) and vimentin (green). The bladder lumen (LU), the urothelium (UR) and the suburothelial layer (SU) are marked. (B) shows a high power image of the urothelium of the lateral wall of a guinea pig bladder, stained with the antibody to cGMP (red), vimentin (green) and Hoechst (blue). The black and white panels show the individual images of cGMP, vimentin and Hoechst. Calibration bars: $50 \mu \mathrm{m}$. 
In figure 3, double stainings of cGMP with the general neuronal marker PGP9.5 are shown. A few nerve fibres that are CGMP-negative and PGP9.5-positive, running from the suburothelium through the urothelial layer, are shown (marked \#). After visual inspection of two different PGP9.5-stained slides for each of the nine guinea pigs, it was concluded that a small minority of PGP9.5-positive fibres showed a weak CGMP signal after PDE 5 inhibition. In panel $B$, an enlarged image of such cGMP-positive suburothelial nerves staining positive for PGP9.5 (marked +) are shown.
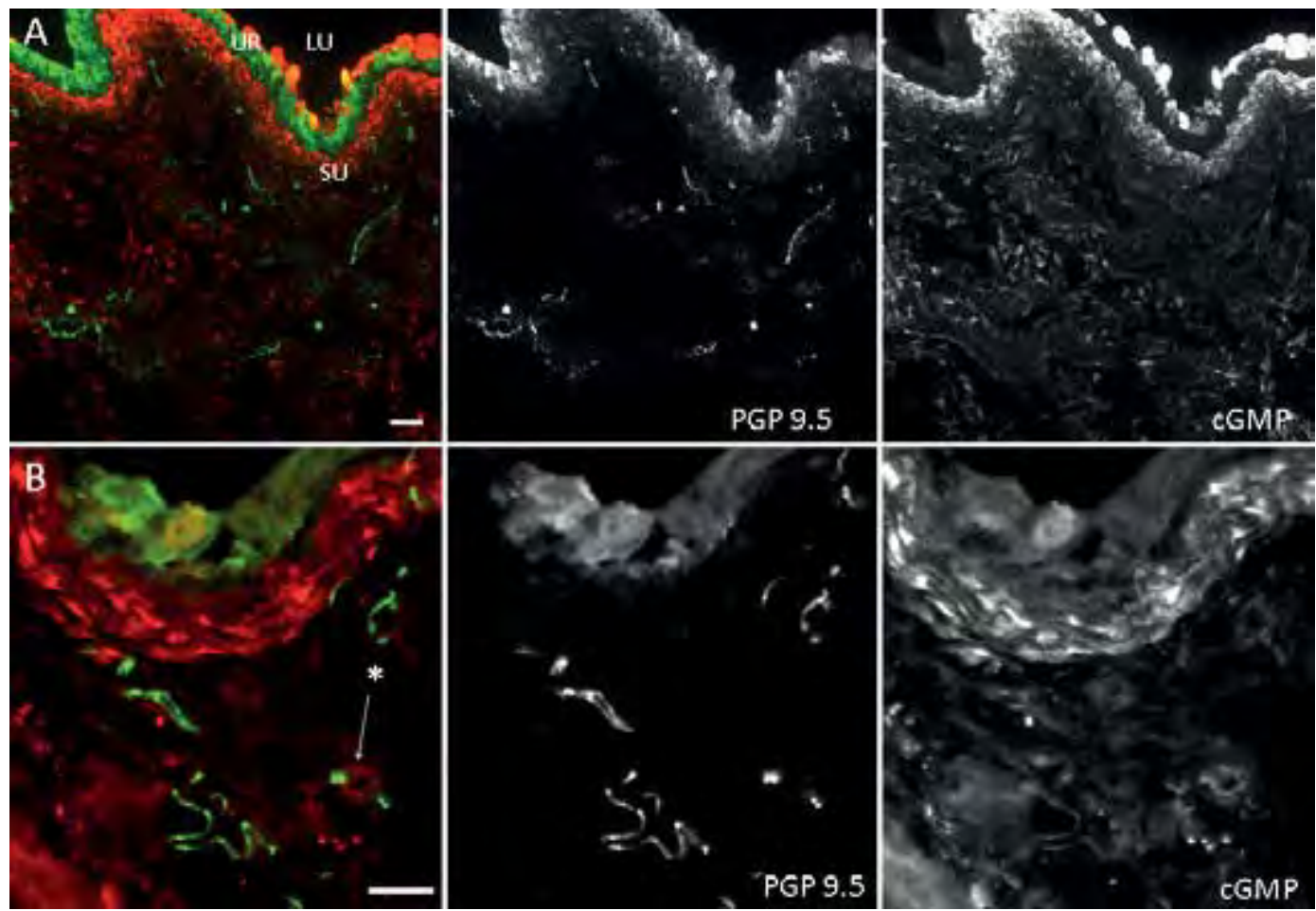

Figure 3. The distribution of CGMP and PGP9.5 after PDE 5 inhibition in the nerves of the lateral wall of the guinea pig bladder. The urothelium and suburothelial layer of the lateral wall of a guinea pig bladder, stained with the antibody to cGMP (red) and PGP9.5 (green), are shown. In panel A, the bladder lumen (LU), the urothelium (UR) and the suburothelial layer (SU) are marked. Panel B shows an enlarged image of cGMP positive suburothelial nerves staining positive for PGP9.5. A blood vessel staining positive for CGMP only can be noted in the suburothelium of panel B marked by astriks (*). The black and white panels show the individual images of CGMP and PGP9.5. Calibration bars: $50 \mu \mathrm{m}$. 

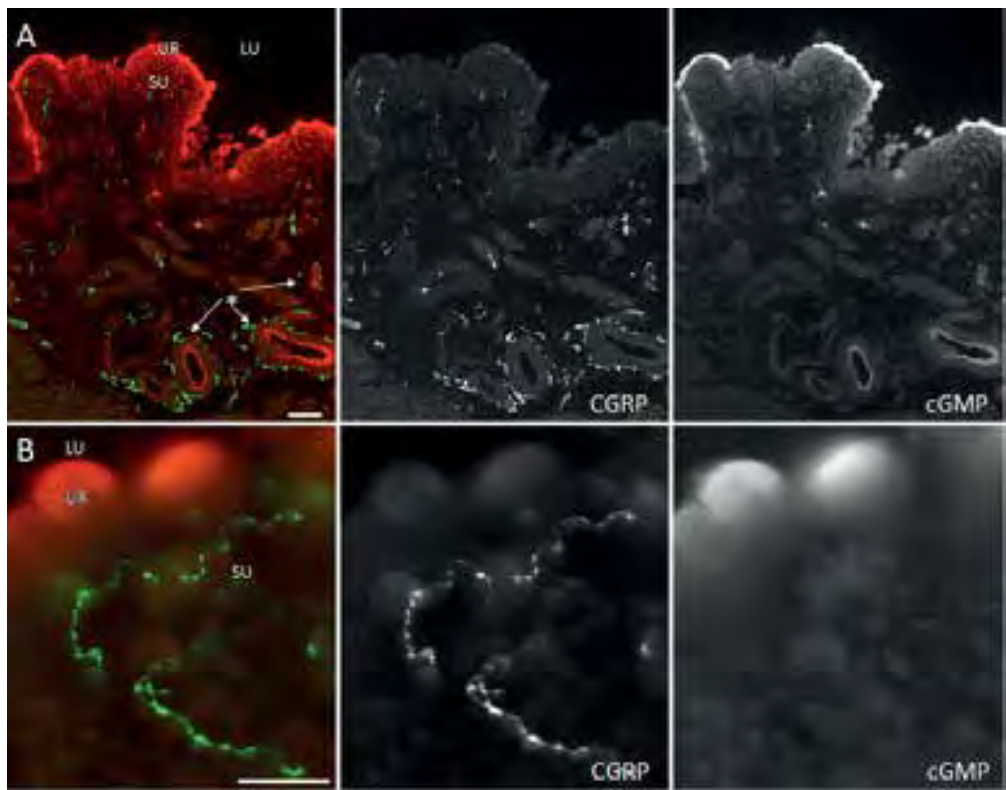

Figure 4. The distribution of CGMP and CGRP after PDE5 inhibition, in the urothelium and suburothelium of the lateral wall of the guinea pig bladder. Panel A shows a low power image and panel $B$ a high power image of the urothelium of the lateral wall of a different guinea pig bladder, stained with the antibody to CGMP (red) and CGRP (green). The bladder lumen (LU), the urothelium (UR) and the suburothelial layer (SU) are marked in panel A. The black and white panels show the individual images of CGMP and CGRP.

Calibration bars: $50 \mu \mathrm{m}$ in panel A and $20 \mu \mathrm{m}$ in panel B.

CGMP co-stained with the afferent nerve marker CGRP is shown in figure 4. Panel A shows the CGRP-positive nerve fibres that were all CGMP- negative. An enlarged image of a nerve in the suburothelial layer is shown in panel B. We did not find any CGRP-positive nerve fibres in the urothelium or suburothelium that were co-stained for CGMP. The distribution of CGMP stained with the efferent nerve marker $\mathrm{SV}_{2}$ is shown in figure 5 . In all SV2- stained slide studies, none of the SV2-positive nerve fibres were found to stain positive for CGMP after PDE5 inhibition. An enlarged image showing a SV2-positive, CGMP-negative nerve fibre is shown in panel B. Stainings with the afferent nerve marker NF are shown in figure 6. Again, all the NF-positive fibres were cGMP-negative. An NF-positive fibre is shown in more detail in panel B. Another observation was the strong expression of $\mathrm{CGMP}$ in the blood vessels after PDE 5 inhibition as indicated in figures 3, 4 and 6 by asterisks. More specifically, cGMP expression was seen in the endothelium of the arterioles running through the urothelium and the suburothelial layers. Figures 7 and 8 show CGMP expression in the blood vessels of the suburothelium counterstained with vimentin, CGRP, 
PGP9.5, SV2 and NF, respectively. Vimentin co-stains with cGMP in the endothelium of the blood vessels. From all the nerve markers stained, only PGP9.5 co-stains with cGMP around the blood vessels.

In panel A of figure 8 it can be noted that, the endothelium and the muscle layer below the endothelium of the artery stain strongly positive for $\mathrm{CGMP}$ after PDE 5 inhibition by vardenafil but are PGP9.5-negative; however, around the artery, PGP9.5 and CGMP co-stain. The endothelium of the artery shown in panel $B$, stains strongly positive for $\mathrm{CGMP}_{\text {after PDE}}$ inhibition by vardenafil but is SV2-negative. Moreover, panel C also shows an artery where the subendothelial layer shows PDE5 activity. Again the endothelium and the subendothelial layer of this artery stain strongly positive for CGMP after PDE5 inhibition by vardenafil but are NF-negative.

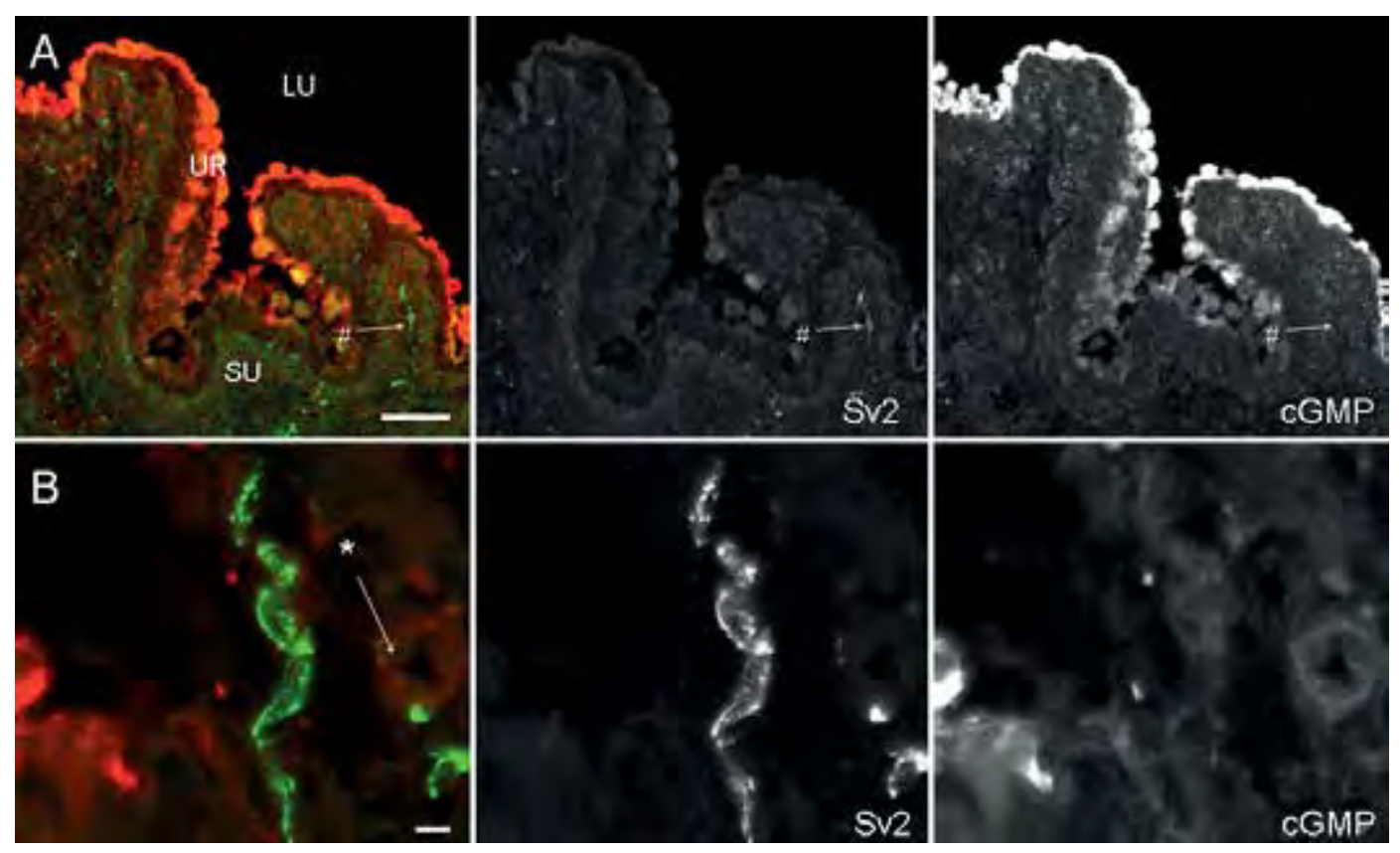

Figure 5. The distribution of CGMP and $\mathrm{SV}_{2}$ after PDE 5 inhibition in the urothelium and suburothelium of the lateral wall of the guinea pig bladder. Panel A shows a low power image of the urothelium and suburothelium. A SV2-positive fibre is marked (\#). The bladder lumen (LU), the urothelium (UR) and the suburothelial layer (SU) are marked in panel A. Panel B shows an enlarged image of a suburothelial nerve staining positive for SV2 but not for cGMP. The black and white panels show the individual images of CGMP and SV2. Calibration bars: $50 \mu \mathrm{m}$ in panel A and $20 \mu \mathrm{m}$ in panel B. 

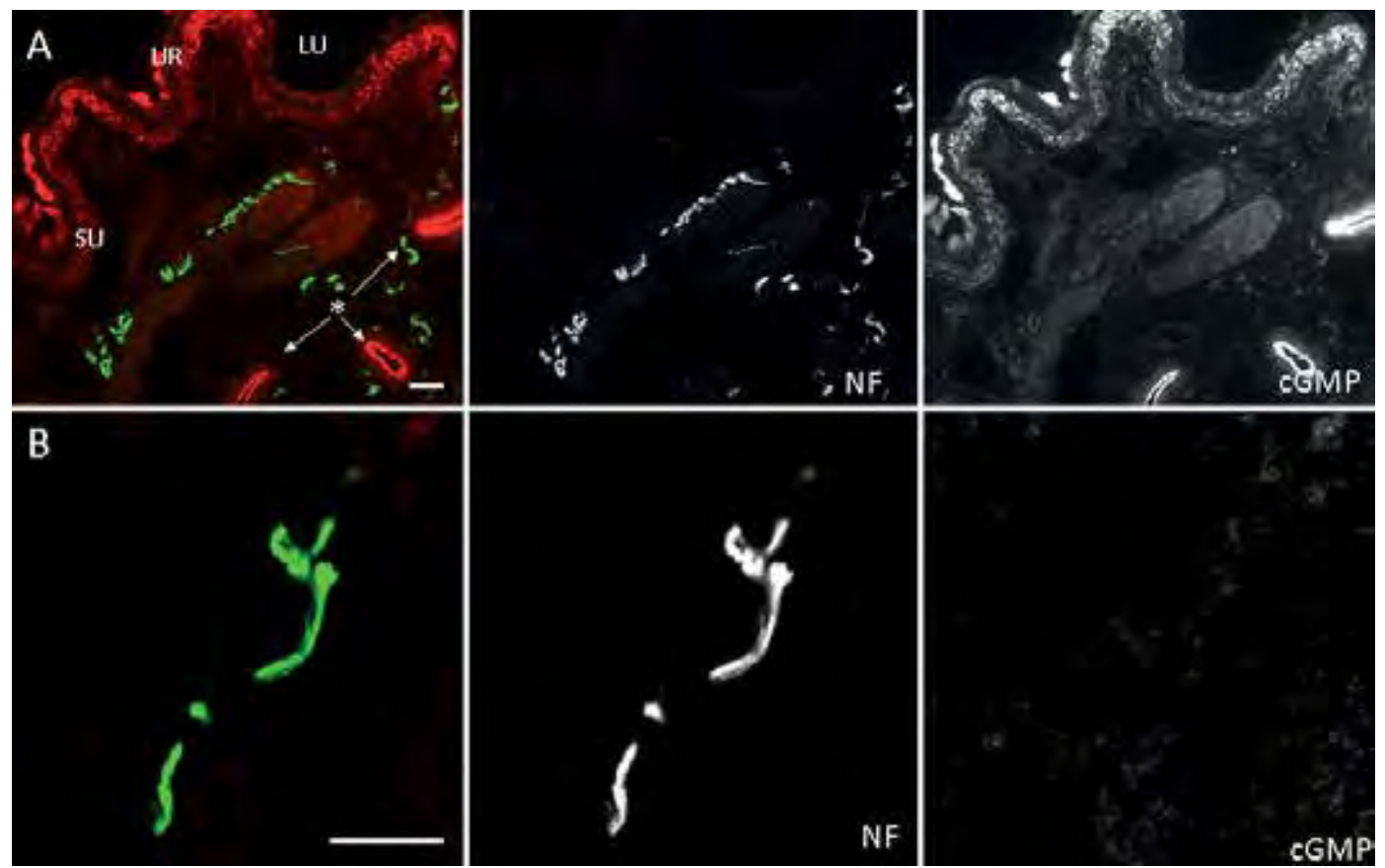

Figure 6. The distribution of CGMP and NF after PDE 5 inhibition in the lateral wall of the guinea pig bladder. The urothelium and suburothelium of the lateral wall of a guinea pig bladder, stained with the antibody to cGMP (red) and NF (green), are shown. In panel A the bladder lumen (LU), the urothelium (UR) and the suburothelial layer (SU) are marked. Panel B shows an enlarged image of a different guinea pig bladder. A suburothelial nerve, positive for neurofilament but negative for cGMP is shown. The black and white panels show the individual images of CGMP and neurofilament. Calibration bars: $50 \mu \mathrm{m}$ in panel A and $20 \mu \mathrm{m}$ in panel B.

\section{Discussion}

The most recent support for NO-cGMP involvement in the bladder physiology comes from a study in rats showing that long-term administration of a soluble guanlylate cyclase activator (BAY 41-2272) prevents bladder dysfunction in NO-deficient rats, resulting in the normalisation of the increased threshold pressure, peak pressure and micturition frequency. These data indicate that restoration of the NO/CGMP pathway by this compound may be of benefit in the treatment of bladder symptoms ${ }^{16}$. Moreover, it has been shown that compounds activating the NO/cGMP pathway inhibited bladder hyperactivity, whereas compounds inhibiting the NO/CGMP pathway increased it ${ }^{17}$. These results suggest that the NO/cGMP signalling pathway is involved in the regulation of the micturition reflex ${ }^{17}$. In addition, carbachol-pre-contracted human detrusor strips are shown to be relaxed by the PDE 5 inhibitor sildenafil ${ }^{8}$. In earlier studies, it has been suggested that the relaxant effect of the same PDE5 inhibitor used in the present study, vardenafil, in bladder smooth muscle, could at least in part be ascribed to a cGMP/protein kinase-dependent inhibition of RhoA-RhoA/Rho-kinase 
signalling ${ }^{6}$. In fact, vardenafil does not affect responsiveness to a physiological stimulus such as carbachol, suggesting that PDE 5 inhibitors may not interfere with bladder function in physiological conditions. In pathological conditions, however, as in the case of overactive bladder ${ }^{19}$, it is suggested that increasing CGMP levels through PDE 5 inhibition restore normal bladder calcium sensitivity by reducing RhoARhoA/ Rho-kinase signalling overactivity. Together with data from recent clinical studies $^{10,20,21}$, these results indicate that vardenafil may reduce RhoA-RhoA/ Rho-kinase signalling in the dysfunctional bladder, thus decreasing bladder overactivity ${ }^{6}$. Currently, no antibodies are available to directly visualise the presence of PDE 5 enzymes; therefore, an indirect measurement was chosen in the present study. NO stimulation is known to induce an increase of intracellular CGMP, which is in turn degraded by PDE enzymes. At the chosen concentration of $1 \mathrm{mM}$, vardenafil has been shown to inhibit the PDE 5 enzyme ${ }^{22}$, so pre-incubating the bladder with vardenafil, leads to an increased cellular level of cGMP, which can be visualized by specific antibodies against cGMP.

The presence of high levels of cGMP then demonstrates sites that contain the PDE5 enzyme. The

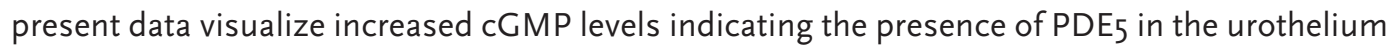
and in a large population of suburothelial interstitial cells, as well as in the endothelium of the blood vessels running through the suburothelial layer. Furthermore, from all slides studied, PDE5 activity was only found in a very small number of PGP9.5 nerves, whereas the SV2-, NF- and CGRPpositive nerve fibres did not show any PDE5 activity. As shown in figures 2-6, a small population of suburothelial interstitial cells do not stain positive for $\mathrm{CGMP}_{\text {after }} \mathrm{PDE}_{5}$ inhibition. This observation is explained by the idea that interstitial cells form a very diverse population and a subpopulation that apparently does not respond to NO stimulation with an increase in CGMP after PDE5 inhibition. This idea has been suggested previously's.

The presence of $\mathrm{PDE}_{5}$ activity in the interstitial cells of the bladder raises the suggestion that after PDE5 inhibition a rise in CGMP occurs in the umbrella cells and in the interstitial cells and that this effect might be spread through the network of interstitial cells. In fact, the idea of the existence on an interstitial network as a modulatory network through which signal propagation is achieved is not new. This idea has been put forward previously, in relation to the coordination of localized contractions in the bladder wall ${ }^{23}$. Coordinated non-voiding contractions, also referred to as autonomous activity, are thought to be part of a motor/sensory system which might regulate bladder afferent activity ${ }^{23}$. The idea of the involvement of an interstitial cell network in bladder nonvoiding activity is further supported by experimental evidence showing that bladder interstitial cells are indeed excitable ${ }^{24}$. Moreover, it has been shown that activation of these cells can initiate smooth muscle contraction, possibly via direct electrical coupling between these cells through gap junction ${ }^{25}$. With regard to the present data, the hypothesis can be put forward that PDE 5 inhibition alters the $\mathrm{cGMP} / \mathrm{NO}$ system in the interstitial cells, which might play a role in the transduction of signals from the urothelium. This idea is consistent with the fact that, in the present study, $\mathrm{PDE}_{5}$ activity was virtually absent in the bladder nerve fibres (figures $3-5$ ). Thus, we conclude that the relatively low PDE 5 activity in efferent nerve fibres is not the main site of action of $\mathrm{PDE}_{5}$ in 
the guinea pig bladder, given the small numbers of the cGMP-positive fibres (i.e. only a small number of PGP9.5 fibres as shown in figure $3 \mathrm{~B}$ ) compared with the strong CGMP staining on the interstitial cells. We therefore suggest that the PDE 5 effect in the bladder is situated in the umbrella cells of the urothelium and interstitial cells. In the present study, we also observed PDE5 activity in the endothelium of blood vessels in the bladder. It is known that PDE 5 inhibitors have a relaxant effect 7 and 8 show that the blood vessels are surrounded by nerve fibres. A more close observation shows these blood vessels to be surrounded by a layer of PGP9.5-positive cells co-staining
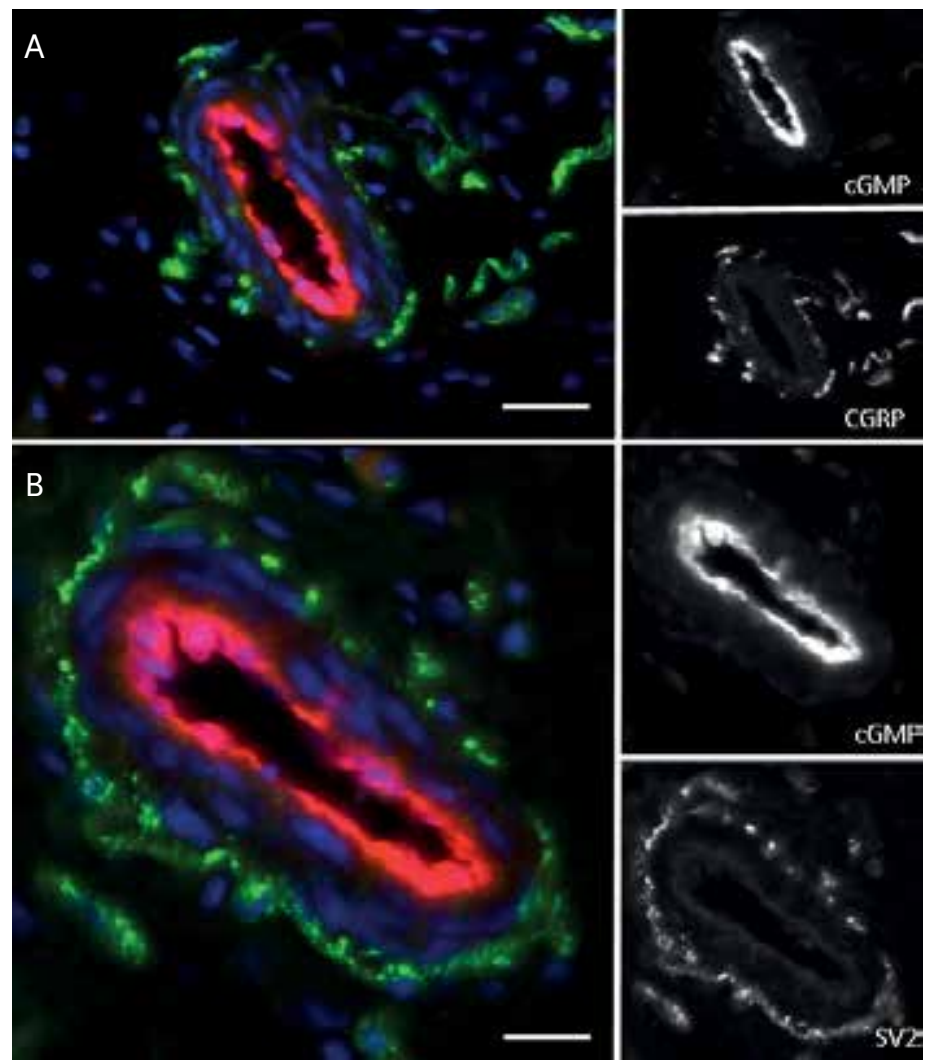

Figure 7. The distribution of cGMP and vimentin and cGMP and CGRP after PDE5 inhibition in the veins of the lateral wall of the guinea pig bladder. The coloured panels show a high power images of blood vessels (veins) in the suburothelium of the lateral wall of a guinea pig bladder. In panel A, the tissue is stained with the antibody to cGMP (red), vimentin (green) and Hoechst (blue). The black and white panels show the individual images of CGMP and vimentin. In panel $B$, the tissue is stained with the antibody to CGMP (red), CGRP (green) and Hoechst (blue). The black and white panels show the individual images of CGMP and CGRP.

Calibration bars: $25 \mu \mathrm{m}$. 

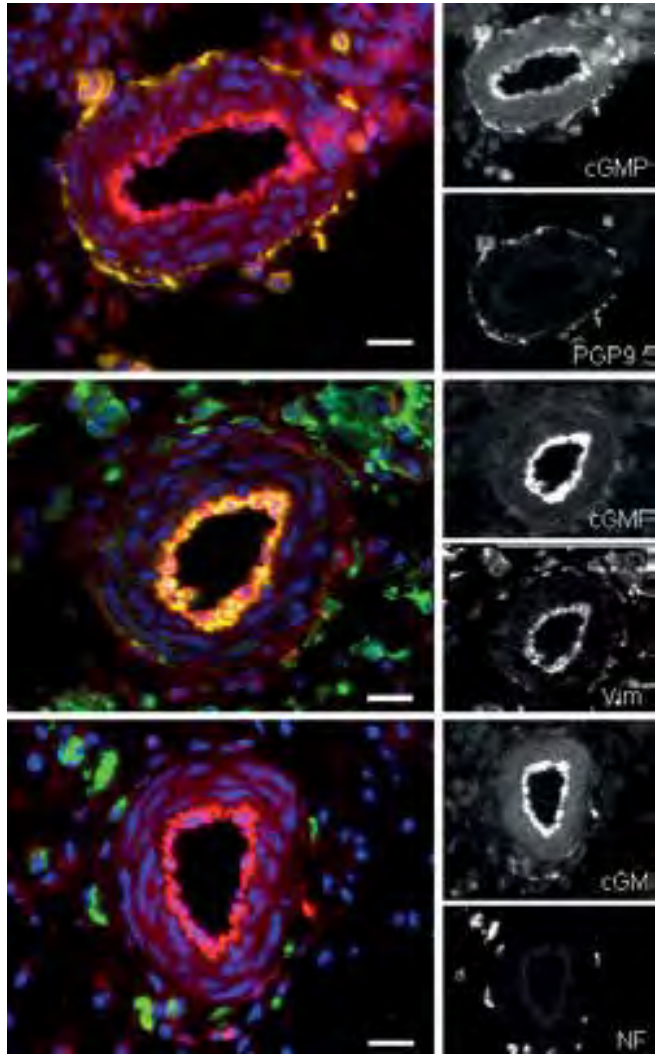

Figure 8. The distribution of $\mathrm{CGMP}$ counterstained with $\mathrm{SV}_{2}$, PGP9.5 and NF after PDE5 inhibition in the arteries of the lateral wall of the guinea pig bladder. In the coloured panels, high power images of different blood vessels (arteries) in the lateral wall of a guinea pig bladder are shown. $\ln (A)$ the tissue is stained with the antibody to CGMP (red), PGP9.5 (green) and Hoechst (blue). The black and white panels show the individual images of CGMP and PGP9.5. In (B), the tissue is stained with the antibody to CGMP (red), SV2 (green) and Hoechst (blue). The black and white panels show the individual images of $\mathrm{CGMP}$ and $\mathrm{SV} 2$. In panel $\mathrm{C}$, the tissue is stained with the antibody to cGMP (red), NF (green) and Hoechst (blue). The black and white panels show the individual images of $\mathrm{CGMP}$ and NF.

Calibration bars: $25 \mu \mathrm{m}$. 
for $\mathrm{CGMP}_{\text {after PDE}}$ inhibition (figure 8B). Moreover, in figure $7 \mathrm{~A}$, it can be seen that the same layer of cells ensheathing the blood vessels is vimentin-positive. It is known that vimentin can be used to characterize blood vessels by staining endothelial cells, fibroblasts and smooth muscle cells, which are all found in the blood vessel ${ }^{27}$. In addition, it has been shown previously that a subpopulation of vimentin-positive interstitial cells also stain positive for PGP9. $5^{28}$. The exact physiological meaning of PDE5 activity in the bladder endothelium is not yet understood; however, it may be suggested that the known vasodilatative effect of PDE 5 inhibitors, such as vardenafil, might be coordinated in the bladder through these interstitial cells surrounding the blood vessels. In conclusion, a few possible sites of action for PDE 5 inhibitors in the guinea pig urinary bladder lateral wall can now be suggested, i.e. the urothelium, the endothelium of bladder blood vessels and the network of interstitial cells. The involvement of nerve fibres is less probable as in the present study we found only a very limited number of nerve fibres were stained positive for $\mathrm{CGMP}_{\text {after PDE}}$ inhibition. This suggests that PDE 5 inhibition has its effect mainly through the NO-mediated cGMP system in the interstitial cells. As the present data are the first available on the site and distribution of PDE5 activity in the bladder and are limited to a study of the distribution of PDE 5 activity in the bladder, future in vitro and in vivo experiments are needed to determine the exact physiological meaning of the PDE 5 activity arrangement found in the guinea pig urinary bladder. 


\section{References}

1. Essayan, D.M. Cyclic nucleotide phosphodiesterases. Journal of Allergy and Clinical Immunology 108, 671-680 (2001).

2. Morelli, A., Filippi, S., Sandner, P., Fibbi, B., Chavalmane, A,K., Silvestrini, E., Sarchielli, E., Vignozzi, L, Gacci, M., Carini, M., Vannelli, G.B. \& Maggi, M. Vardenafil Modulates Bladder Contractility Through cGMPmediated Inhibition of RhoA/Rho Kinase Signaling Pathway in Spontaneously Hypertensive Rats. Journal of Sexual Medicine (2009).

3. Gillespie, J.I. \& Drake, M.J. The actions of sodium nitroprusside and the phosphodiesterase inhibitor dipyridamole on phasic activity in the isolated guinea-pig bladder. British Journal of Urology International 93, $851-858$ (2004).

4. Wespes, E., Amar, E., Hatzichristou, D., Hatzimouratidis, K., Montorsi, F., Pryor, J. \& Vardi, Y. EAU Guidelines on erectile dysfunction: an update. European urology 49, 806-815 (2006).

5. Bechara, A., Romano, S., Casabé, A., Haime, S., Dedola, P., Hernández, C. \& Rey, H. Comparative efficacy assessment of tamsulosin vs. tamsulosin plus tadalafil in the treatment of LUTS/BPH. Pilot study. Journal of Sexual Medicine 5, 2170-2178 (2008).

6. Morelli, A., Filippi, S., Sandner, P., Fibbi, B., Chavalmane, A,K., Silvestrini, E., Sarchielli, E., Vignozzi, L, Gacci, M., Carini, M., Vannelli, G.B.\& Maggi M. Vardenafil modulates bladder contractility through cGMP-mediated inhibition of RhoA/Rho kinase signaling pathway in spontaneously hypertensive rats. Journal of Sexual Medicine 6, 1594-1608 (2009).

7. Mulhall, J.P., Guhring, P., Parker, M. \& Hopps, C. Assessment of the impact of sildenafil citrate on lower urinary tract symptoms in men with erectile dysfunction. Journal of Sexual Medicine 3, 662-667 (2006).

8. Sairam, K., Kulinskaya, E., McNicholas, T.A., Boustead, G.B. \& Hanbury, D.C. Sildenafil influences lower urinary tract symptoms. British Journal of Urology International 90, 836-839 (2002).

9. McVary, K.T., Siegel, R.L. \& Carlsson, M. Sildenafil citrate improves erectile function and lower urinary tract symptoms independent of baseline body mass index or LUTS severity. Urology 72, 575-579 (2008).

10. Stief, C.G., Porst, H., Neuser, D., Beneke, M. \& Ulbrich, E. A randomised, placebo-controlled study to assess the efficacy of twice-daily vardenafil in the treatment of lower urinary tract symptoms secondary to benign prostatic hyperplasia. European Urology 53, 1236-1244 (2008).

11. Tinel, H., Stelte-Ludwig, B., Hutter, J. \& Sandner, P. Pre-clinical evidence for the use of phosphodiesterase-5 inhibitors for treating benign prostatic hyperplasia and lower urinary tract symptoms. British Journal of Urology International 98, 1259-1263 (2006).

12. de Jongh, R., van Koeveringe, G.A., Van Kerrebroeck, Ph.E.V., Markerink-van Ittersum, M., de Vente, J. \& Gillespie, J.I. Alterations to network of NO/cGMP-responsive interstitial cells induced by outlet obstruction in guinea-pig bladder. Cell and Tissue Research 330, 147-160 (2007).

13. Rahnama'i, M. S., de Wachter, S.G., van Koeveringe G.A., Van Kerrebroeck, Ph.E.V., de Vente, J. \& Gillespie, J.I. The relationship between prostaglandin E receptor 1 and cyclooxygenase I expression in guinea pig bladder interstitial cells: proposition of a signal propagation system. The Journal of Urology 185, 315-322 (2011). 
14. Smet, P.J., Jonavicius, J., Marshall, V.R. \& de Vente, J. Distribution of nitric oxide synthase-immunoreactive nerves and identification of the cellular targets of nitric oxide in guinea-pig and human urinary bladder by cGMP immunohistochemistry. Neuroscience 71, 337-348 (1996).

15. Gillespie, J.I., Markerink-van Ittersum, M. \& de Vente, J. cGMP-generating cells in the bladder wall: identification of distinct networks of interstitial cells. British Journal of Urology International 94, 1114-1124 (2004).

16. Monica, F.Z., Reges, R., Cohen, D., Silva, F.H., De Nucci, G., D’Ancona, C.A. \& Antunes, E. Long-term administration of BAY 41-2272 prevents bladder dysfunction in nitric oxide-deficient rats. Neurourology and Urodynamics 30, 456-460 (2011).

17. Caremel, R., Oger-Roussel, S., Behr-Roussel, D., Grise, P. \& Giuliano, F.A. Nitric oxide/cyclic guanosine monophosphate signalling mediates an inhibitory action on sensory pathways of the micturition reflex in the rat. European Urology 58, 616-625 (2010).

18. Oger, S., Behr-Roussel, D., Gorny, D., Lebret, T., Validire, P., Cathelineau, X., Alexandre, L. \& Giuliano F. Signalling pathways involved in sildenafil-induced relaxation of human bladder dome smooth muscle. British Journal of Pharmacology 160, 1135-1143 (2010).

19. Morelli, A., Vignozzi, L., Filippi, S., Vannelli, G.B., Ambrosini, S., Mancina, R., Crescioli, C., Donati, S., Fibbi, B., Colli, E., Adorini, L. \& Maggi M. BXL-628, a vitamin D receptor agonist effective in benign prostatic hyperplasia treatment, prevents RhoA activation and inhibits RhoA/Rho kinase signaling in rat and human bladder. Prostate 67, 234-247 (2007).

20. Stief, C.C., Porst, H., Neuser, D., Beneke, M., Ulbrich, E. A randomised, placebo- symptoms secondary to benign prostatic hyperplasia. European Urology 2008;53:1236-44 (2008).

21. Mostafa, T. Oral phosphodiesterase type 5 inhibitors: nonerectogenic beneficial uses. Journal of Sexual Medicine 5, 2502-2518 (2008).

22. Saenz de Tejada, I., Angulo, J., Cuevas, P., The phosphodiesterase inhibitory selectivity and the in vitro and in vivo potency of the new PDE5 inhibitor vardenafil. International Journal of Impotence Research; 13: 282-90 (2001)

23. Gillespie, J.I., van Koeveringe, G.A., de Wachter, S.G. \& de Vente, J. On the origins of the sensory output from the bladder: the concept of afferent noise. British Journal of Urology International 103, 1324-1333 (2009).

24. McCloskey, K.D. Interstitial cells in the urinary bladder--localization and function. Neurourology and Urodynamics 29, 82-87 (2010).

25. Hashitani, H., Yanai, Y. \& Suzuki, H. Role of interstitial cells and gap junctions in the transmission of spontaneous $\mathrm{Ca} 2+$ signals in detrusor smooth muscles of the guinea-pig urinary bladder. The Journal of Physiology 559, 567-581 (2004).

26. Vlachopoulos, C., loakeimidis, N., Rokkas, K. \& Stefanadis, C. Cardiovascular effects of phosphodiesterase type 5 inhibitors. Journal of Sexual Medicine 6, 658-674 (2009).

27. Lim, K.C., Tyler, C.M., Lim, S.T., Giuliano, R. \& Federoff, H.J. Proteolytic processing of proNGF is necessary for mature NGF regulated secretion from neurons. Biochemistry and Biophysics Research Communication 361 , 599-604 (2007).

28. Grol, S., Essers, P.B., van Koeveringe, G.A., de Vente, J. \& Gillespie, J.I. Ubiquitin hydrolase (protein gene product 9.5) in the obstructed bladder: evidence for tissue remodelling involving a subset of interstitial cells. British Journal of Urology International 104, 698-706 (2009). 




\section{Chapter 9 \\ General Discussion}

\section{Aim of study}

The lack of satisfactory therapeutic options for the symptoms of the Overactive Bladder syndrome $(O A B)$ is mainly due to an incomplete understanding of the complex bladder physiology and the multi-factorial cause of the $O A B$ symptoms. In our studies summarized in this thesis, we have aimed at studying two local control systems of the bladder; namely: the prostaglandin E2 ( $\left.\mathrm{PGE}_{2}\right)$ and the $\left(P G E_{2}\right)$ and the Nitric Oxide (NO) - Guanosine 3',5'-cyclic monophosphate (cGMP) phosphodiesterase (PDE) system. We have applied immunohistochemistry techniques by which we can identify different receptors and enzymes by fluorescence labelling. Signal transduction is one of the most fundamental processes underlying the basics of living organisms. This process includes the recognition of signals by cells and their appropriate transformation into biological responses'. It has become evident that neurons can also communicate with their targets without synaptic connections and that this form of non-synaptic interactions is of physiological significance ${ }^{2}$. Therefore, a disruption of this mechanism, can be of pathological significance ${ }^{2}$. In the bladder, a part of such non synaptical cellular signal is mediated through prostaglandin and the NO/CGMP pathway which is explored in our studies presented in this thesis.

\section{Study model}

Both clinical and basic researchers try to gain a better understanding of the principles involved in the integrated control of the lower urinary tract. To this end, the scientifically preferable study subjects are human subjects. However, legal, ethical and moral issues make experiments in human subjects difficult and in some cases even impossible. Moreover, it is often not possible to acquire enough human bladder tissue to conduct all the in vitro experiments needed. Therefore, the use of animal models in this field of research is necessary. In our studies we have chosen the guinea pig bladder since it shows significant structural similarities with the human bladde ${ }^{3-6}$. Previous studies have shown that, obstructed guinea pig bladders show similar cystometric changes as in patients suffering from $O A B^{3-6}$. 


\section{Definition of interstitial cells}

Smet $e t$ al., reported the presence of stellate shaped cells located throughout human and guinea pig bladders, called interstitial cells (IC's)'7. These cells were identified by an immunohistochemical marker called vimentin. In a later study, McCloskey et al. used a different marker, called C-kit to identify IC's that were called interstitial cells of Cajal in analogy with IC's in the gut ${ }^{8}$. It was found that vimentin stains a larger population of IC's than C-Kit ${ }^{8}$. Hence, it is better to use the general term 'interstitial cells' when referring to vimentin-positive IC's. The term interstitial cells of Cajal has to be used to indicate C-kit-positive cells and the term 'interstitial cells of Cajal like' can be used to point to the population of IC's which are vimentin positive but C-kit-negative. All previous research in Maastricht, has been consistent in using vimentin staining to identify IC's. These cells are defined as cells lying in the interstitium, that are vimentin positive. In order to retain consistency in terminology and to make a comparison with previous papers possible, vimentin was used instead of C-kit to stain IC's.

\section{$E P_{1}$ and $E P_{2}$ distribution in the bladder wall}

From all prostanoids, $\mathrm{PGE}_{2}$ has been put forward as the most likely candidate to contribute to overactivity of the urinary bladder ${ }^{9}$. This is due to the presence of clear evidence that $\mathrm{PGE}_{2}$ infused into the bladder reduces bladder capacity ${ }^{10-13}$. Furthermore, it has been shown that in detrusor overactivity models ${ }^{14,15}$, as well as in patients with symptoms of overactive bladder syndrome $\mathrm{e}^{16-18}$ local $P G E_{2}$ production in the bladder is increased. $P \mathrm{PE}_{2}$ is a subtype of prostaglandin (PG) targeting the EP receptors that mediate its physiological effect ${ }^{19}$. There are four subtypes (EP1-EP4), each responding to the natural agonist $P G E_{2}$ in a different manner ${ }^{20}$.

Each of the EP receptors uses a different G-protein coupled transduction system ${ }^{21,22}$. EP1 and $\mathrm{EP}_{3}$ are thought to cause contraction of the smooth muscle, whereas $\mathrm{EP}_{2}$ and $\mathrm{EP}_{4}$ are thought to cause relaxation ${ }^{21,22}$. This difference in response of the muscle to each of the EP receptors has been shown in the uterine smooth muscle ${ }^{23}$. EP1 receptors are found in many tissues in which intracellular signals are generated in response to PG, involving diacylglycerol and 1,4,5-triphosphate ${ }^{24}$. In such systems, EP1 is involved in regulating intracellular $\mathrm{Ca}^{2+}$ and cell excitability. EP2 receptors have been shown to couple to a G-protein, resulting in increased formation of CAMP. In the smooth muscle of different organs, this rise in CAMP through EP2 leads then to muscle relaxation ${ }^{25}$.

In our studies on the distribution of EP1 and EP2 receptor in the urothelium and suburothelial layer of the guinea pig bladder, we found that the EP1 staining was located in urothelial cells and in the suburothelium. Both $E P_{1}$ and $E P_{2}$ receptor are expressed by the urothelium and the suburothelial interstitial cells (SU-IC's) ${ }^{26}$. The EP2 expression in the urothelium is clearly stronger than the $E P_{1}$ expression. Furthermore, unlike in umbrella cells, cyclooxygenase 1 (COX 1 ) was present in basal urothelial cells, making them a possible site of PG synthesis ${ }^{26}$. These results suggest that, $\mathrm{PG}$ produced by the urothelium could target $\mathrm{EP}_{1}$ and $E \mathrm{P}_{2}$ receptors in the urothelium and 
suburothelium. Furthermore, these findings indicate that the urothelium of the lateral wall and the lamina propria have a high degree of structural complexity and potential for signalling, despite their relatively low nerve density. Hence, it can be suggested that complex signalling systems operate in the urothelium and between the urothelium and lamina propria suburothelial interstitial cells (SU-IC's).

The basal urothelial cell layer and, to a lesser extent the intermediate layer, express COXı. Hence, this layer is capable of generating PG. The local cellular targets for PG are most probably the intermediate layers and the umbrella cells of the urothelium, and SU-IC's. Therefore, we can hypothesize that this close spatial arrangement of signalling and responding cells could reflect some functional specialization involving interaction between the basal and outer urothelial cell layers.

It is known that guinea pig SU-IC's express type 3 muscarinic receptors ${ }^{27}$. Since the urothelium may synthesize and release acetylcholine ${ }^{28}$, this raises the possibility that SU-IC's receive multiple inputs like acetylcholine and/or PG. Our observations show further that SU-IC's also express EP1 and $E P_{2}$, indicating that they respond to $P G$. In the intact animal, a major source of PGs acting on these cells may be derived from the basal and intermediate urothelial layers. As a consequence, SU-IC's may be a site of integration of different signals. If some signals such as PG are also under modulation by other urothelial signals (ATP and NO), the physiology of this bladder wall region is particularly complex.

In the muscle layer, we showed that the EP1 receptor was expressed on smooth muscle cells, on surface muscle interstitial cells (SM-IC's) and on intramuscular interstitial cells (IM-IC's ${ }^{29}$. Muscle staining however, was less intense than stainings on the SM-IC's and IM-IC's. Both SM-IC's and IM-IC's have been suggested as the potential source of PG in the muscle layers before ${ }^{30}$ which was confirmed in our study ${ }^{29}$. This localized expression of the EP1 and EP2 receptors and the sites of PG production ( $\mathrm{COX}_{1}$ expression) indicate an unusual and interesting micro-anatomical arrangement in IC's.

In addition, the PG production site $\left(\mathrm{COX}_{1}\right)$ in the IC's was shown to be different from the site that expresses the receptors, which could imply a classic autocrine arrangement. Moreover, the specialization of discrete signal producing regions and signal responsive regions suggests a further degree of complexity. As EP1 and EP2 receptors act through different mediators in the cell and have been shown to have different and in some cases, opposing effects ${ }^{32,33}$, we make a distinction in our hypothesis between these two receptors. In case of $\mathrm{EP}_{1}$, we propose the hypothesis that the PG system operates to facilitate signal propagation in the IC network. Cell activation would stimulate the $\mathrm{COX}_{1}$ enzyme and induce local PGE ${ }_{2}$ production and release, which would then activate an adjacent cell via its $\mathrm{EP}_{1}$ receptor region. The physiological consequence of this structural finding needs further exploration. Based on micro-anatomical evidence however, we can suggest that the network of suburothelial, lamina propria and muscle interstitial cells may form a communicating network ${ }^{30}$. Support for this hypothesis can be found in the studies on an isolated lamina propria 
preparation which have revealed that signals released from urothelium are targeted at the suburothelial cell layer ${ }^{31}$.

Similar results as found for $\mathrm{EP}_{1}$ were found in our studies on $\mathrm{EP}_{2}$ receptor distribution in the muscle layer. The EP2 receptor was shown to be located on SM-IC's, IM-IC's and to a lesser extend on the smooth muscle cells ${ }^{32}$. The EP2 receptor and the COX 1 enzyme were also found to be co-expressed in the same cell. However, a spread and augmentation of a signal mediated by $P_{2} E_{2}$ via $E_{2}$ is unlikely as in most smooth muscle preparations, EP2 has been shown to cause muscle relaxation ${ }^{21}$. In several tissues, EP2 receptors have been shown to couple to a G-protein (G_s), resulting in increased formation of CAMP. In the smooth muscle of different organs, this rise in cAMP through $E P 2$ leads then to muscle relaxation ${ }^{25}$. It is not yet known whether this is the predominant effect of $E P_{2}$ in the detrusor muscle.

\section{The EP1/EP 2 balance hypothesis}

The question to be answered is the possible physiological meaning of the shown EP2 arrangement in relation to the previously shown EP1 distribution in the bladder muscle layers. It is known that, $P G E_{2}$ may have multiple and at times apparently opposing functional effects on a given target tissue such as vascular smooth muscle ${ }^{33,34}$. Although no functional experiment was included in our studies on $\mathrm{EP}_{1}$ and $\mathrm{EP}_{2}$, some possible hypothesis could be put forward. It is explicitly mentioned that these hypotheses are not based on data and need to be confirmed in future functional studies. A possible explanation could be found in the differences in affinity of $P G E_{2}$. It has been shown that the rat $E P 2$ receptor signal transduction pathway is approximately 20 -fold more sensitive for $P G E_{2}$ than for $E_{1}$, as the concentration of $P_{E_{2}}$ required to produce a half-maximal response was 37 $\mathrm{nM}$ for $\mathrm{EP}_{2}$ against 2.1 $\mathrm{nM}$ for $\mathrm{EP}_{1}{ }^{35}$. Furthermore, in order to determine the affinity of $\mathrm{PGE}_{2}$ for $\mathrm{EP}_{1}$ and $E P_{2}$, saturation analysis has been performed showing $K D$ values of $P G E_{2}$ for $E P_{1}$ and $E P_{2}$ be around 24 and $5 \mathrm{nM}$, respectively 35 . Therefore, we hypothesize that under normal conditions, $\mathrm{PGE}_{2}$ levels in the detrusor might be such that the inhibiting EP2 effect predominates the activating EP1 effect, which might result in a stabilization of the muscle layer. Under certain circumstances, the $P G E_{2}$ levels may increase above a certain threshold level in which case the contractile EP1 effect becomes more predominant. Small sub-threshold increases of $P G E_{2}$ might be, in such a case, due to subtle bladder wall irritation, inflammation or stretch. The exact role of the EP2 receptor in the bladder wall remains to be determined by future analysis of the activation, signal propagation and bladder sensory pathways by functional studies. The PGE signal is suggested to spread out through suburothelial and intramuscular interstitial cells expressing EP1. The narrow balance between the contractile $E P_{1}$ and the possible relaxant $E_{2}$ effect might be a system that modulates the autonomous, non-voiding contractions and relaxation which can become disrupted when $P G E_{2}$ levels reach certain higher levels. As there is a CAMP coupling of the EP2 receptor in many other tissues and a lower dissociation constant of $E_{2}$ compared to $E_{1}$, it is suggested that a rise in $P G$ levels may gradually push the balance from a relaxant $\mathrm{EP}_{2}$ effect towards a contractile $\mathrm{EP}_{1}$ effect. 
Hence, PG could have a modulatory role on non-voiding bladder contractions by changing the threshold level for excitability of the IC network. This idea is supported by earlier studies showing that frequency and amplitude of the non-voiding activity is reduced by stimulation of an adrenergic/ cAMP-linked mechanism ${ }^{36}$.

\section{Autonomous bladder activity}

Activating IC's can initiate smooth muscle contraction, possibly via direct electrical coupling through gap junctions ${ }^{37}$. This idea was put forward in relation to the coordination of localized contractions in the bladder wall (autonomous activity) as part of a motor/sensory system regulating bladder afferent activity ${ }^{38,39}$. Many studies described and characterised IC's, which are known to form a network throughout the bladder wall ${ }^{8,38,40,41}$. Our results show that this network of IC's extends from the suburothelial layer and runs through the muscle layer and expresses EP1 and EP2 among other receptors. $\mathrm{PGE}_{2}$ mediated signals can then be relayed through this network via the $\mathrm{PGE}_{2}$ produced by the $\mathrm{COX}_{1}$ enzyme that was recognized in the basal urothelial cell layer. In both our studies in the bladder muscle, we found that the COX 1 enzyme was also expressed on SM-IC's and IM-IC's. COX1-positive IC's were more prevalent in the muscle bundles of the inner muscle than in the outer muscle layers. Signal transduction through coupled IC's would be more rapid than via the spread of electrical or muscle $\mathrm{Ca}^{2+}$ signals. Hence, such coordinated contractions are more likely to be mediated via EP1 and EP2 receptors on IC's than on muscle cells, since by local PG release, random activation of the latter would result in random uncoordinated activity. Thus, the $E P_{1}$ and/or EP2 stimulation of muscle IC's are suggested to be involved in the modulation of the rapid generation of coordinated contractile responses.

\section{The $P G E_{2}$ signal and $O A B$}

The $P G E_{2}$ signal is suggested to be spread out through suburothelial and intramuscular IC's expressing $\mathrm{EP}_{1}$. The narrow balance between the contractile $\mathrm{EP}_{1}$ and the possible relaxant $\mathrm{EP}_{2}$ effect might be a system that modulates the aforementioned autonomous, non-voiding contractions and relaxation which can become disrupted when $\mathrm{PGE}_{2}$ levels reach certain higher levels. Increased bladder sensation is suggested to be associated with localized contractile activity in the bladder wall of human subjects (micro-motions) which are significantly more prevalent in patients with urgency than in asymptomatic volunteers ${ }^{42}$. Hence, urgency is suggested to be associated with autonomous activity of the detrusor and altered micro-motions. If the hypothesis is right and a PGE ${ }_{2}$ system is involved in the modulation of autonomous bladder activity, this system could be a potential therapeutic target. Cyclooxygenase inhibiting drugs, have been shown to alter normal voiding function in rats as well as bladder hyperactivity induced by chemical irritation ${ }^{43}$. Furthermore, it is known that intra-arterial administration of $\mathrm{PGE}_{2}$ to the urinary bladder enhances the micturition reflex'3 . It would be interesting to study the possible role of selective drugs which modulate the EP1 and/or EP2 receptor in the bladder. The $\mathrm{EP}_{1}$ receptor is shown to be involved in the initiation of the 
micturition reflex in normal rats and more specifically, in animals with bladder outlet obstruction ${ }^{44}$. Therefore, it is suggested that EP1 contributes to the generation of detrusor overactivity after bladder outlet obstruction ${ }^{44}$.

There is hardly any literature about the exact role of the EP2 receptor in the bladder. However, it is known that the normal guinea pig bladder does express EP2 receptors ${ }^{26}$ and that the combined $E P_{1} / E P_{2}$ receptor antagonist $A H 6809$ decreases detrusor contraction in isolated human bladder experiments ${ }^{45}$.

\section{The effect of COX inhibition}

A link between the PG system and the muscarinic system had been suggested before ${ }^{46,52,53}$. In the guinea pig bladder, ATP can activate $\mathrm{PGE}_{2}$ production by a complex mechanism, involving the purinergic receptors $\mathrm{P}_{2} \mathrm{X}$ and $\mathrm{P}_{2} \mathrm{Y}^{46}$. This ATP response was shown to be inhibited by the COX inhibitor indomethacin ${ }^{46}$. Another clue for a link between PG and the muscarinic system comes from clinical data. It is known that inhibition of cholinergic activity in the bladder by antimuscarinic drugs, although effective in reducing the symptoms of urgency and frequency, does not have a high enough dosage to target the muscle cells $s^{47,48}$. Therefore, the suggestion is made that anticholinergic drugs could target the mechanisms, operating during the filling phase ${ }^{49-51}$ through locally produced substances such as ATP, NO and PG ${ }^{30,52}$. Our data show that blocking PG synthesis with indomethacin, decreased the cholinergically stimulated autonomous contractions in the isolated bladder. These data suggest that PG could modify normal cholinergically evoked responses.

In order to evaluate the effect of PG on the autonomous activity in the presence of local reflex loops and control by the central nervous system, more experiments should be performed in vivo. A combination of drugs inhibiting both muscarinic receptors and PG function or production could be proposed as an interesting focus of research in the quest for a better treatment for OAB.

\section{The role of PDE's in the bladder}

The cyclic nucleotide mono-phosphates, cAMP and CGMP, are now generally accepted to be important intracellular regulators of several physiological processes, including smooth muscle function ${ }^{53}$. A possible new target for drug therapy in patients with $O A B$, is the PDE 5 enzyme. These drugs prescribed to men with erectile disorders, have appeared to exert an inhibitory effect on the symptoms of $\mathrm{OAB}^{54}$. The role of $\mathrm{CGMP}$ in the modulation of detrusor contractile activity, has clearly been shown ${ }^{55,56}$. The intensity and the duration of the existence of intracellular cyclic nucleotides, are regulated by PDE's. Different PDE subtypes have been shown to be present in animal and human bladders, including PDE 5 in the rat ${ }^{57}, \mathrm{PDE}_{1}$ to $\mathrm{PDE}_{5}$ in the rabbit ${ }^{58-60}$ and $\mathrm{PDE}_{1}$ to $\mathrm{PDE}_{5}$ and $\mathrm{PDE}_{7}$ to PDEg in the human urinary bladder ${ }^{59-62}$.

We have studied the distribution of the PDE5 enzyme in the urothelium and suburothelium of the guinea pig bladder. In our study, we stimulated cGMP production in fresh guinea pig bladder tissue by an NO-donor, with or without pre-incubation with the PDE5 inhibitor, vardenafil. After 
that, tissue stainings were conducted with a cGMP antibody. A positive cGMP staining in the tissue indicated the site of action of vardenafil. A few possible sites of action for PDE 5 inhibitors in the guinea pig urinary bladder lateral wall can be suggested based on our results, i.e. the urothelium, the endothelium of bladder blood vessels and the network of IC's. The urothelium can release NO which is needed for cGMP production. We have shown PDE5 activity in the urothelium which suggests that the urothelium can be the site where CGMP is generated.

As both blood vessels and IC's express the PDE 5 enzyme, this signal could be relayed in both ways. Moreover, $\mathrm{PDE}_{5}$ inhibitors are known to have a relaxant effect on the smooth muscle cells of the blood vessel wall, particularly arteries ${ }^{63}$ and can therefore, increase the blood flow in these arteries ${ }^{63}$. This might also be an effect of the cGMP signal generated in the urothelium.

The involvement of nerve fibers is less probable since in our study we found only a very limited number of nerve fibers to stain positive for CGMP after PDE5 inhibition.

As we have not conducted any functional studies, only a hypothesis can be forwarded which needs to be further investigated and proven. Based on our morphological data it is suggested that PDE5 inhibition has its effect mainly through the nitric oxide mediated cGMP system in the IC's, rather than having a direct effect on neuronal activity. Our data belong to the first set of data available on the site and distribution of PDE 5 activity in the bladder and is limited to a study of distribution of the PDE5 activity in the bladder. Therefore, future in vitro and in vivo experiments are needed to reveal the exact physiological meaning of the found PDE5-activity arrangement in the guinea pig urinary bladder.

Although we have reasons to think that PDE reduces the symptoms of OAB, it is still not known how this effect might be explained. The safety and high tolerability of PDE inhibitors make them an attractive tool to investigate. Their additional physiological and pharmacological functions, for example, the modulation of intracellular cGMP pools and interactions with other local modulatory mechanisms are interesting for future investigation. Some recent papers show that PDE inhibition suppressed rhythmic bladder contractions in humans, guinea pig and rat ${ }^{64}$. This implies that PDE's alter micro contractions and exert their effect on $O A B$ via the non-voiding bladder contractions as explained by the autonomous bladder theory. The clinical application of other PDE inhibitors, including those of the PDE4 and recently developed PDE 5 inhibitors in storage and voiding disorders, certainly needs more scientific attention and seems likely to become a challenging new treatment alternative in the future.

\section{Future perspectives}

A logical next step after the morphological studies presented in this thesis, would be to study the functional meaning of the structural data found. In this thesis, the distribution of EP1 and EP 2 in the guinea pig bladder has been studied and presented. In vitro studies using selective EP1 and/or EP2 blockers and agonists are necessary to explore the exact role of these receptors in bladder physiology by assessing excitation-contraction coupling, excitatory synchronization and contractility. One way 
to do so, is by organ bath studies, such as the one used in our study. A further step, and a more challenging one, would be to study the effects of selective EP1 and EP2 blockers and agonist in vivo. Urodynamic measurements of the effects of PG given intravesically in anaesthetized rats have been conducted in our lab as a pilot study. A challenging problem is the effect of anesthesia in these animals which could be prevented by using decerebrate animals. The ultimate in vivo study would be to study both voiding parameters as well as urodynamic effects of $P G E_{2}$ or $E_{1}$ and $E P_{2}$ selective inhibition in an awake animal. These studies require accurate measuring devices. Since the urodynamic measurement devices are wired, the moving awake animal will present significant technical challenge. Depending on the results, these studies could lead to phase I and II studies in human subjects. A selective modulation of the EP1 and EP2 receptor could be a therapeutic target in functional bladder disorders such as OAB.

In case of phosphodiesterase inhibitors, future clinical use is closer. As these drugs have been studied and registered for other indications such as erectile dysfunction in men, in vivo studies in human subjects can be conducted on short term. However, from a scientific point of view it is equally important to unravel the exact site of action and role of PDE inhibition with in vitro and in vivo studies as is the case with prostaglandin receptors. This information, in combination with clear and reproducible biomarkers, is needed when we target to modulate different excitatory and or inhibitory control systems at the same time.

In order to achieve this, we need to be able to improve our categorization of patients with symptoms of $O A B$, and offer more tailored pharmacological treatment. More specifically, patients with OAB but without proven DO on urodynamic studies, might need a different therapy than patients who exhibit DO at the same time. A combination of drugs targeting different mechanisms involved in bladder physiology such as PG, cGMP, cAMP, TRPV-channels and muscarinic receptors, could then, due to lower necessary concentrations, provide us with a more favorable effect/side effect balance. 


\section{References}

1. Garthwaite, J. Glutamate, nitric oxide and cell-cell signalling in the nervous system. Trends in Neurosciences 14, 60-67 (1991).

2. Dawson, V.L., Dawson, T.M. Nitric oxide in neurodegeneration. Progress in Brain Research 118, 215-229 (1998).

3. Mostwin, J.L., Karim, O.M., van Koeveringe, G. \& Brooks, E.L. The guinea pig as a model of gradual urethral obstruction. The Journal of Urology 145, 854-858 (1991).

4. Klevmark, B. Motility of the urinary bladder in cats during filling at physiological rates. II. Effects of extrinsic bladder denervation on intramural tension and on intravesical pressure patterns. Acta Physiologica Scandinavica 101, 176-184 (1977).

5. Vaughan, C.W. \& Satchell, P.M. Role of sympathetic innervation in the feline continence process under natural filling conditions. Journal of Neurophysiology 68, 1842-1849 (1992).

6. Gillespie, J.I. A developing view of the origins of urgency: the importance of animal models. British Journal of Urology International 96 Suppl 1, 22-28 (2005).

7. Smet, P.J., Jonavicius, J., Marshall, V.R. \& de Vente, J. Distribution of nitric oxide synthase-immunoreactive nerves and identification of the cellular targets of nitric oxide in guinea-pig and human urinary bladder by cGMP immunohistochemistry. Neuroscience 71, 337-348 (1996).

8. McCloskey, K.D. \& Gurney, A.M. Kit positive cells in the guinea pig bladder. The Journal of urology 168 , 832-836 (2002).

9. Rahnama'i, M.S., Van Kerrebroeck, Ph.E.V., de Wachter, S.G. \& van Koeveringe, G.A. The role of prostanoids in urinary bladder physiology. Nature Reviews Urology 9, 283-290 (2012).

10. Maggi, C.A., Giuliani, S., Conte, B., Furio, M., Santicioli, P., Meli, P., Gragnani, L. \& Meli, A. Prostanoids modulate reflex micturition by acting through capsaicin-sensitive afferents. European Journal of Pharmacology 145, 105-112 (1988).

11. McCafferty, G.P., Misajet, B.A., Laping, N.J., Edwards, R.M. \& Thorneloe, K.S. Enhanced bladder capacity and reduced prostaglandin E2-mediated bladder hyperactivity in $\mathrm{EP}_{3}$ receptor knockout mice. American Journal of Physiology. Renal Physiology 295, F507-514 (2008).

12. Schussler, B. Comparison of the mode of action of prostaglandin $\mathrm{E}_{2}\left(\mathrm{PGE}_{2}\right)$ and sulprostone, a $P G \mathrm{E}_{2}$-derivative, on the lower urinary tract in healthy women. A urodynamic study. Urology Research 18, 349-352 (1990).

13. Ishizuka, O., Mattiasson, A. \& Andersson, K.E. Prostaglandin E2-induced bladder hyperactivity in normal, conscious rats: involvement of tachykinins? The Journal of Urology 153, 2034-2038 (1995).

14. Park, J.M., Yang T., Arend L.J., Schnermann J.B., Peters C.A., Freeman M.R. \& Briggs J.P. Obstruction stimulates $\mathrm{COX}_{2}$ expression in bladder smooth muscle cells via increased mechanical stretch. The American Journal of Physiology 276, F129-136 (1999).

15. Hu, V.Y., Malley, S., Dattilio, A., Folsom, J.B., Zvara, P. \& Vizzard, M.A. COX2 and prostanoid expression in micturition pathways after cyclophosphamide-induced cystitis in the rat. American Journal of Physiology Regulatory Integrative and Comparative Physiology 284, R574-585 (2003). 
16. Kim, J.C., Park, E.Y., Seo, S.I., Park, Y.H. \& Hwang, T.K. Nerve growth factor and prostaglandins in the urine of female patients with overactive bladder. The Journal of Urology 175, 1773-1776; discussion 1776 (2006).

17. Kim, J.C., Park, E.Y., Hong, S.H., Seo, S.I., Park, Y.H. \& Hwang, T.K. Changes of urinary nerve growth factor and prostaglandins in male patients with overactive bladder symptom. International Journal of Urology 12 875-880 (2005).

18. Cho, K.J., Kim, H.S., Koh, J.S. \& Kim, J.C. Changes in urinary nerve growth factor and prostaglandin E(2) in women with overactive bladder after anticholinergics. International Urogynecology Journal (2012).

19. Alexander, S.P., Mathie, A. \& Peters, J.A. Guide to Receptors and Channels (GRAC), 3rd edition. British Journal of Pharmacology 153 Suppl 2, S1-209 (2008).

20. Negishi, M., Sugimoto, Y. \& Ichikawa, A. Prostaglandin E receptors. Journal of Lipid Mediators and Cell Signalling 12, 379-391 (1995).

21. Coleman, R.A., Smith, W.L. \& Narumiya, S. International Union of Pharmacology classification of prostanoid receptors: properties, distribution, and structure of the receptors and their subtypes. Pharmacological Reviews 46, 205-229 (1994).

22. Ikeda, M., Kawatani, M., Maruyama, T. \& Ishihama, H. Prostaglandin facilitates afferent nerve activity via EP1 receptors during urinary bladder inflammation in rats. Biomedical Research (Tokyo, Japan) 27, 49-54 (2006).

23. Astle, S., Thornton, S. \& Slater, D.M. Identification and localization of prostaglandin $E_{2}$ receptors in upper and lower segment human myometrium during pregnancy. Molecular Human Reproduction 11, 279-287 (2005).

24. Breyer, M.D., Jacobson, H.R. \& Breyer, R.M. Functional and molecular aspects of renal prostaglandin receptors. Journal of American Society of Nephrology 7, 8-17 (1996).

25. Breyer, R.M., Bagdassarian, C.K., Myers, S.A. \& Breyer, M.D. Prostanoid receptors: subtypes and signaling. Annual Review of Pharmacology and Toxicology 41, 661-69o (2001).

26. Rahnama'i, M.S., van Koeveringe, G.A., Essers, P.B., de Wachter, S.G., de Vente, J., Van Kerrebroeck, Ph.E.V. \& Gillespie, J.I. Prostaglandin receptor EP1 and EP2 site in guinea pig bladder urothelium and lamina propria. The Journal of Urology 183, 1241-1247 (2010).

27. Grol, S. Essers, P.B., van Koeveringe, G,A., Martinez-Martinez, P., de Vente, J. \& Gillespie J.I. M(3) muscarinic receptor expression on suburothelial interstitial cells. British Journal of Urology International 104, 398-405 (2009).

28. Lips, K.S., Wunsch, J., Zarghooni, S., Bschleipfer, T., Schukowski, K., Weidner, W., Wessler, I., Schwantes, U., Koepsell, H., \& Kummer W. Acetylcholine and molecular components of its synthesis and release machinery in the urothelium. European Urology 51, 1042-1053 (2007).

29. Rahnama'i, M.S., de Wachter, S.G., van Koeveringe, G.A., Van Kerrebroeck, Ph.E.V., de Vente, J. \& Gillespie, J.I. The relationship between prostaglandin E receptor 1 and cyclooxygenase I expression in guinea pig bladder interstitial cells: proposition of a signal propagation system. The Journal of Urology $185,315-322$ (2011). 
30. de Jongh, R., Grol, S., van Koeveringe, G.A., Van Kerrebroeck, Ph.E.V., de Vente, J. \& Gillespie, J.I., The localization of cyclooxygenase immuno-reactivity (COXI-IR) to the urothelium and to interstitial cells in the bladder wall. Journal of Cellular and Molecular Medicine 13, 3069-3081 (2009).

31. Nile, C.J., de Vente, J. \& Gillespie, J.I. Stretch independent regulation of prostaglandin E(2) production within the isolated guinea-pig lamina propria. British Journal of Urology International 105, 540-548 (2010).

32. Rahnama'i, M.S., Biallosterski, B.T., de Wachter, S.G., Van Kerrebroeck, Ph.E.V. \& van Koeveringe, G.A. The distribution of the prostaglandin E receptor type $2\left(\mathrm{EP}_{2}\right)$ in the detrusor of the guinea pig. Prostaglandins and Other Lipid Mediators (2012).

33. Bonvalet, J.P., Pradelles, P. \& Farman, N. Segmental synthesis and actions of prostaglandins along the nephron. The American Journal of Physiology 253, F377-387 (1987).

34. Smith, W.L. Prostanoid biosynthesis and mechanisms of action. The American Journal of Physiology 263, F181-191 (1992).

35. Boie, Y., Stocco, R., Sawyer, N., Slipetz, D.M., Ungrin, M.D., Neuschäfer-Rube, F., Püschel, G.P., Metters, K.M. \& Abramovitz, M. Molecular cloning and characterization of the four rat prostaglandin E2 prostanoid receptor subtypes. European Journal of Pharmacology 340, 227-241 (1997).

36. Gillespie, J.I. Noradrenaline inhibits autonomous activity in the isolated guinea pig bladder. British Journal of Urology International 93, 401-409 (2004).

37. Hashitani, H., Yanai, Y. \& Suzuki, H. Role of interstitial cells and gap junctions in the transmission of spontaneous Ca2+ signals in detrusor smooth muscles of the guinea-pig urinary bladder. The Journal of Physiology 559, 567-581 (2004).

38. Gillespie, J.I. The autonomous bladder: a view of the origin of bladder overactivity and sensory urge. British Journal of Urology International 93, 478-483 (2004).

39. Gillespie, J.I., van Koeveringe, G.A., de Wachter, S.G. \& de Vente, J. On the origins of the sensory output from the bladder: the concept of afferent noise. British Journal of Urology International 103, 1324-1333 (2009).

40. Gillespie, J.I., Markerink-van Ittersum, M. \& de Vente, J. cGMP-generating cells in the bladder wall: identification of distinct networks of interstitial cells. British Journal of Urology International 94, 1114-1124 (2004).

41. Sui, G.P., Rothery, S., Dupont, E., Fry, C.H. \& Severs, N.J. Gap junctions and connexin expression in human suburothelial interstitial cells. British Journal of Urology International 90, 118-129 (2002).

42. Drake, M.J., Harvey, I.J., Gillespie, J.I. \& Van Duyl, W.A. Localized contractions in the normal human bladder and in urinary urgency. British Journal of Urology International 95, 1002-1005 (2005).

43. de Groat, W.C. \& Yoshimura, N. Pharmacology of the lower urinary tract. Annual Review of Pharmacology and Toxicology 41, 691-721 (2001).

44. Lee, T., Hedlund, P., Newgreen, D. \& Andersson, K.E. Urodynamic effects of a novel EP(1) receptor antagonist in normal rats and rats with bladder outlet obstruction. Journal of Urology 177, 1562-1567 (2007).

45. Palea, S., Toson G., Pietra C., Trist D.G., Artibani W., Romano O. \& Corsi M. Pharmacological characterization of thromboxane and prostanoid receptors in human isolated urinary bladder. British Journal of Pharmacology 124, 865-872 (1998). 
46. Nile, C.J., de Vente, J. \& Gillespie, J.I. Stretch independent regulation of prostaglandin E production within the isolated guinea-pig lamina propria. British Journal of Urology International (2009).

47. Finney, S.M., Andersson, K.E., Gillespie, J.I. \& Stewart, L.H. Antimuscarinic drugs in detrusor overactivity and the overactive bladder syndrome: motor or sensory actions? British Journal of Urology International 98, 503-507 (2006).

48. Andersson, K.E. \& Yoshida, M. Antimuscarinics and the overactive detrusor-which is the main mechanism of action? European Urology 43, 1-5 (2003).

49. de Groat, W.C. The urothelium in overactive bladder: passive bystander or active participant? Urology 64 , 7-11 (2004).

50. Fry, C.H., Ikeda, Y., Harvey, R., Wu, C. \& Sui, G.P. Control of bladder function by peripheral nerves: avenues for novel drug targets. Urology 63, 24-31 (2004).

51. Gillespie, J.I. Inhibitory actions of calcitonin gene-related peptide and capsaicin: evidence for local axonal reflexes in the bladder wall. British Journal of Urology International 95, 149-156 (2005).

52. de Jongh, R., van Koeveringe, G.A., Van Kerrebroeck, Ph.E.V., Markerink-van Ittersum, M., de Vente, J. \& Gillespie, J.I. The effects of exogenous prostaglandins and the identification of constitutive cyclooxygenase I and II immunoreactivity in the normal guinea pig bladder. British Journal of Urology International 100, 419-429 (2007).

53. Antoni, F.A. Molecular diversity of cyclic AMP signalling. Frontiers in Neuroendocrinology 21, 103-132 (2000).

54. Sandner, P., Hutter, J., Tinel, H., Ziegelbauer, K. \& Bischoff, E. PDE5 inhibitors beyond erectile dysfunction. International Journal of Impotence Research 19, 533-543 (2007).

55. Gillespie, J.I. Phosphodiesterase-linked inhibition of non-micturition activity in the isolated bladder. British Journal of Urology International 93, 1325-1332 (2004).

56. Truss, M.C., Uckert, S., Stief, C.G., Forssmann, W.G. \& Jonas, U. Cyclic nucleotide phosphodiesterase (PDE) iso-enzymes in the human detrusor smooth muscle. II. Effect of various PDE inhibitors on smooth muscle tone and cyclic nucleotide levels in vitro. Urological Research 24, 129-134 (1996).

57. Filippi, S., Morelli, A., Sandner, P., Fibbi, B., Mancina, R., Marini, M., Gacci, M., Vignozzi, L., Vannelli, G.B., Carini, M., Forti, G. \& Maggi, M. Characterization and functional role of androgen-dependent PDE5 activity in the bladder. Endocrinology 148, 1019-1029 (2007

58. Uckert, S., Sigl, K., Waldkirch, E.S., Sandner, P., Ulbrich, E., Oelke, M., Stief, C.G. \& Kuczyk, M.A. Significance of phosphodiesterase isoenzymes in the control of human detrusor smooth muscle function. An immunohistochemical and functional study. Der Urologe Ausgabe A 48, 764-769 (2009)

59. Morley, D.J., Hawley, D.M., Ulbright, T.M., Butler, L.G., Culp, J.S. \& Hodes, M.E. Distribution of phosphodiesterase I in normal human tissues. Journal of Histochemistry and Cytochemistry 35, 75-82 (1987)

6o. Nagasaki, S., Nakano, Y., Masuda, M., Ono, K., Miki, Y., Shibahara, Y. \& Sasano, H. Phosphodiesterase type 9 (PDE9) in the human lower urinary tract: an immunohistochemical study. British Journal of Urology International 109, 934-940 (2012). 
61. Uckert, S., Kuthe, A., Jonas, U. \& Stief, C.G. Characterization and functional relevance of cyclic nucleotide phosphodiesterase isoenzymes of the human prostate. The Journal of Urology 166, 2484-2490 (2001)

62. Kuthe, A., Mägert, H., Uckert, S., Forssmann, W.G., Stief, C.G. \& Jonas, U.Gene expression of the phosphodiesterases 3A and 5A in human corpus cavernosum penis. European Urology 38, 108-114 (2000).

63. Vlachopoulos, C., loakeimidis, N., Rokkas, K.\& Stefanadis, C. Cardiovascular effects of phosphodiesterase type 5 inhibitors. Journal of Sexual Medicine 6, 658-674 (2009).

64. Buyuknacar, H.S., Kumcu, E.K., Gocmen, C. \& Onder, S. Effect of phosphodiesterase type 4 inhibitor rolipram on cyclophosphamide-induced cystitis in rats. European Journal of Pharmacology (2008). 



\section{Summary}

This thesis is composed of two parts. The first part focuses on the distribution and the role of prostaglandins $(\mathrm{PG})$ in the guinea pig urinary bladder and the second part on the distribution of the phosphodiesterase (PDE) enzymes, in particular the type 5 enzyme (PDE5).

A general introduction presenting the overactive bladder syndrome (OAB) and its impact on the quality of life and economical burden in patients affected, is given in chapter 1. Moreover, the anatomy, physiology and histology of the lower urinary tract are discussed, followed by a brief overview on the possible role of PG and PDE 5 in the urinary bladder.

The current literature on the role and distribution of $\mathrm{PGE}_{2}$ and its receptors in the urinary bladder is discussed in chapter 2. Five primary prostanoids are synthesized by the cyclo oxygenase enzymes, COX-1 and COX-2: the prostaglandins $\mathrm{PGE}_{2}, \mathrm{PGF}_{2 \alpha^{\prime}}, \mathrm{PGI}_{2}, \mathrm{PGD}_{2}$ and thromboxane $\mathrm{A}_{2}$. In both animal models and in human studies, high levels of these signaling molecules have been implicated, in decreased functional bladder capacity and micturition volume, as well as in increased voiding contraction amplitude. As a consequence, inhibition of prostanoid production or the use of prostanoid receptor antagonists, might be a rational way to treat patients with detrusor overactivity. Similarly, prostanoid receptor agonists, or agents that stimulate their production, might have a function in treating bladder underactivity.

The distribution of the $P \mathrm{CE}_{2}$ receptors $E \mathrm{P}_{1}$ and $E P_{2}$ in the urothelium and suburothelium of the guinea pig urinary bladder is presented in chapter 3 . In this morphological study of the guinea pig bladder, immunohistochemical stainings with antibodies against $\mathrm{EP}_{1}, \mathrm{EP}_{2}$, vimentin and $\mathrm{COX}_{1}$ were applied. EP1 staining was seen in urothelial cells and in the suburothelium. Urothelial EP1 staining was punctuate, weak and detected in all urothelial cell layers, including suburothelial cells. In contrast, strong EP2 staining was seen in the urothelium and in suburothelial cells. COX 1 was absent in interstitial cells and umbrella cells and had the highest concentration in the basal cell layer. Vimentin was used to identify interstitial cells. These interstitial cells express both EP1 and $E P_{2}$, indicating that they can respond to $P_{E_{2}}$. The COX1 enzyme was present in basal urothelial cells, making them a possible site of $\mathrm{PGE}_{2}$ synthesis. $\mathrm{PGE}_{2}$ produced by urothelium may target $\mathrm{EP}_{1}$ and $\mathrm{EP}_{2}$ in the urothelium and suburothelium. Therefore, $\mathrm{PGE}_{2}$ is hypothesized to have a role in signal regulation in the bladder wall. 
The distribution of EP1 in the detrusor muscle layer of the guinea pig is portrayed in chapter 4 . Immunohistochemical stainings with antibodies against $\mathrm{EP}_{1}$, vimentin and $\mathrm{CO}_{1}$ were used to visualize the $\mathrm{EP}_{1}$ distribution. $\mathrm{EP}_{1}$ was identified on smooth muscle cells, vimentin positive surface muscle cells and intramuscular interstitial cells. Muscle staining was less intense than on interstitial cells and had a punctuate appearance. EP1 expression on interstitial cells was highly localized. Discrete regions of intense staining were noted on interstitial cell long stretched cell bodies, also known as processes. COX 1 was also expressed in muscle interstitial cells. COX 1 positive interstitial cells were more prevalent in the muscle bundles of the inner muscle than in the outer muscle layers. $\mathrm{COX}_{1}$ staining was noted on discrete regions of the cell or cell processes. Double staining with $\mathrm{EP}_{1}$ and $\mathrm{COX}_{1}$ suggested that cell regions expressing the former are different from those expressing the latter. The discovered arrangement of $E_{1}$ and $C_{1} O X_{1}$ may have the potential to facilitate the propagation of signals in the interstitial cell network. Such a signalling system may have a role in coordinating events, as in bladder pathology, facilitating the global coordinated changes associated with bladder wall remodelling.

In chapter 5 , the distribution of the EP2 receptor in the detrusor muscle layer is described. EP2 distribution was studied through immunohistochemical stainings with antibodies against EP2, vimentin and $\mathrm{COX}_{1}$. EP2 receptor immunoreactivity was located on the smooth muscle cells as well as on vimentin positive surface muscle cells and intramuscular interstitial cells. EP2 expression on interstitial cells was highly localized. Discrete regions of intense staining were observed on the interstitial cell processes. COX 1 expression was shown in the muscle interstitial cells and was found to be located on discrete regions of the cell and cell processes. Double staining with $\mathrm{EP}_{2}$ and $\mathrm{CO}_{1}$ suggests that the regions of a cell expressing EP2 are different from those expressing COX $\mathrm{X}_{1}$. The presence of $\mathrm{COX}_{1}$, and $\mathrm{EP}_{2}$ on the network of interstitial cells suggests a role of this network in the propagation of signals. Due to a CAMP coupling of the EP2 receptor in many other tissues and a lower dissociation constant of EP2, it is suggested that a rise in PG levels may gradually push the balance from a relaxant EP2 effect towards a contractile effect. Hence, PG could have a modulatory role on the non-voiding bladder contractions by changing the threshold level for excitability of the interstitial cell network.

The effect of PG depletion by means of COX-inhibition on cholinergic enhanced spontaneous contractions is displayed in chapter 6 . In this study, the urethra and bladder of male guinea pigs were placed in an organ bath with Krebs' solution and a transurethral catheter was introduced to measure intravesical pressure. The muscarinic agonist arecaidine, the non-selective COX inhibitor indomethacin, and $P G E_{2}$ were subsequently added to the organ bath. The average frequency $\left(F_{\text {ini }}\right)$ and amplitude $\left(\mathrm{P}_{\text {ini }}\right)$ of spontaneous contractions in the first 2 minutes after arecaidine as well as the average frequency $\left(\mathrm{F}_{\text {steady }}\right)$ and amplitude $\left(\mathrm{P}_{\text {steady }}\right)$ during the 5 minutes before the next wash out, were studied. Application of $1 \mu \mathrm{M} \mathrm{PGE}_{2}$ increased the amplitude of spontaneous contractions without 
affecting frequency. Indomethacin $(10 \mu \mathrm{M})$ reduced amplitude but not frequency. The addition of indomethacin did not alter $F_{i n i}$ after the first application $(p=0.7665)$. However, after the second wash, $F_{i n i}$ was decreased $(p=0.0005) . F_{\text {steady }}, P_{\text {steady }}$ and $P_{\text {ini }}$ were not significantly different in any of the conditions. These effects of indomethacin were reversible by $\mathrm{PGE}_{2}$ addition. Blocking PG synthesis decreased the cholinergically stimulated autonomous contractions in the isolated bladder. These data suggest that PG could modify normal cholinergically evoked responses.

A review of the current knowledge on the role of PDE in the bladder pathophysiology is given in chapter 7. PDE enzymes hydrolyse the cyclic nucleotide monophosphates CAMP and CGMP, which have been suggested to play a role in bladder physiology. The inhibition of PDE, resulting in an increase in CAMP- and CGMP levels, has been shown to relax isolated urinary bladder smooth musculature of different species. Different PDE subtypes are known to be present in animal and human bladders, including PDE 5 in the rat, $\mathrm{PDE}_{1}$ to $\mathrm{PDE}_{5}$ in the rabbit and $\mathrm{PDE}_{1}$ to $\mathrm{PDE}_{5}$ and $\mathrm{PDE}_{7}$ to PDEg in the human urinary bladder. The majority of preclinical functional studies have been conducted in the rat bladder, focussing on selective inhibitors of the PDE4 and PDE 5 and inducing a relaxation effect. To date, only the significance of PDE 1 and PDE 5 has been studied clinically for the management of storage and voiding disorders. PDEı inhibition has been suggested to improve micturition frequency. However, there are, to date, only limited clinical studies to prove this theory. PDE5 inhibition has been studied widely and shown to improve IPSS in men with lower urinary tract symptoms with or without benign prostate hyperplasia. Furthermore, PDE5 inhibitors in combination with an alpha-adrenoceptor antagonist have been shown to be superior to monotherapy with either of the agents to improve IPSS. The role of PDE5 inhibitors in the treatment of women with detrusor overactivity remains unclear and is an interesting field for future research. The clinical application of other PDE inhibitors, including those of the PDE4 and the recently developed $\mathrm{PDE}_{5}$ inhibitors, in storage and voiding disorders, certainly needs more scientific attention and seems likely to become a challenging new treatment alternative in the future.

The distribution and the site of action of PDE 5 in the guinea bladder are discussed in chapter 8. The data of this chapter were obtained through an indirect visualization technique. This was accomplished by visualizing the result of PDE 5 inhibition (i.e. CGMP) in the guinea pig bladder tissue that was stimulated with nitric oxide (NO) and pre-incubated with the PDE5 inhibitor Vardenafil.

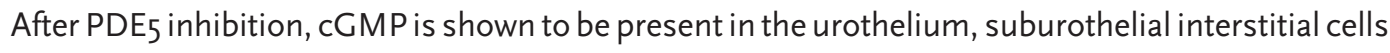
and the endothelium of blood vessels. CGMP is not expressed in nerves positive for CGRP, NF, and SV2 and only in very few efferent nerves positive for PGP9.5 staining. The possible site of action of $\mathrm{PDE}_{5}$ inhibition in the bladder is on urothelium, suburothelial interstitial cells and blood vessels, rather than on bladder nerve fibers. 
A general discussion of all the studies presented in the thesis is written in chapter 9. Functional studies would be a next step to understand the functional meaning of the data described in this thesis. The data presented are a basis for further research on selective modulation of the EP1 and $E P_{2}$ receptor which could be a therapeutic target in functional bladder disorders such as OAB. PDE inhibitors are closer to clinical use, as these drugs have been studied and registered for other indications such as erectile dysfunction in men. Therefore, in vivo studies in human subjects can be conducted on short term. However, from a scientific point of view, it is very important to unravel the exact site of action and role of PDE inhibition with in vitro and in vivo studies as is the case with PG. In this way, a combination of drugs targeting different mechanisms involved in bladder physiology such as PG, cGMP, cAMP, and muscarinic receptors, could reduce side effects and improve efficacy. 




\title{
Samenvatting
}

\author{
(Summary in Dutch)
}

In dit proefschrift wordt de verspreiding en de rol van prostaglandinereceptoren en de verdeling van de fosfodiësterase (PDE)-enzymen, in het bijzonder het type 5 (PDE5) in de urineblaas van de cavia besproken.

Het eerste hoofdstuk is een algemene inleiding over het overactieve blaas syndroom (OAB) en de invloed ervan op de kwaliteit van leven met de daarbij behorende economische gevolgen. In het kort wordt de anatomie, fysiologie en histologie van de lage urinewegen besproken, gevolgd door een kort overzicht van de mogelijke rol van prostaglandine (PG) en PDE5 in de urineblaas.

De huidige kennis over de rol en de verspreiding van $\mathrm{PGE}_{2}$ en de receptoren in de urineblaas wordt besproken in hoofdstuk 2. Er zijn vijf primaire prostanoïden: de prostaglandines $P G E_{2}, P G F_{2 \alpha^{\prime}}, P G I_{2}$, $\mathrm{PGD}_{2}$ en Thromboxaan $\mathrm{A}_{2}$. Deze prostanoïden worden gesynthetiseerd door de cyclo oxygenase enzymen, $\mathrm{COX}_{1}$ en $\mathrm{COX}_{2}$. Zowel in diermodellen als in studies bij proefpersonen, zijn deze signaalmoleculen aangetoond in geval van verminderde functionele blaas capaciteit. Op basis hiervan is de gedachte ontstaan dat remming van de prostanoïd productie of het gebruik van de prostanoïd receptorantagonisten, een potentiële behandeling van patiënten met overactive blaas syndroom kan zijn. Op dezelfde manier kunnen wellicht prostanoïd receptor agonisten of stoffen die de productie van prostanoïden stimuleren een plaats hebben bij de behandeling van blaas onderactiviteit.

In hoofdstuk 3 wordt een studie gepresenteerd naar de verdeling van de $P G E_{2}$ receptoren $E P_{1}$ en $E P_{2}$ in het urotheel en het suburotheel van de urineblaas van de cavia. In deze morfologische studie worden immunohistochemische technieken met antilichamen tegen $\mathrm{EP}_{1}, \mathrm{EP}_{2}$, vimentin en $\mathrm{COX}_{1}$ toegepast. De resultaten tonen een zwak en puntsgewijze EP1 kleuring verdeeld over alle cellagen van het urotheel met inbegrip van de suburotheliale cellen. Daarnaast wordt in het urotheel en het suburotheel een sterke EP2 kleuring waargenomen. Het COX1 enzym was afwezig in interstitiële cellen en paraplu cellen maar had de hoogste concentratie in de basale cellaag van het urotheel. Het antilichaam vimentin werd gebruikt voor de identificatie van interstitiële cellen. Deze cellen kleurden aan voor $\mathrm{EP}_{1}$ en $E \mathrm{P}_{2}$, hetgeen erop wijst dat zij op $\mathrm{PGE}_{2}$ kunnen reageren. Het COX enzym was aanwezig in basale urotheliale cellen. Dit toont aan dat deze laag mogelijk een plaats is van $\mathrm{PGE}_{2}$ productie. $\mathrm{PGE}{ }_{2}$ geproduceerd door het urotheel kan zo zijn werking hebben via de EP1 en $\mathrm{EP}_{2}$ receptoren in het urotheel en het suburotheel. 
De verdeling van de $\mathrm{EP}_{1}$ receptoren in de spierlaag van de caviablaas (de detrusor) wordt weergegeven in hoofdstuk 4. Immunohistochemische technieken met antilichamen tegen $E P_{1}$, vimentin en $C_{1} O X_{1}$ werden gebruikt om $E P_{1}$ te visualiseren. $E P_{1}$ werd gezien op de gladde spiercellen, vimentin positieve oppervlakte interstitiële cellen en de intramusculaire interstitiële cellen. De kleuring van de gladde spiercellen was minder intens dan die op interstitiële cellen. EP1 expressie op interstitiële cellen was steeds op een klein stuk van de cel gelokaliseerd. Daarnaast werd het $\mathrm{COX}_{1}$ enzym op de interstitiële cellen in de spierlaag aangetoond. $\mathrm{COX}_{1}$ positieve interstitiële cellen werden vaker in de spierbundels van de binnenste spierlaag gevonden dan in de buitenste spier lagen. Uit de ontdekte rangschikking van $\mathrm{EP}_{1}$ en $\mathrm{COX}_{1}$ kan worden geconcludeerd dat de PG signalen via het netwerk van interstitiële cellen door de spierlagen van de blaas verspreid zou kunnen worden. Dit systeem kan dan een rol vervullen in de coördinatie van verschillende processen in de blaas.

In hoofdstuk 5, wordt de verspreiding van de EP2 receptor in de spierlaag beschreven. De verspreiding van de EP2 receptoren werd bestudeerd door middel van immunohistochemische technieken met antilichamen tegen $\mathrm{EP}_{2}$, vimentin en $\mathrm{COX}_{1}$. EP2 receptoren werden gezien op gladde spiercellen, op vimentin positieve oppervlakte interstitiële cellen en intramusculaire interstitiële cellen. EP2 expressie op interstitiële cellen was steeds op een klein gedeelte van de cel gelokaliseerd. Op de uitlopers van de interstitiële cellen werd afzonderlijke regio's van intense EP2 kleuring waargenomen. Het COX 1 enzym werd in de interstitiële cellen gelokaliseerd. Dit enzym was op afzonderlijke regio's van de cel en de cel uitlopers gelokaliseerd. Dubbel kleuringen met $E_{2}$ en $C_{1} O_{1}$ wijzen erop dat de expressie plaats van EP2 een andere is dan die van $C_{2} X_{1}$. De aanwezigheid van $\mathrm{COX}_{1}$ en $\mathrm{EP}_{2}$ op het netwerk van interstitiële cellen kan erop wijzen dat het netwerk van interstitiële cellen een rol heeft in de verspreiding van PG signalen.

Op basis van een lagere dissociatieconstante van EP2, wordt voorgesteld dat een stijging van PG niveaus geleidelijk het evenwicht van een relaxerend EP2 effect naar een contractiele EP1 effect kan doen doorslaan. PG kan derhalve een rol hebben in het regelmechanisme van de blaas middels verandering van de drempelwaarde voor de prikkelbaarheid van het netwerk.

Het effect van PG concentratieverlaging middels COX-remming op cholinerg geïnduceerde spontane contracties wordt uiteengezet in hoofdstuk 6. In deze studie, werd een katheter door de urinebuis geplaatst om de intravesicale druk van geïsoleerde cavia blazen te meten. De blazen werden geplaatst in een orgaanbad met Krebs oplossing. Een cholinerge, muscarinerge agonist (Arecaidine), een niet-selectieve COX-remmer (indomethacin) en $\mathrm{PGE}_{2}$ werden opeenvolgend toegevoegd aan het orgaanbad. De gemiddelde frequentie $\left(F_{\text {ini }}\right)$ en de amplitude $\left(P_{\text {ini }}\right)$ van spontane contracties in de eerste 2 minuten na arecaidine werden bestudeerd, evenals de gemiddelde frequentie $\left(F_{\text {steady }}\right)$ en de amplitude $\left(\mathrm{P}_{\text {steady }}\right)$ tijdens de 5 minuten voordat de volgende wasstap gebeurde. Toevoeging van $1 \mu \mathrm{M}$ $P G E_{2}$ verhoogt de amplitude van spontane contracties zonder een effect te hebben op de frequentie. 
COX-remming middels indomethacin $(10 \mu \mathrm{M})$ verminderde de amplitude maar niet de frequentie. De toevoeging van indomethacin had geen effect op $F_{\text {ini }}$ na de eerste stimulatie $(p=0.7665)$. Echter, na de tweede wasstap, was $F_{\text {ini }}$ verlaagd $(p=0.0005) . F_{\text {steady }}, P_{\text {steady }}$ en $P_{\text {ini }}$ veranderen niet significant. Door $P G E_{2}$ toevoeging werd de omkeerbaarheid van deze effecten van indomethacin gecontroleerd en aangetoond. De frequentie van muscarinerg gestimuleerde autonome contracties in de geïsoleerde blaas daalt door het blokkeren van de PG synthese. Deze gegevens duiden erop dat PG nodig is voor de normale muscarinerg geïnduceerde contractie.

Een overzicht van de huidige kennis over de rol van PDE in de blaas pathofysiologie wordt in hoofdstuk 7 geven. PDE enzymen hydrolyseren de cyclische nucleotide monophosphates CAMP en cGMP die een rol spelen in de blaas fysiologie. De remming van PDE, resulterend in een verhoging in CAMP- en cGMP niveaus, heeft een ontspannende werking in geïsoleerde urineblaas gladde spieren cellen van verschillende diersoorten. Er zijn verschillende PDE subtypen aangetoond in de dierlijke en menselijke blaas waaronder PDE5 in rat, $\mathrm{PDE}_{1}$ en $\mathrm{PDE}_{5}$ in konijn en $\mathrm{PDE}_{1}$ - $\mathrm{PDE}_{5}$ en PDE7 -PDEg in de menselijke urineblaas. De meerderheid van de preklinische functionele studies zijn uitgevoerd in de rattenblaas en zijn toegespitst op selectieve inhibitoren van de PDE4 en PDE5. Tot op heden is alleen de betekenis van PDE1 en PDE5 klinisch bestudeerd. Van PDE1 inhibitie is gesuggereerd dat het de plasfrequentie verlaagt. Er zijn echter, tot nu toe, alleen beperkte klinische studies beschikbaar om deze suggestie te onderbouwen. PDE 5 inhibitie is uitgebreid bestudeerd en daarvan is aangetoond dat het een verbetering geeft op de scorelijst van plasklachten (IPSS) bij mannen met lage urineweg symptomen met of zonder goedaardige prostaatvergroting. Bovendien, is bekend dat PDE5-remmers in combinatie met een alpha-adrenoceptor antagonist superieur zijn aan monotherapie met een van de twee genoemde medicijnen als het gaat om de verbetering van IPSS. De rol van PDE5-remmers bij de behandeling van vrouwen met detrusor overactiviteit blijft onduidelijk en is een interessant gebied voor toekomstig onderzoek. De klinische toepassing van andere PDE-remmers, waaronder PDE4 en de onlangs ontwikkelde PDE5-remmers, verdienen zeker meer wetenschappelijke aandacht en kunnen in de toekomst een uitdagend therapeutisch alternatief worden.

De verdeling en de lokatie van effect van het PDE5 enzym in de caviablaas wordt besproken in hoofdstuk 8. De gegevens van dit hoofdstuk zijn verkregen door middel van een indirecte visualisatie techniek. Hierbij werd het product van PDE5 inhibitie (d.w.z. cGMP) bestudeerd in blaas weefsels welke na voorbewerking met de PDE5-remmer vardenafil met stikstofmonoxide (NO) waren gestimuleerd. $\mathrm{Na}$ PDE5 remming, wordt cGMP aangetoond in het urotheel, de suburotheliale interstitiële cellen en het endotheel van bloedvaten. CGMP is niet aanwezig in zenuwen die aankleurden met een CGRP, NF of SV2 kleuring. In slechts enkele efferente zenuwen was er een cGMP kleuring te zien na $\mathrm{PDE}_{5}$ inhibitie. De mogelijke werkingsplaats van PDE 5 inhibitoren is daarom het urotheel, de suburotheliale interstitiële cellen en de bloedvaten, en niet de eerder gesuggereerde zenuwvezels. 
Een algemene discussie van alle studies gepresenteerd in dit proefschrift volgt in hoofdstuk 9. Functionele studies zijn de volgende stap om de betekenis van de gegevens die in dit proefschrift worden beschreven beter te begrijpen. De gepresenteerde gegevens vormen een basis voor verder onderzoek naar selectieve modulatie van de EP1 en EP2 receptoren. Deze kunnen een potentieel therapeutisch middel zijn in de behandeling van functionele blaas aandoeningen zoals OAB. PDEremmers, zijn dichterbij klinisch gebruik, daar deze middelen reeds zijn bestudeerd en geregistreerd voor andere indicaties zoals erectie stoornissen bij mannen. Klinisch onderzoek bij proefpersonen kan daarom op korte termijn worden uitgevoerd. Echter, vanuit een wetenschappelijke visie is het belangrijk de exacte werkingsplaats van PDE remming met in vitro en in vivo studies te ontrafelen. Op deze manier kan wellicht een combinatie van middelen worden gevonden waarvan elk gericht is op een bepaald mechanisme van de blaas fysiologie bijvoorbeeld PG, cGMP, cAMP en muscarinerge receptoren. Hierdoor kunnen hopelijk de bijwerkingen van de behandeling verminderd, en de werkzaamheid, verhoogd worden. 


\section{Acknowledgment - Dankwoord}

Mij realiserend dat dit deel van het proefschrift het meest gelezen wordt, wil ik trachten mijn dank te uiten aan eenieder, die een bijdrage heeft geleverd aan de totstandkoming van mijn proefschrift. Hoewel de opsomming verre van compleet zal zijn, hoop ik toch de meeste betrokkenen te kunnen bedanken. Dit proefschrift is een optelling van bijdragen van velen. Graag wil ik beginnen met het bedanken van mijn promotieteam, zonder wie het niet mogelijk zou zijn geweest om mijn doctoraat af te ronden.

Mijn $7^{\text {ste }}$ promotor, Prof. Dr. Philip Van Kerrebroeck: dank voor mijn aanstelling als promovendus en voor het verstrekken van alle nodige middelen om mijn onderzoek uit te kunnen voeren. Vooral in de laatste fase van het schrijven aan mijn proefschrift is uw inbreng onmisbaar gebleken. Tevens ben ik u zeer erkentelijk voor uw steun en begeleiding tijdens de selectieprocedure voor de opleiding urologie.

Mijn $2^{\mathrm{e}}$ promotor, Prof. Dr. Stefan de Wachter: beste Stefan, bedankt voor alle aanwijzingen, suggesties, discussies en commentaren. Jouw inbreng heeft een substantiële bijdrage geleverd aan de artikelen die we samen geschreven hebben.

Mijn co-promotor, Dr. Gommert van Koeveringe: beste Gommert. Jij was mijn dagelijkse begeleider en de meest stabiele factor tijdens mijn promotie. Ondanks jouw zeer drukke agenda, stond je altijd voor me klaar wanneer ik je echt nodig had. Zowel inhoudelijk als procesmatig heb jij de grootste inbreng gehad in mijn proefschrift. Van jou heb ik, behoudens wetenschappelijke zaken, vooral veel geduld geleerd. Bovendien heb ik geleerd, dat het geen kunst is om samen te werken als het goed gaat, de uitdaging is om een samenwerking te doen slagen als het juist heel moeilijk is! Ik waardeer jouw steun en bijdrage tijdens mijn onderzoek.

Hoewel ze formeel geen lid zijn van mijn promotieteam, hebben de volgende personen, inhoudelijk dan wel procesmatig, een onmisbare bijdrage geleverd aan mijn proefschrift.

Prof. Dr. Harrie Steinbusch: graag wil ik u bedanken voor uw voortdurende belangstelling en aanmoediging. Van u kreeg ik altijd veel steun in moeilijke tijden en mede door u heb ik mij altijd thuis gevoeld in uw laboratorium bij de afdeling neuroscience. Zonder uw tussenkomst, had ik nooit een NWO Mozaïek subsidieaanvraag ingediend, dit zal ik nooit vergeten. 
Dr. Jan de Vente: beste Jan, basaal wetenschappelijk onderzoek doen heb ik feitelijk van jou geleerd. Ook al was jij al gepensioneerd toen ik aan mijn onderzoek begon, heb jij geen moment getwijfeld je voor mijn promotietraject in te zetten. Bedankt voor je commentaren en suggesties.

Professor James Gillespie: I would like to thank you for your contribution in the papers we wrote together.

Mijn experimenten waren niet goed gelukt zonder de hulp en expertise van Hellen Steinbusch en Marianne Markerink. Hen wil ik bedanken voor het feit dat zij telkens klaar stonden met hulp om de technische problemen van mijn experimenten op te lossen. Zij hebben veel tijd met mij doorgebracht in het lab en achter de microscoop. De kwaliteit van de immunohistochemische kleuringen en foto's, dank ik mede aan hun deskundigheid en ervaring.

De dames van het secretariaat urologie: Cindy Botty, Nancy Logjes en Anja Dullens hebben mij steeds fantastische secretariële ondersteuning verleend. Ook hen wil ik graag bedanken voor al hun hulp.

Dr. Seyped Mohammad Miri: Dear Siawash, Thank you for your help and support with the completion of my thesis text and layout.

Jeu ten Koppel en Jean Erkens, dank voor jullie fantastische inzet en geduld bij de opmaak van mijn thesis.

Tijdens mijn drieëneenhalf jaar onderzoek heb ik met diverse collega-onderzoekers samengewerkt, die ieder op zijn of haar eigen manier en in meer of mindere mate een rol hebben gespeeld in mijn onderzoek.

Met Drs. Bart Biallosterski heb ik het grootste deel van mijn onderzoeksperiode samen mogen werken. Beste Bart: ik zal onze kleine kamer waar wij ruim drie jaar samen hebben doorgebracht missen. Wij hebben veel experimenten samen uitgevoerd, kleuringen gedaan, weefsel gesneden, cavia's geopereerd en blaasdrukmetingen verricht. Ik ben je dankbaar voor jouw steun en hulp en je luisterend oor wanneer het nodig was.

Dr. Simone Grol wil ik bedanken voor haar heldere uitleg en mijn inwerkperiode in het laboratorium aan het begin van mijn onderzoek.

Mijn collega's: Dr. Rik de Jongh, Drs. Dennis Oerlemans, Dr. Randal Leong, Drs. Paul Essers, Dr. Rhea Heeringa, Dr.Tom Marcellissen, Drs. Kevin Rademakers en Drs. Jamie Drosseart hartelijk dank voor jullie hulp, adviezen en gezelligheid tijdens mijn onderzoeksperiode. 
Mijn paranymfen: Drs. Ramona Hohnen en Drs. Martijn Smits wil ik in het bijzonder nog bedanken voor hun hulp bij de aanpassingen van de opmaak van mijn proefschrift en voor al hun inzet bij mijn promotie

Mijn proefschrift draag ik op aan mijn familie.

Zij zijn alles voor mij en zonder hun onvoorwaardelijke steun en hun vertrouwen in mij, was ik nooit zover gekomen.

Mijn ouders hebben ongelofelijk veel opgeofferd voor mijn succes. Daarvoor ben ik hen eeuwig dankbaar.

Mijn lieve partner Elham Siasati, heeft mij heel vaak thuis moeten missen. Lieve Elham, jij stond altijd achter mij en zonder jouw steun en geduld had ik mijn onderzoek niet af kunnen maken. Jij hebt je eigen carrière en studie, secundair gesteld aan ons gezin en mijn carrière en zorgde voor een veilige en stabiele thuishaven. Steeds als ik weg moest voor cursussen en congressen, heb jij ervoor gezorgd, dat ik met een gerust hart en zonder al te veel zorgen, mijn gang kon gaan. Daarvoor ben ik je zeer dankbaar. Bovendien heb jij mij ons dierbaarste bezit, onze 3 prachtige kinderen, geschonken. Daar kan geen enkele prestatie tegenop. 



\section{Abbreviations}

AC, Adenylyl Cyclase

ATP, Adenosine Triphosphate

$\mathrm{BPH}$, Benign Prostate Hyperplasia

BOO, Bladder Outlet Obstruction

cAMP, Adenosine 3', 5'-cyclic Monophosphate cGMP, Guanosine 3', 5'-cyclic Monophosphate CGRP, Calcitonin Gene-Related Peptide

CNP, C like Natriuretic Peptide

COX, Cyclooxygenase

$\mathrm{COX}_{1}$, Cyclooxygenase type 1

COX2, Cyclooxygenase type 2

DO, Detrusor Overactivity

$\mathrm{DP}_{1}$, Prostaglandin D Receptor Type 1

ED, Erectile Dysfunction

$E P_{1}$, Prostaglandin E Receptor Type 1

$E P 2$, Prostaglandin E Receptor Type 2

$E P_{3}$, Prostaglandin E Receptor Type 3

EP4, Prostaglandin E Receptor Type 4

DP2, Prostaglandin D Receptor Type 2

FP2, Prostaglandin F Receptor Type 2

GC, Guanylyl Cyclase

GTP, Guanosine Triphosphate

$\mathrm{Gs} \alpha$, Stimulatory $\mathrm{G}$ protein Subunit $\alpha$

IBMX, 3 Isobutyl 7-Methylxanthine

ICs, Interstitial Cells

IHC, Immunohistochemistry

IM, Inner Muscle Layer

IM-ICs, Intramuscle Interstitial Cells

IP, Prostaglandin I Receptor

IPSS, International Prostate Symptom Score

Ki, Inhibitor Binding Activity

LP, Lamina Propria

LPICs, Lamina Propria Interstitial Cells

LUTS Lower Urinary Tract Symptoms

MBC, Maximum Bladder Capacity

MFP, Maximum Filling Pressure

MVP, Maximum Voiding Pressure

$n$, Number of Patients

NB, Northern Blot

$N F$, Neurofilament
NO, Nitric Oxide

NOS, Nitric Oxide Synthase

$\mathrm{OAB}$, Overactive Bladder Syndrome

OM, Outer Muscle Layer

pAC, Particulate (Plasma Membrane) Adenyl Cyclase

PDE, Phosphodiesterase

PDE5, Phosphodiesterase Type 5

$\mathrm{PG}$, Prostaglandin

pGC, Particulate (Plasma Membrane) Guanylyl Cyclase

$P G D_{2}$, Prostaglandin $D_{2}$

$P G E_{2}$, Prostaglandin $\mathrm{E}_{2}$

PGF ${ }_{2 \alpha^{\prime}}$, Prostaglandin $\mathrm{F}_{2 \alpha}$

$\mathrm{PGI}_{2}$, Prostaglandin $\mathrm{I}_{2}$

PGP9.5, Protein Gene Product 9.5

PLA, Phospholipase A

QoL, Quality of life

Qmax, Maximum Urinary Flow Rate

RCT, Randomized Controlled Trial

RhoA, Ras Homolog Gene Family, Member A

ROCK, Rho-Associated Protein Kinase

ROI, Region Of Interest

RT PCR, Reverse Transcription Polymerase Chain

Reaction

sAC, Soluable Adenylyl Cyclase (Located in the

Cytoplasm)

sGC, Soluable Guanylyl cyclise (Located in the

Cytoplasm)

SM-IC, Surface Muscle Interstitial Cell

SU-IC, Suburothelial Interstitial Cell

SV2, Synaptic Vesicle Protein 2

TBS, Tris Buffered Saline

TBS-T, Tris Buffered Saline with 0.3\% (volume per

volume) Triton X-100

TP, Tromboxaan A Receptor Type 1

UR, Urothelium

WB, Western Blot 



\section{List of publications}

Rahnama'i, M.S., Ückert, S., Hohnen, R. \& van Koeveringe, G.A. The Role of Phosphodiesterases in Bladder Pathophysiology. Nature Reviews Urology (2013) PMID: 23670184

Rahnama'i, M.S., van Koeveringe, G.A., Hohnen, R., Ona, S., Van Kerrebroeck, Ph.E.V. \& de Wachter S.G. Distribution of phosphodiesterase type 5 (PDE5) in the lateral wall of the guinea pig urinary bladder. British Journal of Urology International (2013) PMID: 23452226

Rahnama'i, M.S., van Koeveringe, G.A., Van Kerrebroeck, Ph.E.V. \& de Wachter, S.G. The effect of indomethacin on the muscarinic induced contractions in the isolated normal guinea pig urinary bladder. Biomed Central Urology (2013) PMID:23388044

Rahnama'i, M.S., Biallosterski, B.T., de Wachter, S.G., Van Kerrebroeck Ph.E.V. \& van Koeveringe G.A. The distribution of the prostaglandin E receptor type $2(E P 2)$ in the detrusor of the guinea pig. Prostaglandins and Other Lipid Mediators (2012) PMID: 22960431

Rahnama'i, M.S., Van Kerrebroeck, Ph.E.V., de Wachter, S.G. \& van Koeveringe, G.A. The role of prostanoids in urinary bladder physiology. Nature Reviews Urology (2012) PMID: 22410675

Callewaert, P.R., Biallosterski, B.T., Rahnama'i, M.S. \& Van Kerrebroeck Ph.E.V. Robotic extravesical anti-reflux operations in complex cases: technical considerations and preliminary results. Urologica Internationales (2012) PMID:22076472

Gakis, G., Ninkovic, M., van Koeveringe, G.A., Raina, S., Sturtz, G., Rahnama'i, M.S., Sievert, K.D. \& Stenzl, A. Functional detrusor myoplasty for bladder acontractility: long-term results. The Journal of Urology (2011) PMID:21168866

Rahnama'i, M.S., de Wachter, S.G., van Koeveringe, G.A., Van Kerrebroeck, Ph.E.V., de Vente, J. \& Gillespie, J.I. The relationship between prostaglandin E receptor 1 and cyclooxygenase I expression in guinea pig bladder interstitial cells: proposition of a signal propagation system. The Journal of Urology (2011) PMID:21075388

Callewaert P.R., Rahnama'i, M.S., Biallosterski, B.T. \& Van Kerrebroeck, Ph.E.V. Scrotal Approach to Both Palpable and Impalpable Undescended Testes: Should It Become Our First Choice? Urology (2010) PMID: 20156655 
Rahnama'i, M.S., van Koeveringe, G.A., Essers, P.B., de Wachter, S.G., de Vente, J., Van Kerrebroeck, Ph.E.V. \& Gillespie, J.I. Prostaglandin receptor EP1 and EP2 site in guinea pig bladder urothelium and lamina propria. The Journal of Urology (2010) PMID: 20096878

Van Koeveringe, G.A., Rahnama'i, M.S. \& Berghmans, B.C.. The additional value of ambulatory urodynamic measurements compared with conventional urodynamic measurements. British Journal of Urology International (2010) PMID:19673868

Rahnama'i, M.S., Leue, C. \& van Koeveringe, G.A. Wired Bladder in a cordless era. British Medical Journal case reports (2009) PMID:21686350

Rahnama'i, M.S., Wagenvoort, J.H. \& van der Linden, C.J. Amoxicillin/clavulanate (Augmentin) resistant Escherichia coli in bacterial peritonitis after abdominal surgery--clinical outcome in ICU patients. The Netherlands Journal of Medicine (2009) PMID: 19581666

Rahnama'i, M.S., Geilen, R.P, Singhi, S., van den Akker, M. \& Chavannes, N.H. Which clinical signs and symptoms predict hypoxemia in acute childhood asthma? Indian Journal of Pediatrics (2006) PMID:17006033

Vestjens, J.H., Rahnama'i, M.S., Brans, B.T. \& Buijs, J. A case of abdominal mesothelioma diagnosed by indium-III leucocyte scintigraphy. The Netherlands Journal of Medicine (2006) PMID:16702616 


\section{Abstracts and Presentations}

International Continence Society (ICS) Beijing 2012, Poster presentation

Effectivity and complications of repeated botulinum toxin-A injections in patients with therapy resistent detrusor overactivity

M.S. Rahnama'i, F.T. Jansen, K.P.J. Delaere

Nederlandse Vereniging voor de Urologie (NVU) 2010, Oral presentation

De lokalisatie van de activiteit van phosphodiesterase type-5 in de cavia blaas

M.S. Rahnama'i, G.A. van Koeveringe, S.G.G. de Wachter, J. de Vente, Ph.E.V. Van Kerrebroeck, J.I. Gillespie

European Association of Urology (EAU) Barcelona 2010, Poster presentation

Phosphodiesterase type 5 Site of Action in the Guinea Pig Bladder, a novel visualization technique

M.S. Rahnama'i, G.A. van Koeveringe, S.G.G. de Wachter, J. de Vente, Ph.E.V. van

Kerrebroeck, J.I. Gillespie

International Continence Society (ICS) San Francisco 2009, Oral presentation

Evidence for Prostaglandin involvement in neuron-modulation in the guinea pig bladder

M S. Rahnama'i, G.A. van Koeveringe, S. G.G. de Wachter, J. de Vente, J.I Gillespie, Ph.E.V. Van Kerrebroeck

American Urology Association (AUA) Chicago 2009, Poster presentation

Evidence for prostaglandin involvement in afferent signaling of the guinea pig bladder

M.S. Rahnama'i, J. de Vente, G.A. van Koeveringe, Ph.E.V. Van Kerrebroeck , J.I. Gillespie

European Association of Urology (EAU) Stockholm 2009, Poster presentation

Latissimus Dorsi Detrusor Myoplasty (LDDM) in patients with acontractile bladder, long-term results of a multicenter study

G. Gakis G , G.A. van Koeveringe, S. Raina, S, Lorenz, M.S. Rahnama'i, K.D. Sievert M. Ninkovic, A. Stenzl

Nederlandse Vereniging voor de Urologie (NVU) 2008, Oral presentation

De Lokalisatie en de rol van Prostaglandine receptoren (Type 1 : Ep1) in de Cavia blaas en urethra

M.S. Rahnama'i, J. de Vente, G.A. van Koeveringe, Ph.E.V. Van Kerrebroeck, J.I. Gillespie 
Nederlandse Vereniging voor de Urologie (NVU) 2007, Oral presentation

De Lokalisatie van EP1- en EP2-prostaglandine receptoren in de blaas en hun mogelijke rol in de behandeling van de overactieve blaas

M.S. Rahnama'i, S. Grol, J. de Vente, G.A. van Koeveringe, Ph.E.V. Van Kerrebroeck

Controversies in Urology congress (CURY) Barcelona 2007, Poster presentation

Localization of COX limmunoreactivity (COX-I-IR) and prostaglandin receptors (EP1 and $\left.E_{2}\right)$ in the Human bladder

M.S. Rahnama'i, G.A. van Koeveringe, J. De Vente, J.I. Gillespie, Ph.E.V. Van Kerrebroeck

European Association of Urology (EAU) Milaan 2008, Poster presentation

Complex signalling within the urothelium and suburothelial interstitial cell layer involving prostaglandins and nitric oxide

M.S. Rahnama'i, J. De Vente, G.A. van Koeveringe, Ph.E.V. Van Kerrebroeck,

International Continence Society (ICS) Cairo 2008, Poster presentation

The location and role of prostaglandin receptors (type 1: EP1) in the bladder and urethra

M S. Rahnama'i, P. Essers, J. de Vente, G.A. van Koeveringe, Ph.E.V. Van Kerrebroeck, J.I. Gillespie

International Continence Society (ICS) Cairo 2008, Poster presentation

The additional value of ambulatory urodynamic studies in patients with an overactive bladder syndrome and patients with an acontractile detrusor

M.S. Rahnama'i, G.A. van Koeveringe, Ph.E.V. Van Kerrebroeck

Nederlandse intensivisten dagen (NVIC) 2005, Poster presentation

Sepsis behandeling op de Intensive Care.

M S. Rahnama'i, M. van de Woude, C. van der Linde 




\section{Curriculum Vitae}

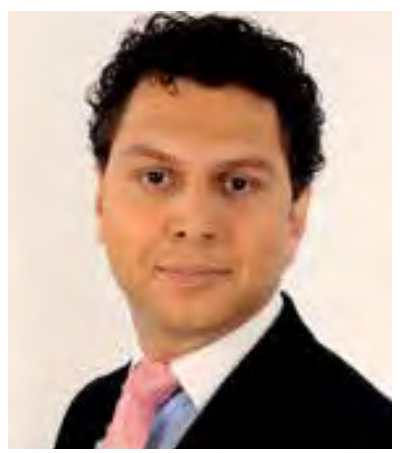

Mohammad Sajjad Rahnama'i was born on May 18th 1979 in Tehran (Iran). After finishing elementary school at the age of twelve in Iran, his family emigrated to the Netherlands, where he was sent to a school for basic technical skills (LTS, Delta college in Brunssum), like all newly arrived, foreign children. After figuring out the Dutch schooling system, he tried to change his high school to a higher level, in order to gain access to University and study medicine. After one year of LTS and one year at a middle level high school (MAVO), he was able to convince the school board to make an exception and let him attend the Dutch grammar school (Atheneum, Rombouts College in Brunssum), from which he graduated in 1998. During that year, he was not selected at the Dutch national lottery for entrance into medical school. He therefore took the entrance exam for the medical school in Belgium and entered the medical school in this country (LimburgsUniversitair Centrum LUC in Diepenbeek). He passed the first year with honours and returned to the medical faculty of the Maastricht University in 1999, from where he graduated his bachelors in 2003 and masters in 2005 , both with honours degree. He started his clinical work as a medical doctor at the intensive care unit in Heerlen followed by one year at the surgery department in Sittard. In 2007, he started his PhD research at the urology department in Maastricht, under the supervision of Prof. Philip Van Kerrebroeck, Dr. Gommert van Koeveringe and Prof. James Gillespie from Newcastle university (United Kingdom). In 2008, he received a personal Mozaïek grant from the Netherlands Organization for Scientific Research (NWO). He was accepted to the Dutch urology resident program in 2009 and started his training in January 2011. Besides his research, Sajjad has always kept working as a medical doctor at emergency departments and intensive care units of different hospitals during the weekends. Moreover, he has been a member of the city counsel of his hometown Heerlen from 2006 and has taken part in Persian music ensembles like Mezrab and Pardis. He is married to Elham Siasati and is a proud father of two sons and a daughter, Behzad (2008), Niekdad (2010) and Dorzad (2013), respectively. 


